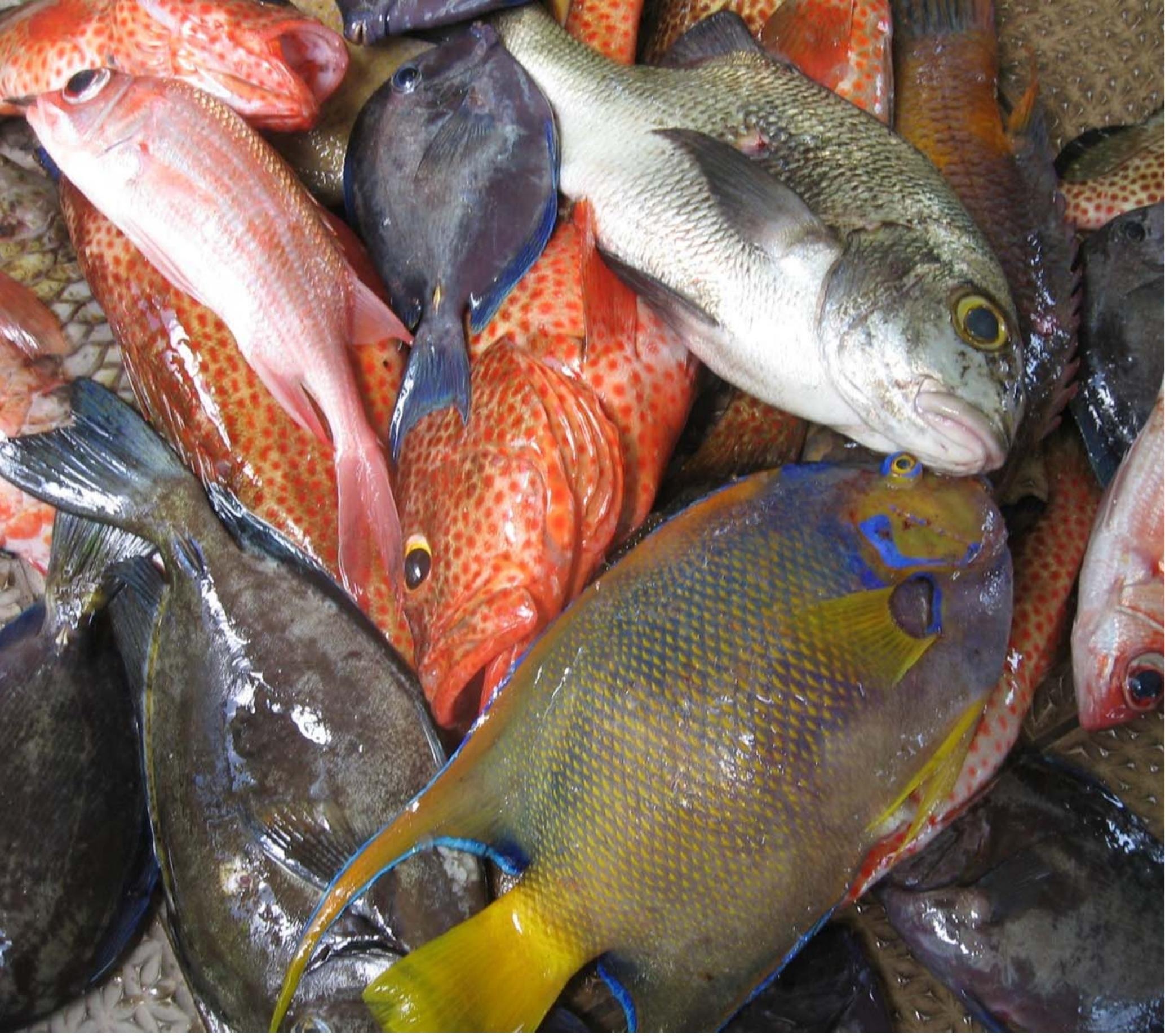

\title{
Status and trends Saba Bank fisheries: 2015
}





\section{Status and trends Saba Bank fisheries: 2015.}

Author(s): $\quad$ M. de Graaf, T.P.A. Brunel, L.A.J. Nagelkerke, A.O. Debrot

Publication date: $9^{\text {th }}$ of October 2017

This research project was carried out by Wageningen Marine Research at the request of and with funding from the Ministry of Economic Affairs for the purposes of Policy Support Research Theme Caribbean Netherlands (project no's. BO-11-011.05-008; BO-11-019.02-008; BO-11-019.02-049). 
M. de Graaf, T Brunel, L. Nagelkerke, A.O. Debrot, 2017. Status and trends Saba Bank fisheries: 2015.; Wageningen, Wageningen Marine Research (University \& Research centre), Wageningen Marine Research report C077/17. 124 pp.

Keywords: Saba Bank, fisheries, redfish, snapper, spiny lobster, shark bycatch.

Client: $\quad$ Ministry of Economic Affairs

Attn.: Ir. A. H. M. Schutjes

Bezuidenhoutseweg 73

2594AC, Den Haag

BAS code BO-11-011.05-008; BO-11-019.02-008; BO-11-019.02-049

This report can be downloaded for free 2 months after publication from :

https://doi.org/10.18174/424549

Wageningen Marine Research provides no printed copies of reports

Wageningen Marine Research is ISO 9001:2008 certified.

Photo cover: Martin de Graaf

(C) 2017 IMARES Wageningen UR

Wageningen Marine Research institute of Stichting Wageningen Research is registered in the Dutch traderecord nr. 09098104, BTW nr. NL 806511618
The Management of Wageningen Marine Research is not responsible for resulting damage, as well as for damage resulting from the application of results or research obtained by Wageningen Marine Research, its clients or any claims related to the application of information found within its research. This report has been made on the request of the client and is wholly the client's property. This report may not be reproduced and/or published partially or in its entirety without the express written consent of the client. 


\section{Contents}

Executive Summary

$\begin{array}{llr}1 & \text { Introduction } & 10\end{array}$

$2 \quad$ Materials and Methods $\quad 13$

$2.1 \quad$ Study area $\quad 13$

2.2 Fisheries survey $\quad 14$

2.2.1 General Fleet Description $\quad 14$

2.2.2 Port sampling 14

2.2.3 Reproductive biology 16

2.3 Sustainable fish traps 16

2.3.1 Biodegradable panels 16

$\begin{array}{ll}2.3 .2 \text { Ghost fishing } & 17\end{array}$

$\begin{array}{ll}\text { 2.3.3 Escape slots } & 17\end{array}$

$\begin{array}{lll}2.4 & \text { Whales and dolphins } & 19\end{array}$

$\begin{array}{lll}2.5 & \text { Queen conch survey } & 20\end{array}$

2.5.1 Reproductive biology 20

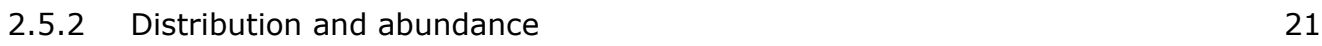

$\begin{array}{llr}3 & \text { Results } & 23\end{array}$

3.1 Annual catch and effort $\quad 23$

$\begin{array}{lll}3.2 & \text { Lobster Trap Fishery } & 24\end{array}$

3.2.1 Lobster $\quad 24$

3.2.2 Mixed reef fish 33

$\begin{array}{ll}3.3 & \text { Redfish Fishery } \\ \end{array}$

$\begin{array}{lll}\text { 3.3.1 Trap fishery } & 37\end{array}$

$\begin{array}{ll}\text { 3.3.2 Bottom longline fishery } & 41\end{array}$

3.4 Pelagic Fishery $\quad 43$

3.5 Shark bycatch $\quad 45$

3.5.1 Shark bycatch released $\quad 45$

3.5.2 Shark bycatch landed $\quad 46$

$\begin{array}{lll}3.6 & \text { Sustainable fish traps } & 47\end{array}$

$\begin{array}{lll}3.6 .1 & \text { Biodegradable panel } & 47\end{array}$

$\begin{array}{lll}3.6 .2 & \text { Ghost fishing } & 47\end{array}$

$\begin{array}{lll}3.6 .3 & \text { Escape slots } & 48\end{array}$

$\begin{array}{lll}3.7 & \text { Whales and dolphins } & 55\end{array}$

$\begin{array}{lll}3.8 & \text { Queen conch } & 58\end{array}$

$\begin{array}{lll}3.8 .1 & \text { Reproductive biology } & 58\end{array}$

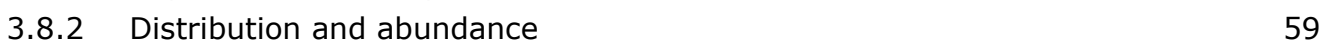

$\begin{array}{lll}3.9 & \text { Lionfish } & 61\end{array}$

4 Discussion $\quad 62$

4.1 Historical overview Saba Bank fishery $\quad 62$

4.2 Lobster fishery $\quad 65$

4.2.1 Trend and status lobster fishery $\quad 65$

$\begin{array}{lll}4.2 .2 & \text { Reproductive biology } & 67\end{array}$

$\begin{array}{lll}\text { 4.2.3 } & \text { Mixed reef fish bycatch from lobster fishing } & 69\end{array}$

$\begin{array}{lll}4.3 & \text { Deep-water snapper fishery } & 71\end{array}$

$\begin{array}{lll}4.4 & \text { Pelagic fishery } & 73\end{array}$

$\begin{array}{lll}4.5 & \text { Shark bycatch } & 74\end{array}$ 
$\begin{array}{lll}\text { 4.5.1 Shark bycatch landed } & 75\end{array}$

$\begin{array}{lll}4.6 & \text { Sustainable fish traps } & 75\end{array}$

$\begin{array}{lll}\text { 4.6.1 Biodegradable panels } & 75\end{array}$

$\begin{array}{lll}4.6 .2 & \text { Ghost fishing } & 76\end{array}$

$\begin{array}{lll}4.6 .3 & \text { Escape slots } & 78\end{array}$

$\begin{array}{llr}4.7 & \text { Lionfish } & 80\end{array}$

$\begin{array}{lll}4.8 & \text { Cetaceans } & 81\end{array}$

4.9 Queen conch $\quad 82$

4.9.1 Reproductive biology $\quad 82$

$\begin{array}{lll}\text { 4.9.2 Distribution and abundance } & 83\end{array}$

$5 \quad$ Conclusions and recommendations $\quad 85$

5.1 Precautionary management $\quad 85$

$\begin{array}{ll}5.2 & \text { Adaptive management } \\ 5.3 & 86\end{array}$

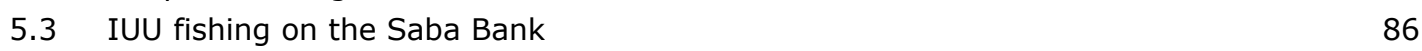

\begin{tabular}{ll}
5.4 & Lobster fishery recommendations \\
\hline 5.5 & 87
\end{tabular}

$\begin{array}{llr}5.5 & \text { Redfish fishery recommendations } & 88\end{array}$

$\begin{array}{llr}5.6 & \text { Conch stock recommendations } & 88\end{array}$

$\begin{array}{lr}\text { References } & \mathbf{8 9}\end{array}$

$\begin{array}{lr}\text { Quality Assurance } & 94\end{array}$

$\begin{array}{lr}\text { J ustification } & 94\end{array}$

$\begin{array}{lll}\text { Annex } 1 & \text { Length composition fish by-catch from lobster traps } & 95\end{array}$

Annex 2 Length composition of the catches for the escape slot experiments on redfish traps

$\begin{array}{llr}\text { Annex } 3 & \text { Length composition red fish species } & 106\end{array}$

$\begin{array}{llr}\text { Annex } 4 & \text { Maturity information on snappers } & 112\end{array}$

Annex 5 Declaration on Conservation, Management and Sustainable Use of the Caribbean Spiny Lobster (Panulirus argus) 


\section{Executive Summary}

The Saba Bank is a $2200 \mathrm{~km}^{2}$ shallow bank area that lies fully within the Dutch Kingdom's Caribbean exclusive economic zone (EEZ) waters. In recent years it has gained international recognition as an area of exceptional biodiversity value and been accorded increasingly higher and more extensive conservation status. For instance, in 2012 it was accorded "Particularly Sensitive Sea Area (PSSA)" status by the International Maritime Organization (IMO) which forbids tanker traffic and in 2015 it became part of the "Yarari Marine Mammal and Shark Sanctuary" emphasizing its value to both endangered cetaceans and sharks.

The nineteen seventies, eighties and early nineties saw extensive overfishing of the bank by foreign vessels with major depletion of its stocks of large groupers and conch. Once the exclusive fishing zone (EFZ) had been claimed in 1993 for the Netherlands Antilles fisheries regulation was enacted and the Coast Guard was established in 1995, foreign illegal, undocumented and unmanaged (IUU) fishing was quickly brought to an end. This allowed renewed local interest in fishing on the bank and has given the bank new ecological perspective.

Today the bank supports two important long-time fisheries operating from Saba. These are a directed fishery for the West-Indian spiny lobster (Panulirus argus) and a "redfish" fishery for deep-water snappers (redfish). Both fisheries are principally based on the use of traps. Pelagic fishing for wahoo and dolphin fish is currently almost negligible, representing only about $2 \%$ of total landings by weight. About $60 \%$ of the annual commercial effort (in terms of fishing trips) is directed towards the lobster and $40 \%$ towards redfish. The total value of the fishery ten years ago amounted to about US\$1.3 million per year ex-vessel value (Toller \& Lundvall, 2008), involved roughly 10 fishing boats and provided direct employment for about 30 persons. In the period 2012-2015 the total fishery landings grew from 78.4 tons to 135.2 tons and still involved 10 boats. This is a major contribution to the local economy of this small island to which by comparison the main economic pillar for future development (nature tourism) contributes US\$7.6 million annually (Van de Kerkhof et al., 2014).

Recent sightings by fishermen and Saba Bank Management Unit (SBMU) of fishing activities by foreign fishing vessels without commercial or recreational fishing license, (even inside the seasonal closed area during the Red Hind spawning aggregation season) suggest that IUU may again on the rise due to the lack of regular Coast Guard patrols and enforcement.

We here assess the current status of these two main fisheries and report on the monitoring results as funded by the Netherlands Ministry of Economic Affairs and as collected by the SMBU hosted by the Saba Conservation Foundation (SCF ) in collaboration with Wageningen Marine Research (WMR) during the period spanning 2012-2015. In addition, we discuss issues such as reef fish and shark bycatch and the status of the Queen conch stocks of the bank (Lobatus gigas).

Lobster trap fishery: This fishery only began during the 1980 s with the advent of tourism on St. Maarten. Lobsters are fished with lobster traps (principally traditional Caribbean arrowhead traps with a modified entrance) up to depths of $45 \mathrm{~m}$. This means that about $84 \%$ of the bank is potentially suitable for this fishery, but only a part of the bank is usually fished. The fishery is strongly seasonal. Highest catches were realized in the months August through January while the lowest catches were made April to July. Egg-bearing (berried) females can be found all year long but there seemed to be a peak in berried females February to May. Recent years (2012-2015) has seen the annual number of traps set from about 48000 traps set/y to about $73000 / y$. The average soak time is 11.6 days and almost all the catch was exported to St. Maarten. Total annual catches in 1999, 2007 and 2012 respectively were estimated to be 62 tons, 92 tons and 36.8 tons. Since 2012 annual catches have steadily increased to about 76.5 tons in 2015 . The information and data collected over the 5 years covered by the present study indicate a $50 \%$ increase in the effort (in terms of trap drops) of the lobster fishery, with a corresponding doubling in the lobster landings. Standardized catch per unit 
effort (CPUE) development shows that lobster abundance dropped from higher levels in 2000 to lower levels in 2011, with a progressive increase towards the level of 2007 since then. The observed pattern of catches for the Saba Bank since 2000 appears to mirror regional catch patterns (which are driven by regional recruitment patterns) but not local fishing pressure on the bank.

The average size of landed lobsters appears to have fluctuated between 108 and $118 \mathrm{~mm}$ carapace length (CL) since 2000, with no signs of significant decrease in average lobster size landed (which might have suggested overfishing). In fact, the average size of lobsters landed remains consistently high compared to other fisheries of the region. Average size at landing (113 $-117 \mathrm{~mm})$ is larger than size at maturity (females $=88 \mathrm{~mm}$; males $=92.2 \mathrm{~mm}$ ). Additional good news is that the landing of sublegal lobsters ( $<95 \mathrm{~mm} \mathrm{CL}$ ) has steadily decreased from about $28 \%$ in 2012 to about $4 \%$ in 2015.

We conclude that overall, based on our current analysis, there appears to be no strong sign of overfishing. We recommend the development of a spiny lobster fishery management plan which defines harvest goals and enforcement strategies that are simple, robust and cost-effective. Options to consider would be limits to the number of fishing licences, the number of traps per fishermen/licence (currently about 300 per fisherman), a total limit to traps deployed in the fishery, registry and visible marking of all traps and trap sets. Effective marking of gear for identification can also help prevent gear loss, and gear theft. The use of escape slots and biodegradable panels is an easy way to help limit negative impacts of gear without major costs. Finally a total quota for the combined catch can serve to cap the total harvest.

It is highly recommended that the management of spiny lobster is aligned with the principles outlined in the lobster conservation and management declaration of the 17 island state Caribbean Regional Fisheries Mechanism (CRFM, Annex 5). The Netherlands could become a member of CRFM for full participation in this regional management mechanism.

Mixed reef fishes: The lobster fishery results in a certain degree of bycatch. Reef fish caught in lobster traps are in part landed for sale, for own consumption, or to serve as food for the spiny lobsters in their holding traps in the harbor. This bycatch is composed of a broad range of reef fish species. The three main reef fish species landed were the queen triggerfish, Balistes vetula, white grunt, Haemulon plumierii and the red hind, Epinephelus guttatus, representing upwards of $50 \%$ of the weight of landings. About 33\% of the mixed reef fish (by weight) is discarded and mostly consists of nurse sharks, Ginglymostoma cirratum, honeycomb cowfish, Acanthostracion polygonius, cottonwick grunts, Haemulon melanurum and white grunt, $\mathrm{H}$. plumieri. The catches of mixed reef fish have increased from 6.6t to 13.6t between 2012 and 2015, representing on average just under 20\% of the overall total catch (all species combined) on Saba Bank. Overall, reef fish yields on Saba Bank appeared to be low compared to other areas. Based on the results from this study, a rough estimate of the yield is between 0.025 and $0.10 \mathrm{t} / \mathrm{km}^{2} /$ year. These low yields can in part be due to the low reef fish densities on Saba Bank as estimated in fisheries-independent studies. Lower fish catchability of traps designed for lobsters likely also contributes to lower catches compared to studies using fish traps. The low fish density is unlikely to be caused by current overexploitation but to one or a combination of factors such as a naturally lower biomass of reef fish and losses of habitat for reef fishes due to bleaching-induced coral mortalities.

Redfish fishery: The "redfish" fishery is also largely conducted using traps. These are typically deployed at depths of between 50 en 250 m and catch mainly silk snapper, Lutjanus vivanus ( $69 \%$ by weight), blackfin snapper Lutjanus buccanella (10\%), vermillion snapper, Rhomboplites aurorubens (7\%), and "others" (14\%). In 2000, redfish was exclusively still caught by line. However, by 2007 most snapper was being caught using fish traps and by 2012 there was practically no more line fishing for snapper. These shifts in gear use coincided with a change in fish size, (and species composition) from large adult snapper to smaller sub-adult snapper of about $30 \mathrm{~cm}$ fork length. In 2007 the average total trap haul was 28 traps/day while in 2012 it was about 33 traps/day and in 2015 about 25 traps/day. As fishing pressure increased from 2007 to 2012, annual landings seemed to decline from 41.3 tons in 2007 to 34.6 tons in 2012. Since then total landings increased (to 50.5 tons in 2014), but now may have started declining again (39.1 tons in 2015). When looking at CPUE which is an index of population size, it is evident that CPUE (landings) has fluctuated between roughly $2.5-5 \mathrm{~kg}$ 
of snapper per trap, with no appreciable trend. Therefore, the recent changes in total annual catch appear to be largely driven by changes in effort. This peaked in 2014 (at 537 total trips) but was less in 2015 (481 trips). These most recent data hence suggest no worrisome developments for this fishery, other than that the current fish stock is significantly $(75 \%)$ lower than in the early 1970 s "virgin" state. There is currently a small but growing fishery using deep-water long lines to target redfish in deeper waters (average depth: $260 \mathrm{~m}$ ) where catches are dominated by the wenchman snapper (Pristipomoides aquilonaris) and the queen snapper (Etelis oculatus, sabonechi).

The status of the trap fishery is perceived by the fishers as undesirable with a CPUE 75\% lower compared with underexploited conditions. On the $1^{\text {st }}$ April 2017 a six month closed season was implemented through an agreement between fishermen. It is recommended to develop a harvest strategy for the deep-water snapper fishery and ensure that sufficient (on-board) samples are collected.

\section{Shark bycatch}

Sharks are considered unwanted bycatch or nuisance in especially the lobster trap fishery. Nurse sharks, were caught in around $60 \%$ of the trips using lobster traps but most of the time in low numbers (less than 7 sharks per trips). However for $5 \%$ of the trips, large numbers (from 11 up to 71 individuals) were caught. The estimated annual number of discarded nurse sharks varied between 1712 and 2499 individuals, mainly coming from the lobster fishery. Almost all sharks are discarded (alive) and very few sharks were killed and landed. Of 319 trips sampled between 2011 and 2016, a total of 11 landed sharks were observed, most of them from the lobster fishery ( 7 sharks in 139 samples). Based on our port sampling interviews we estimate that 40 sharks per year (mainly nurse sharks) were landed in the whole Saba Bank fishery. Nevertheless, personal observations during onboard observation show that catches may also amount to tens or even up to 60 sharks per lobster fishing trip (A. Debrot, and J. Odinga, pers. comm.). Further on-board observation is clearly needed to obtain direct figures on shark catch rates. As the Saba Bank is a designated shark sanctuary since August 2015 it is important to work together with the fishermen to fully eliminate all shark taken and ensure that they are released unharmed. The development of nurse shark exclusion devices for the lobster traps would be highly recommended to protect the nurse sharks and to reduce the damage to fishing gear and catch.

\section{Sustainable fish traps}

Biodegradable panels: Biodegradable panels did not show any degradation during a 480 daylong experiment but tested panel attachment materials did. Biodegradable panels attached to traps by material with short breakage time (max. 20 days) as required in the current fishery regulations may not be accepted by fishers due to potential loss of catch and time associated with replacing the panels. If the regulations on biodegradable panels is to be maintained, it is recommended to adjust the breakage time to 3-12 months and to clearly describe in the regulations the type and diameter of the material that is to be used to attach the biodegradable panel.

Ghost fishing: In 2012-2015 Saban fishers lost on average 0.6 lobster traps per fishing trip, resulting in ca. 400-600 derelict lobster traps annually. Our experiments show that mortality of reef fish and lobster was low and most fish and lobster appeared to be able to enter and exit the ghost traps freely. Nevertheless, derelict traps kill 2.7 to 7 lobsters and $2.7-3.9 \mathrm{~kg}$ of reef fish per trap per year. As wire traps continue to ghost fish for roughly two years we estimate the total annual kill by ghost fishing amounts to $\$ 23000-\$ 51000$ for reef fish and $\$ 46000-\$ 176000$ for lobster. Fortunately, simple modification to lobster traps such as correctly functioning escape panels will significantly reduce mortality from ghost fishing. Our studies show that the average deterioration time in days (including range between brackets) for escape panels attached with hemp and cotton is respectively, 105 (85-114), 150 (128-241). All other options such as wire or hog rings lasted more than twice as long and are not recommended.

Escape slots: We examined the effects of biodegradable panels with 2 trap design (5ft D-type traps and $4 \mathrm{ft}$ M-type traps) as well as the effect of 25 and $38 \mathrm{~mm}$ escape slots on reef fish bycatch and sub-adult snapper catches. Trap type did not affect the average number of lobsters or fish caught per trap. The only exception was for the white grunt for which the catch rates were markedly higher in the larger D-traps. However catch rates in terms of weight of bycatch were almost double for the type D-traps with $25 \mathrm{~mm}$ escape vents compared with the control traps. This difference was mainly due to 
an increase in the catch rate of species of intermediate economic value. So the larger $5 \mathrm{ft} D$-traps catch no more lobster but do catch a lot more bycatch. Hence the larger D-type traps are not recommended.

Lobster traps: Our results indicate that both trap types with escape slot had higher catch rates for lobster than the control traps. There was a significant difference of 0.55 lobster per trap for the experiment with the $38 \mathrm{~mm}$ escape vent. The difference for the $25 \mathrm{~mm}$ escape slot was not significant ( 0.20 lobster per trap). The results suggest that crowding with fish reduces lobster entry into traps.

It was different for reef fish bycatch. Escape slots of $25 \mathrm{~mm}$ greatly increased the catch rate of bycatch species like grunts. In contrast, the $38 \mathrm{~mm}$ escape vent reduced the catch rates of bycatch substantially; by about $60 \%$ for the D-type traps, and $80 \%$ for the M-type traps.

The most important result of these experiment is the observation that both $25 \mathrm{~mm}$ and $38 \mathrm{~mm}$ escape slots and trap size (4ft M-trap or 5ft-D traps) appeared to have little negative effect on lobster catches. The traps with $38 \mathrm{~mm}$ escape slots even caught significantly more lobsters (ca. 0.5 lobsters per trap). Therefore, the bycatch of mixed reef fish in the lobster trap fishery could be limited by regulating trap size and the use of escape slots. Reducing trap size and/or implementing $38 \mathrm{~mm}$ escape slots will drastically reduce the amount of mixed reef fish without impacting (possibly even improving) the catch of lobster, the main target species.

Snapper traps: Escape vents of $25 \mathrm{~mm}$ seem to increase snapper catch rate by about $20 \%$ (though not statistically significant). In contrast, escape vents of $38 \mathrm{~mm}$ greatly reduced snapper catches. A $25 \mathrm{~mm}$ escape vent also increased the proportion of vermillion snapper in the catch. Based on studies elsewhere, Johnson (2010) reported an increase in average size of (reef) fish in traps fitted with $25 \mathrm{~mm}$ escape vents. Our experiments indicated that the $25 \mathrm{~mm}$ escape slot did function as intended and did not reduce the proportion of sub adult silk snappers.

So as for the effect of escape slots on fish catch the results are consistent: the $25 \mathrm{~mm}$ vent increases fish catch while the $38 \mathrm{~mm}$ slot lets almost all fish escape and yields low catches. We suggest that this might mean that when traps become too crowded, less fish will enter. By using $25 \mathrm{~mm}$ escape vents, small, non-target species easily escape thereby creating more room in the trap for target species.

\section{Whales and dolphins}

The cetacean sighting frequency for Saba bank fishing trips amounted to an average of one sighting for every 13.2 trips. Between 2012 and 2016 a total of 142 sightings were generated. Only 25\% of whale sightings and $8 \%$ of dolphin sightings allowed reliable species identification. Of the $25 \%$ of confirmed whale sightings $23 \%$ concerned the humpback whale and $2 \%$ the sperm whale. While the collected data provide some indication of the presence of cetaceans on and around the bank, clearly, there is much room for improvement of baseline data collection.

\section{Queen conch}

After the de facto (but not formal) closure of the conch fishery on the Saba Bank in the mid-1990s, the queen conch population has recovered. Out of the 131 transects conducted during our video survey, adult conch were found in 91 transects, ranging from 16 conch/ha to 882 conch/ha (mean 130.8 conch/ha, 99.7-161.8 95\% CI). In 52 transects (40\% of all transects) more than $100 \mathrm{conch} / \mathrm{ha}$ were found. So maybe $800 \mathrm{~km}^{2}$ or more of the Saba Bank have conch densities that could justify a limited fishery. Adult queen conch were found at depths of 17 to $58 \mathrm{~m}$, with highest densities documented at $22 \mathrm{~m}$. Mating success in queen conch is density dependent and studies recommended that a mean density of 100 adult conch/ha should be the minimum to avoid the risk that recruitment might be impaired. This means that at present a controlled limited fishery should well be possible, if judiciously controlled and regulated. Based on our data, an estimated 14 million adult queen conch are currently present on the Saba Bank in the 20-40 depth zone.

A sustainable annual quota could be set ca. 1 million adult queen conch (ca. $8 \%$ of the adult population). If a fishery is re-opened, it is recommended to: 1) introduce a minimum legal size at $10 \mathrm{~mm}$ lip thickness and an annual closed season during May-September, 2 ) ensure that queen conch are landed with shell, 3) regular stock assessment are conducted to adjust the quota and avoid recruitment impairment, 4) identify and open only those areas to the fishery where densities are high 
enough, 5) set strict regulations on harvesting methods to prevent development of dangerous 'hookah' fishing practices. Any development of a conch fishery will take time as both bringing the species in from the sea to land and export will require permits.

\section{Lionfish}

Based on observations, it appears that the invasive lionfish first arrived on the Saba Bank between 2008 and 2011. Since then it has spread and is a frequent bycatch species in redfish and lobster traps. Our data show that it had much higher catch rates in the deeper waters during fishing for redfish. Average catches in the last three years amount to about 1 lionfish for every one or two snapper traps hauled. The availability of lionfish bycatch has led to a local market arising. Based on this, several fishermen have expressed interest in testing special traps which concentrate and trap lionfish and may allow the development of a directed deep-water lionfish fishery. 


\section{Introduction}

Coastal fish stocks are a key natural resource for many small islands like Saba that lack other major natural resources or that have to deal with the many limitations that typically characterize Small Island Developing States (SIDS). Therefore, they play a critical role in ecosystem service provision for the island, where dive tourism, and small scale fisheries fulfil important roles in the local economic and socio-cultural well-being (Dienst Landelijk Gebied, 2009). Marine and terrestrial nature is in fact, exceptionally important on Saba. Recent studies estimated the Total Economic Value of the ecosystem services provided by the marine and terrestrial ecosystems at 28.4 million USD on Saba (Cado van der Lely et al. 2014) and fisheries conducted on the Saba Bank are known to have long provided almost $10 \%$ of the island gross domestic product (GDP) (Dilrosun 2000). For this reason the island has also explicitly chosen for a sustainable development scenario (DLG, 2009). This is no accident: "The people of the Netherlands Antilles have always been strongly aware of their dependency of the surrounding sea and its natural resources" (quote by former Netherlands Antilles Minister of Economic Affairs, Mr. E. Tjin A Sjoe).

Quantitative insight into fish stocks, and factors governing their abundance, species and size composition are key to understanding the provision of ecosystem services, and consequently also provide an essential underpinning for marine spatial planning, fishery management and conservation. Therefore, the need for baseline descriptive marine resource assessment has been highlighted as a priority within the exclusive economic zone (EEZ) management plan for the Caribbean Netherlands (Meesters et al. 2010) and forms an essential part of the implementation of the latest Nature Management Plan for the Caribbean Netherlands (MinEZ, 2013). Consequently, several studies that quantify habitat diversity and associated fish stocks and fishing activity throughout the Dutch Caribbean, have been conducted in the last couple of years, including the Saba Bank. For the largest part, the Saba Bank lies in the EEZ (as opposed to island territorial waters) and hence since 2010, within the direct responsibility of the Ministry of Economic Affairs as further specified in the Nature Conservation Framework Act BES [Wet grondslagen natuurbeheer en -bescherming BES].

This report largely addresses matters pertaining to the sustainability of the (local) fisheries but it is important to note that the bank is also of great importance in international treaty and conservation context. In recent years the bank has successively been accorded increasingly higher and more extensive conservation status:

- 15 December 2010: "Nature Park" by the Netherlands

- 20 September 2012: "National Park" by the Netherlands

- 5 October 2012: "Particularly Sensitive Sea Area (PSSA)" as accorded by the International Maritime Organization (IMO)

- 23 October 2012: "Specially Protected Areas and Wildlife (SPAW) Protected Area", within the SPAW Protocol,

- 5 December 2012: "Ecologically or Biologically Significant Marine Area (EBSA)" within the Convention on Biological Diversity (CBD)

- 2 September 2015: "Yarari Marine Mammal and Shark Sanctuary" (by decree)

The bank is also habitat to a large number of International Union for Conservation of Nature (IUCN) Red List species of concern (Lundvall 2008) that either reside there year round (like the Nassau grouper, Epinephelus striatus, and the Hawksbill turtle, Eretmochelys imbricata), or that only seasonally migrate over the bank (like the scalloped hammerhead shark (Sphyrna lewini), many for which one or more treat obligations may apply (Table 1.1.1). 
Table 1.1.1. Overview of international treaties and conventions and reporting obligations for the Saba Bank biological resources.

\begin{tabular}{|c|c|}
\hline Treaty, Convention, Organisation & Species/habitats \\
\hline Food and Agricultural Organisation (FAO) & $\begin{array}{l}\text { Status and trends landings pelagic fish, mixed reef fish, } \\
\text { spiny lobster and conch; status and trend fishing effort }\end{array}$ \\
\hline $\begin{array}{l}\text { Convention on international trade in endangered species } \\
\text { of wild fauna and flora (CITES) }\end{array}$ & $\begin{array}{l}\text { International trade in Queen conch; status and trends } \\
\text { conch population and its fishery to determine quota (non- } \\
\text { detriment finding) }\end{array}$ \\
\hline $\begin{array}{l}\text { Specially Protected Areas and Wildlife (SPAW) (Multilateral } \\
\text { Environmental Agreement, a Protocol under the } \\
\text { Convention for the Protection and Development of the } \\
\text { Marine Environment in the Wider Caribbean Region (WCR) } \\
\text { or Cartagena Convention) }\end{array}$ & $\begin{array}{l}\text { Status and trends whales and dolphins; status and quality } \\
\text { coral reef ecosystem; queen conch and spiny lobster } \\
\text { Annex III SPAW protocol }\end{array}$ \\
\hline $\begin{array}{l}\text { Convention on the Conservation of Migratory Species of } \\
\text { wild animals (CMS) }\end{array}$ & Status and trends population and distribution sharks \\
\hline $\begin{array}{l}\text { International Coral Reef Initiative (ICRI) and its Global Coral } \\
\text { Reef Monitoring Network (GCRMN) }\end{array}$ & Status and trends of coral reefs \\
\hline $\begin{array}{l}\text { Shark and Whale Sanctuary "Yarari" EEZ Bonaire and Saba } \\
\text { since } 2015\end{array}$ & Status and trends whales and sharks \\
\hline $\begin{array}{l}\text { International Commission for the Conservation of Atlantic } \\
\text { Tunas (ICCAT)* }\end{array}$ & $\begin{array}{l}\text { Status and trends catch and effort ICCAT listed fish species } \\
\text { (e.g. tuna's, marlin, sharks) }\end{array}$ \\
\hline
\end{tabular}

*The Netherlands (the Caribbean Netherlands, incl. Saba) is not a member of ICCAT but membership is currently under consideration.

It is also important to note that Caribbean coral reefs have been declining for decades due to a combination of anthropogenic drivers such as unsustainable fishing practices, pollution, and coastal development and natural phenomena like hurricanes. The degradation of coral reefs is characterised by, among others, a decline in coral cover, apex predators (e.g. sharks, large groupers and snappers), herbivorous fish and invertebrates (Diadema) and an increase in macro-algal cover. In the past 40 years throughout the Caribbean large-scale shifts have occurred from coral-dominated to macro-algaldominated reef communities.

The main fisheries occurring on the Saba Bank are the fishery for the West-Indian spiny lobster and the fishery for deep water snappers ("redfish") (Meesters et al. 2010). Several preliminary studies suggested potential problems or even alarming developments for the bank and its two main fisheries. For instance, Meesters et al. (1996) pointed out the practically complete depletion of conch and large groupers on the bank. Dilrosun (2000) and Toller and Lundvall (2008) examined the lobster and snapper fisheries and raised concern about the small size of the silk snappers caught. Lundvall (2008) drew attention to benthic habitat destruction caused by anchoring tankers and found evidence to suggest that coral cover had drastically declined since the study by Meesters et al. (1996). She also presented evidence that ghost fishing by derelict traps might be problem. Finally, Toller et al. (2010) studied fish assemblages of the bank and confirmed Meesters et al.'s (1996) prior suggestion that large groupers were all but absent but also drew attention to the seeming abundance of sharks in the ecosystem. This all meant that further investigation was clearly urgently needed.

Above, we have clarified the economic, policy, and conservation context of fisheries on the Saba bank for our study as well as how preliminary studies suggested that there were actual problems on the bank. The work reported on herein principally flows forth from two key needs as formulated within the EEZ management plan (Meesters et al., 2010). These were to:

- facilitate the development and implementation of a catch recording system for commercial and recreational fisheries in the territorial waters outside the marine park boundaries and in the waters of the EEZ, and to

- $\quad$ promote the development of a stock assessment program for species targeted by commercial and recreational fisheries in the territorial waters outside the marine park boundaries and in the waters of the EEZ, including an assessment of conch stocks on the Saba Bank. 
So, in this report we present and discuss several recent years of research conducted by Wageningen Marine Research (WMR) to provide baseline quantitative insights towards sustainable management of the biological resources of the Saba Bank.

Because of its international implications a specific matter of concern was the issue of IUU fishing. This refers specifically to illegal, unreported and unregulated fishing which world-wide is major problem in management implementation and which leads to overfishing and causes billions in annual losses to the fisheries sector (Agnew, 2009). It is particularly problematic in artisanal fisheries (Farrugio, 2015). On the Saba Bank major IUU did take place in the past, particularly from the 1970 s through the mid1990s. As a consequence, the populations of large groupers and conch were largely wiped out (Meesters et al., 1996). While grouper populations have not recovered to this day (Toller et al., 2010) the conch populations clearly have (this study). Recent observations by the Saba bank Management Unit suggest that this problem may be on the rise again.

\section{Objectives}

The specific objectives of this work which was begun in 2012 were to:

- design and start an annual catch and effort monitoring program for both the lobster and snapper fisheries to gain insight into trends in catch per unit effort (CPUE) as indicators of population status

- document the reproductive status of the main species and be able to draw inferences about possible overfishing

- $\quad$ address the concerns about the sustainability of trap fishing by evaluating the ghost trap question and examining the utility of biodegradable panels and escape slots

- quantify conch density distribution and reproductive state on the bank

- $\quad$ evaluate shark and other bycatch and screen the generated data for opportunistic insights into the occurrence of lionfish in the traps and cetacean distribution on the bank.

- Based on experience and findings, comment on the IUU issue.

\section{Acknowledgments}

This research was financed by the Ministry of Economic Affairs as part of their "BO" policy support research program with Wageningen University and Research under the projects BO-11-011-05-008 (2012-2014), BO-11-019.02-049 (2016), BO-11-019.02-008 (2015, 2017). We are especially grateful to Hayo Haanstra, Guus Schutjes, Gelare Nader, Paul Hoetjes, and Pieter van Baren for their support throughout the years during which this multi-year project was funded.

We thank the many college and university students and interns who conducted fieldwork, data collection and partial analyses as part of their academic training and without whose contributions this work simply would not have been possible. These were: Wouter van Looiengoed, Twan Stoffers, Imke van Gerwen, Michelle Boonstra, Guido Leurs, Sanne Koenen, Dagmar van Nieuwpoort, Anne Regtien, Jan Kemme and Melanie Meijer Zu Schlochteren.

Special thanks are due to Kai Wulf, the Saba Conservation Foundation crew and volunteers, and the Saba Bank Management Unit that generously provided facilities and logistical assistance in all aspects of the fieldwork. A special note of thanks to: Jimmy van Rijn, Brooke Rogers, Jennifer Rahn, Gregoor van Laake, Laszlo Charles, Pouchie Dozlyn, Jelle van der Velde, Dahlia Hassell, Gia Heyliger, Keith Murphy and Jens Odnga.

A special note of thanks is extended to the fishermen, deckhands of Saba and many others for their essential for their cheerful assistance and pleasant cooperation: Ivan Hassel, Craig Hassel, Augustino Hassel, Walter Hynds, Hendrick Hassel, Julian "Bogan" Hassel, Randall "China" Zeegers, Nicky Johnson, Michelle Peterson, Wes, Kenneth Johnson, Roley Levinstone and Ryan Hassell. Finally, we are very grateful to Drs. Jacqueline Tamis for her critical review that has allowed many improvements to this report. 


\section{Materials and Methods}

\section{$2.1 \quad$ Study area}

The Caribbean EEZ consists of two sectors, a southern sector (Aruba, Bonaire and Curacao) lying off the coast of Venezuela, and a northern sector, associated with the windward islands of Saba, St. Eustatius and St. Maarten. The Saba Bank pertains to the northern sector (Meesters et al. 2010).

The Saba Bank is a flat offshore bank, located 3-5 km Southwest of Saba and $25 \mathrm{~km}$ West of St. Eustatius in the Dutch Caribbean (Fig. 2.1.1). It has a total surface area is approximately 2,200 $\mathrm{km}^{2}$, (to 200-meter depths). It slants downward the shallower south-eastern part to the deeper northwestern part. The surrounding sea floor lies at depths of about $1000 \mathrm{~m}$. Most coral development is found in a narrow band of $55 \mathrm{~km}$ along the eastern and south-eastern edges of the platform. The largest part of the Saba Bank is between 20 and $50 \mathrm{~m}$ depth, in the eastern section about $230 \mathrm{~km}^{2}$ lies between 10 and 20 m depth (Macintyre et al., 1975; Land, 1977).

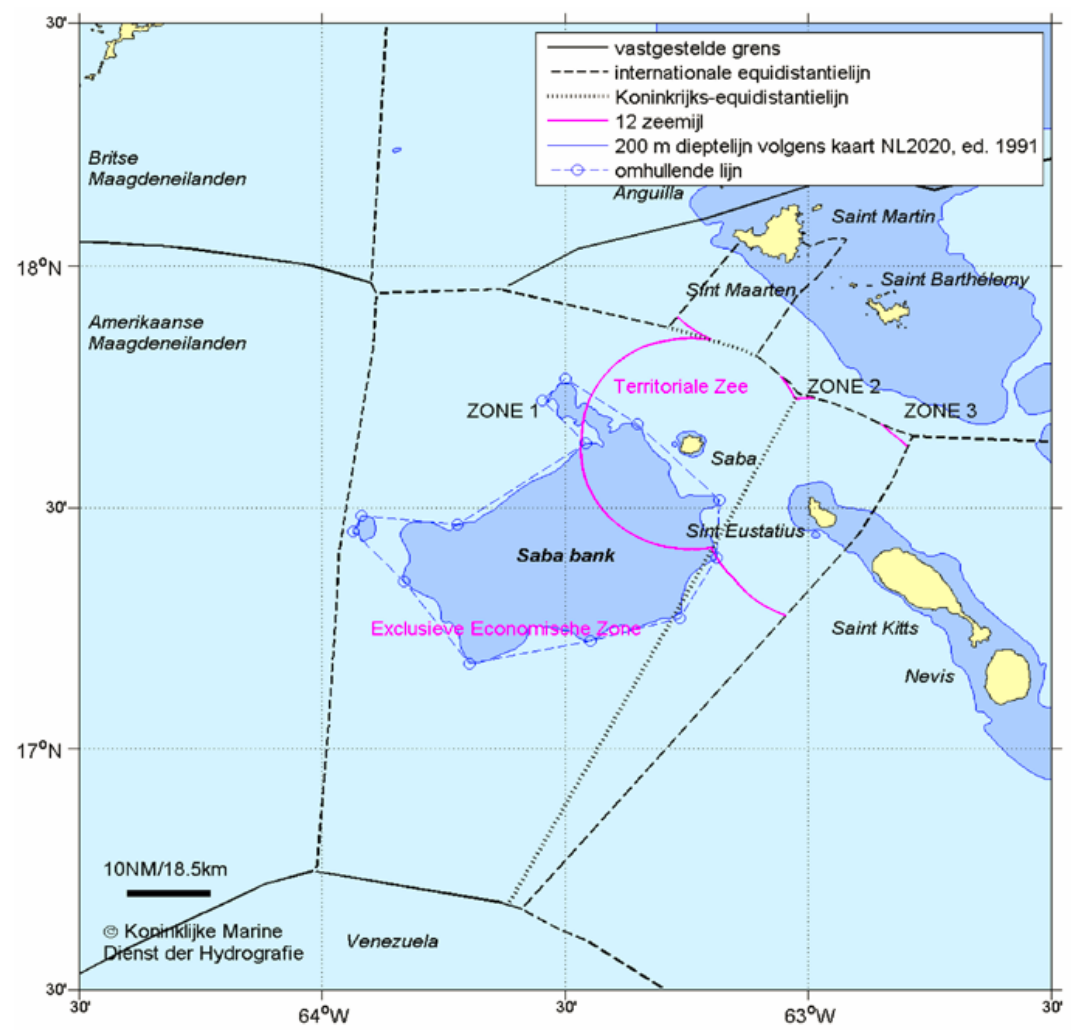

Fig. 2.1.1. Location and zonation of the Saba Bank, Exclusive Economic Zone and the Territorial Sea (Staatscourant 2010 no. 20424).

Very little is so far known about the biodiversity and ecology of the bank. Ecological research on the bank has only recently begun and the first preliminary biological inventories for the bank only date from 2010 (Etnoyer et al., 2010, Hoeksema et al., 2011, Hoetjes \& Carpenter, 2010, McKenna \& Etnoyer, 2010, Littler et al., 2010, Thacker et al., 2010, Toller et al., 2010, Williams et al., 2010). This is being followed up with more extensive ecological investigations funded largely by the Ministry of Economic Affairs and led by the Wageningen UR. Those results are now starting to trickle in (e.g. Bakker et al., 2016). The whole bank lies within the EEZ of the Netherlands. Part of the Bank lies within 12 nautical miles of Saba and falls under their island jurisdiction (Fig. 2.1.1). In recent years the Saba Bank has successively been accorded increasingly important conservation status. Most 
important are its designation as PSSA by the IMO (see introduction) and status as the Netherlands' first "Marine Mammal and Shark Sanctuary".

While this report is fully about the Saba bank, most of the work discussed was not actually done directly on the Saba Bank. For instance, experiments with fish traps for sustainable fishing were not conducted on the Saba Bank but at the nearby island of St. Eustatius. Fisheries assessment as done by port sampling largely took place in Fort Bay, the harbour of Saba and not on the Saba Bank.

\subsection{Fisheries survey}

\subsubsection{General Fleet Description}

In recent years the fleet size of Saba involved in fishing on the bank has generally fluctuated between eight (2012) and ten vessels (2007) (Toller \& Lundvall, 2008). The boats are currently all fiberglass, imported New England-style lobster boats. The length of the vessels varies between 9 and $12 \mathrm{~m}$, and are generally powered by single diesel engines of 300 -600 HP. Typically 2 men man each boat while fishing. All vessels are equipped with GPS, depth finders and a hydraulic winch. All of the vessels use traps, mostly of the typical chevron-shaped trap design (also called "swallowtail" or "arrowhead") found throughout the Caribbean. They are made of coated wire mesh, with mesh sizes of $1 \times 2$ to $2 \times 2$ inch $(2.5$ to $5 \mathrm{~cm})$. The traps with the smaller mesh size are those used for redfish. Fish and lobster traps differ in funnel size, with the funnel of fish traps being narrower. Salted cow hides $(20 \times 20 \mathrm{~cm})$, are used as bait and attached to the traps with coated wires (Toller \& Lundvall, 2008). All traps are provided with an escape panel, a trapdoor on the top of the trap that is fastened with corrodible wire, which is both convenient to get lobsters out of the traps but it is also mandatory. Fisherman interviews in 2012 indicate that there were about 1780 lobster traps in use (222 per fisherman and 8 fishermen). The number of fishermen has since increased back to 10 and the number of traps per fisherman has increased to between 250 and 300. So at present there are between 2500 and 3000 traps in use in the fishery. Most fishing effort is distributed in the northern and eastern quadrants of the bank that lie closest to Saba (Gerwen, 2013).

Gear regulations that apply and which are more or less enforced by the coastguard are as follows:
a) mandatory biodegradable escape trap (not enforced)
b) mesh size of minimally $3.8 \mathrm{~cm}$ or 1.5 inch
c) landing egg-bearing females or moulting specimen is forbidden
d) minimum carapace length (CL) for landed lobsters is $95 \mathrm{~mm}$ (Dilrosun 2000).

\subsubsection{Port sampling}

A sample-based fishery survey (Stamatopoulos, 2002) was implemented in Oct 2013-Dec 2015 (and which continues to date) to collect basic data on catch, effort, species composition and length frequency of the fishery on the Saba Bank (Fig 2.2.1). Rather than directly counting all catches, the total catch was estimated by using data on the number and type of boats (frame survey), the activity level of the boats (boat activity and active days surveys) and the mean catches per boat per day (landings survey). 
Schematic representation of the survey design

The generic formula for estimating catch is:

Catch $=$ CPUE $\times[B A C \times F \times A]$

Where:

CPUE is estimated from a Landings Survey

BAC is estimated from a Boat Activity Survey

$F$ is provided by a Frame Survey

$A$ is determined by an Active Days Survey
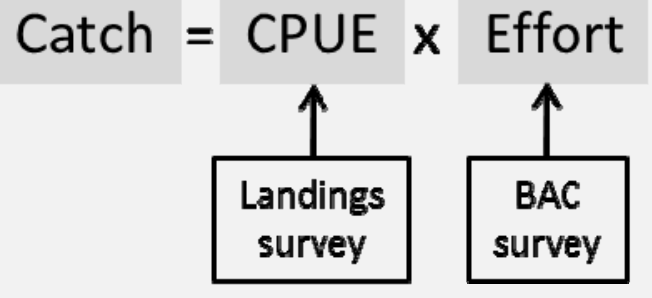

Fig. 2.2.1. Schematic representation of the survey design (from Stamatopoulos 2002).

Frame Survey: A frame survey is a census-based approach to collate a list of homeports and boat/gear categories which is used as the basis for the Active Days, Boat Activity and Landings surveys.

Boat Activity Survey: Boat Activity Surveys were conducted at the only homeport on Saba (Fort Bay) to determine how many boats were active on a given day. Boat activity was recorded nearly every day.

Active Days Survey: Active Day Surveys were conducted at the end of each month to determine the number of active fishing days for each strata in the survey design (e.g. home port, boat/gear category). In the current survey, active days were simply defined as the number of days in a month.

Landings Survey: Landings Surveys were conducted to collect data on catch, effort, species composition and length frequency. In addition to the standard landings data, information was collected on the observations of lionfish, whales and dolphins by fishermen.

Fishing effort was monitored on a daily basis through a trip log. Catch per Unit of Effort (CPUE) for lobster and red fish was monitored through interviews with the fishermen in port ("short interviews"). In these interviews, data was collected on marine mammal sightings and bycatch of shark and lionfish. Data on fishing with other gear types like pelagic trolling, surface and deep-water long lining was also collected. Around 30-40 "short interviews" were conducted each month. Actual length frequency data was collected on lobster, red fish and mixed fish (bycatch species), in port as well as on board during so-called "long interview". During on-board sampling (always "long interviews") additional data on discards was obtained and independent verification was possible of data collected based interviews in port. All data and input obtained from fishermen was treated as confidential.

The calculation of the annual effort and catches was done boat by boat, by month, and per gear. The number of trips conducted by each boat was estimated on a monthly basis. To do so, the number of trips per boat and per month registered during the boat activity survey was corrected to account for the fact that there were always a number of days per month without sampling. The missing observations being predominantly in the weekend, when the activity of the boat was also reduced, this correction was made separately for weekend days, and non-weekend days by dividing the observed number of trips (days for which the boat left the port) by the inverse of the sampling rate (proportion of the days for which the survey took place).

Based on the port sampling interviews, the frequency with which each type of gear was used was calculated per month, per boat, together with the mean number of gear of each type used per trip. Then, for each boat, the number of trips carried out each month for each type of gear was calculated by multiplying the number of trips estimated from the activity survey by the frequency with which each gear was used by a given boat in a given month, obtained from the port sampling. The total 
number of gears for each gear type, and per boat and per month was then obtained by multiplying the number of trips during which each gear was used, by the corresponding mean number of gear per trip. The monthly catches (numbers or kg per gear) for each gear was then calculated per boat by multiplying the monthly average of the catches per trip for the sampled trips by the total number of fishing trips per month estimated from the activity survey.

Annual effort and catches were obtained by summing over months and boats. Since collection started in July 2012, there is therefore roughly only a half year of data available for this year. The total catches and effort for 2012 were raised to take account of this. For each gear, the proportion of the annual effort occurring from July to December was computed for the years with 2013 to 2015. The total effort per gear in 2012 was then divided by this proportion to obtain an estimate for the full year. Catches per group of species was raised in the same way.

While in general the short interviews were conducted properly, the number of on-board long interviews were not conducted according to plan. On-board observation and data collection is critical and in the future this needs to improve.

\subsubsection{Reproductive biology}

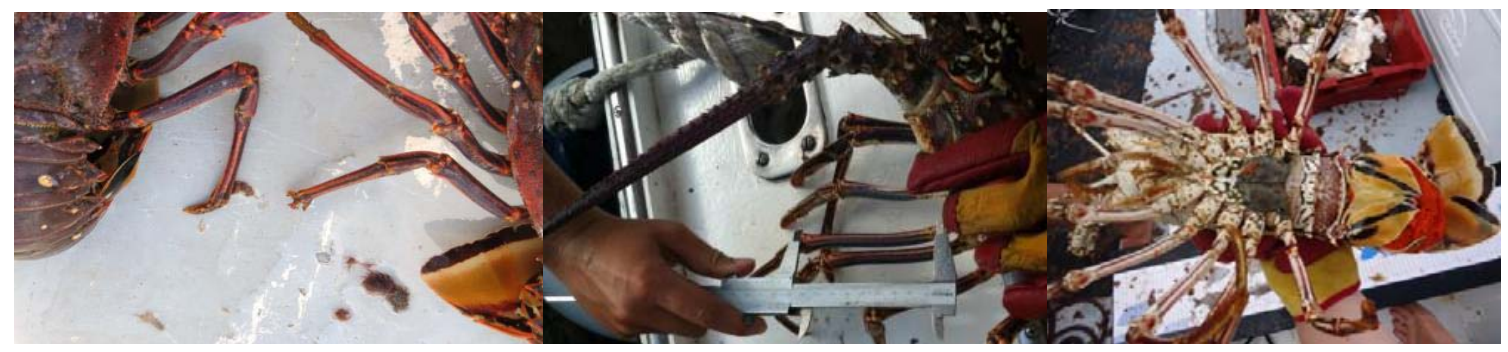

Fig. 2.2. Difference between male (pointed) and female (forked) tip of the last pair of walking leg (left), measuring the merus length of the left walking leg of male (middle) and female lobster with tarspot and egg clutch (right).

In the several crustacean species, i.e. Panulirus cygnus, allometric growth of the second walking leg (periopod) of males has been found to be an indicator for their maturity (Evans et al., 1995; MelvilleSmith \& de Lestang, 2006). The males of P. argus were considered morphometrically mature based on changes in the relationship between the length of the merus (ML) and the carapace length $(\mathrm{CL})$ as determined by a regression analysis following the method described in Melville-Smith \& de Lestang (2006). Female lobster were considered mature when a "tar spot" and/or egg clutch were present (Fig 2.2.2). To determine $C L$ at which $50 \%$ of the male and female P. argus were mature a logistic curve was fitted to the data.

\subsection{Sustainable fish traps}

\subsubsection{Biodegradable panels}

Experiments with fish traps on biodegradable panels, escape slots, trap types and ghost fishing were not conducted on the Saba Bank but at the nearby island of St. Eustatius. There we tested the durability of different materials that can be used to attach escape panels to fish traps. In total seven materials were tested: cotton ( $3 \mathrm{~mm}$ diameter), hemp ( $3 \mathrm{~mm}$ diameters), uncoated (ferrous) steel wire $(1.6 \mathrm{~mm})$, three types of ( $2 \mathrm{~mm}$ diameter) ferrous hog rings (one type of hog ring from a Dutch hardware store and two types of hog rings used in the State of Maine and Atlantic and Gulf trap fisheries) and a biodegradable panel $(4.7 \times 13 \mathrm{~cm}, 5 \mathrm{~mm}$ diameter; Mobjack Binnacle Products). The biodegradable panel was made from Polyhydroxy-alkanoates which are a family of naturally occurring bio-polyesters that are produced by bacteria and are completely biodegradable by microbes typically found in the marine environment. 


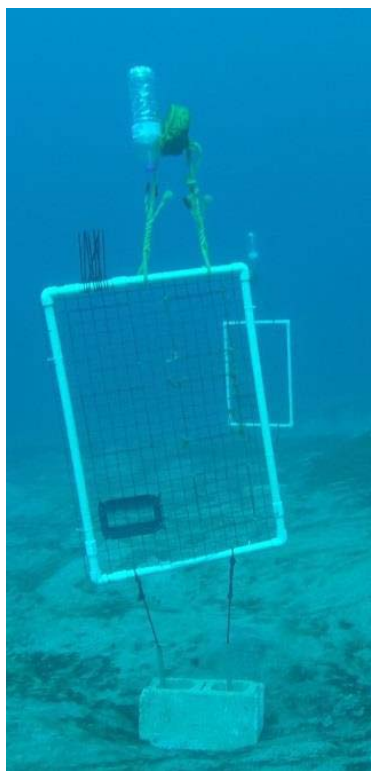

With PVC pipes (diameter $2.7 \mathrm{~cm}) 12$ frames $(91 \times 53 \mathrm{~cm}$ ) were made. In this PVC frame, coated fish trap wire $(2.5 \times 2.5 \mathrm{~cm})$ was connected to the frame with cable ties. In each of the 12 frames, 6 squares of $20.3 \times 20.3 \mathrm{~cm}$ were cut. This size equals the US Government Caribbean Fisheries regulations and NOAA descriptions (NOAA, 2014) for escape panels in fish traps. Each cutout square was replaced in the frame reconnecting them randomly with one of the test materials. Frames 1-9 comprised all materials except the Gulf and Maine hog rings. Frames 10-12 consisted only of randomly placed Gulf and Main hog rings. The exact positions of the testing materials for each panel are provided (Hekkema 2015).

Fig. 2.3.1. Frame placement for assessment of biodegradable panels.

The frames were connected to a concrete block and floats in order to keep the panels in a vertical position (Fig 2.3.1). Frames 1-9 were deployed at 710-2014, panels $10-12$ at 28-10-2014. All frames were deployed $\left(17^{\circ} 29^{\prime} 04.73^{\prime \prime} \mathrm{N} 62^{\circ} 59^{\prime} 52.60^{\prime \prime} \mathrm{W}\right)$ at a depth of ca. $21 \mathrm{~m}$. Every two weeks, an underwater observation was conducted using scuba. Photos and/or video were taken of each corner of each square. Each corner was individually checked whether the material was still in place or if material was missing. In addition, observations on appearances of the material were made, such as the presence of rust, ravels, or algae.

\subsubsection{Ghost fishing}

Two experiments were conducted in the inshore waters of St Eustatius to determine the impact of ghost fishing by derelict traps. In the first experiment one rectangular coated wire trap $(5 \times 2.5 \mathrm{~cm}$ mesh) (Fig. 2.3.2) was positioned next to a small wreck near Smoke Alley at a depth of $\sim 2-3 \mathrm{~m}$. The trap was monitored three times a week for a period of 75 days (23/9/2014-4/12/2014). During each

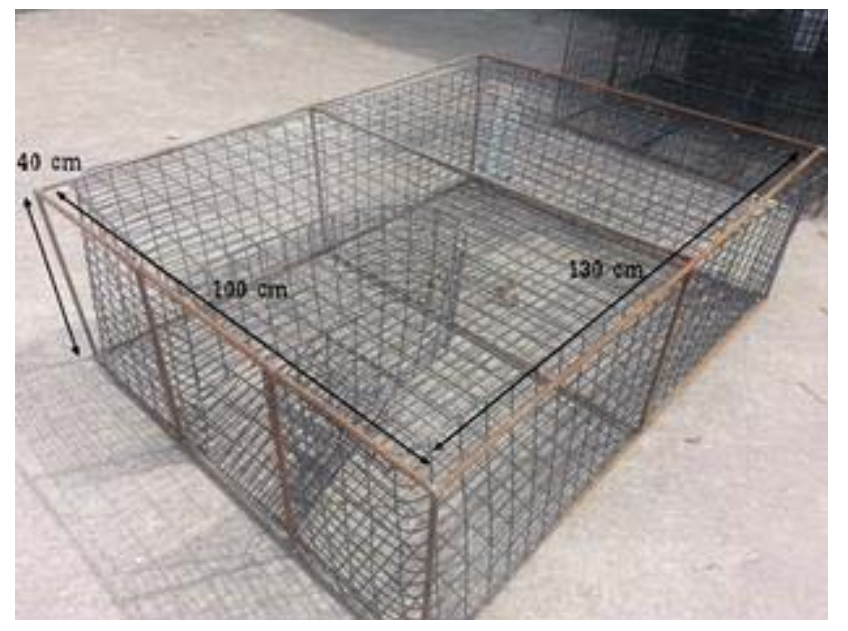
visit all live and dead fish were identified to species level. In the second experiment three rectangular coated wire traps $(5 \times 2.5 \mathrm{~cm}$ mesh) were positioned near the dive site "Crooks Castle" between 7-11 meters deep. Using SCUBA, the traps were observed three times a week for a period of 89 days (2/12/2014-27/2/2015). During each dive the lobsters and fish in the traps were identified to species level, counted and the length was estimated to the $\mathrm{cm}$ level (and above $20 \mathrm{~cm}$ in length classes of $5 \mathrm{~cm}$ ). Dead and damaged individuals were counted.

Fig. 2.3.2. Wire fish traps used for ghost fishing experiments.

\subsubsection{Escape slots}

\subsubsection{Lobster traps}

In the first experiment, traditional Antillean lobster traps of the arrowhead design were fitted with two escape vents with a height of $250 \mathrm{~mm}$ and a width of $25 \mathrm{~mm}$ (Fig. 2.3.3). In the second experiment traps were fitted with two escape vents with a height of $250 \mathrm{~mm}$ and a width of $38 \mathrm{~mm}$. Vents were placed at the left front corner and the opposite, right back corner from of the entrance funnel. 


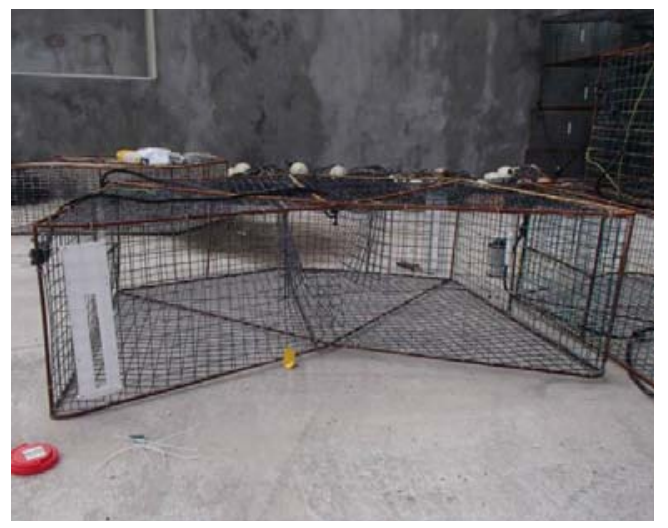

At the start of the first experiment nine D-traps ( 5 feet lobster traps, $25 \mathrm{~mm}$ mesh) were used of which five were fitted with two $25 \mathrm{~mm}$ escape vents and four other traps were used as a control. In addition, 10 smaller traps of a co-operating fisher (M-traps; 4 feet lobster traps, $38 \mathrm{~mm}$ mesh) were used, five where fitted with two $25 \mathrm{~mm}$ escape vents and five were used as control. During the first experiment between June and July 2015 there were five fishing days when the traps were lifted and the catches recorded.

Fig. 2.3.3. Placement of escape slots on traditional arrowhead trap.

At the start of the second experiment seven D-traps (5 feet lobster traps, $25 \mathrm{~mm}$ mesh) were used of which three were fitted with two $38 \mathrm{~mm}$ escape vents and four traps others were used as a control. In addition, 10 smaller traps of a co-operating fisher (M-traps; 4 feet lobster traps, $38 \mathrm{~mm}$ mesh) were used, four were fitted with two $38 \mathrm{~mm}$ escape vents and six were used as control. During the second experiment between August 2015 and April 2016 there were 12 fishing days when the traps were lifted and the catches recorded.

During both experiments, traps were baited with $20 \times 20 \mathrm{~cm}$ salted cow hides and deployed at a depth of ca. 10 meters with $50 \mathrm{~m}$ between the traps. Traps were pulled and bait replaced every seven days, depending on the weather. Captured fish and lobster were identified to species level and measured to the nearest $\mathrm{cm} \mathrm{FL,} \mathrm{TL} \mathrm{or} \mathrm{mm} \mathrm{CL}$ (lobster).

\subsubsection{Redfish traps}

Between February and May 2015, fifteen fishing days with seven coated wire mesh $(5 \times 2.5 \mathrm{~cm})$ redfish traps (two control traps, three traps with $25 \times 250 \mathrm{~mm}$ escape vents and two traps with $38 \times 250 \mathrm{~mm}$ escape vents) were conducted on the Saba Bank. Escape vents were fitted in the left front and right back corner of the trap. All seven traps were used for all 15 trips, so in total 105 traps were pulled. Traps were baited with "Japanese bait" (Cololabis saira) and set for 3-13 days at depths varying from $92 \mathrm{~m}$ to $103 \mathrm{~m}$. All fish were identified to species level and measured to the nearest $\mathrm{cm}$. 


\section{$2.4 \quad$ Whales and dolphins}

In addition to data collection relating specifically to the fishing areas used by the fishermen on the bank, data was also collected on cetacean sightings during navigation to and from the fishing grounds. Hence, for this aspect the actual study area was much larger than for fishery monitoring. The study area consisted of the waters around the island of Saba, with the largest part being covered by the Saba Bank (Fig. 2.4.1). The study area was divided into 20 sub-areas (A1 to D5). The observations were made by fishermen and recorded during port sampling.

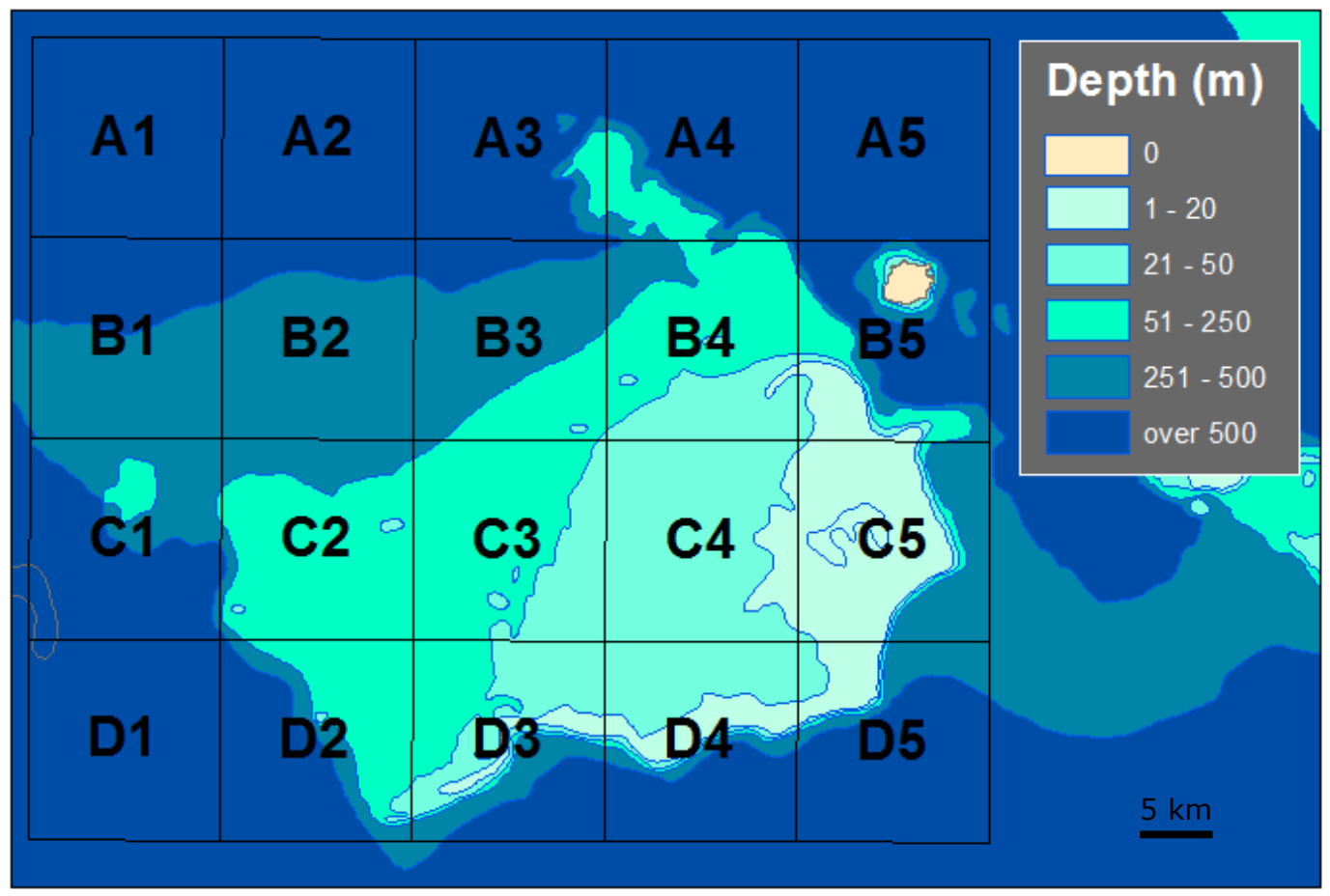

Fig. 2.4.1. Overview of the study area with the 20 sub-areas used in the fishery monitoring scheme.

Data collection followed the methods described in Scheidat et al. (2015). For this study only the landings surveys were used. This component of the fisheries survey was conducted when the fishermen had returned into the harbour. Information collected was aimed to monitor fishing catch and effort, but it also included the question if any dolphin(s) or whale(s) had been sighted and fishermen were asked to provide details on their sightings.

For the cetacean database derived from the port sampling the following information was included: date, boat name, fishing sub-area, sub-area of cetacean sightings, number of whale and/or dolphin sightings, number of whales and/or dolphins, group size, group composition (e.g. presence of calves), behaviour and species. When a range for group size was given, the mean of that range was used as a best estimate. Effort was calculated by using the frequency of visitations to each sub-area in which the observation was recorded. In some records this information was not available; in those cases sightings were assumed to be in the sub-area in which the main fishing effort occurred. The relative frequency of cetaceans was described as sightings per fishing days (or animals per fishing days). Data were collected from 10 July 2012 to 30 May 2016. The fishing vessels leave from Fort Bay (Saba's only harbour in the Southwest of the island) to their fishing grounds. In 2012 the fishermen of Saba were given laminated field guides describing the most common cetacean species in the area to aid in the identification of sightings.

To obtain a relative value for cetacean occurrence we calculated the mean number of sightings per effort (fishing day) as well as the mean number of animals per effort (fishing day). This resulted as the frequency of occurrence indices of cetacean sightings per fishing day and cetacean numbers per 
fishing day (separately for dolphins and whales). For the distribution of sightings, this value (sightings per animals per day) was calculated per sub-area for the three islands. To look into the spatial distribution the number of times fishing occurred in a sub-area was used as a proxy for observation effort. Fishermen could fish in more than one fishing area per day. The GIS analysis followed the steps of data collection, data formatting and classification. The main parameters for analysis were sightings/animal numbers by days fishing. The size of each sub-area $\left(\mathrm{m}^{2}\right)$ was calculated using ArcGIS (ESRI Ocean World Ocean Reference, which included bathymetry data). The mid-point of each subarea, indicating the middle of the fishing zone, was identified using the 'finding middle point' construction tool in ArcGIS. The number of sightings/animal numbers by the effort (fishing days) were fused with the middle point of the each fishing zone.

\subsection{Queen conch survey}

\subsubsection{Reproductive biology}

\section{Size at maturity}

Queen conch were collected on the south eastern part of the Saba Bank $\left(17.34^{\circ},-63.27^{\circ}\right)$. A first collection of 65 conch with flared shell lips was made on the $21^{\text {st }}$ and $22^{\text {nd }}$ of July 2014 . An additional collection of 20 conch with flared shell lips was made at the same location on the $6^{\text {th }}$ of August 2015. Conchs were collected during the peak reproductive season to ensure that the collected conch, if mature, had fully developed gonads. The samples were collected at depths between $20-25 \mathrm{~m}$ on sand and hard-bottom. To determine the relationship between sexual maturity and shell lip thickness (i.e. queen conch age), male and female conch were collected from eight lip thickness interval groups between 0-40 mm. Although effort was made to collect a minimum of 5 conch from each lip thickness interval group of both genders, due to the difficulty of finding males $<10 \mathrm{~mm}$ lip thickness, only 1 conch from the $<5 \mathrm{~mm}$ lip thickness interval group and two conch between $5-9 \mathrm{~mm}$ lip thickness interval group were collected. Gender was determined by visual examination of the conch after being removed from the shell. The presence of a verge (male) or egg grove (female) was used to determine gender. A sample of the gonad tissue was removed (ca. $10 \mathrm{~mm}^{3}$ ) from each gonad for histological preparation. Samples were prepared and mounted on glass slides according to the steps described by Stoner et al. (2012a). All samples underwent histological analysis and were inspected for stages of gametogenesis, percent cover of gametogenic tissue and given a reproductive classification following procedures adapted from Delgado et al. (2004). Minimum ( $L T_{\min }$ ) size at maturity and the size at which $50 \%$ of the queen conch were mature $\left(\mathrm{LT}_{50}\right)$ were determined for both females and males. To estimate $\mathrm{LT}_{50}$ a logistical curve was fitted through a relationship between the proportion of mature conch $\left(P_{m}\right)$ and $L T$.

\section{Reproductive season}

Due to logistical and safety hazards it was not possible to conduct regular surveys using scuba to study seasonality in reproductive behaviour. The area right outside the harbour on Saba (Fort Bay; $17.615^{\circ},-63.252^{\circ}$ ) was use to study seasonality in reproductive activity. Surveys were conducted from September 2013 until May 2015, in depths between 9-24m on a sand/algae bottom. During each survey two to three SCUBA divers search the study area for queen conch and classified each conch encountered to a reproductive category as described by Stoner et al., 1992; (1) Pairing: Two conch were aligned, with the anterior part of the shell of one animal overlapping the posterior part of the shell of the other; but copulation was not observed. (2) Copulating: Animals were engaged in copulation, with the verge of the male beneath the mantle of the female. (3) Egg-laying: A female was actively laying an egg mass. (4) Non-reproductive: Conch was not engaged in reproductive behavior. Life status, presence of a flared shell lip and thickness of flared lip if present were also recorded. Reproductive seasonality was quantified by calculating the percent of the total amount of queen conch participating in each reproductive behavior category for each month. Surveys from 2013-2015 were pooled during analysis. Due to fishing activities in the survey location during several months of 2013 and 2014 the amount of conch was drastically decreased and the densities of conch in these months were estimated to be so low that reproductive behavior was unlikely to occur, due to the strong allee effect in conch reproductive behavior (Stoner et al., 2012b). These months were removed from the analysis. 


\subsubsection{Distribution and abundance}

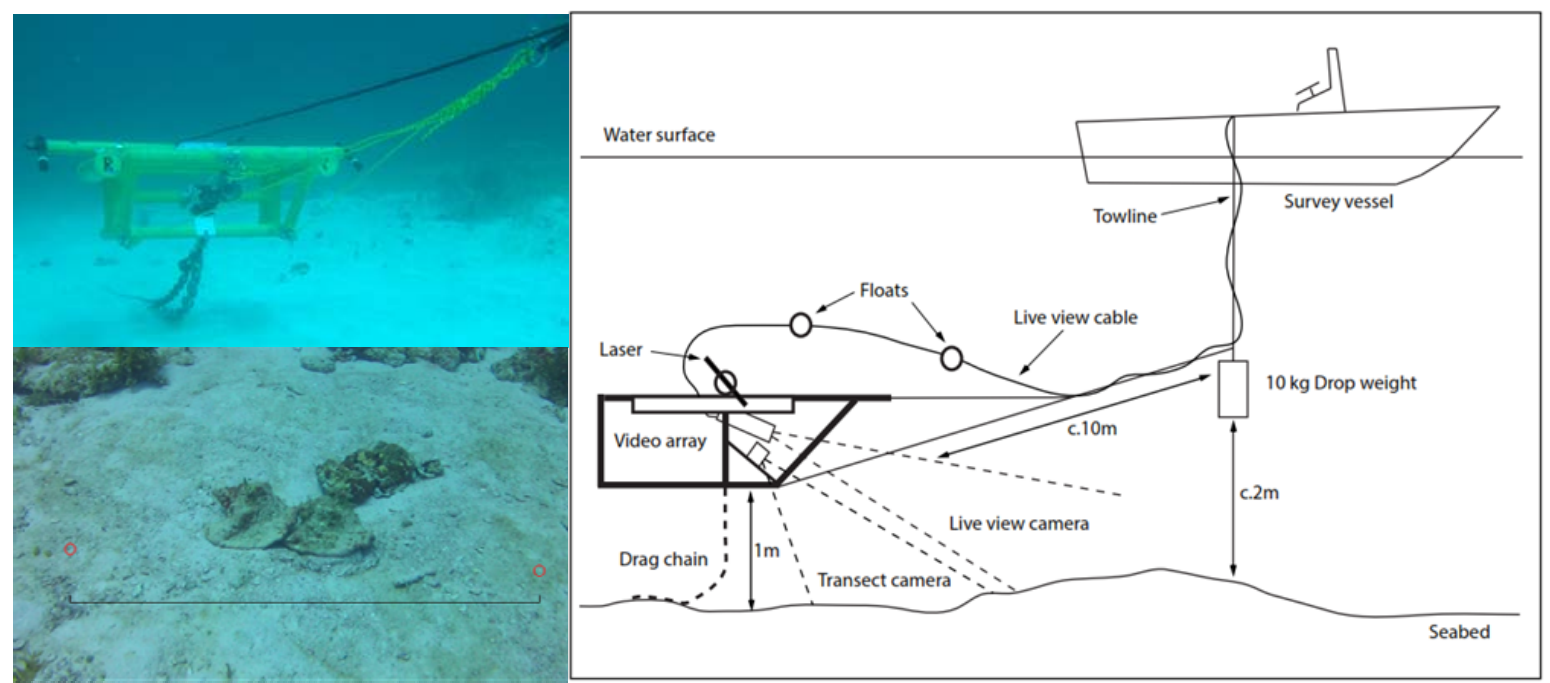

Fig. 2.5.1. Towed video method for adult conch surveys.

To survey the adult conch population of Saba Bank, also at greater depths, a towed video method was used (Boman et al., 2016) (Fig. 2.5.1). In addition to the video surveys a limited amount of belt transects using scuba was conducted during the 2013 Saba Bank expedition. The towed video method consisted of a PVC frame with a live view camera (Seaview super mini by Seaviewer Cameras Inc., www.seaviewer.com) and a transect camera (GoPro Hero 2 by GoPro, www.gopro.com). The $1 \mathrm{~m}$ width of the transect was indicated by two green laser (Z- bolt SCUBA-1 Underwater green laser (Beam of Technologies Inc., www.z-bolt.com) mounted parallel on a PVC bar on top of the frame at a fixed distance of $1 \mathrm{~m}$ apart. The array was towed behind a small vessel, using a towline, which was connected to the frame. Two sealed and air-filled PVC pipes attached on top of the frame kept the array slightly positively buoyant. A length of chain attached to the bottom of the frame secured the downward position of the frame and allowed the array to hover over the bottom. The array was towed behind a small vessel using a towline which was connected to the frame. The length of the towline was adjusted depending on depth. A $10 \mathrm{~kg}$ drop weight was attached to the towline $10 \mathrm{~m}$ in front of the frame to ensure that the frame was kept in a horizontal forward position and helped to absorb some of the movements caused by surface waves. The video array was towed at low speeds $\left(0.25-0.5 \mathrm{~m} \cdot \mathrm{s}^{-1}\right)$ or when possible the vessel drifted with the current and/or the wind. GPS points of the begin and end point were determined with a handheld GPS (Garmin GPSmap 78), which was set to track the position every 10 seconds to accurately follow the transect and calculate transect length. Begin and end depths were also recorded for each transect and determined by the vessel's depth sounder. The video recordings of the transects were saved on SD cards and converted to AVI-files using Xilisoft video converter (Xilisoft Corporation, www.xilisoft.com).

In order to limit handling time of the equipment, three transects, each approximately $500 \mathrm{~m}$ long $\left(500 \mathrm{~m}^{2}\right)$ were towed consecutively, separated by a 200 meters perpendicular distance to the transect direction. Sampling locations were assigned randomly, stratified over two depth zones (20-30m and $>30 \mathrm{~m}$. No sampling locations were assigned in the shallow eastern and south-eastern ridge, due to the high relief areas (e.g. coral reefs) in this part of the Saba Bank. Such areas are unsuitable to use the towed video method in as the array is unable to navigate over high obstacles. High relief areas are also not commonly associated with queen conch (Acosta, 2006).

After conversion videos were analyzed for the occurrence of adult queen conch using TransectMeasure computer software (SeaGIS Pty. Ltd., www.seagis.com.au). All adult conch inside the transect as well as all adult conch who's shell was more than $50 \%$ inside the transect were counted by the video 
analyst. Additionally, for each transect 20 random screenshots were taken and overlaid with 10 random dots per screenshot for which habitat-substrate was recorded.

The density (per ha) for adult (flared-lip) live conch was calculated for each transect in relation to its length, width of the transects was always $1 \mathrm{~m}$. The video analyst determined live from dead conch based on visual cues (e.g. position of the conch, damage to shell, tracks on the sea bottom, movement).

The belt transects using scuba dive were conducted in the east and south east edge of the Saba Bank in reef habitat where the towed video is not a suitable sampling method. At each location a $50 \mathrm{~m}$ long and $10 \mathrm{~m}$ wide belt transect was conducted, covering and area of $500 \mathrm{~m}^{2}$. Coordinates of the dive survey location were taken by a GPS (Garmin GPSmap 78). The density (per ha) for adult (flared-lip) live conch was calculated for each transect in relation to its length.

Relationship between abundance of conch and depth was investigated through regression and correlation analysis in the software environment R ( $R$ Core Team, 2016). Due to the high numbers of 0 values in the data a spearman's rank correlation was done for density against depth in meters.

The adult queen conch stock on the Saba Bank was estimated by depth stratification; 20-30m and 30.1-40m. Mean conch densities (per ha) for each depth zone was calculated by bootstrapping (performing 1000 bootstraps and BCa confidence intervals) in the software environment R ( $R$ Core Team, 2016). Estimation of stock size was given by multiplying the mean conch density per depth category with the corresponding surface area on the Saba Bank. 


\section{Results}

\subsection{Annual catch and effort}

As most fishermen had their traps in the water, the number of traps each fishermen had could not be independently counted. Based on the average number of traps lifted per trip and the average soak time it was possible to estimate the actual number of traps per fisherman. Based on our calculations the average number of traps was about 250-300 traps per fisherman. Only few traps were typically on land for repairs and not fishing at any particular time. Average trap soak time was 10.0 days for the lobster fishery and 3.7 days for the redfish fishery. The data show an increase in the number of fishing trips using lobster traps from roughly 600 days in 2012 for around 50,000 trap drops to 900 days in 2015 corresponding to around 74,000 trap drops (Fig. 3.1.1). The landings of lobster have also increased over these 4 years, from 37 to 76 tonnes annually (Fig. 3.1.1 and Table 3.1.1). Landings of fish in the lobster traps also doubled over the same period. The number of trips using redfish traps has also increased until 2014 and decreased in 2015 and the catches of redfish followed a similar trend. The number of trolling trips has been rather constant, with a small increase in 2014. The estimated landings of pelagic fish have doubled over the period studied (from 1.5 tonnes in 2012 to 3 tonnes in 2015). The number of trips using longlines has been stable for the first 3 years and increased in the last year. The effort in number of hooks is very variable, reflecting the fact that the few vessels involved change between the years and that they each have different number of hooks per lines. Landings also increased in the last year, to reach 3 tonnes of fish.
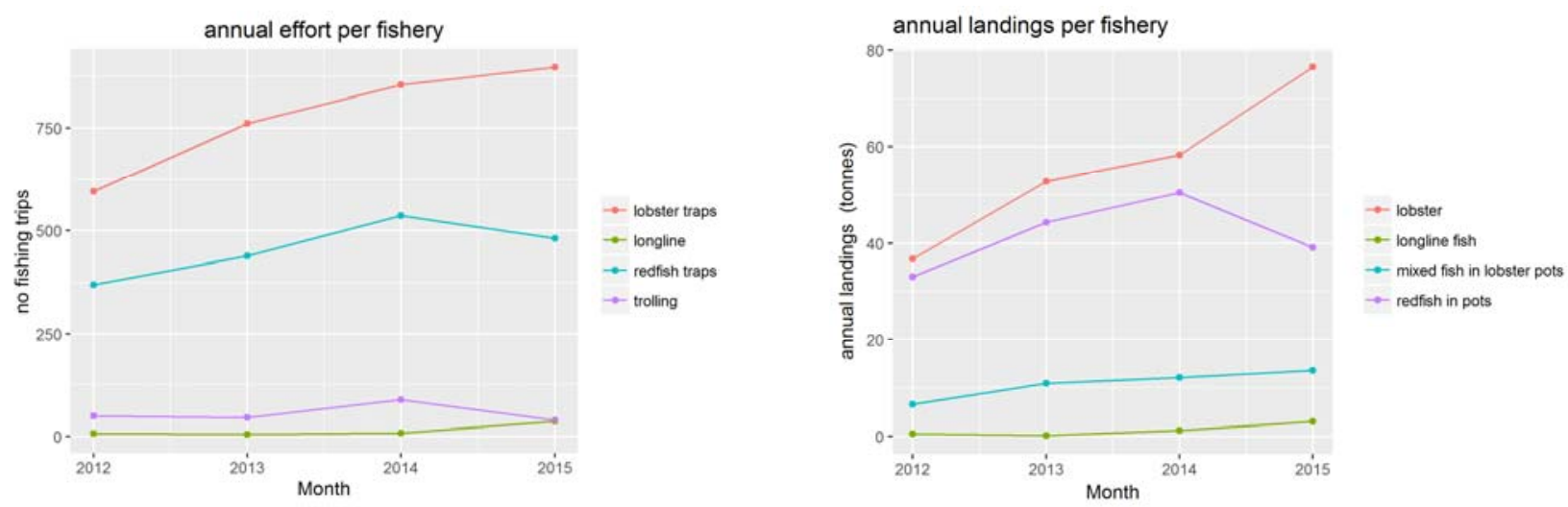

Fig. 3.1.1. Annual landed catch per group of species (in tonnes) and fishing effort per gear in fishing days estimated from the port sampling and activity survey carried out from 2012 to 2015. 
Table 3.1.1. Estimates of the annual effort (number of gear used and number of fishing trips) and annual landed catches for the year 2012 to 2015.

\begin{tabular}{|c|c|c|c|c|c|}
\hline fishery & landings & & $\begin{array}{l}\text { number of gear } \\
\text { denlovments }\end{array}$ & & $\begin{array}{l}\text { fishing } \\
\text { davs }\end{array}$ \\
\hline \multicolumn{6}{|l|}{2012} \\
\hline Lobster trap (lobster) & 36.8 & $\mathrm{~T}$ & 48565 & traps & 596 \\
\hline Lobster trap (mixed reef fish) & 6.6 & $\mathrm{~T}$ & 48565 & traps & 596 \\
\hline Redfish traps (fish) & 33.0 & $\mathrm{~T}$ & 11217 & traps & 369 \\
\hline Bottom longline (fish) & 0.5 & $\mathrm{~T}$ & 1955 & hooks & 7 \\
\hline Pelagic trolling (fish) & 1.5 & $\mathrm{~T}$ & 142 & lines & 49 \\
\hline \multicolumn{6}{|l|}{2013} \\
\hline Lobster trap (lobster) & 52.8 & $\mathrm{~T}$ & 63000 & traps & 761 \\
\hline Lobster trap (mixed reef fish) & 10.9 & $\mathrm{~T}$ & 63000 & traps & 761 \\
\hline Redfish traps (fish) & 44.3 & $\mathrm{~T}$ & 13067 & traps & 439 \\
\hline Bottom longline (fish) & 0.1 & $\mathrm{~T}$ & 228 & hooks & 5 \\
\hline Pelagic trolling (fish) & 1.6 & $\mathrm{~T}$ & 181 & lines & 45 \\
\hline \multicolumn{6}{|l|}{2014} \\
\hline Lobster trap (lobster) & 58.3 & $\mathrm{~T}$ & 66076 & traps & 854 \\
\hline Lobster trap (mixed reef fish) & 12.1 & $\mathrm{~T}$ & 66076 & traps & 854 \\
\hline Redfish traps (fish) & 50.5 & $\mathrm{~T}$ & 15381 & traps & 537 \\
\hline Bottom longline (fish) & 1.2 & $\mathrm{~T}$ & 4545 & hooks & 8 \\
\hline Pelagic trolling (fish) & 2.5 & $\mathrm{~T}$ & 240 & lines & 88 \\
\hline \multicolumn{6}{|l|}{2015} \\
\hline Lobster trap (lobster) & 76.5 & $\mathrm{~T}$ & 73604 & traps & 896 \\
\hline Lobster trap (mixed reef fish) & 13.6 & $\mathrm{~T}$ & 73604 & traps & 896 \\
\hline Redfish traps (fish) & 39.1 & $\mathrm{~T}$ & 10939 & traps & 481 \\
\hline Bottom longline (fish) & 3.0 & $\mathrm{~T}$ & 2081 & hooks & 36 \\
\hline Pelagic trolling (fish) & 3.0 & $T$ & 107 & lines & 39 \\
\hline
\end{tabular}

\subsection{Lobster Trap Fishery}

\subsubsection{Lobster}

\subsubsection{CPUE}

\section{Catch and effort data:}

The mean number of traps set per fishing trip has been relatively stable over the period studied at around 75 traps per trip in 2000 and since 2013, with a small increase in 2007, 2011 and 2012 at around 85 traps per trip (Fig. 3.2.1). Taking in consideration the annual number of trips (estimated since 2012 by the boat activity survey), the effort expressed as the annual number of traps set has increased between 2012 and 2015 from around 48000 traps/year to 73000 traps/year (Table 3.1.1)

The spatial distribution of the effort is reported accurately only since 2013 (Fig. 3.2.2). The data since 2013 show that the annual distribution has been stable, with the main fishing areas remaining in B4, B5 and C5 (north-western part of the bank, closer to the Saba island). The data also show some seasonality in the distribution of the effort on the bank, with for instance a decrease of the effort in proportion on the south of the bank (D3-5) during summer. 


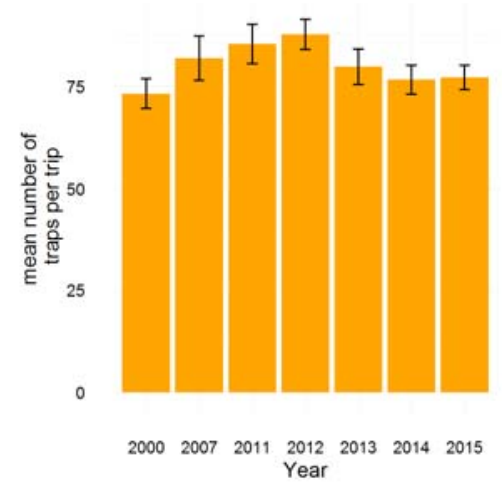

Fig. 3.2.1. Mean number of traps lifted per trip (with $95 \%$ confidence intervals).
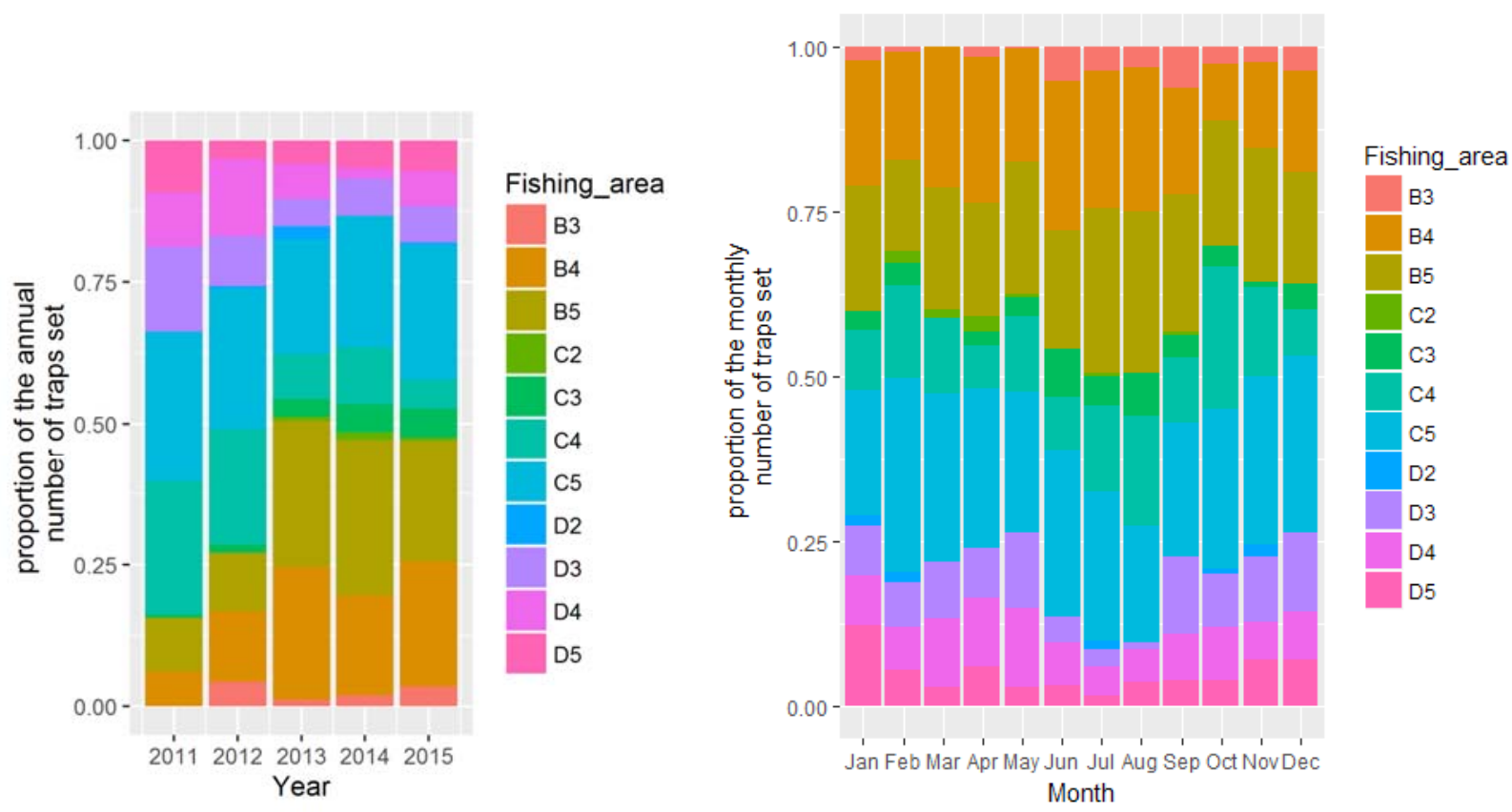

Fig. 3.2.2. Proportion of the annual (left) and monthly (right) effort of the lobster fishery (in total number of traps set) per fishing area.

Given that the number of traps per trip has been fairly stable, the temporal variation over the period covered by the data in the number of lobster landings per trap and in the landings per trip are similar (Fig. 3.2.3). Catch rates were substantially higher in 2000, and decreased in 2007 and 2011 where the lowest value was observed. Catch rates have slowly increased since then, but have not recovered to the level observed in 2007.

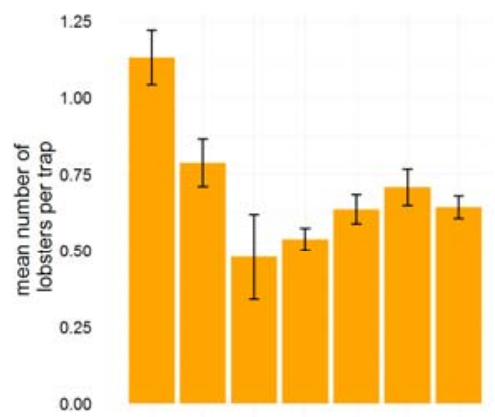

2000200720112012201320142015
Year

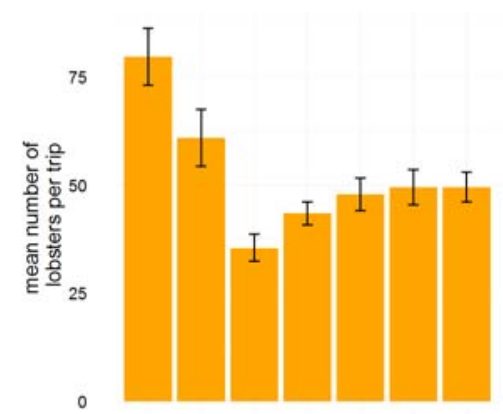

$2000200720112012 \quad 2013 \quad 20142015$
Year

Fig. 3.2.3. Yearly mean number of lobster per trap (left) and per trip (right) (with $95 \%$ confidence intervals). 


\section{Standardisation of the CPUE using a GLM model}

Part of the variations in the annual mean catch rates reflect other factors than changes in lobster abundance, such as changes in overall effort, monthly or spatial repartition of the effort, different contribution of different vessels to the annual effort. In order to standardise the catch rates and extract an annual abundance index, the landings of lobster per trip where modelled using a GLM with a Poisson distribution. The formulation of the full model is as follows:

$\begin{array}{ll}\log (\text { lobster number per trip) } \quad=\quad \text { intercept } & + \text { Year effect } \\ & + \text { Month effect } \\ & + \text { Boat effect } \\ & + \text { Fishing area effect } \\ & + \text { log(trap number })\end{array}$

In this formulation of the model, one parameter is estimated for the intercept and for each of the levels of the different effects (year, month, boat and area). One parameter is also estimated for the linear regression of $\log$ (lobster number) against log(trap number). This model formulation implies a power function between catch and effort, which is the formulation typically used for ad hoc standardisation of catch rates in trap fisheries. The year effects estimated by this method correspond to the variations in the catch rates which are explained by the year, when all other sources of variation have been taken into account (including the changes in effort). These year effects can therefore be interpreted as abundance indices for lobsters of commercial size.

The model was fitted two times, on two different dataset. The first one, using all the effects as in the formula above, was fitted on the data for the years 2011-2015. For the earlier years, the information boat name and fishing area was not available and the model was fitted again without these effects for the years 2000-2015.

All factors appeared to be significant in the model fitted to the data for the years 2011-2015, except for the fishing area (table 3.2.2). For the model fitted on the data for the longer time period, all effects (month, year, trap number) were significant. The estimated effects are shown in figure 3.2.4. There were differences observed in the catch rates of the 5 vessels, with the most efficient vessel landing 20\% more than the less efficient one. The month effect shows the seasonality of the catch rate for a standard trip. There is a clear seasonal pattern, with highest catch rates toward the end of the year, and low catch rates during late spring/early summer. The modelled year effect is a standardised annual abundance index. It shows that the abundance dropped from higher levels in 2000 to lower levels in 2011, with a progressive increase towards the level of 2007 since then.

Table 3.2.1. Significance of each model term tested by removing them one by one and comparing to the full model (GLM model of lobster catches per trip). AlC stands for Akaike information criterion (the lower the value the higher the effect), a P-value lower than $0.05\left(^{*}\right.$ ) indicates that the effect of the corresponding factor in the model is significant. $(* *=\mathrm{P}$-value lower than $0.01, * * *=\mathrm{P}$-value lower than 0.001)

\begin{tabular}{rrrrrr}
\hline Model term removed & $\begin{array}{r}\text { Number of } \\
\text { parameters }\end{array}$ & AIC & $\begin{array}{r}\text { Log-Likelihood } \\
\text { ratio }\end{array}$ & p. value & $\begin{array}{r}\text { Significance } \\
\text { level }\end{array}$ \\
\hline <none (full model) & & 6645 & & & \\
factor(Year) & 4 & 6759 & 121 & $<2 \mathrm{e}-16$ & $* * *$ \\
factor(Month) & 11 & 6850 & 226 & $<2 \mathrm{e}-16$ & $* * *$ \\
factor(Boat_name) & 4 & 6650 & 12 & 0.0144 & $*$ \\
factor(Fishing_area) & 8 & 6639 & 10 & 0.2858 & $* * *$ \\
logTraps & 1 & 7082 & 439 & $<2 \mathrm{e}-16$ & $* * 26$ \\
\hline
\end{tabular}



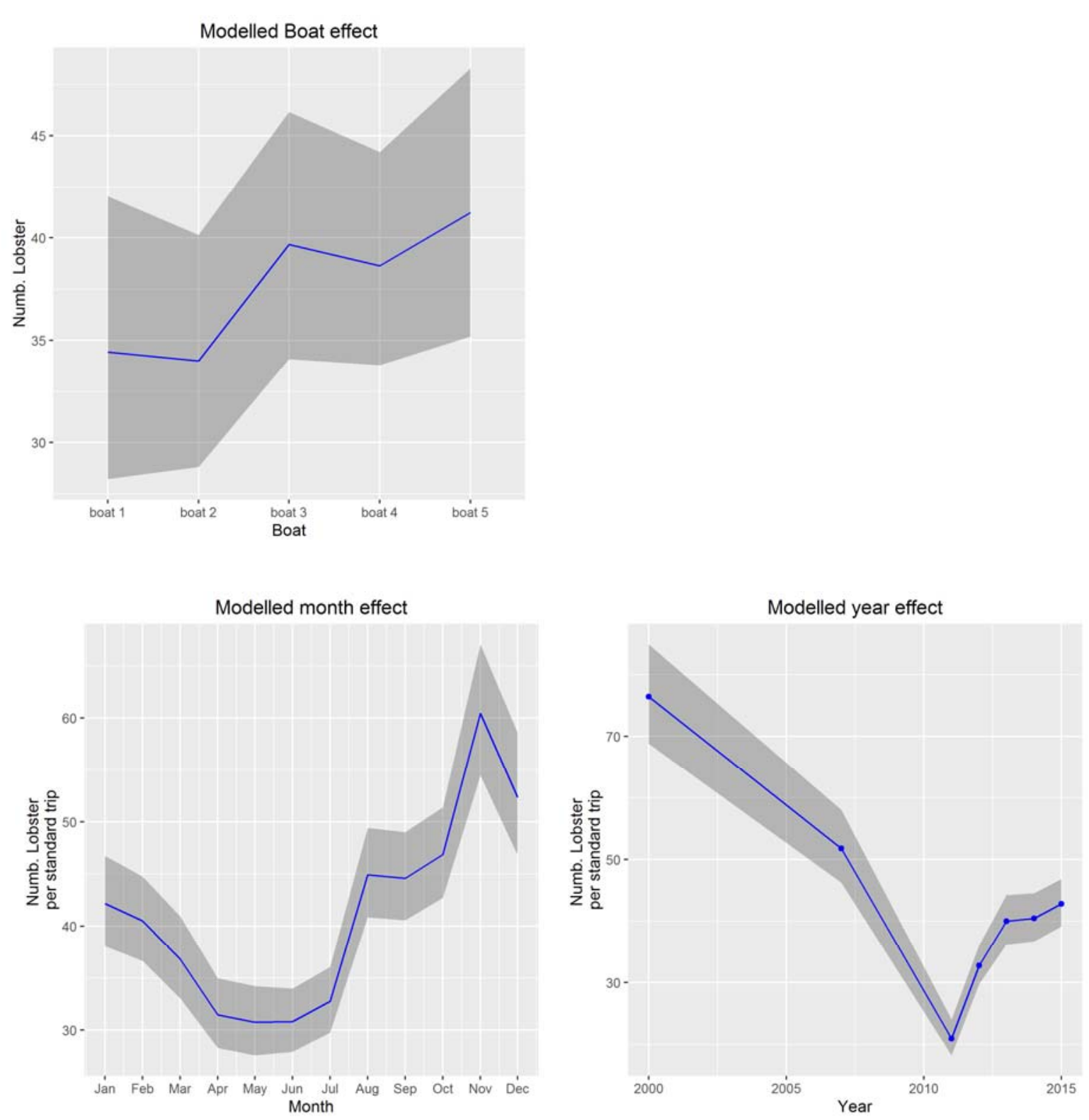

Fig. 3.2.4. Modelled boat effect (model fitted on the data for 2011-2015) and modelled month and year effects (model fitted on the data 2000-2015) on the landings of lobsters per trips (in numbers). Blue lines represent the modelled effect (and corresponding 95\% prediction envelop in grey).

\subsubsection{Length frequency}

Lobster length measurements were taken on the catches during the landing surveys conducted in the harbour at the end of a fishing trip. In addition, for a small number of trips, length measurements were taken by observers on-board, providing information on the length distribution of the whole catch (i.e. including the discarded fish).

The size of the lobsters landed varied from $50 \mathrm{~mm}$ (carapace length) to $200 \mathrm{~mm}$, but the bulk of the landings were between $90 \mathrm{~mm}$ and $150 \mathrm{~mm}$ (Fig 3.2.5) with a mean varying between 105 and 118 $\mathrm{mm}$, above the minimum landing size of $95 \mathrm{~mm}$. There were marked differences in the size composition of the catches between the years, with larger individuals landed (especially the males) in 2011 and small individual landed (especially the females) in 2000 and 2012 (Fig 3.2 .6 and Table 3.2.2). In 2000 and 2012, the proportion of landed lobster below the minimum size were $27 \%$ and $28 \%$ respectively (up to $43 \%$ for the females), whereas in other years, this percentage was lower than $15 \%$. In general the males landed were larger than the females by about $5 \mathrm{~mm}$, but the difference was particularly large in 2000 and 2011 (12 mm). The proportion of males in the catches is also 
higher than the females (except for 2011). It should be noted that the data for 2007 and 2011 was collected only during 6 (mid-year) and 4 (end of the year) months, respectively and therefore may not be directly comparable with the other years.

The data collected during the trips with observer on board allow for comparison of the length composition of the discards and of the landed catches (Fig. 3.2.7). While the mode of the landings is at around $100 \mathrm{~mm}$ (just above the minimum size), the mode of the discarded lobsters is at around $90 \mathrm{~mm}$, just under the minimum size. There were also multiple secondary modes in the distribution of the discards at 110 and $125 \mathrm{~mm}$, corresponding to the discards of berried females (Fig. 3.2.7). The sex ratio shows a large predominance of females in the discards (Table 3.2.2). Discarded females are of a larger mean size than the males, due to the higher proportion of individuals above the minimum size discarded (berried females) (Table 3.2.3).

\section{Lobster length distribution}

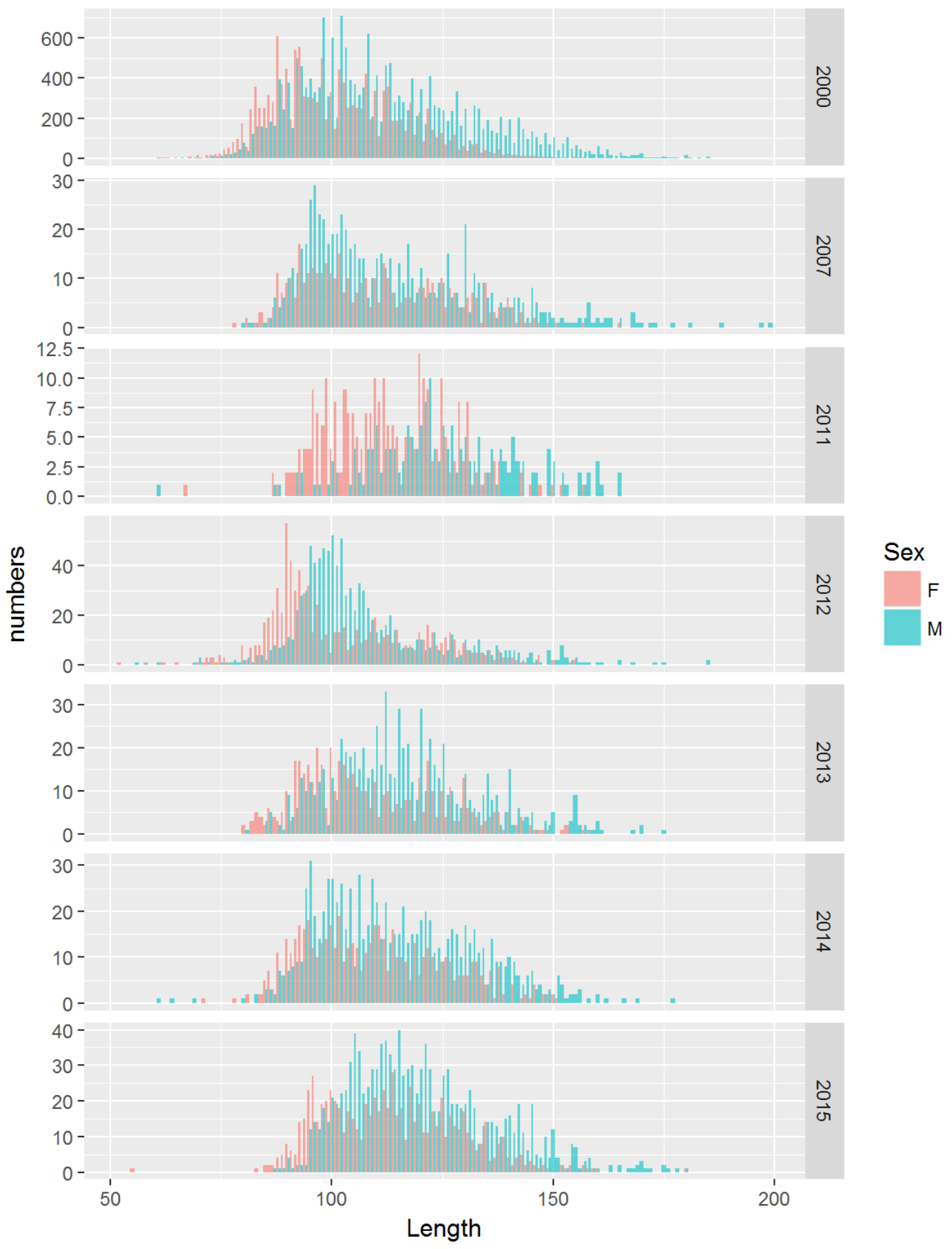

Fig. 3.2.5. Number (val) of landed lobster CL (carapace length, $\mathrm{mm}$ ) and length distribution by sex from the port sampling program (long interviews). 
Table 3.2.2. Mean length $(C L)$ and sex ratio of the discards vs. landed lobsters.

\begin{tabular}{lrr}
\hline & discarded & landed \\
\hline mean Length & 93 & 113 \\
mean Length (females only) & 96 & 110 \\
mean Length (males only) & 84 & 115 \\
\hline sex ratio (males per female) & $33 \%$ & $153 \%$ \\
\hline
\end{tabular}

Table 3.2.3. Lobster catches annual mean length, sex ratio and proportion of undersized individuals

\begin{tabular}{|c|c|c|c|c|c|c|c|}
\hline \multirow[b]{2}{*}{ year } & \multicolumn{3}{|c|}{ Mean length $(\mathrm{mm})$} & \multirow{2}{*}{$\begin{array}{l}\text { Sex ratio (males } \\
\text { per female) }\end{array}$} & \multicolumn{3}{|c|}{ Proportion $<95 \mathrm{~mm}$} \\
\hline & females & males & combined & & Females & Males & Combined \\
\hline 2000 & 102 & 112 & 108 & $142 \%$ & $38 \%$ & $19 \%$ & $27 \%$ \\
\hline 2007 & 111 & 114 & 113 & $164 \%$ & $19 \%$ & $12 \%$ & $15 \%$ \\
\hline 2011 & 113 & 125 & 118 & $71 \%$ & $7 \%$ & $4 \%$ & $5 \%$ \\
\hline 2012 & 103 & 107 & 105 & $123 \%$ & $43 \%$ & $15 \%$ & $28 \%$ \\
\hline 2013 & 109 & 116 & 114 & $146 \%$ & $18 \%$ & $7 \%$ & $12 \%$ \\
\hline 2014 & 110 & 115 & 113 & $156 \%$ & $19 \%$ & $9 \%$ & $13 \%$ \\
\hline 2015 & 114 & 120 & 117 & $154 \%$ & $8 \%$ & $1 \%$ & $4 \%$ \\
\hline
\end{tabular}

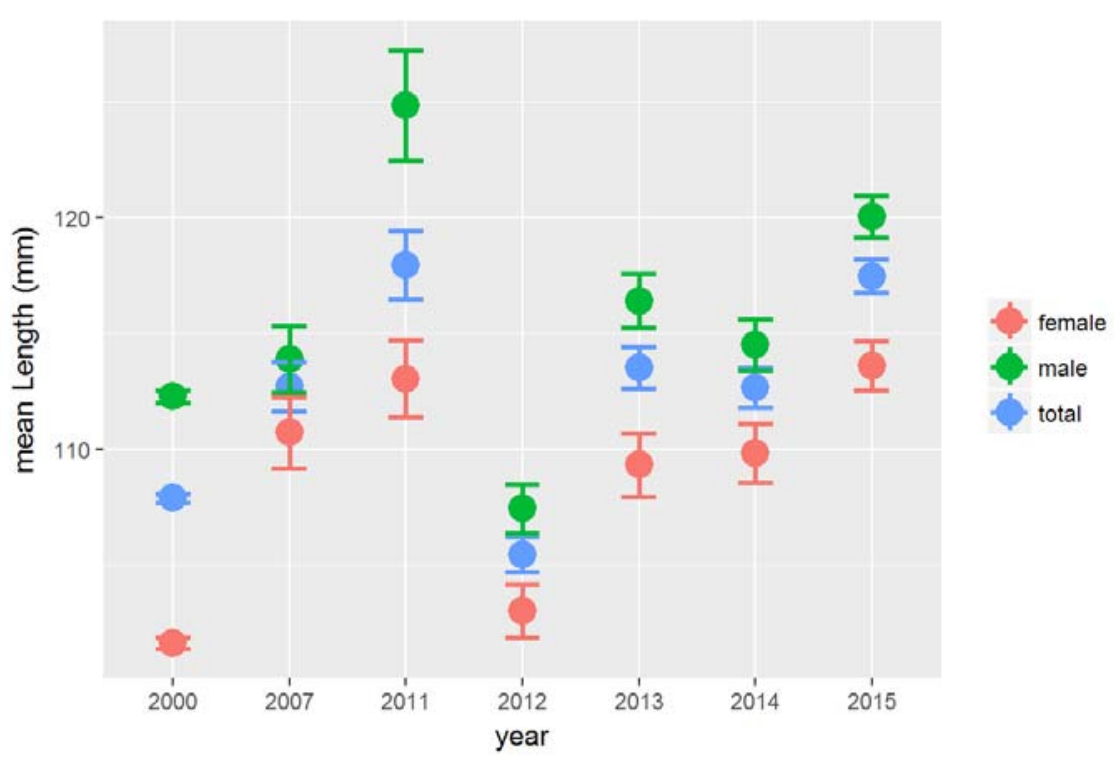

Fig. 3.2.6. Annual mean length of lobster catches (with $95 \%$ confidence intervals). 


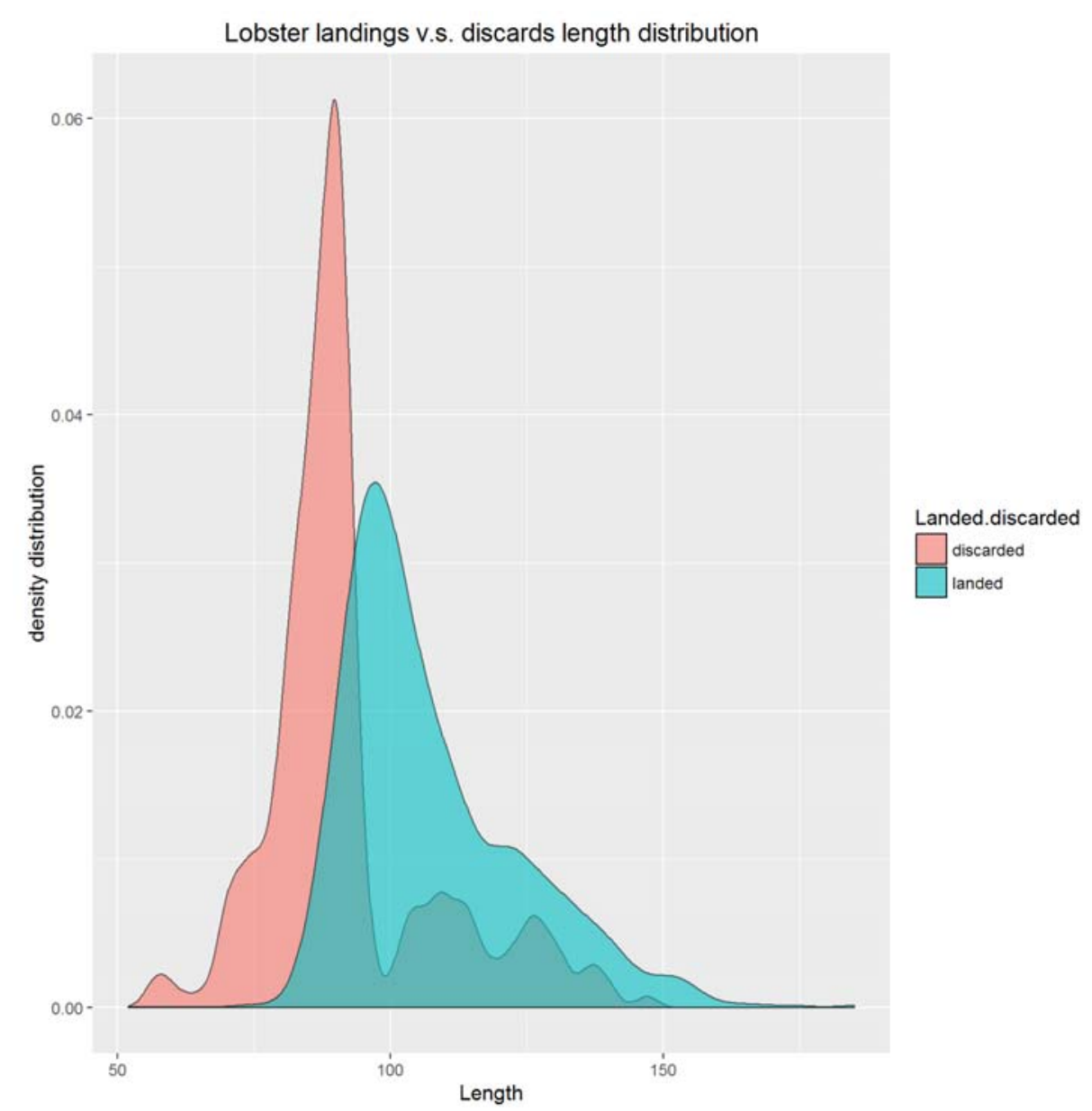

Fig. 3.2.7. Length distribution of the landed lobsters and discards of lobster from the port sampling (long interviews). Data are from 2012 only (not enough discards measured in other years).

\subsubsection{Recruitment I ndex}

The number of undersized lobster caught during each fishing trip was also provided during the port interviews. The catches of undersize lobster per trips were modelled using the same GLM approach as for the marketable size lobsters (section 3.2.1.1) in order to extract a yearly index for the small lobster, indicative of the strength of the incoming recruitment. For this model, all the factors tested were found to be significant (Table 3.2.4).

The catches of undersize lobster show a seasonal pattern opposite to the pattern in the catches of marketable size lobsters, with higher values in late spring early summer and lower values at the beginning and the end of the year (Fig. 3.2.8). The year effect shows a higher value in 2014, and a lower value in 2015 . The time series of undersize lobster abundance is still too short to evaluate whether it could potentially be use to forecast lobster abundance in the subsequent year. The index is stable from 2012 to 2013 and increases from 2013 to 2014, which is somewhat in agreement with the pattern seen in the adult lobster abundance between 2013, 2014 and 2015 (figure 3.2.4). However, more years of data are necessary in order to assess whether this correlation observed based on 3 points still holds with a longer time series.

The model also shows that there are substantial differences in the catches of undersized lobsters between boats, with boat 2 and 4 catching substantially more undersized than the other two boats. Finally, catches of undersized lobsters are higher in the northern/central part of the bank (areas B3, B4, C3 and C4) and are low in the southern part (areas D3-5). 
Table 3.2.4. Significance of each model term tested by removing them one by one and comparing to the full model (GLM model of undersize lobster catches per trip). AIC stands for Akaike information criterion (the lower the better), a P-value lower than $0.05\left(^{*}\right)$ indicates that the effect of the corresponding factor in the model is significant. $(* *=\mathrm{P}$-value lower than $0.01, * * *=\mathrm{P}$-value lower than 0.001)

\begin{tabular}{rcrrrr}
\hline Model term removed & $\begin{array}{c}\text { Number of } \\
\text { parameters }\end{array}$ & AIC & $\begin{array}{r}\text { Log-Likelihood } \\
\text { ratio }\end{array}$ & p. value & $\begin{array}{r}\text { Significance } \\
\text { level }\end{array}$ \\
factor(Year) & 3 & 4612.9 & & & \\
factor(Month) & 11 & 4649.1 & 52.722 & $2.10 \mathrm{E}-11$ & $* * *$ \\
factor(Boat_name) & 4 & 4707.6 & 58.181 & $2.02 \mathrm{E}-08$ & $* * *$ \\
factor(Fishing_area) & 8 & 4640.7 & 102.739 & $<2.2 \mathrm{e}-16$ & $* * *$ \\
logTraps & 1 & 4703.7 & 43.804 & $6.20 \mathrm{E}-07$ & $* * *$ \\
& & & 92.792 & $<2.2 \mathrm{e}-16$ & $* * *$ \\
\hline
\end{tabular}
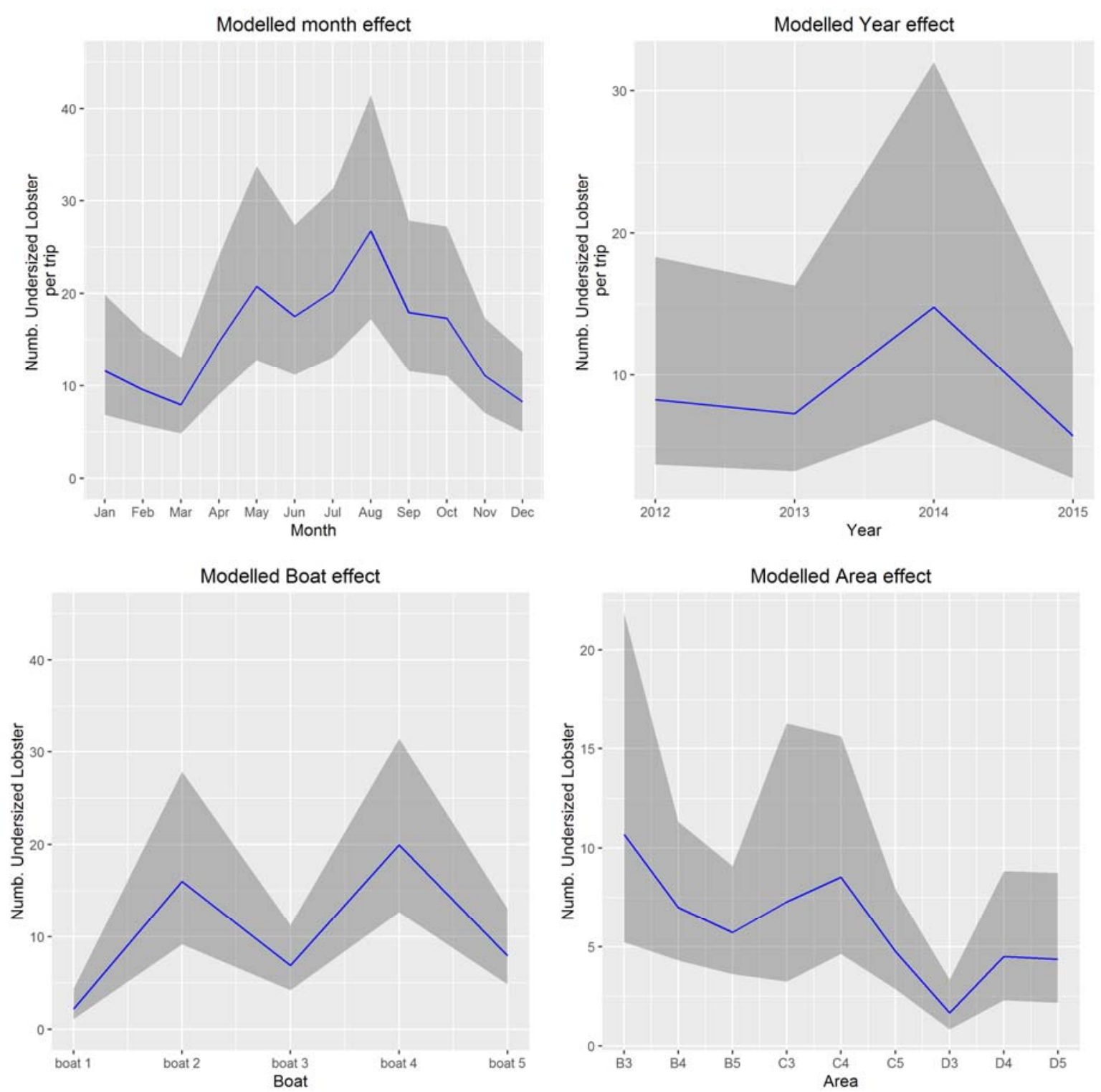

Fig. 3.2.8. Modelled effects of the month, year, boat and fishing area on the catches of undersized lobsters per trips (in numbers). Blue lines represent the modelled effect (and corresponding 95\% prediction envelop in grey). 


\subsubsection{Spawning season}

The number of berried lobster per trip was also modelled using the GLM approach. All model factors were significant, except the fishing areas (Table 3.2.5). Berried females are caught throughout the year, but are more abundant between February and May (Figure 3.2.9). The year effect suggest a low abundance in 2012, but higher, similar, values in 2013-2015.

Table 3.2.5. Significance of each model term tested by removing them one by one and comparing to the full model (GLM model of berried female lobster catches per trip). AIC stands for Akaike information criterion (the lower the better), a P-value lower than $0.05(*)$ indicates that the effect of the corresponding factor in the model is significant. $(* *=\mathrm{P}$-value lower than $0.01, * * *=\mathrm{P}$-value lower than 0.001)

\begin{tabular}{rcrrrr}
\hline Model term removed & $\begin{array}{c}\text { Number of } \\
\text { parameters }\end{array}$ & AIC & $\begin{array}{r}\text { Log-Likelihood } \\
\text { ratio }\end{array}$ & p. value & $\begin{array}{r}\text { Significance } \\
\text { level }\end{array}$ \\
\hline <none> & & 4352 & & & $* * *$ \\
factor(Year) & 3 & 4367 & 21 & 0.000118 & $* * *$ \\
factor(Month) & 11 & 4375 & 45 & $4.93 \mathrm{E}-06$ & $* * *$ \\
factor(Boat_name) & 4 & 4421 & 77 & $6.81 \mathrm{E}-16$ & $* .050237$ \\
factor(Fishing_area) & 8 & 4351 & 15 & $0.2 \mathrm{e}-16$ & $* * *$ \\
\hline logTraps & 1 & 4494 & 144 & $<2.2 \mathrm{r}$ & \\
\hline
\end{tabular}
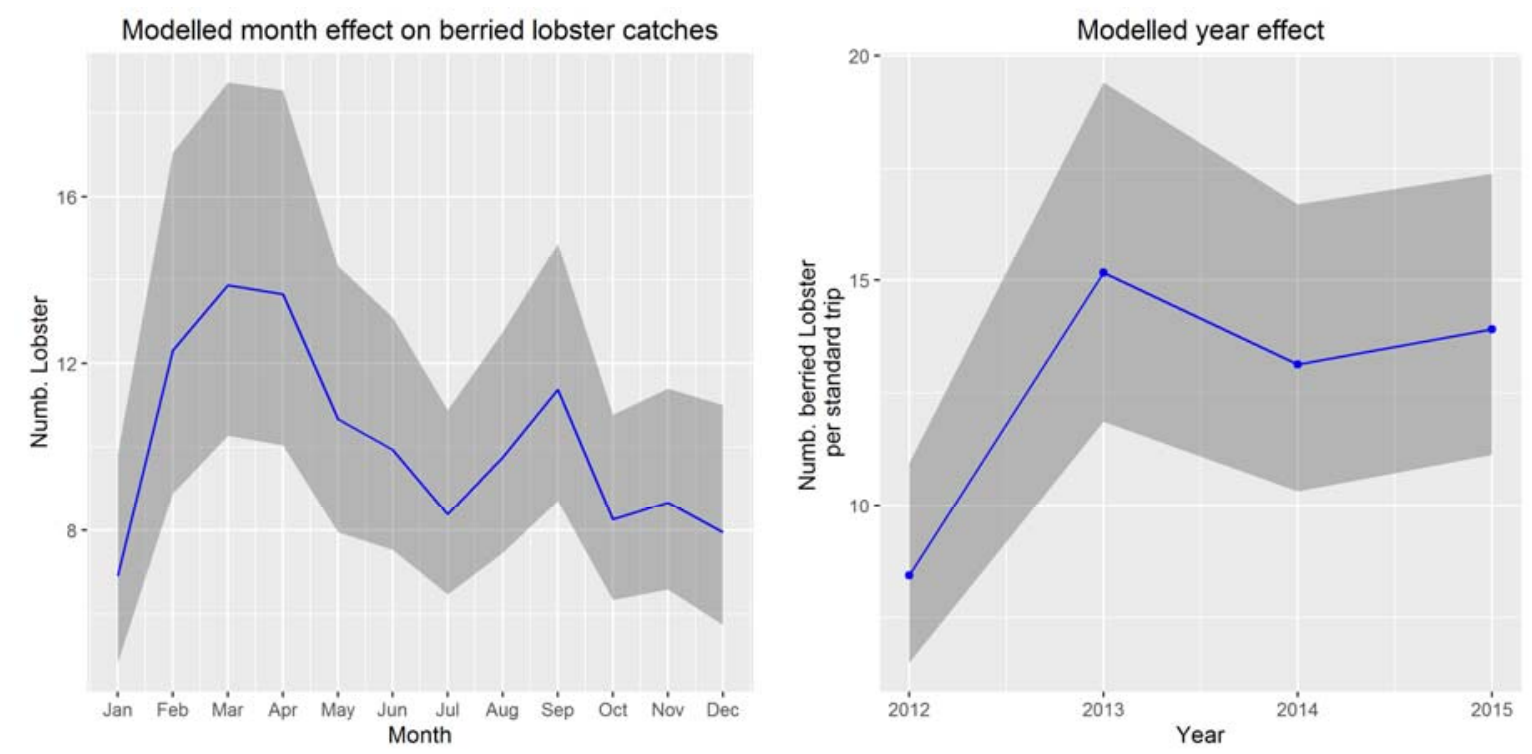

Figure 3.2.9. Seasonality and annual variations of the catches of berried lobsters (distribution of the monthly number of berried lobster by trip, corrected for the effect of the number of traps and the year effect from the model of lobster catches from figure 3.2.4).

\subsubsection{Size at Maturity}

Lobster size at maturity (carapace length at which $50 \%$ of the individuals are mature) was estimated using logistic regression (binomial GLM). The size at maturity for female and male spiny lobster was estimated at $\mathrm{CL}=88 \pm 0.62 \mathrm{~mm}$ and $\mathrm{CL}=92.2 \pm 5 \mathrm{~mm}$, respectively (Figure 3.2.10). 

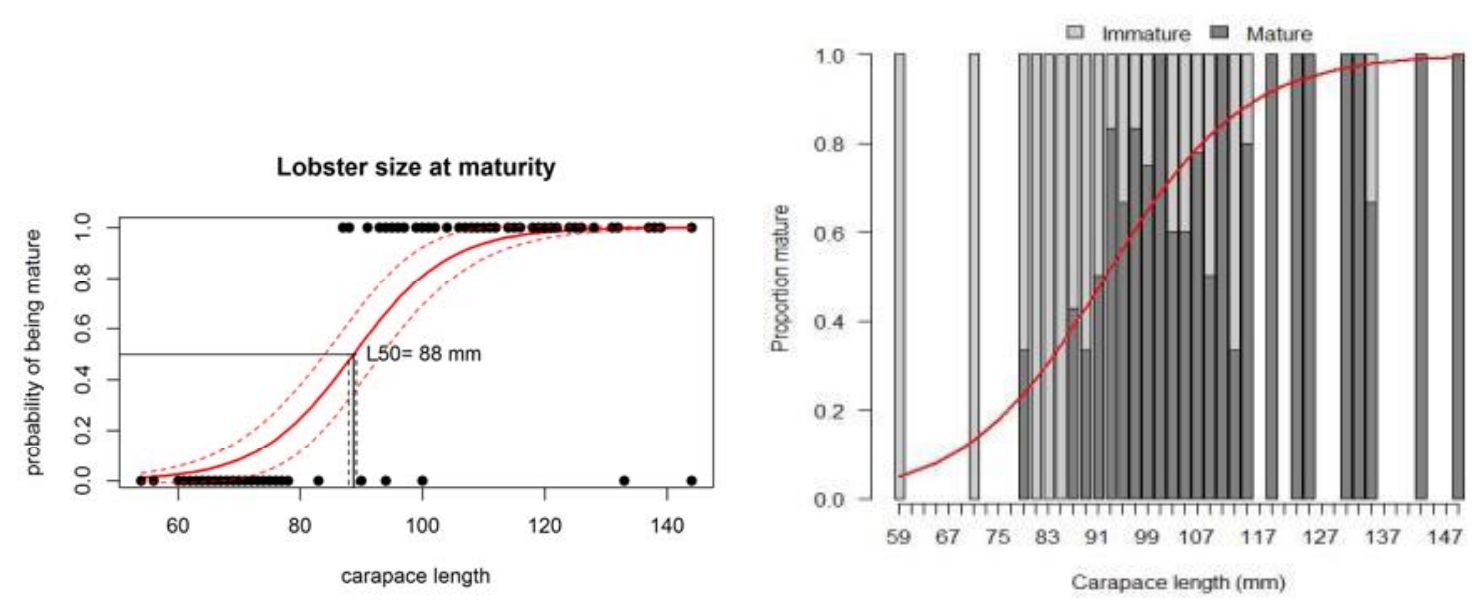

Fig. 3.2.10. Modelled size-maturity for female (left) and male (right) spiny lobster and estimated size at $50 \%$ mature. Black dots represent the raw data (being either immature, 0 , or mature, 1) and red curve presents the logistic regression (uncertainty associated depicted by the dotted red line).

\subsubsection{Mixed reef fish}

\section{Catch and Effort data}

The temporal variations of the effort and its distribution between the different fishing areas was the same as for the lobster, and are shown in Figure 3.1.1. The mean landings per trap and per trip show only limited variations, with slightly higher values in the earlier years (2000 and 2007) and decrease by roughly $30 \%$ in 2011, and stable intermediate values since 2012 (Figure 3.2.11).
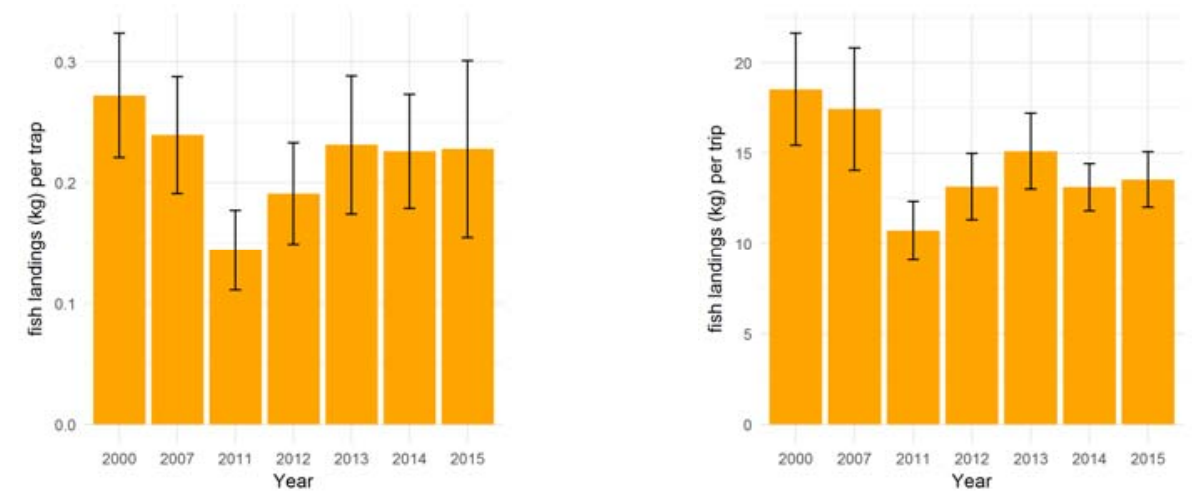

Fig. 3.2.11. Yearly mean landed catches of mixed reef fish $(\mathrm{kg})$ per lobster trap (left graph) and per fishing trip (right graph). Error bars are 95\% confidence intervals.

\section{GML analyses}

The GLM model fitted on the data set covering the years 2011-2015 showed a significant effect of month, boat and trap numbers, but not for year and fishing area (Table 3.2.6). The model fitted on the data set covering the years 2000-2015 showed a significant effect of year, month and trap number (Table 3.2.7). Large differences were observed in the fish landing rate in lobster traps between boats (from 4 to $12.5 \mathrm{~kg}$ for a standard trip, Fig. 3.2.11). The month effect did not show any seasonality, but indicated low landing rates in January and February compared to the rest of the year. The year effect indicated a similar temporal development as the raw data (Fig. 3.2.12) with a decrease from higher levels in 2000 and 2007 to lower levels in 2011, followed by an increase in 2012 and stable levels since then. 
Table 3.2.6. Significance of each model term tested by removing them one by one and comparing to the full model (GLM model of mixed fish landed per trip) for the data covering the period 2011-2015. AIC stands for Akaike information criterion (the lower the better), a P-value lower than 0.05 indicates that the effect of the corresponding factor in the model is significant. ${ }^{* *}=$ P-value lower than 0.01 , $* * *=\mathrm{P}$-value lower than 0.001 )

\begin{tabular}{|c|c|c|c|c|c|}
\hline Model term removed & $\begin{array}{l}\text { Number of } \\
\text { parameters }\end{array}$ & AIC & $\begin{array}{r}\text { Log- } \\
\text { Likelihood } \\
\text { ratio } \\
\end{array}$ & p. value & $\begin{array}{r}\text { Significance } \\
\text { level }\end{array}$ \\
\hline$<$ none $>$ & & 1536 & & & \\
\hline factor(Year) & 4 & 1534 & 1 & 0.22 & \\
\hline factor(Month) & 11 & 1548 & 2 & 0.0006 & $* * *$ \\
\hline factor(Boat_name) & 4 & 1589 & 15 & 8.92E-12 & $* * *$ \\
\hline factor(Fishing_area) & 9 & 1533 & 1 & 0.122607 & \\
\hline logTraps & 1 & 1568 & 33 & $1.30 \mathrm{E}-08$ & $* * *$ \\
\hline
\end{tabular}

Table 3.2.7. Significance of each model term tested by removing them one by one and comparing to the full model (GLM model of mixed fish landed per trip) for the data covering the period 2000-2015. AIC stands for Akaike information criterion (the lower the better), a P-value lower than $0.05(*)$ indicates that the effect of the corresponding factor in the model is significant. $(* *=\mathrm{P}$-value lower than $0.01, * * *=\mathrm{P}$-value lower than 0.001 )

\begin{tabular}{|c|c|c|c|c|c|}
\hline Model term removed & $\begin{array}{l}\text { Number of } \\
\text { parameters }\end{array}$ & \multicolumn{2}{|r|}{$\begin{array}{l}\text { Log- } \\
\text { Likelihood }\end{array}$} & \multicolumn{2}{|c|}{ Significance } \\
\hline$<$ none $>$ & & 3161.3 & & & \\
\hline factor(Year) & 6 & 3180.9 & 5.2524 & $2.34 \mathrm{E}-05$ & $* * *$ \\
\hline factor(Month) & 11 & 3182.8 & 3.9582 & $1.10 \mathrm{E}-05$ & $* * *$ \\
\hline logTraps & 1 & 3188.2 & 28.7989 & $9.50 E-08$ & $* * *$ \\
\hline
\end{tabular}



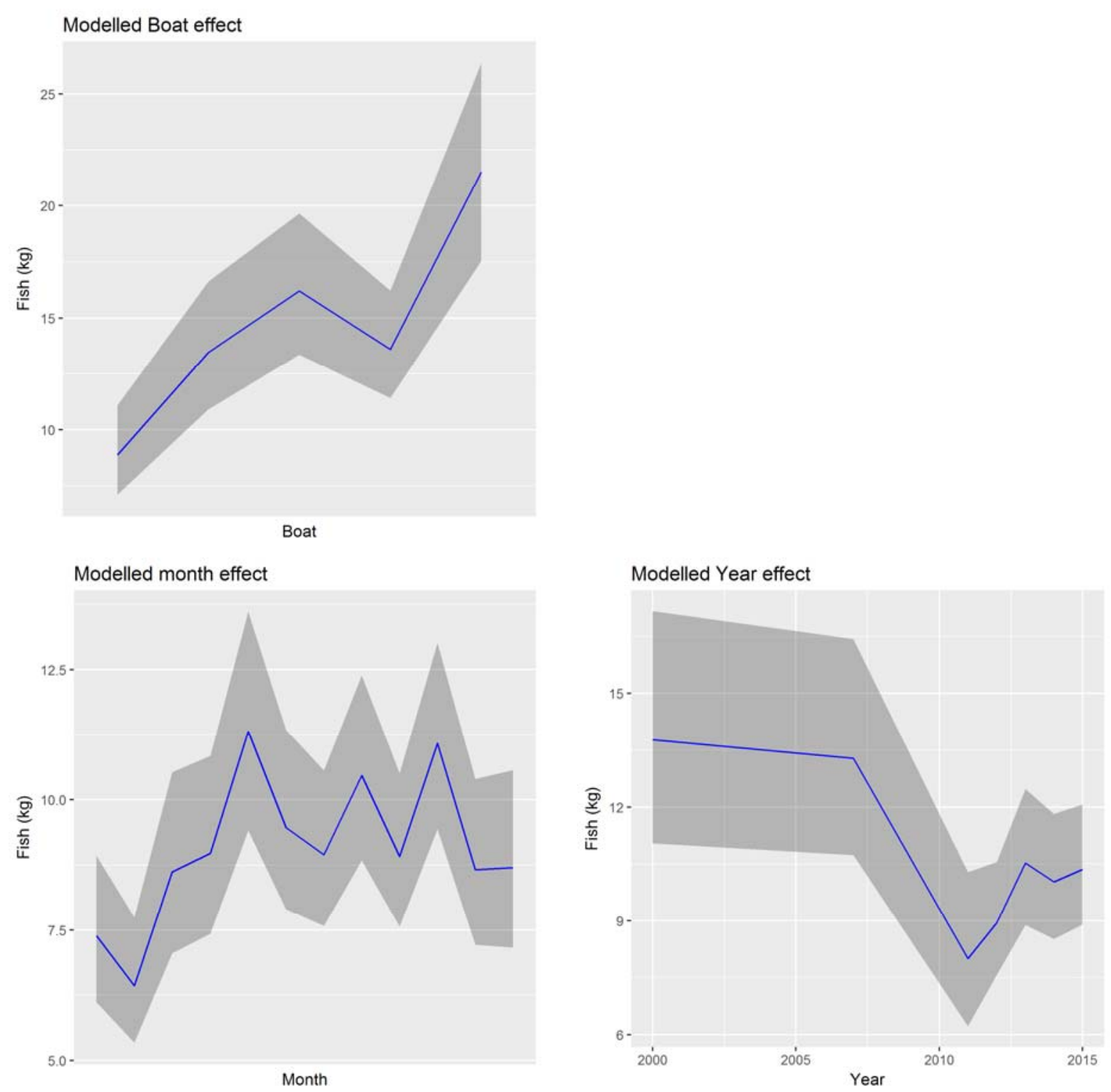

Fig. 3.2.12. Modelled boat effect (model fitted on the data for 2011-2015) and modelled month and year effects (model fitted on the data 2000-2015) on the landings of mixed reef fish in lobster traps per trips (in numbers). Blue lines represent the modelled effect (and corresponding 95\% prediction envelop in grey).

\section{Species composition of Landed catches \& Discards}

The mixed reef fish catch in the lobster trap is composed of a variety of species. The main species landed in number were the white grunt, red hind, doctorfish and ocean surgeonfish (Figure 3.2.13). In weight, queen triggerfish was the main species, followed by the red hind and the white grunt. In both cases, more than a third of the landings corresponding to a mixture of reef fish species, each representing individually less than $5 \%$ of the landings (category "other"). The most common reef fish species in the discards were the honeycomb cowfish and the cotton wick (Figure 3.2.14). Nurse shark also represented nearly $20 \%$ of the discards in weight. Again, almost $2 / 3$ of the discards is represented by the category "other". 

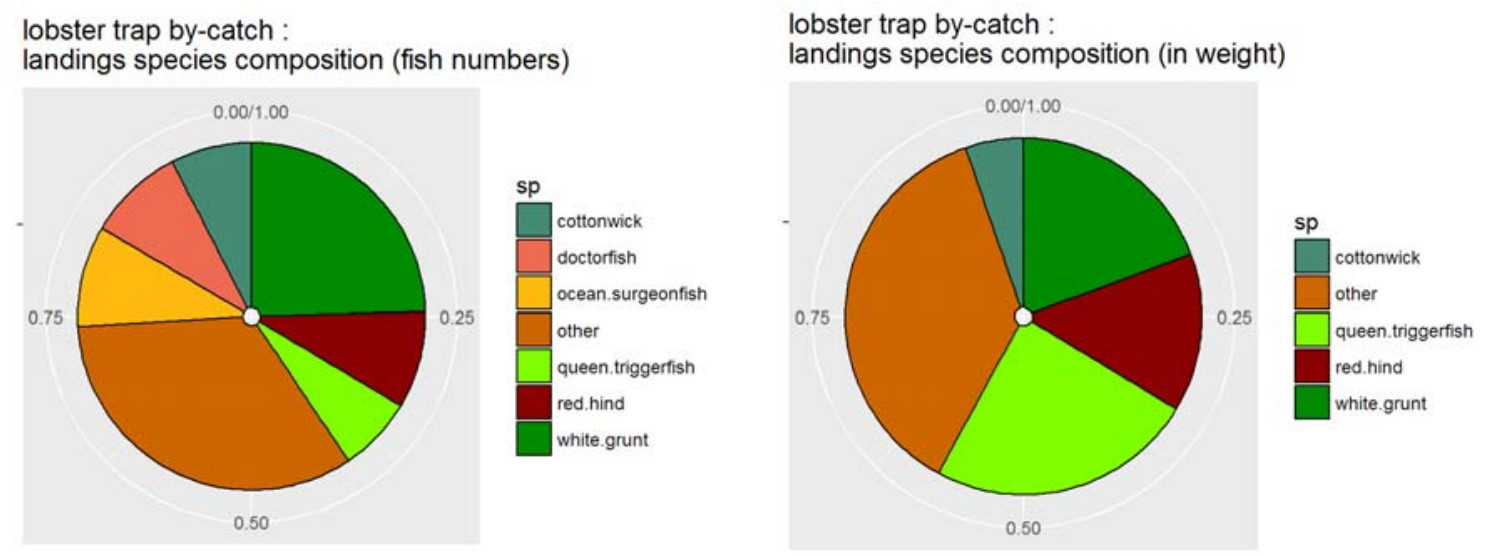

Fig. 3.2.13. Species composition for the mixed reef fish landed in the lobster fishery (based on 112 trips sampled) in 2012-2015.
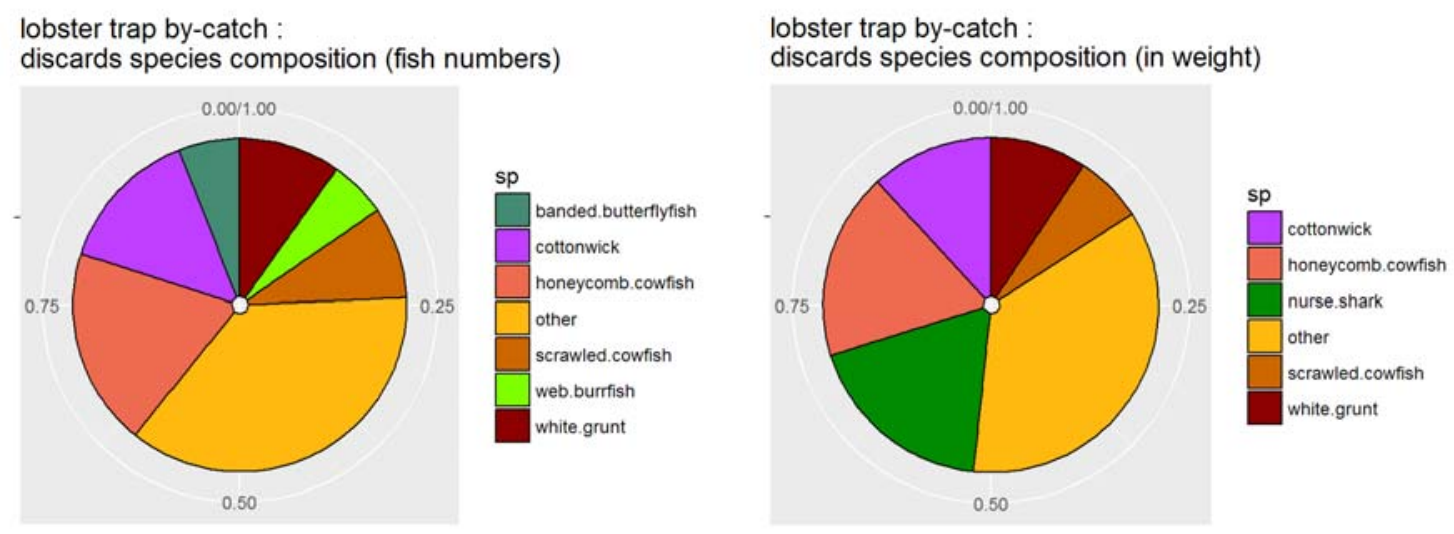

Fig. 3.2.14. Species composition for the mixed reef fish discarded in the lobster fishery (based on 37 trips sampled) in 2012-2015.

Length frequency of the catches

See Annex 1 


\subsection{Redfish Fishery}

\subsubsection{Trap fishery}

All of the vessels use traps, mostly of the "arrowhead" type (Fig. 2.3.3), which are made out of coated wire with a mesh size of $1 \times 2$ to $2 \times 2$ inch $(2.5$ to $5 \mathrm{~cm}$ ) of which the traps with the smaller mesh size are often used for redfish. Furthermore fish and lobster traps differ in funnel size, the funnel of fish traps are more narrow.

\section{Catch and Effort data}

The average number of traps set per fishing trip has increased between 2007 and 2011, and has subsequently been decreasing from 35 to 24 between 2011 and 2015 (Fig. 3.3.1). The spatial distribution of the effort has changed over the years. Most of the effort was concentrated at the centre of the bank (area C4) in 2011 (Fig. 3.3.2), but the effort then increased in the north/north-western part of the bank (B3/B4). In the last 2 years, the effort moved back to the centre of the bank (C4) and also developed in the north-western part (B5) and on the southern part (areas D).

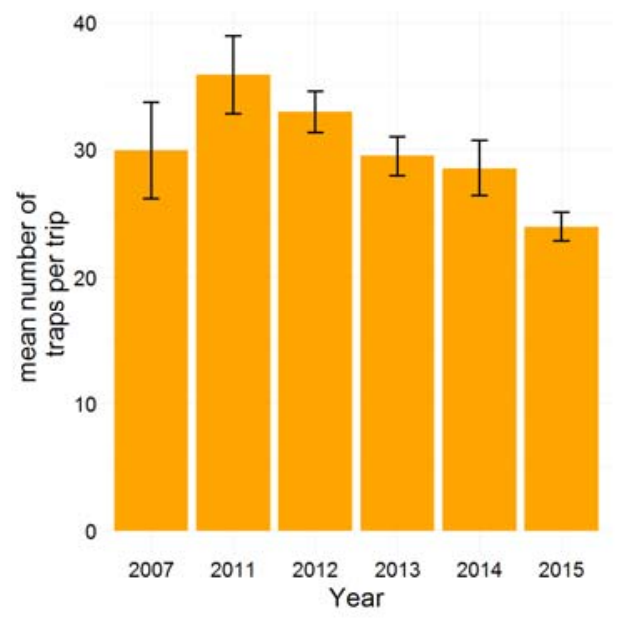

Fig. 3.3.1. Mean annual number of traps lifted per trips (with $95 \%$ confidence intervals).
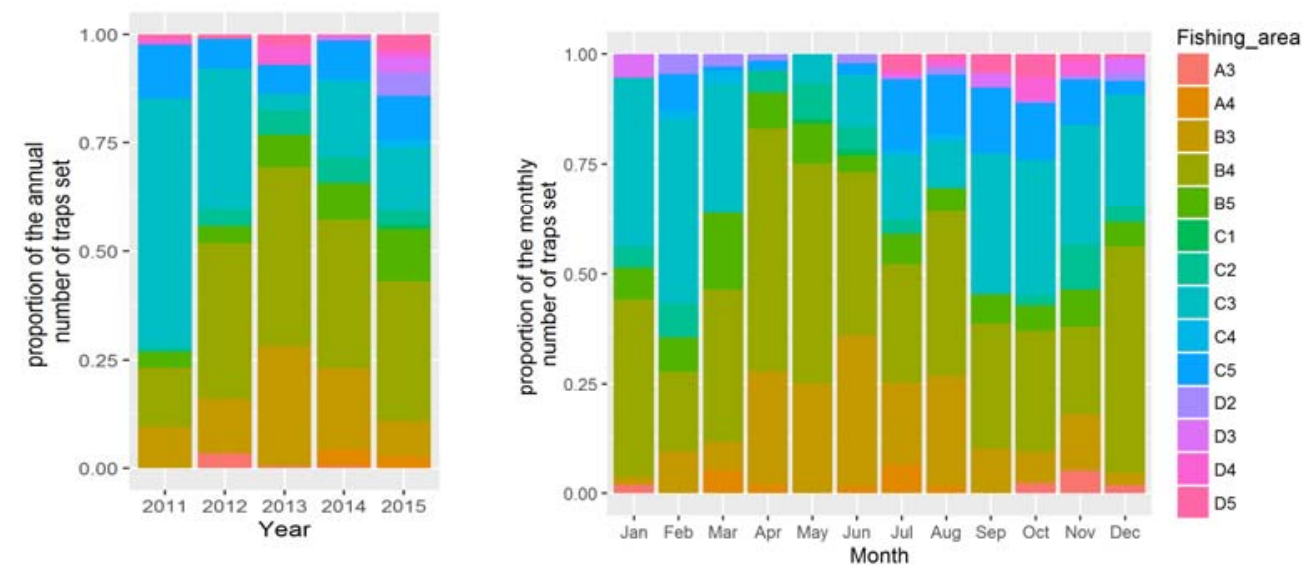

Fig. 3.3.2. Proportion of the annual (left) and monthly (right) effort (in total number of traps set) per fishing area. 
The mean landings per trap and per trip indicate higher catch rates in 2007 (Fig. 3.3.3). Landings per trap were sharply lower in 2011, and have been somewhat increasing since then. As a results of the decrease in the number of traps per trip (Fig. 3.3.1), the landings per trip has also declined since 2012.
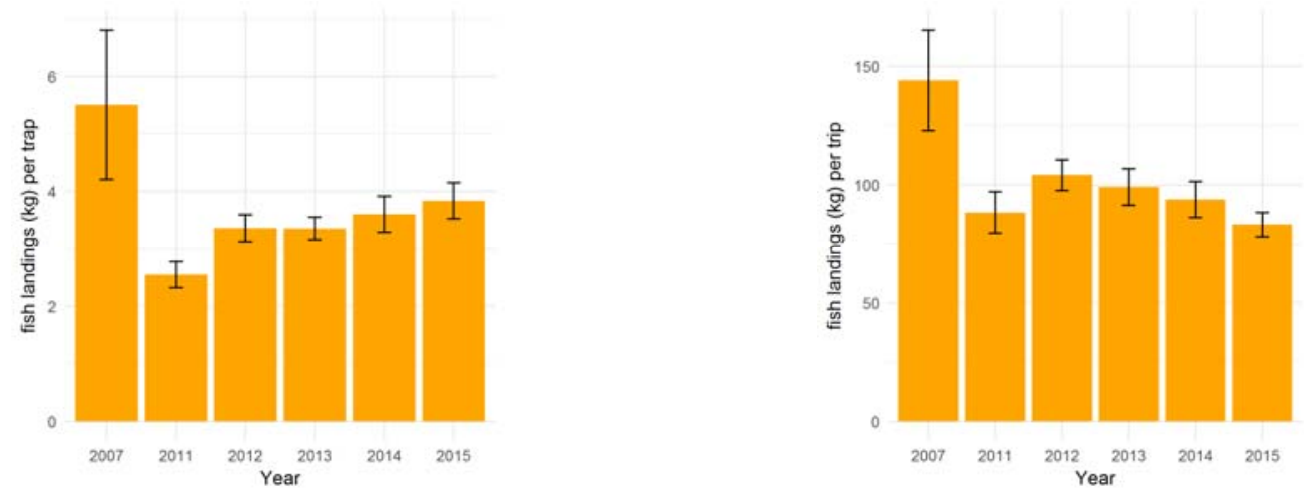

Fig. 3.3.3. Yearly mean catches of red fish $(\mathrm{kg})$ per trap and per trips (with $95 \%$ confidence intervals).

\section{$\underline{\text { GLM model }}$}

The red fish catches per trip were modelled using the same approach as described for the lobster in order to estimate different effects on the catch rates and ultimately extract a standardised biomass index. Again, two models were fitted, one on the years 2011-2015 including all effects, and one on the data since 2007 , including only month, year and trap number effects.

The model fitted on the recent data shows that the year effect and the fishing area effects are not significant (Table 3.3.1). The difference in standardised landings per trip between vessels was larger than for lobster landings, boat with the highest rate landing $65 \%$ more than the boat with the lowest rate (Fig. 3.3.4). When fitting the model to the entire time series, the month, year and trap number effect were all significant. Unlike for the lobster, no clear seasonality is visible in the month effect, but low landing rates are observed between March and June, and high landing rates are observed in September/October and in February. The year effect, which is standardised biomass index for the red fish, indicates higher biomass in 2007 than the rest of the time series. The biomass index is low for 2011, and slightly higher and constant since 2012.

Table 3.3.1. Significance of each model term tested by removing them one by one and comparing to the full model (GLM model of red fish caught and landed per trip). AIC stands for Akaike information criterion (the lower the better), a P-value lower than $0.05\left(^{*}\right)$ indicates that the effect of the corresponding factor in the model is significant. $(* *=\mathrm{P}$-value lower than $0.01, * * *=\mathrm{P}$-value lower than 0.001)

\begin{tabular}{rccrrr}
\hline Model term removed & $\begin{array}{c}\text { Number of } \\
\text { parameters }\end{array}$ & AIC & $\begin{array}{r}\text { Log-Likelihood } \\
\text { ratio }\end{array}$ & $\begin{array}{r}\text { Significance } \\
\text { level value }\end{array}$ \\
\hline <none (full model)> & & 969 & & & \\
factor(Year) & 4 & 969 & 1.96 & 0.09913 &. \\
factor(Month) & 11 & 969 & 1.92 & 0.03426 & $*$ \\
factor(Boat_name) & 4 & 999 & 9.25 & $2.97 \mathrm{E}-07$ & $* * *$ \\
factor(Fishing_area) & 8 & 968 & 1.81 & 0.07237 & $*$ \\
logTraps & 1 & 995 & 27.15 & $2.61 \mathrm{E}-07$ & $* * *$ \\
\hline
\end{tabular}



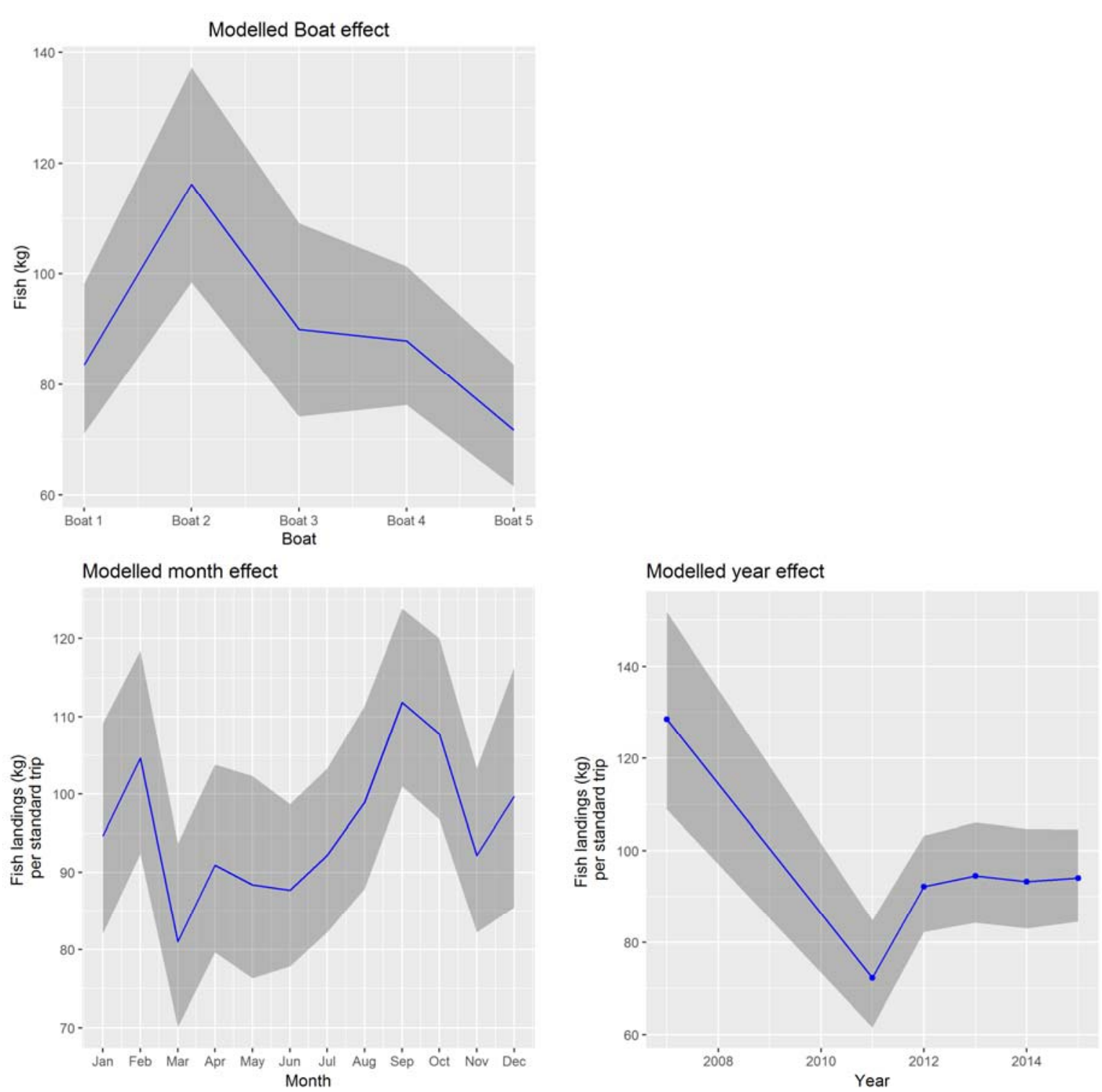

Fig. 3.3.4. Modelled boat effect (model fitted on the data for 2011-2015) and modelled month and year effects (model fitted on the data 2000-2015) on the catches of red fish per trips (in numbers). Blue lines represent the modelled effect (and corresponding 95\% prediction envelop in grey).

\section{Species composition}

The main species landed in the redfish fishery is the silk snapper (Fig. 3.3.5), which represents almost $3 / 4$ of the catch in number and in weight. The two other species well represented in the catches are the blackfin and vermillion snapper. The silk snapper is also the most discarded species, representing around $50 \%$ of the discards in number and in weight (Fig. 3.3.6). Other important discarded species are the lionfish and French angelfish and the nurse shark (for the discards in weight). 

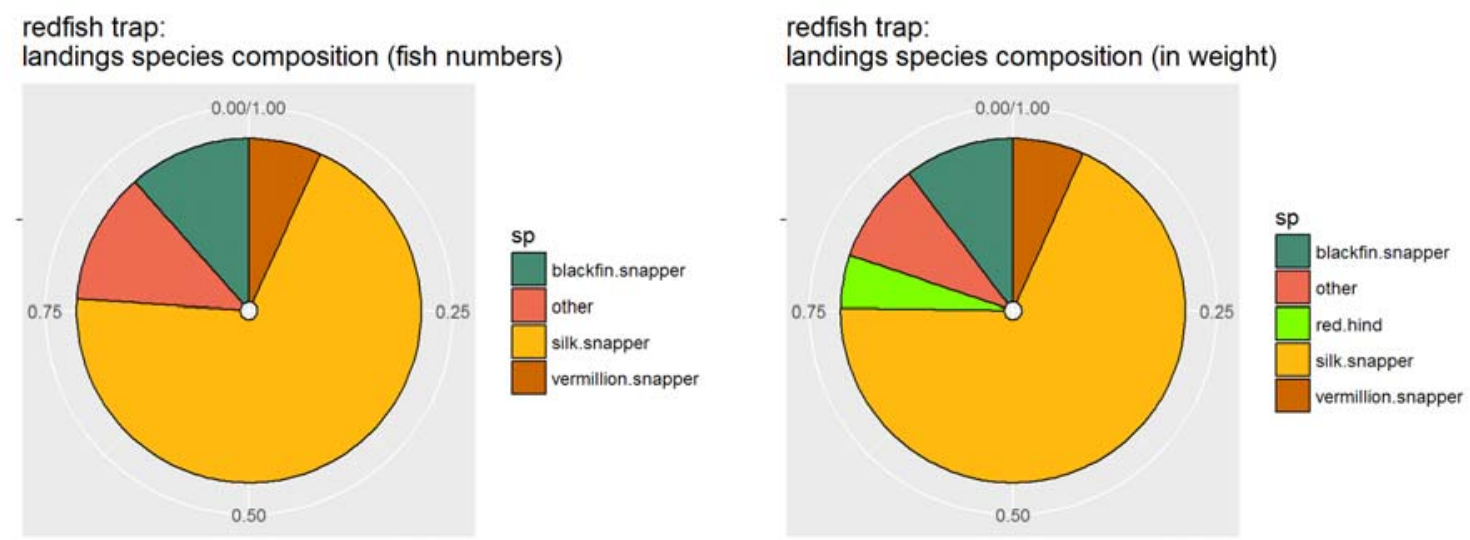

Fig. 3.3.5. Species composition of the catches in the red fish fishery (in numbers, left, and in weight, right) based on 51 trips sampled.
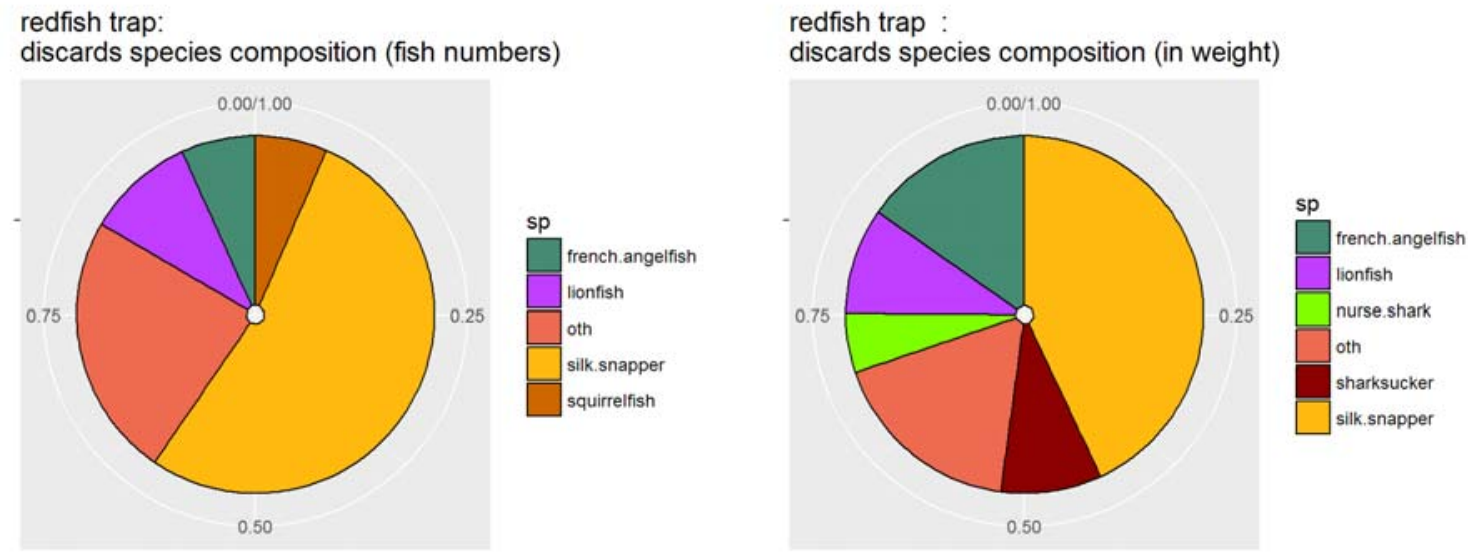

Fig. 3.3.6. Species composition of the discards in the red fish fishery (in numbers, left , and in weight, right) for the year 2011 to 2015 combined based on 9 trips sampled. 


\subsubsection{Bottom longline fishery}

\section{Effort}

Annual effort of the long line fishery is shown in Fig. 3.1.1 and Table 3.1.1. The estimated number of trips using long line per year has been stable between 5 and 8, except for 2015 when the estimate was of 36 trips. However, trips using long line represent, depending on the year, only 0.5 to $4 \%$ of the trips sampled at the harbour. Considering that between 30 and $50 \%$ of the trips are covered by a landing survey, there is a fair chance none of the few trips using longline carried out in a given month was covered by the landing surveys.

Because of the scarcity of the data, it is also difficult to see if there is any seasonality in the long line activity (Fig. 3.3.7). The estimated number of trips per month (based on data since July 2012) suggest that there is no bottom long lining in the first half of the year, but harbour interviews show that there were trips carried out in first half of 2012 (which could not be raised because there was no activity survey at that time).
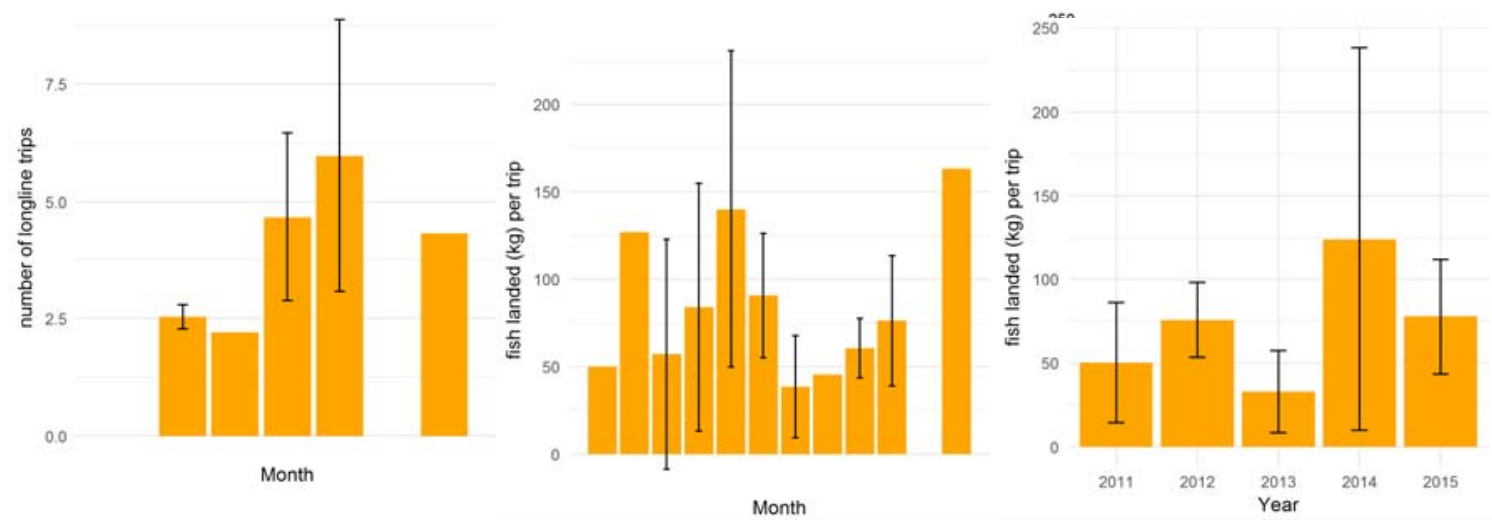

Fig. 3.3.7. Mean number of longline trips per month (left), monthly (middle) and annual (right) mean landed catches (in $\mathrm{kg}$ ) per trip in the long line fishery with 95\% confidence interval (absence of confidence interval correspond to month with a single observation).

\section{Species composition}

The species composition of the long line fishery is based on a small number of sampled trips ( 9 over the period 2012-2015). The long line fishery is targeting mainly snappers, with the wenchman snapper being predominant in the catches in number and the queen snapper being dominant in the catches in weight (Fig. 3.3.8). Species composition of the discards is based on a single trip. The main discarded species was the Cuban dogfish. 

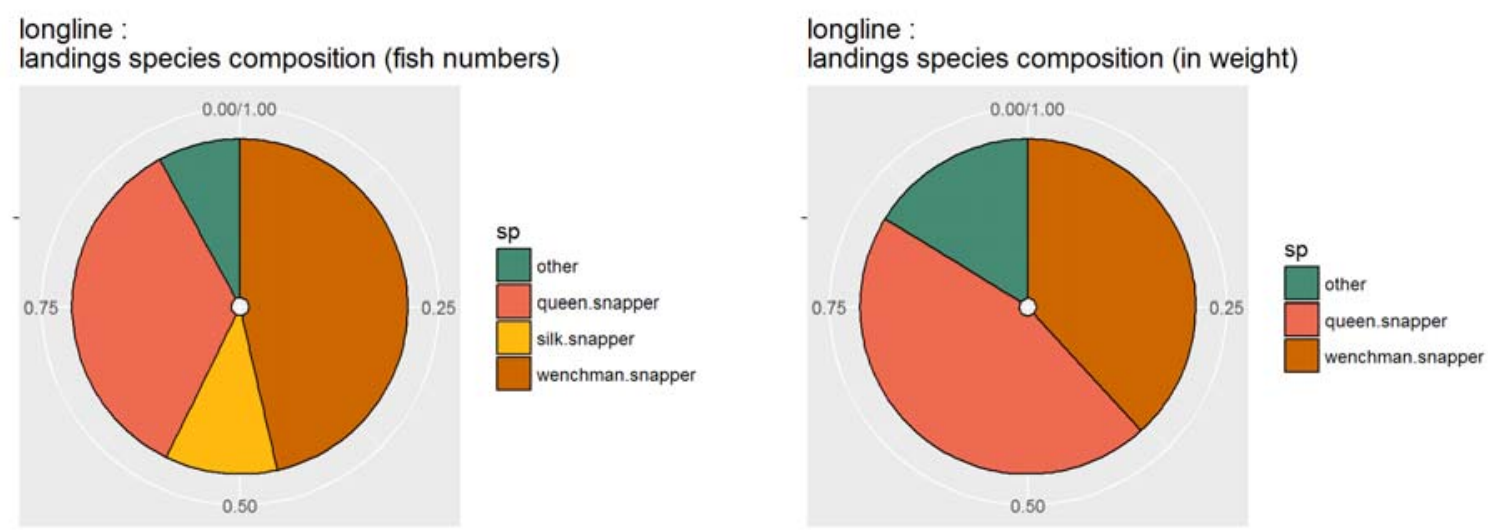

Fig. 3.3.8. Species composition of the landed catches from the long line fishery based on the sampling realised between 2012 and 2015 based on 9 trips sampled.

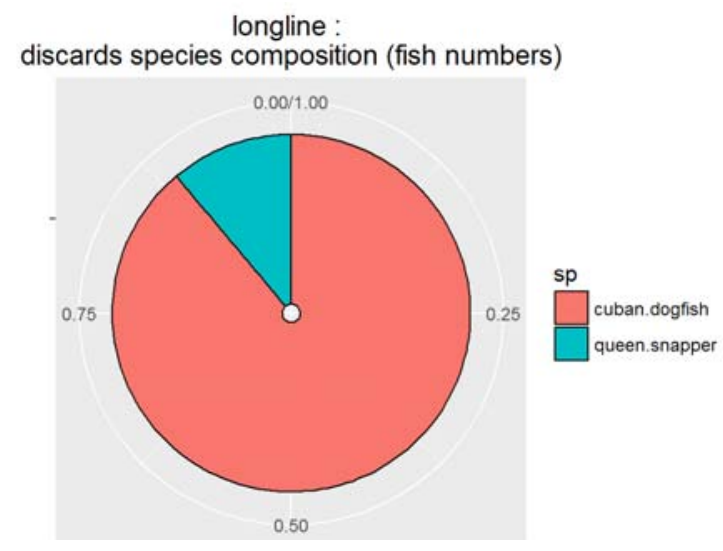

Fig. 3.3.9. Species composition of the discards from one bottom long line fishing trip based on 1 trip sampled for a total of 9 discarded fish. 


\subsection{Pelagic Fishery}

\section{Effort}

The annual number of trolling fishing trips is estimated to have varied between 39 and 88 in the period 2012-2015 (Fig. 3.1.1 and table 3.1.1). Trolling trips appear to be more frequent from October to April, with markedly lower number of trips between May and August (Fig. 3.4.1). However, the monthly number of trips are very variable from year to year, and the monthly mean value have large confidence intervals.
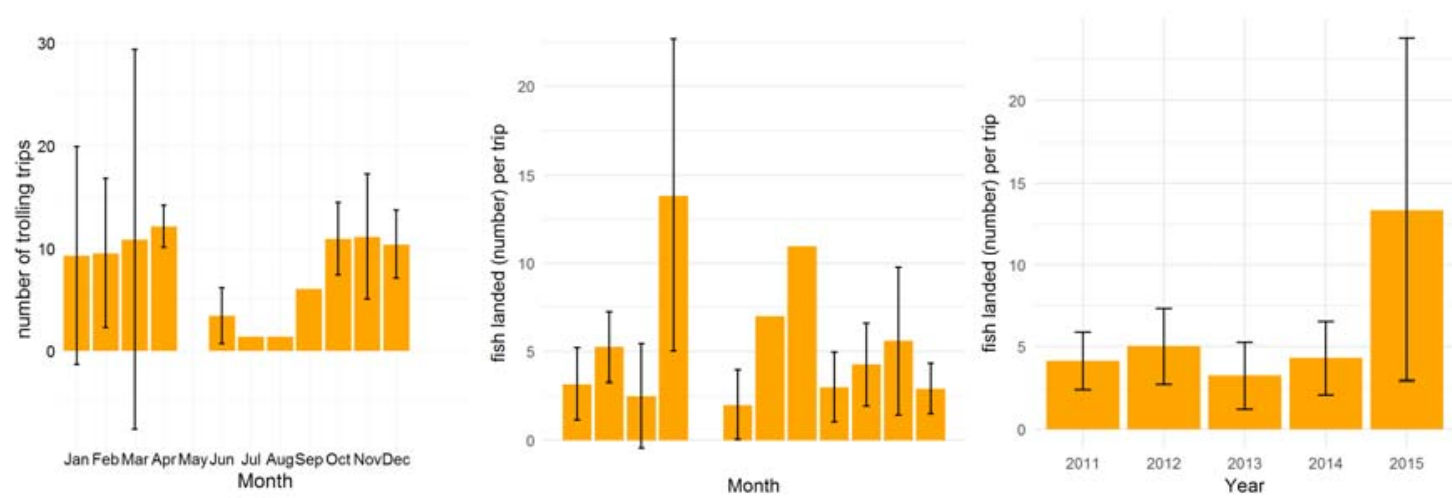

Fig. 3.4.1. Mean number of trips per (left), mean catch per trip (in fish number) per month (middle) and per year (right), with $95 \%$ confidence interval of the mean (absence of confidence interval correspond year or month with a single observation).

\section{Catch rates}

Given the large year to year difference in the monthly number of trip, the confidence intervals of the monthly and annual mean catch rates are wide and often overlap (Fig. 3.4.1). It is difficult to find any trend in the variation of the catch rates of the trolling fishery. The overall mean landing per trip is of $5.6( \pm 1.7)$ fish landed per trip. Given the scarcity and the variability of the data available, no attempt to model the catch rates using GLM was made.

\section{Species composition}

Catches in number of fish are mainly composed of dolphinfish and wahoo (Fig. 3.4.2). Tuna species represent $3 \%$ of the landings in number. There was no length measurement for the tunas, and therefore to compute a species composition in weight, a mean weight of $10 \mathrm{~kg}$ per fish was assumed. Wahoo represent $70 \%$ and dolphin fish about $20 \%$ of the catches in weight. The proportion of tunas (in weight) is about $4 \%$. 
trolling :

landings species composition (fish numbers)

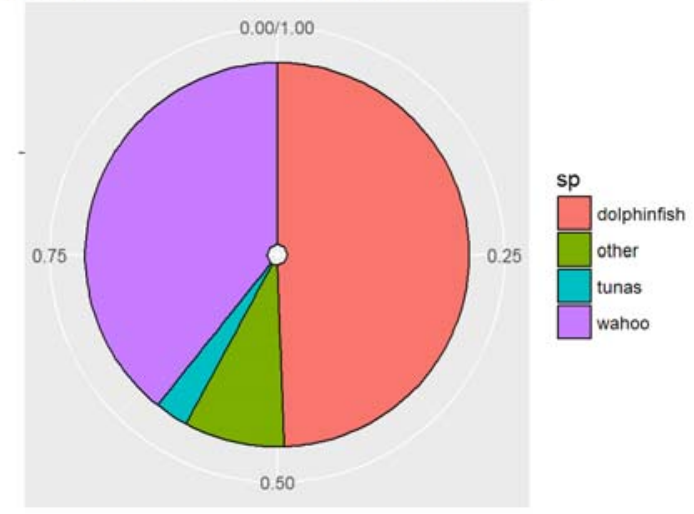

trolling :

landings species composition (in weight)

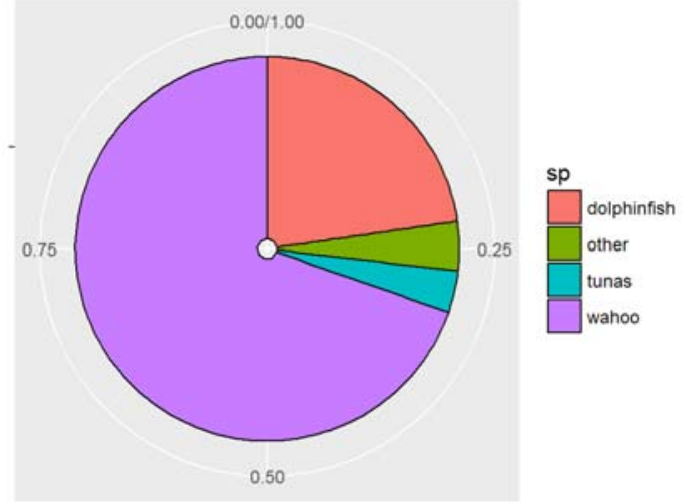

Fig. 3.4.2. Species composition of catches in the trolling fishery (in numbers, left, and in weight, right) based on 425 fish from 67 trips sampled. 


\subsection{Shark bycatch}

\subsubsection{Shark bycatch released}

\section{Landing survey}

Since the start of the year 2016, the number of sharks caught, and subsequently released, during a fishing trip is recorded during the landing survey. The number of Caribbean Reef sharks caught and released so far are very low (2 individuals caught by longlines). Nurse sharks, however, are caught in around $60 \%$ of the trips using lobster traps (Fig. 3.5.1, left), but most of the time in low numbers (less than 7 sharks per trips, Fig. 3.5.1, right). However for $5 \%$ of the trips, large numbers (from 11 up to 71 individuals) were caught.

Bycatches of nurse shark were rare in redfish traps (only $3 \%$ of the trips), but one exceptional event was recorded (up to 40 sharks per trip). No nurse shark was caught by the other gears. The catch rates are around 0.013 nurse sharks per lobster trap (median value), and close to 0 shark per trap for the redfish traps.
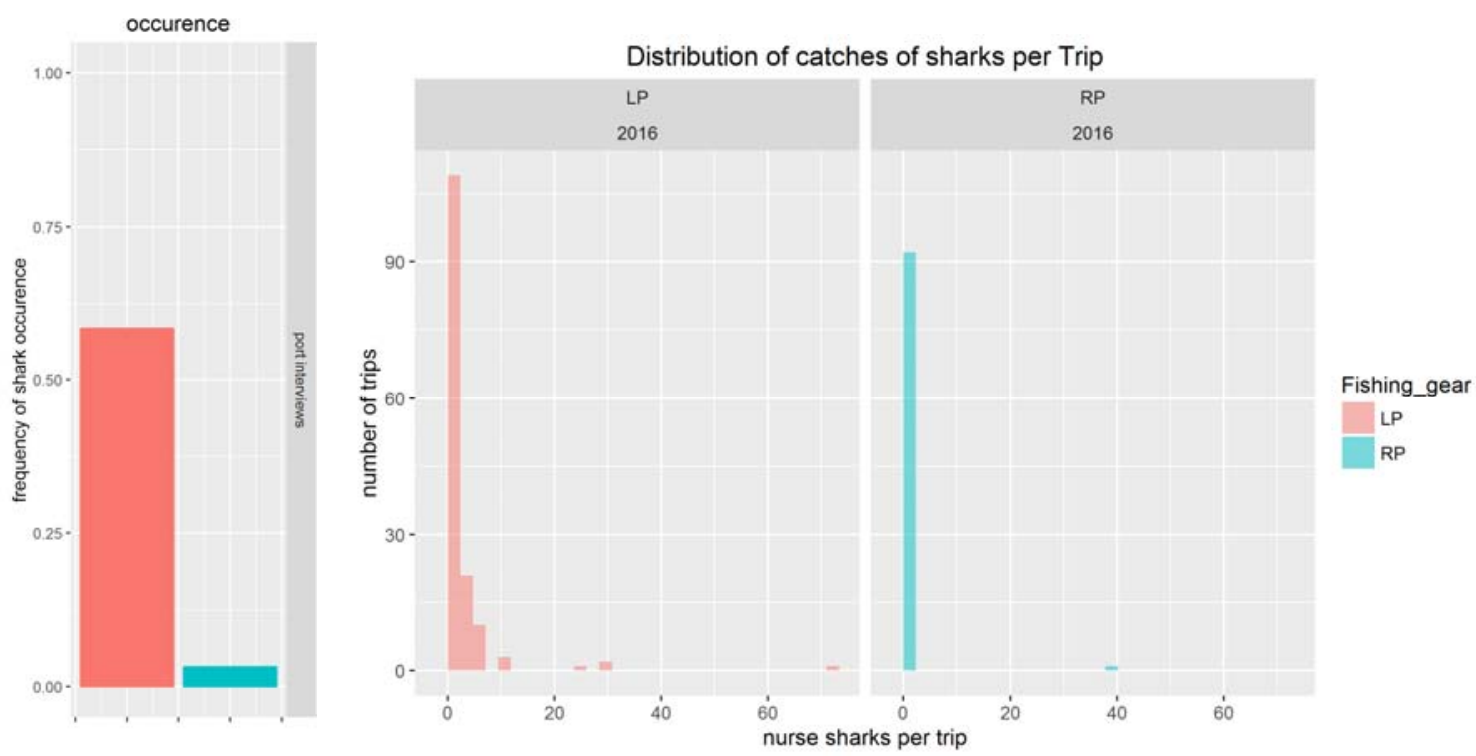

Fig. 3.5.1. Proportion of the fishing trips during which nurse shark are caught (left) and distribution of the number of nurse shark caught per trip (right) in relation with the type of trap used.

The catch rates of nurse shark were estimated on average at $0.032[ \pm 0.012]$ and $0.017[ \pm 0.028]$ individuals/trap for the lobster traps and the redfish traps respectively. An estimate of the annual number of nurse sharks caught and released can be calculated by multiplying these catch rates by the estimates of the annual number of traps lifted (Table 3.1.1), assuming that the catch rates from 2016 are representative of the period 2012-2015 (Table 3.5.1). The annual number of nurse sharks caught and released varies between 1712 and 2499 individuals, mainly coming from the lobster fishery. 
Table 3.5.1. Annual lobster and snapper trap lifts 2012-2015.

\begin{tabular}{lllll}
\hline & $\mathbf{2 0 1 2}$ & $\mathbf{2 0 1 3}$ & $\mathbf{2 0 1 4}$ & $\mathbf{2 0 1 5}$ \\
\hline lobster traps & 1536 & 1992 & 2090 & 2328 \\
redfish traps & 176 & 205 & 241 & 172 \\
total & 1712 & 2197 & 2331 & 2499 \\
\hline
\end{tabular}

\section{Escape slot experiment}

The occurrence of nurse sharks was recorded during the fishing trips conducted in the second half of 2015 and first half of 2016 to test the effect of escape vents on lobster traps catches. For a total of 281 trap drops, distributed over 18 trips, 3 nurse sharks were caught (0.01 nurse shark/trap lift). No shark was caught during the 15 trips (105 trap lifts) realised to experiment escape slots on deep sea redfish traps.

\subsubsection{Shark bycatch landed}

The number of sharks landed were also recorded during the so-called long interviews during which data on species composition and length distribution is collected either on catches landed at the harbour, or during observer trips at sea. Among the 319 trips sampled between 2011 and 2016, a total of 11 landed sharks were observed, most of them from the lobster fishery (Table 3.5.2). Considering that, roughly speaking, about $5 \%$ of the fishing trips were sampled (see Table 3.1.1), a crude estimate of the total landings of sharks can be obtained by multiplying the numbers in table 3.5 .2 by a factor 20 .

Table 3.5.2. Landings of shark landed per gear type. The numerator and denominator are, respectively, the total number of sharks observed per gear and per year and the corresponding number of trips sampled.

\begin{tabular}{rrrrrr}
\hline year & $\begin{array}{r}\text { lobster } \\
\text { traps }\end{array}$ & $\begin{array}{r}\text { redfish } \\
\text { traps }\end{array}$ & trolling & $\begin{array}{r}\text { bottom long } \\
\text { line }\end{array}$ & total \\
\hline 2011 & $0 / 1$ & & $0 / 9$ & & $0 / 10$ \\
2012 & $6 / 32$ & $0 / 12$ & $2 / 26$ & $0 / 5$ & $8 / 75$ \\
2013 & $1 / 31$ & $1 / 22$ & $0 / 7$ & & $2 / 62$ \\
2014 & $0 / 22$ & $0 / 22$ & $0 / 19$ & $0 / 4$ & $0 / 68$ \\
2015 & $0 / 31$ & $0 / 6$ & $0 / 13$ & $0 / 2$ & $0 / 53$ \\
2016 & $0 / 22$ & $1 / 12$ & $0 / 16$ & & $1 / 51$ \\
\hline total & $7 / 139$ & $2 / 74$ & $2 / 90$ & $0 / 11$ & $11 / 319$ \\
\hline
\end{tabular}




\subsection{Sustainable fish traps}

\subsubsection{Biodegradable panel}

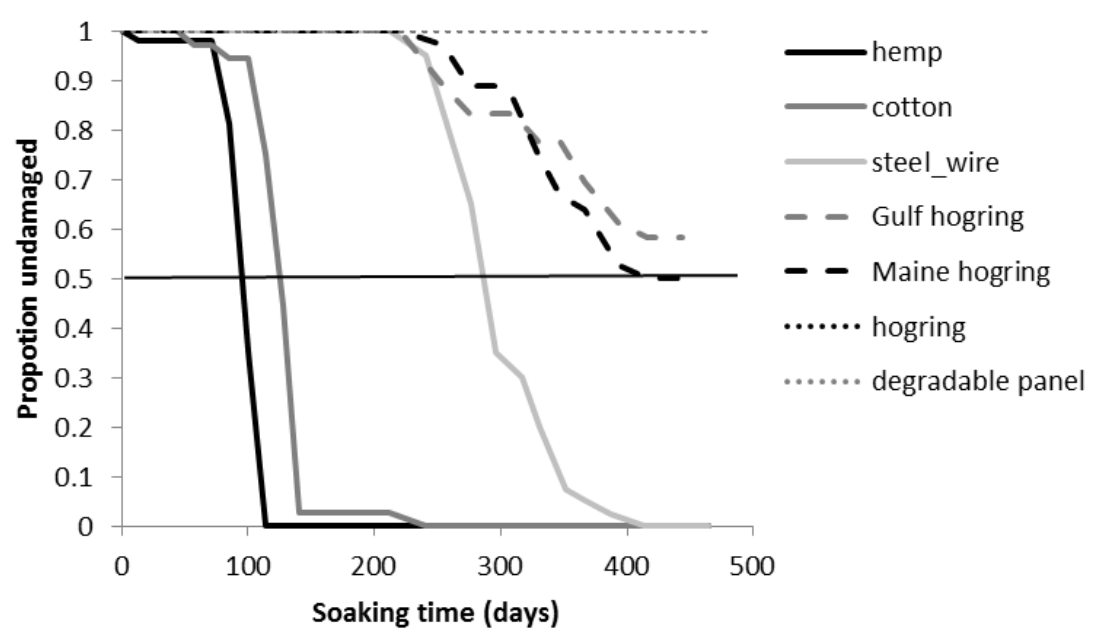

Fig. 3.6.1. Degradation over time of the different materials used to attach the escape panels.

The average breakage time in days and range (between brackets) for escape panels attached with hemp, cotton and wire was 105 (85-114), 150 (128-241) and 333 (276-414) respectively (Fig. 3.6.1). Only $\sim 50 \%$ of the escape panels attached with Maine hog rings and Gulf hog rings had broken after more than 440 days. The biodegradable panels and the panels attached with Dutch hog rings (coinciding horizontal line) were all still in place at the end of the experiments (465 days).

\subsubsection{Ghost fishing}

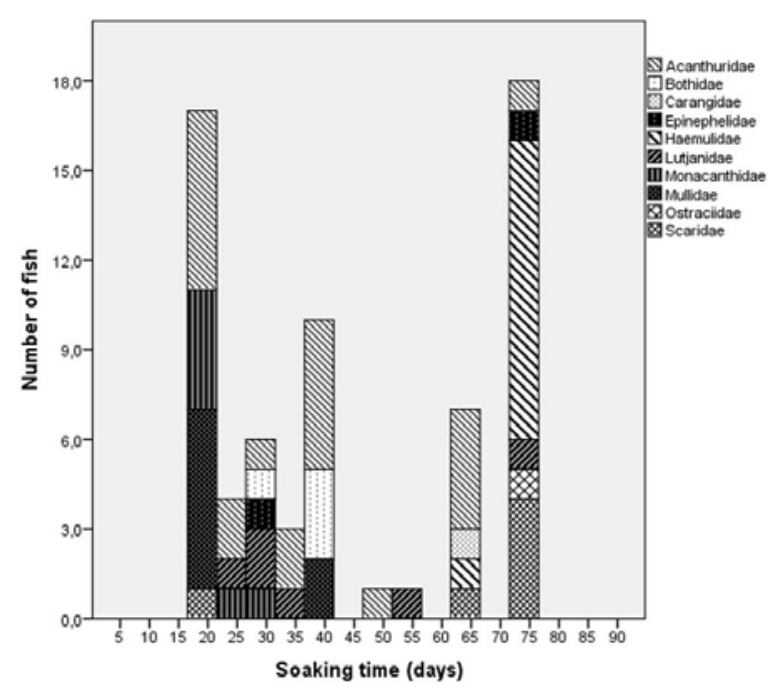

Fig. 3.6.2. Temporal changes in the species composition of the ghost trap at Smoke Alley.

Fish: At Smoke Alley 67 individual fish were observed in the ghost trap (Fig. 3.6.2). Abundance varied between 0 and 18 fish and the most commonly observed fish family were surgeon fishes (Acanthuridae; 32\%). At Crooks Castle 174 individual fishes of 21 species from 13 families were observed in the experimental ghost traps (Fig. 3.6.3). The abundance within the three ghost trap varied between 0 and 26 fishes per observation. In general, the most abundant fish families (cumulative in numbers) were butterfly fishes (Chaetodontidae; 33\%) and surgeon fishes (Acanthuridae; 31\%). In two of the three traps nurse sharks (Ginglymostoma cirratum) were 
observed. The sharks were first observed on day 18 in traps 1 and 3 . In trap 1 , the shark was no longer seen after day 40, in trap 3 the shark was able to escape after day 73.

During the experiment with the four ghost fish traps on the reef at Crooks Castle and the small wreck at Smoke Alley, in total 5 dead (2\%) and 241 live fish were observed during the 342 trap days. Three dead fish ( 1 bar jack (Caranx ruber), 1 scrawled file fish (Aluterus scriptus), 1 rock hind (Epinephelus adscensionis) were observed at the ghost trap at Smoke Alley. Two dead fish both red hinds (Epinephelus guttatus) were observed in the three ghost traps at Crooks Castle. Assuming a weight of $0.5 \mathrm{~kg}$ per fish this would result in roughly $(0.0073 \mathrm{~kg}$ of dead fish per ghost trap per day). A rough estimate of fish mortality per ghost trap per year is $2.7 \mathrm{~kg}$.

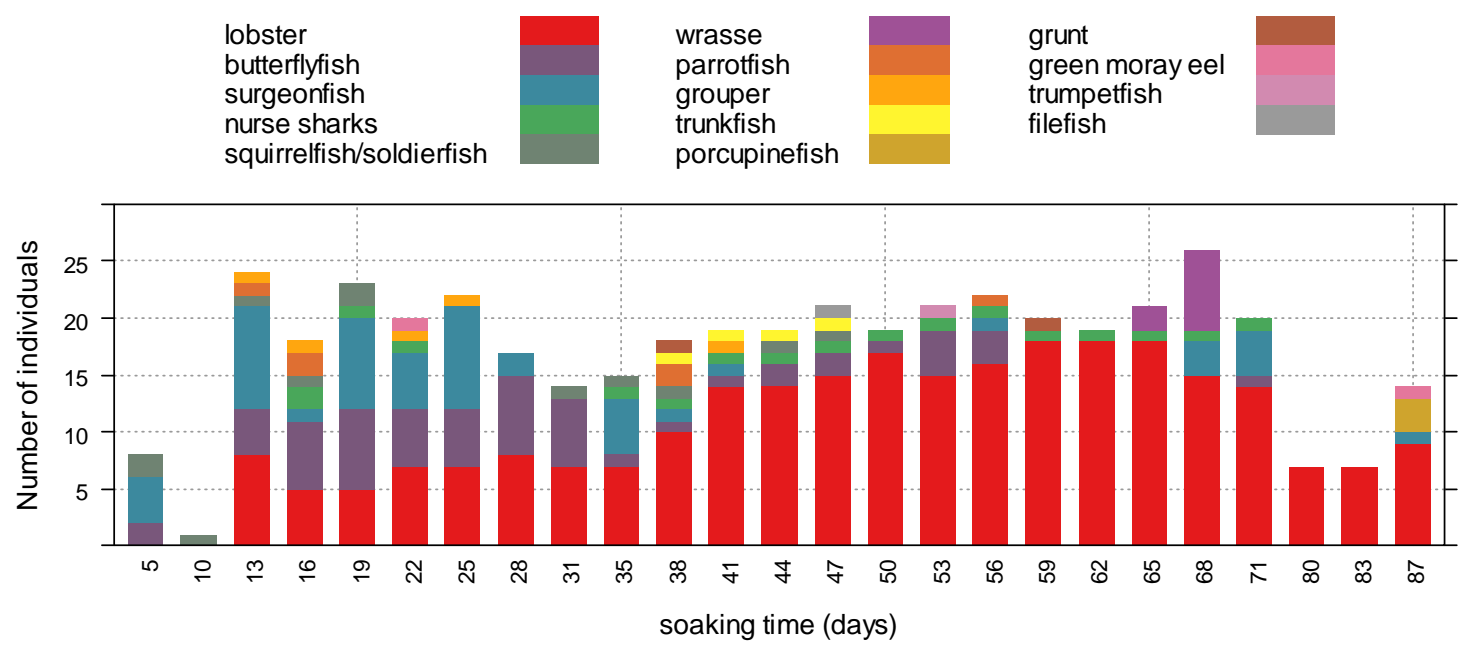

Fig. 3.6.3. Temporal changes in the species composition of the three ghost traps at Crooks Castle.

Lobster: During the experiment with the three ghost fish traps on the reef at Crooks Castle, 261 live and 2 dead lobsters $(<1 \%$ ) were observed during the 267 trap days ( 0.0075 dead lobster per ghost trap per day). A rough estimate of lobster mortality per ghost trap per year was 2.7. Both Spiny lobster (Panulirus argus) and Spotted spiny lobster (Panulirus guttatus) were observed in the ghost traps.

\subsubsection{Escape slots}

\subsubsection{Lobster traps}

\section{Trap type}

The catch composition in the control traps was compared between the two types of trap, D and M (Fig. 3.6.4). A wider range of species was observed in the larger D-traps (Fig 3.6.4, left). A number of species (e.g. blue tang, queen triggerfish, white-spotted filefish) rarely caught in the smaller M-traps were frequently observed in large D-traps. For the most frequently caught species (e.g. ocean surgeonfish, spiny lobster, doctorfish, Fig. 3.6.4, right), the average number of fish caught per trap did not show large differences between the two trap types. The only exception was for the white grunt for which the catch rates were markedly higher in the larger D-traps. In conclusion, the data from the two types of trap should be treated separately if the aim is to look at the effect of escape vents on the species composition or the catch rates of most of the reef fish species. If the aim is to determine if escape vents influence the catches of spiny lobster, the data from the two types of traps can probably be combined. 

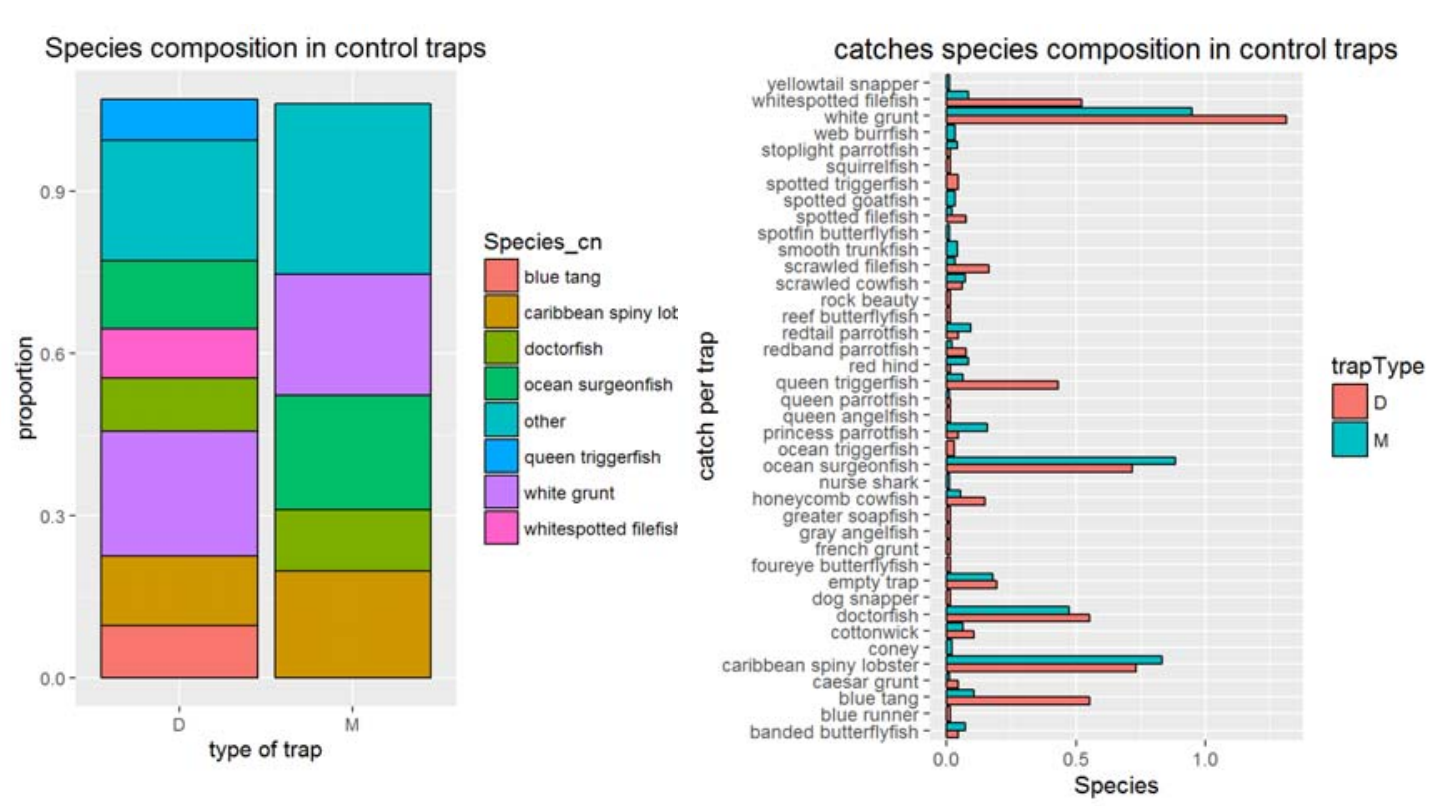

Fig. 3.6.4. Comparison of the species composition and of the catch rates between the $D$ and the $M$ type traps (controls only).

\section{Lobster catch rate}

The number of lobster per trap was modelled using a GLM with a Poisson error distribution, to test for the effect of the type of trap ( $D$ or $M$ ), fishing trip, and the presence or absence of an escape slot. Data for the experiments with the $25 \mathrm{~mm}$ and with the $38 \mathrm{~mm}$ escape slots were modelled separately. The model for the experiments using the $25 \mathrm{~mm}$ slots indicate that the number of lobsters per trap was influenced neither by the escape slot nor by the type of trap used (Fig. 3.6.5). There were, however, differences between fishing trips. The model for the experiment with the $38 \mathrm{~mm}$ escape slots concluded that the type of trap ( $D$ or $M$ ) had no effect, that catches varied depending on the trip, and that the traps with the escape slot had higher catches than the control traps. There was a significant difference of 0.55 lobster per trap for the experiment with the $38 \mathrm{~mm}$ escape vent (Fig. 3.6.5). The difference for the $25 \mathrm{~mm}$ escape slot was not significant ( 0.20 lobster per trap).
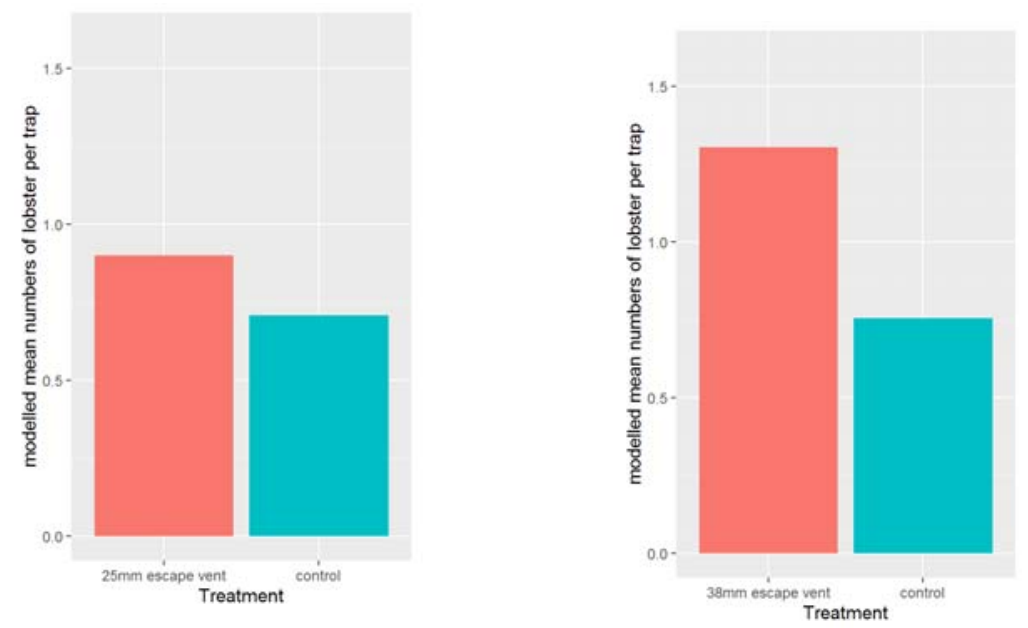

Fig. 3.6.5. Modelled effect of the $25 \mathrm{~mm}$ and the $38 \mathrm{~mm}$ escape vents on the catches of spiny lobster ( $M$ and D-type traps pooled).

\section{Lobster size}

The carapace length distribution of the lobster catches from the control traps and from the traps equipped with escape vents were similar (Fig. 3.6.6). There was no difference in mean carapace length between the control and $25 \mathrm{~mm}$ escape slot ( $p=0.73$ ). For the experiment with the $38 \mathrm{~mm}$ escape slot, however, there was a small $(115 \mathrm{~mm} \mathrm{CL}$ with escape vent and $120 \mathrm{~mm} \mathrm{CL}$ in control traps) but significant ( $p=0.04$ ) difference in the mean carapace length of retained lobster. 

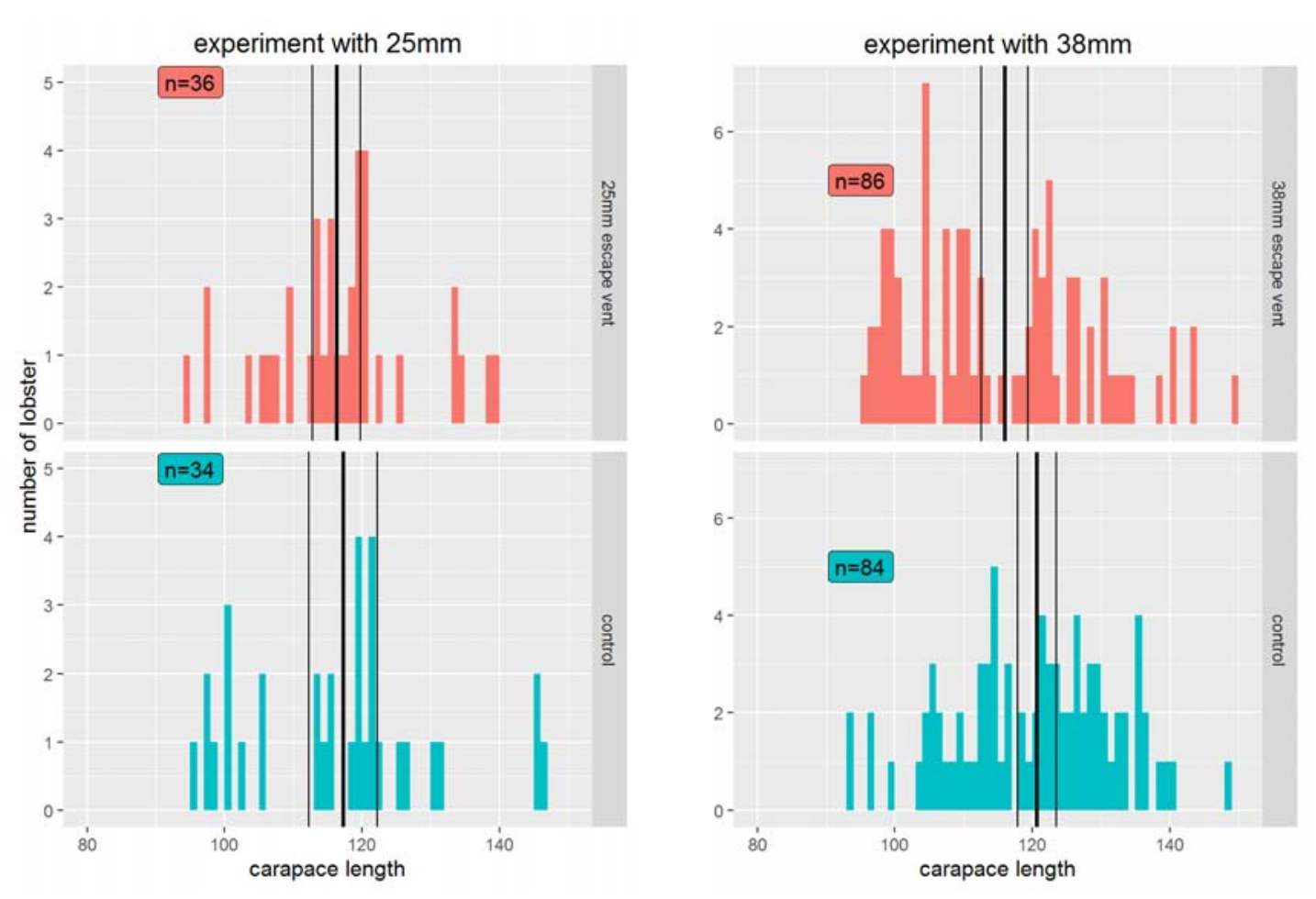

Fig. 3.6.6. Carapace length distribution for the lobster in the different treatments.

\section{Reef fish catch rate}

Fish species caught in the lobster traps were classified in 3 groups depending on their economic value (High value: groupers, snappers; Intermediate value: grunts, jacks; Low value: all other reef fish). The effect of the escape vent on the catch rates for each group was then investigated (Fig. 3.6.7). As mentioned already above, D-traps had substantially higher catch rates for fishes than the smaller Mtraps, and therefore the data for the 2 trap types are presented separately.

The effect of the $25 \mathrm{~mm}$ escape vents on the catch rate was different for the type $D$ and type $M$ traps. Catch rates were almost double for the type D traps with $25 \mathrm{~mm}$ escape vents compared with the control traps. This difference was mainly due to an increase in the catch rate of species of intermediate economic value. Catch rates of high value species were low in the control traps, and almost zero for the traps with the $25 \mathrm{~mm}$ vents. In the type M-traps, there was a small increase in the catch rate of traps with a $25 \mathrm{~mm}$ vent, again mainly due to the intermediate value species. Catch rates of the high value species were low, with little difference between the treatments. The $38 \mathrm{~mm}$ escape vent reduced the catch rates substantially by about $60 \%$ for the D-type traps, and even $80 \%$ for the M-type traps. The decrease in catch rates was observed in all economic value classes, but the decrease was particularly strong for the low value species in type $D$ traps and for intermediate and high value species in type $M$ traps. 

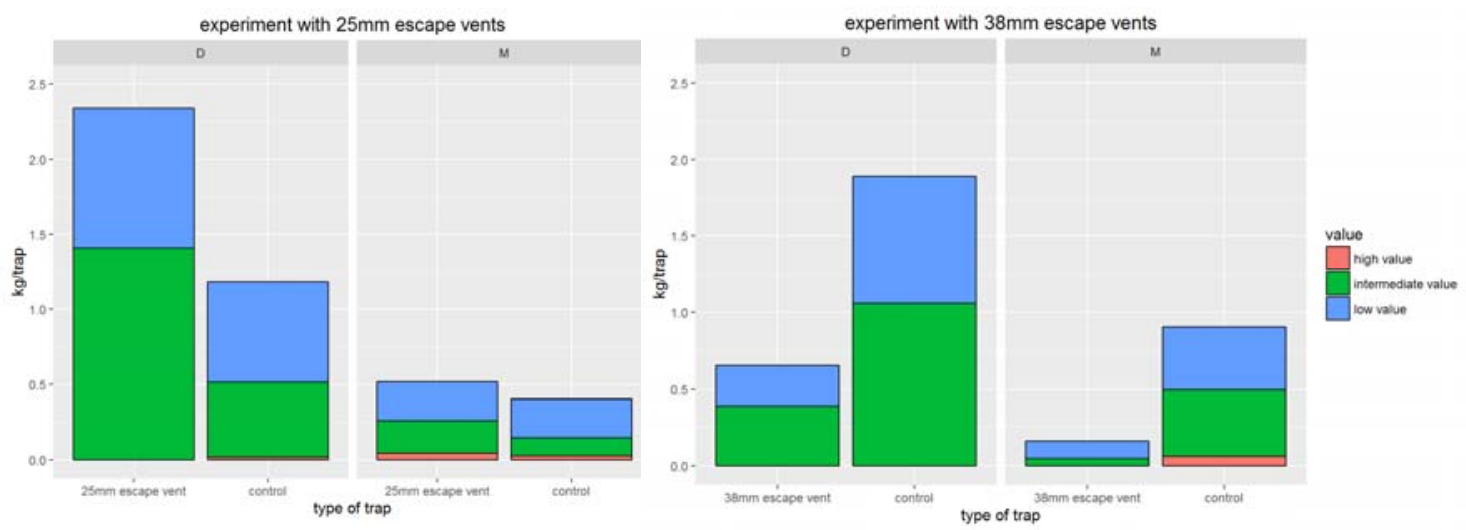

Fig. 3.6.7. Catches rate for fishes according to their economic value during the experiments using a $25 \mathrm{~mm}$ (left panel) and $38 \mathrm{~mm}$ (right panel) escape vent. Data are shown separately for each experiment, and for each type of trap (D or $M)$.

\section{Reef fish size}

There is no clear effect of the escape vents on the length distribution of the reef fish. For the experiment with $25 \mathrm{~mm}$ escape vents, mean fish length is slightly smaller with the escape vent for the D-type trap, and significantly larger for the M-type traps (Fig. 3.6.8). For the $38 \mathrm{~mm}$ escape vent experiment, mean length in the traps with escape vent is slightly larger for the $5 \mathrm{ft} \mathrm{D}$-type traps and slightly smaller for the $4 \mathrm{ft}$ M-type traps, but the differences were not significant. The differences in mean length related to the type of trap were in general larger than the effect of the escape vents on mean length.
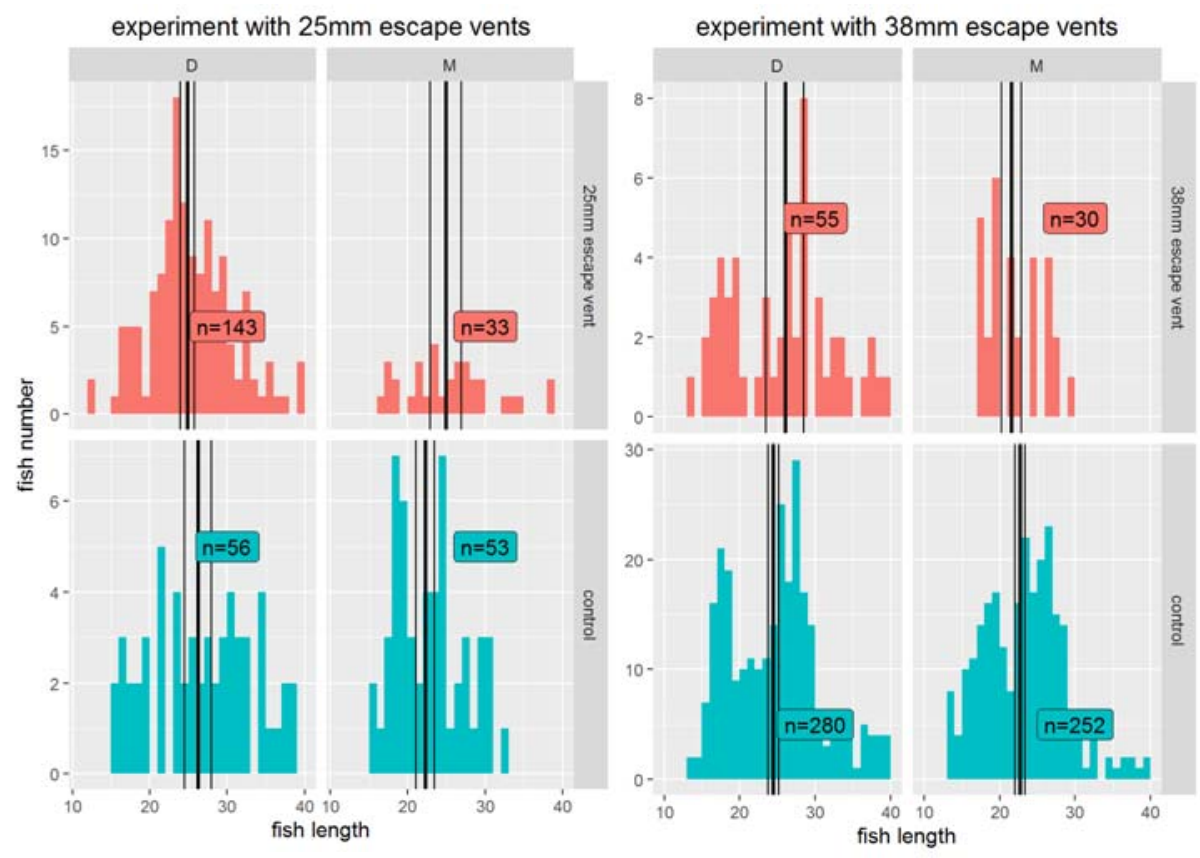

\begin{tabular}{lllll}
\hline \multirow{2}{*}{ trap type } & \multicolumn{2}{l}{$25 \mathrm{~mm}$ experiment } & $38 \mathrm{~mm}$ experiment & \\
& $25 \mathrm{~mm}$ slot & Control & $38 \mathrm{~mm}$ slot & Control \\
\hline D & $24.8 \mathrm{~cm}$ & $26.2 \mathrm{~cm}$ & $26.0 \mathrm{~cm}$ & $24.5 \mathrm{~cm}$ \\
M & $24.9 \mathrm{~cm}$ & $22.3 \mathrm{~cm}$ & $21.5 \mathrm{~cm}$ & $22.7 \mathrm{~cm}$ \\
\hline
\end{tabular}

Fig. 3.6.8. Influence of escape vents and trap type on the length of the fish caught during the two experiments. 


\section{Herbivores}

The catch rates of herbivorous fish (parrotfish and Acanthuridae) were not affected in a consistent way by the $25 \mathrm{~mm}$ escape vent (catch rate increased for the D-type traps and decreased for the M-type traps, Fig. 3.6.9). However, the $38 \mathrm{~mm}$ escape vent considerably reduced the catch rates for herbivores for both trap types.
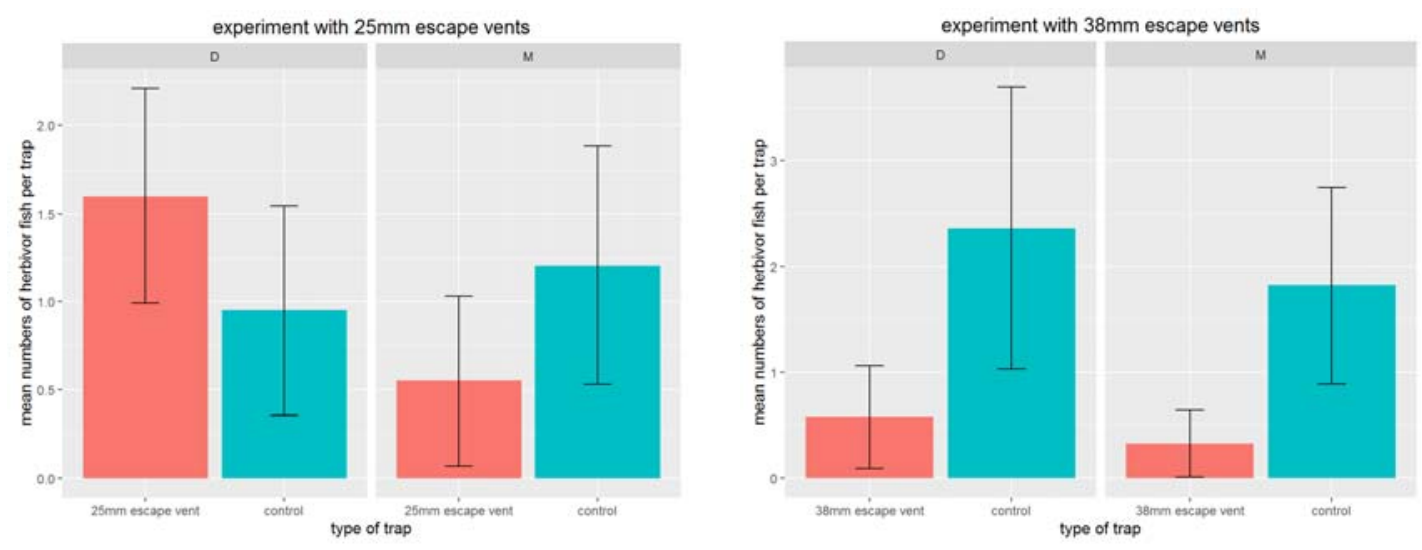

Fig. 3.6.9. Influence of escape vents and trap type on the catch rates for herbivore fish (Scaridae, Acanthuridae).

\subsubsection{Deep-water snapper traps}

\section{Species composition}

The main species caught was silk snapper (Fig. 3.6.10), and to a lesser extent vermillion snapper. The proportion of silk snapper compared to vermillion snapper was also higher in the traps with a $25 \mathrm{~mm}$ escape vent. The catch of traps with $38 \mathrm{~mm}$ escape slots was also dominated by silk and vermillion snapper in number, however, bar jack represented a significant proportion of the catches in weight.
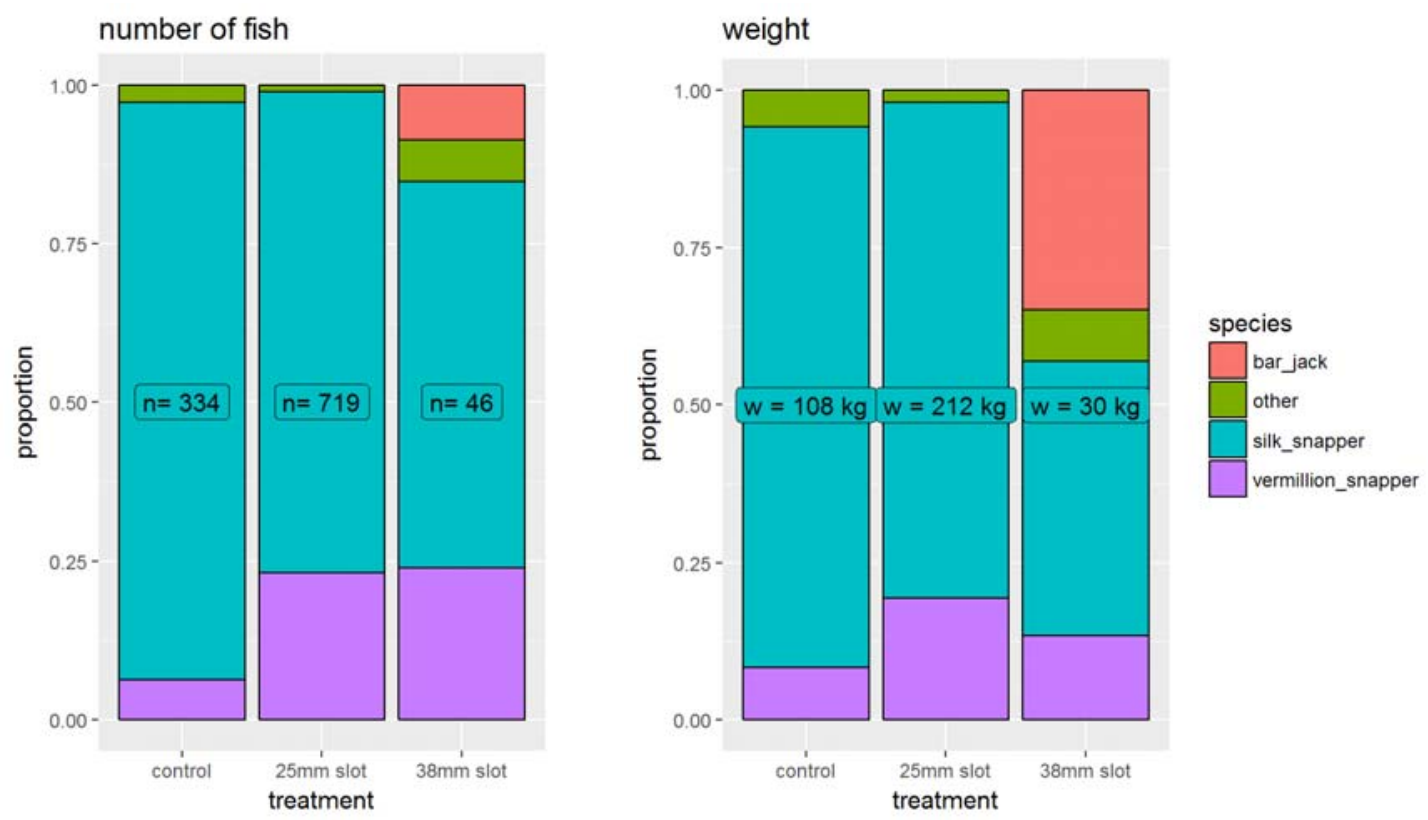

Fig. 3.6.10. Species composition (in number and in weight) for the traps with $25 \mathrm{~mm}(n=45)$ and $38 \mathrm{~mm}(n=30)$ escape vent and for the control traps $(n=30)$. Note that the catches for the traps with a $25 \mathrm{~mm}$ escape vent originate from 3 traps, whereas only 2 traps were used for each of the 2 other cases. 


\section{Catch rate}

The catches of redfish, expressed both in weight or in number of fish per trap, were influenced by the type of escape vent (ANOVA, $\mathrm{p}<0.001$ ). Fishing trip, soaking time and depth did not influence the catch rate significantly. The difference was significant between the traps with a $38 \mathrm{~mm}$ vent and the two other treatments. The difference between the control traps and the traps with the $25 \mathrm{~mm}$ vent were not significant (Fig. 3.6.11).

The traps with a $25 \mathrm{~mm}$ escape vent have more frequently catches of between 15 to 22 fish than the control traps (see Fig. A2.1 in Annex 2). Occasional large catches (>40 fish) were also more frequent. It should be noted that nearly $70 \%$ of the catches of vermillion snapper in the traps with the $25 \mathrm{~mm}$ vents originate from only 2 trap hauls (out of the 45 carried out with this gear, see Fig. A2.2 in the Annex 2). The traps equipped with a $38 \mathrm{~mm}$ slot were found empty $56 \%$ of the time, and when it was not the case, the number of fish caught was low (mostly lower than 5). In comparison, control traps were empty only $7 \%$ of the time, and traps with the $25 \mathrm{~mm}$ escape vent were never found empty.
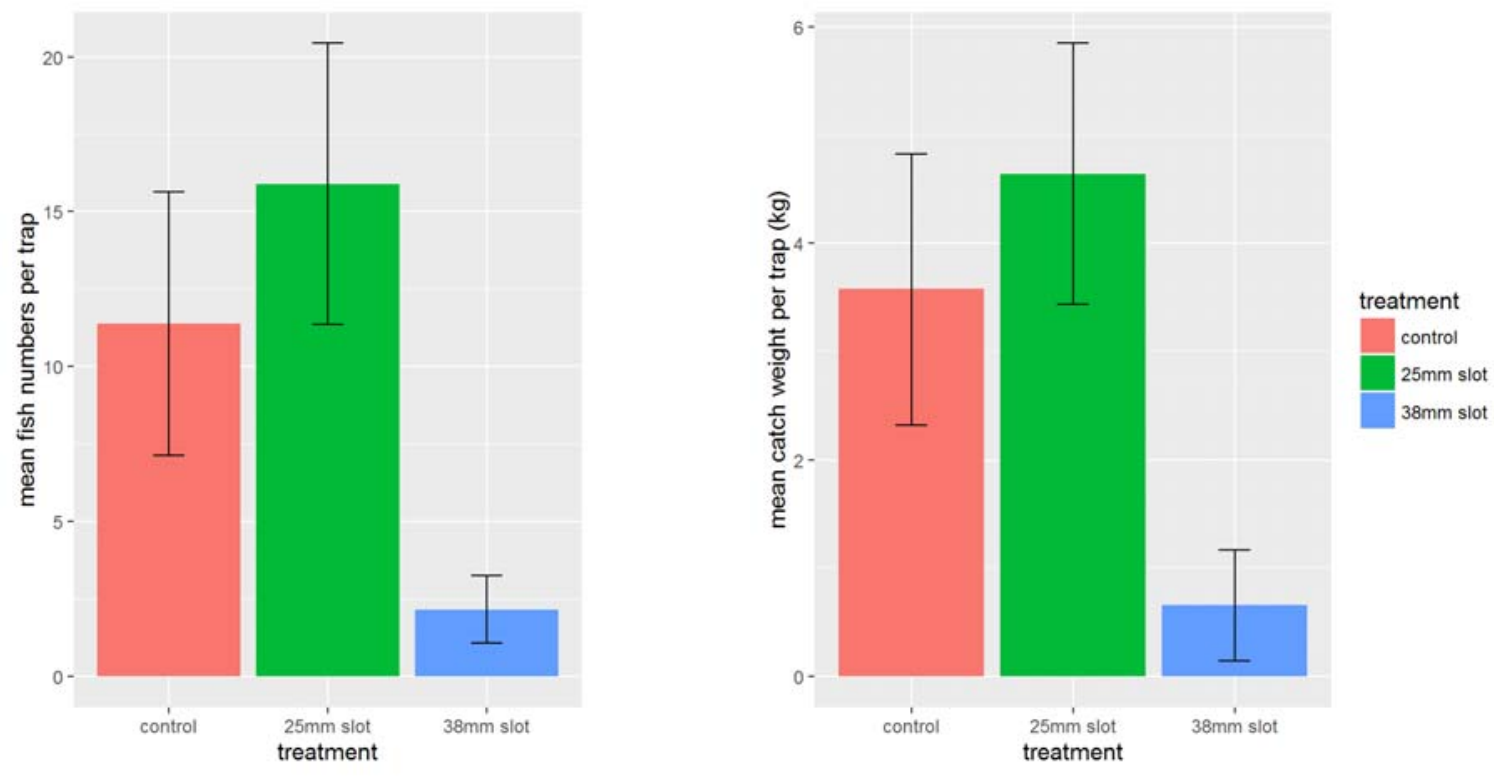

Fig. 3.6.11. Mean catch rate of deep-water snappers per trap (number, left; weight, right) for the three treatments. Error bars are 95\% confidence intervals.

Length:

The $25 \mathrm{~mm}$ escape slot had little effect on the length distribution of the catches of silk snapper, with a similar mean length as in the control trap, at $28 \mathrm{~cm}$ (Fig. 3.6.12). The silk snapper caught in the traps equipped with the $38 \mathrm{~mm}$ escape vent, however, were significantly larger than in the two other treatments, with a mean length of $33 \mathrm{~cm}$.

The effect of the escape vent appeared to be different in the case of the vermillion snapper. For this species, the catches from the traps equipped with the $25 \mathrm{~mm}$ escape vent were significantly smaller than the control traps, with a mean length of $23 \mathrm{~cm}$ and $29 \mathrm{~cm}$ respectively. The catches from the traps with the $38 \mathrm{~mm}$ escape vent had a similar length as for the control traps. 


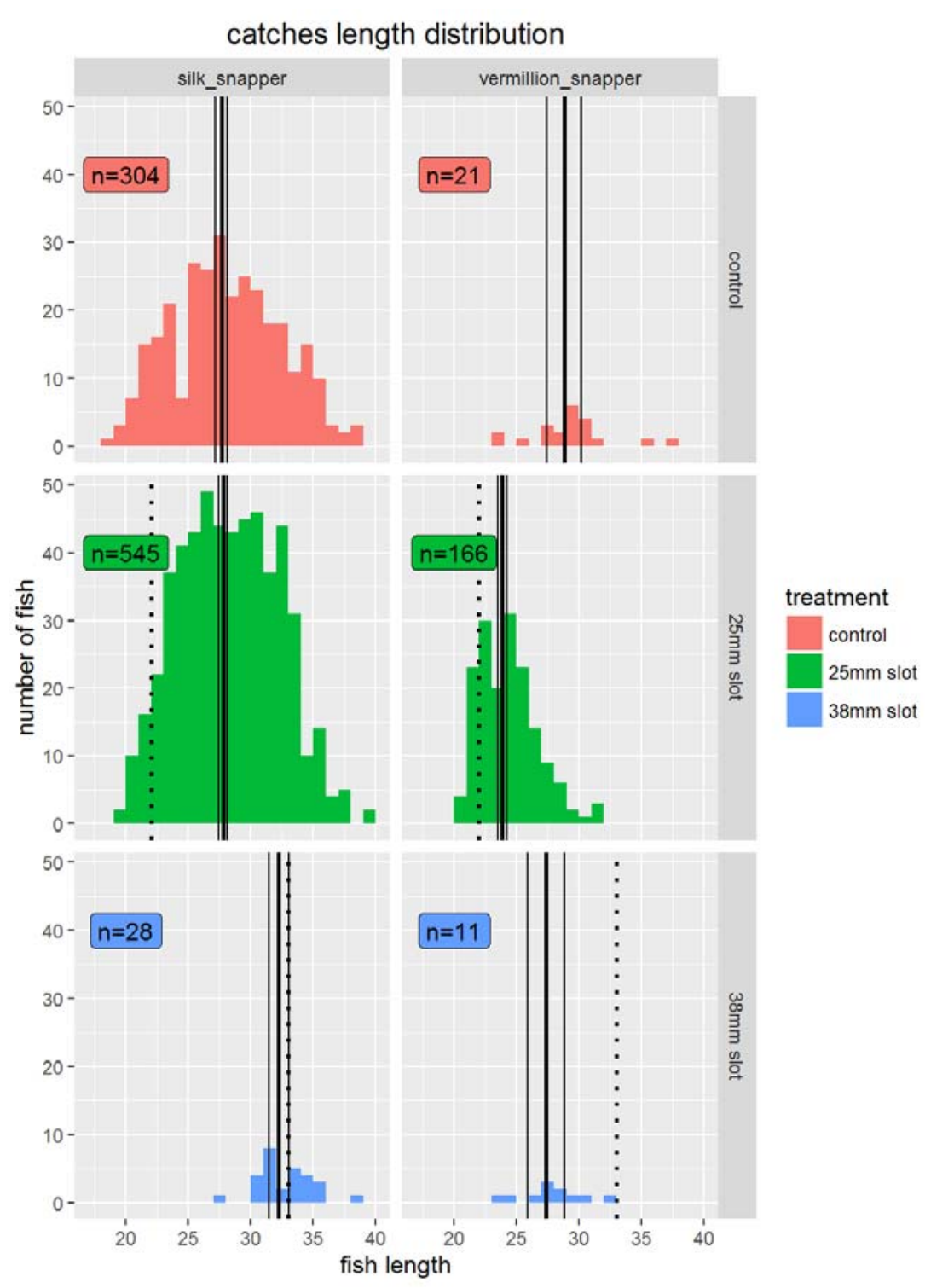

Fig. 3.6.12. Length frequency distribution of the catches of the two main species for each type of trap. Solid vertical lines represent the mean length (and confidence intervals). Dotted vertical lines represent the theoretical minimum retention length for the traps with escape vents based on the length body width relationship. Numbers indicate the total number of fish for each trap type (note that three $25 \mathrm{~mm}$ slot traps were used whereas only two traps were used for the other treatments). 


\subsection{Whales and dolphins}

During the study period at Saba a total of 1870 fishing days were monitored using port sampling (Table 3.7.1). Monitoring effort was highest in 2015, but the effort in 2016 over the same period (January to May) was the same order of magnitude. Each month $(n=37)$ between 2 and 71 "fishing days" of effort were monitored (mean 40 per month).

Table 3.7.1. Monitored fishing days at Saba, presented by month, between 10 July 2012 and 30 May 2016, for which cetacean occurrence data were obtained.

\begin{tabular}{llllllllllllll}
\hline & Jan & Feb & Mar & Apr & May & J un & Jul & Aug & Sep & Oct & Nov & Dec & total \\
\hline 2012 & - & - & - & - & - & - & 32 & 46 & 71 & 65 & 43 & 4 & $\mathbf{2 6 1}$ \\
2013 & 2 & 31 & 10 & 43 & 47 & 39 & 38 & 39 & 24 & 42 & 32 & 28 & $\mathbf{3 7 5}$ \\
2014 & 26 & 41 & 34 & 39 & 29 & 43 & 40 & 28 & 49 & 31 & 58 & 51 & $\mathbf{4 6 9}$ \\
2015 & 52 & 61 & 37 & 47 & 44 & 66 & 76 & 30 & 47 & 34 & 27 & 28 & $\mathbf{5 4 9}$ \\
2016 & 36 & 52 & 29 & 61 & 38 & & & & & & & & $\mathbf{2 1 6}$ \\
\hline Mean & 29.0 & 46.3 & 27.5 & 47.5 & 39.5 & 49.3 & 46.5 & 35.8 & 47.8 & 43.0 & 40.0 & 27.8 & 374 \\
\hline total & 116 & 185 & 110 & 190 & 158 & 148 & 186 & 143 & 191 & 172 & 160 & 111 & 1870 \\
\hline
\end{tabular}

A total of 142 sightings (1126 animals) was made (July 2012 to May 2016) and categorized as either "dolphin" or "whale" (Table 3.7.2). This amounts to an average of a sighting on $7.5 \%$ of all trips, or a sighting for every 13.2 trips. For the 52 whale sightings (88 animals) $23 \%$ of the sightings were identified as humpback whales and $2 \%$ (one sighting of one animal) as a sperm whale. The remaining $75 \%$ were not identified to species level. Mean group size per whale sighting was 1.7 animals/sighting.

Table 3.7.2. Overview of number of whale and dolphin sightings, numbers and mean group size recorded during the Saba port sampling 2012 to 2016.

\begin{tabular}{l|ccc}
\hline & Sightings & numbers & mean group size \\
\hline humpback whale & 12 & 16 & 1.3 \\
sperm whale & 1 & 1 & 1.0 \\
non identified whale & 23 & 61 & 2.7 \\
total whales & $\mathbf{5 2}$ & $\mathbf{8 8}$ & \\
\hline bottlenose dolphin & 5 & 49 & 9.8 \\
"like" bottlenose dolphin & 2 & 6 & 3.0 \\
"like" spinner dolphin & 2 & 115 & 57.5 \\
pilot whale & 3 & 34 & 11.3 \\
non identified dolphin & 78 & 834 & 10.7 \\
total dolphins & $\mathbf{9 0}$ & $\mathbf{1 0 3 8}$ & \\
\hline total whales \& dolphins & $\mathbf{1 4 2}$ & $\mathbf{1 1 2 6}$ & \\
\hline
\end{tabular}

A total of 90 dolphin sightings with a total of 1038 animals was recorded (Table 3.7.2). Of these sightings $6 \%$ were identified as bottlenose dolphins, $2 \%$ as "like" bottlenose, $2 \%$ as "like" spinner and $3 \%$ as pilot whales. The remaining $87 \%$ of the sightings were not identified on a species level. The mean group size of all dolphin sightings was 11.6, but ranged from 1 up to 100 (Fig. 3.7.1). 


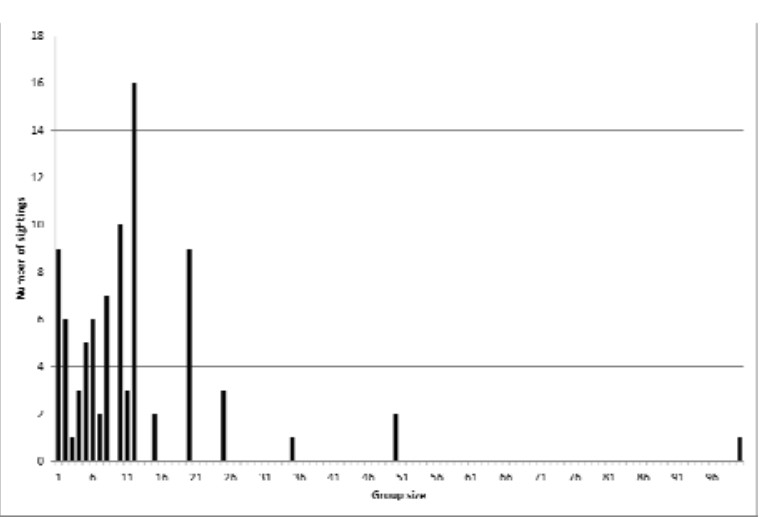

Fig. 3.7.1. Distribution of group sizes for dolphin sightings made from Saba during the port sampling.

Spatial distribution: For the representation of the spatial distribution of dolphins and whales, the sightings (not number of animals) per fishing effort (fishing day) per sub-area were calculated. An " $x$ " indicates that no fishing effort took place in that sub-area shown in the map. For these maps all effort and all sightings were pooled across the sampled period. Effort from Saba was predominantly over the Saba Bank to the west of the island, and up to extend out to $50 \mathrm{~km}$ from the island (Fig. 3.7.1).
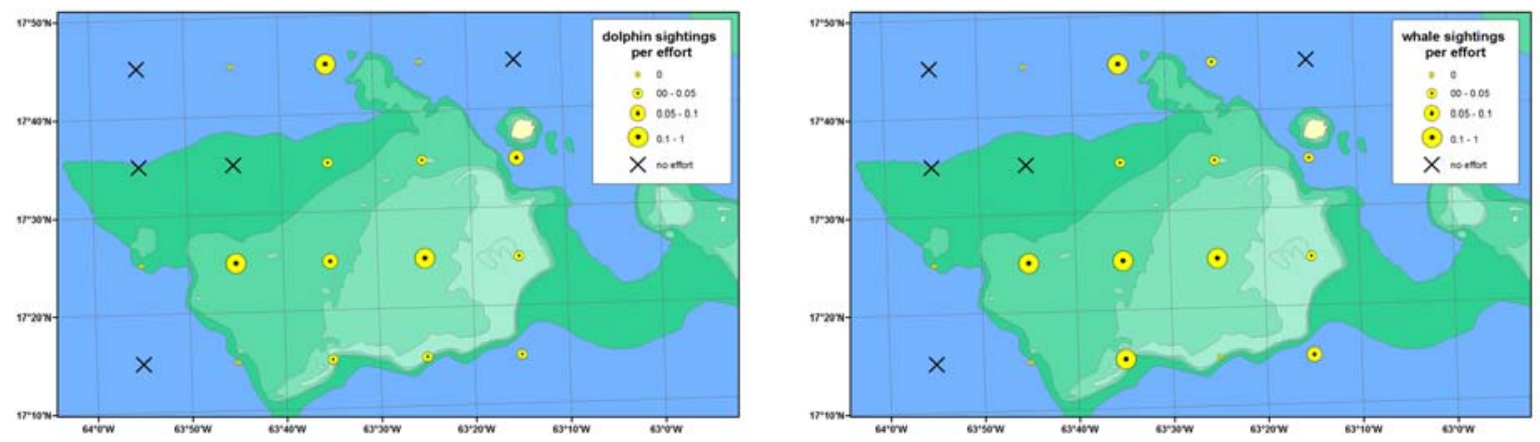

Fig. 3.7.2. Distribution around Saba of dolphin (left) and whale (right) sightings by sub-area per fishing day.

Temporal distribution: Almost all sightings of whales were made in late winter early spring, with the highest numbers in March (Fig. 3.7.3, left). For dolphins, sightings were made every month, but sightings peaked in the third quarter of the year. Effort of sampling was more or less constant throughout the year, but effort was lowest in the winter and early spring months. When looking at the relative occurrence, thus mean number of sightings per fishing day, the chance of seeing dolphins is more or less the same in all months except March (0.2 sightings/fishing day, Fig. 3.7.3, right). We were unable to detect differences in the spatial distribution of dolphins per season (Fig. 3.7.4).
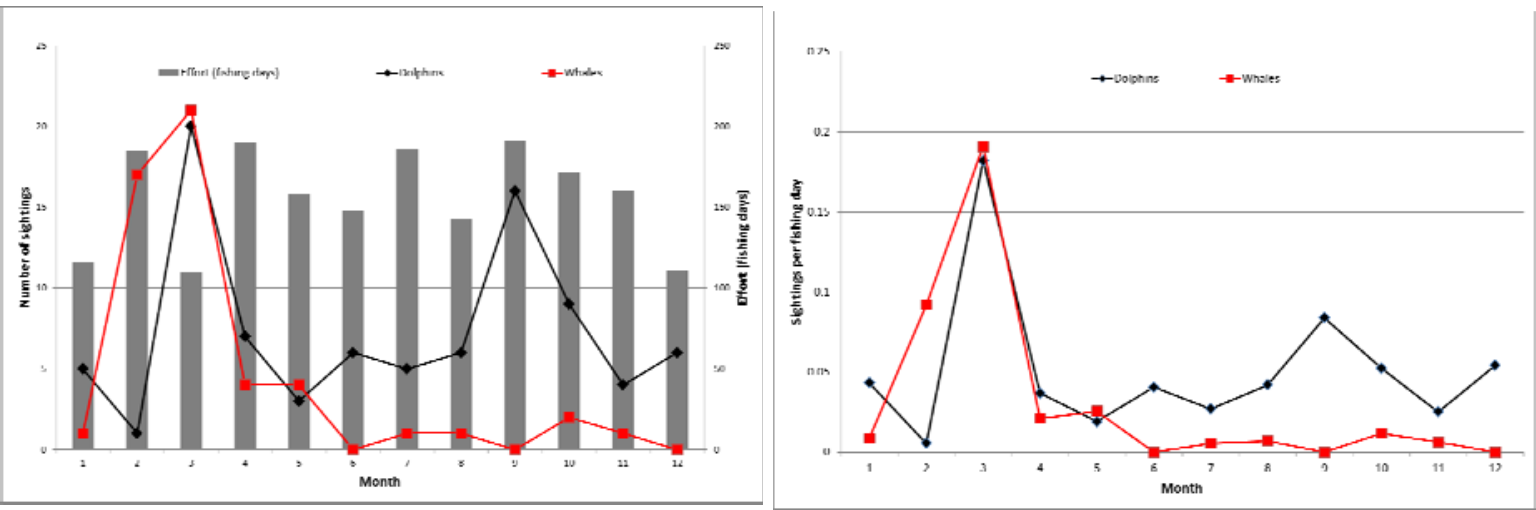

Fig. 3.7.3. (left) Number of whale and dolphin sightings recorded per month during the Saba port sampling (2012 to 2016). Effort of sampling is displayed as fishing days of sampled fishing vessels. (right) Number of whale and dolphin sightings per fishing day per month during the Saba port sampling (2012 to 2016). 


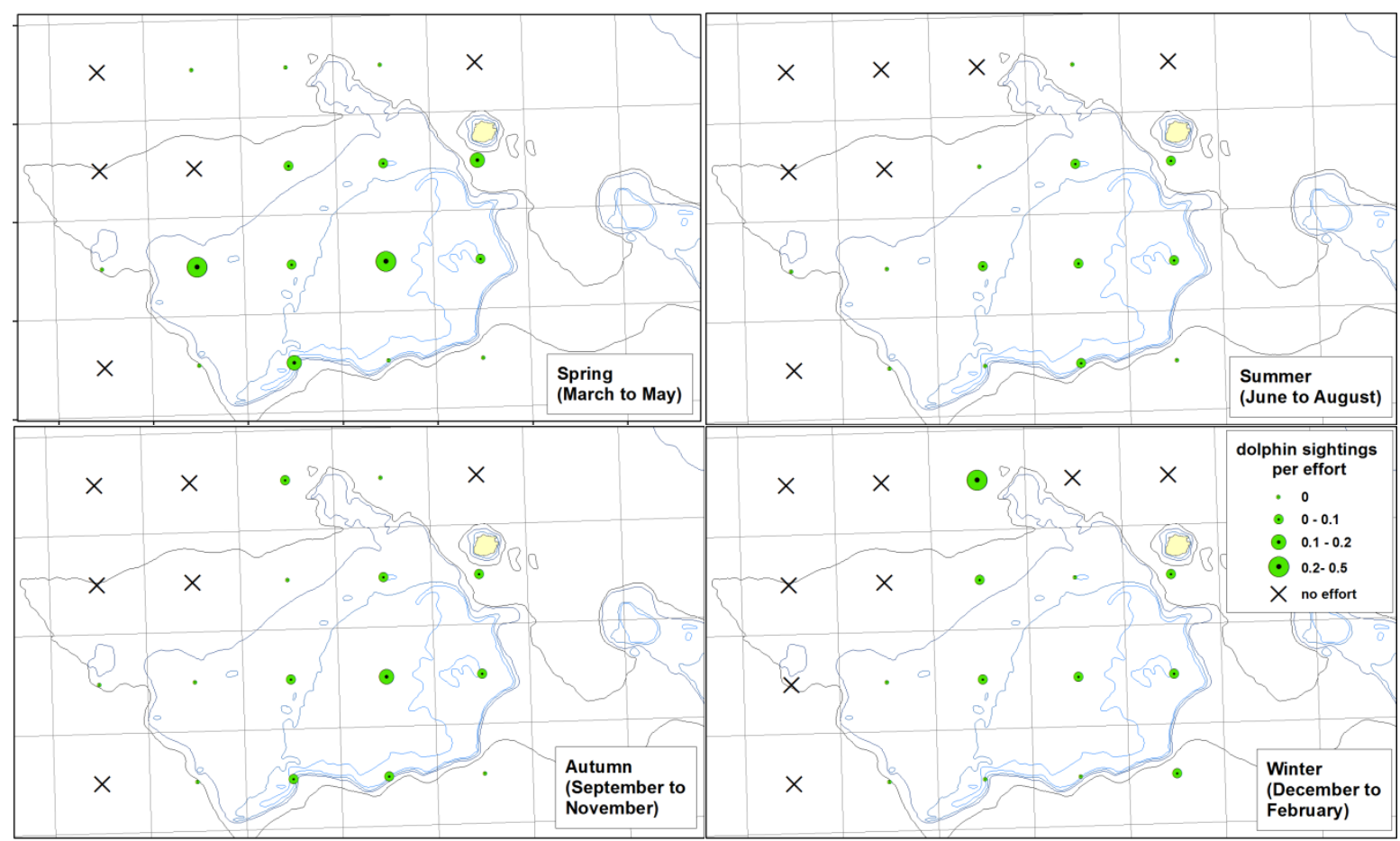

Fig. 3.7.4. Seasonal distribution (spring, summer, autumn and winter) of dolphin sightings per fishing day around Saba as derived from the port sampling. All data combined from 10 July 2012 to 30 May 2016. 


\subsection{Queen conch}

\subsubsection{Reproductive biology}
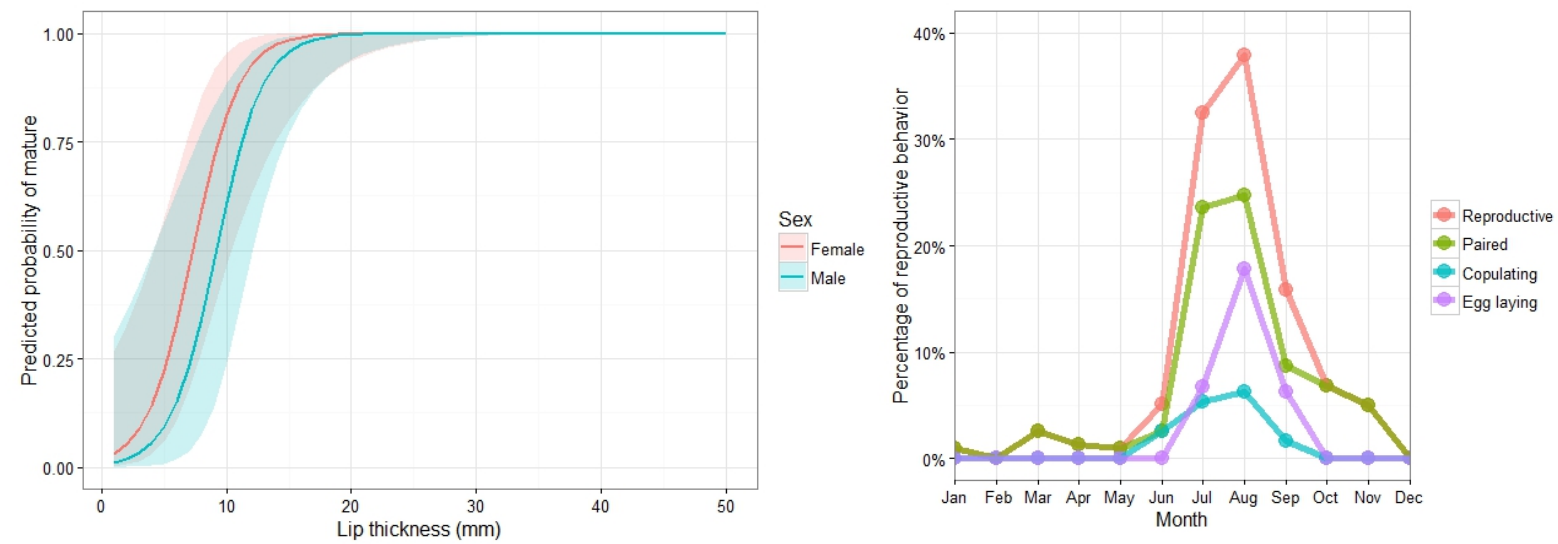

Fig. 3.8.1. Size maturity curve with $95 \%$ confidence interval for flared-lip female (red line) and male (blue line) queen conch on the Saba Bank (left), and seasonal pattern in reproductive activity at Fort Bay (Saba). (Reproductive = sum of paring, copulating and egg laying conch).

Size at maturity: Minimum size of mature queen conch for Saba Bank determined through histological gonad analysis was for females $8 \mathrm{~mm}$ LTmin and for males $9 \mathrm{~mm}$ LTmin. Predicted probability at which $50 \%\left(\mathrm{LT}_{50}\right)$ of the flared-lip queen conch on the Saba Bank were sexually mature was $7 \mathrm{~mm} \mathrm{LT}_{\mathrm{min}}$ (4$10 \mathrm{~mm} \mathrm{95 \% CI)}$ and $9 \mathrm{~mm} \mathrm{LT} \min (4-12 \mathrm{~mm} \mathrm{95 \% CI)}$ for female and males respectively (Fig. 3.8.1, left).

Reproductive season: In the waters around Saba reproductive behaviors (i.e. copulation and egg laying) in queen conch were observed from June till September, peaking in the period July-August (Fig. 3.8.1, right). The minimum size of reproductively active queen conch observed during the surveys was for females $8 \mathrm{~mm}$ LT (egg laying) and for males $17 \mathrm{~mm}$ LT (copulation). 


\subsubsection{Distribution and abundance}

Adult queen conch was found throughout most of the Saba Bank. However, areas with high abundance of conch seemed to be concentrated along the southern and northern edges of bank. Out of the 131 transects conducted during the video survey, adult conch were found in 91 transects, ranging from 16 conch/ha to 882 conch/ha (mean 130.8 conch/ha, 99.7-161.8 95\% CI). In 52 transects (40\% of all transects) more than 100 conch/ha were found (Fig. 3.8.2).

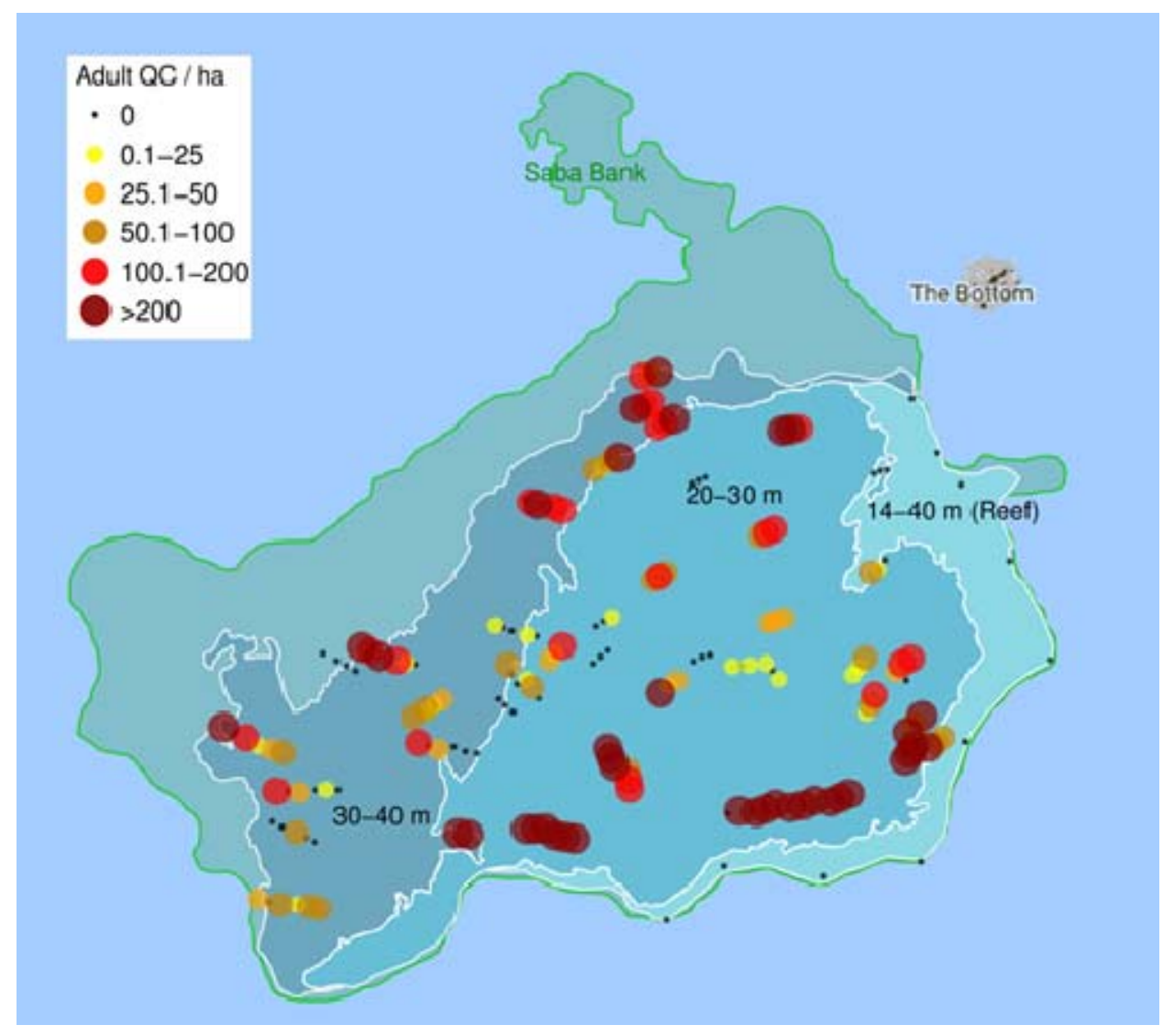

Fig. 3.8.2. Adult queen conch density (no./ha) on the Saba Bank. The outline of Saba Bank is shown in green, the $20-30 \mathrm{~m}$ depth range is shown in light blue and the $30-40 \mathrm{~m}$ depth range is shown in dark blue. Each point on the map represent the density of adult conch from one transect.

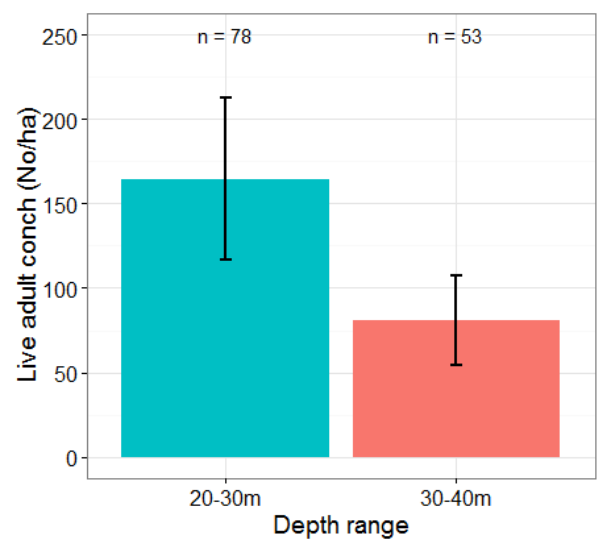

Adult queen conch were found from a depth of $17 \mathrm{~m}$ to $58 \mathrm{~m}$ (survey depth range $17-58 \mathrm{~m}$ ), highest densities of conch were found at $22 \mathrm{~m}$, with 882 and 861 adult conch/ha at two locations. High densities of conch were also found deeper, at $41 \mathrm{~m}$ densities of $392 \mathrm{conch} / \mathrm{ha}$ were found at one location. In the 20-30 m depth-zone 78 transects were conducted and an average number of 164.7 conch/ha (116.6-212.8 95\% CI) was found. In the 30-40 m depthzone 53 transects were conducted and an average number of $80.9 \mathrm{conch} / \mathrm{ha}(54.5-107.295 \% \mathrm{CI})$ was found (Fig. 3.8.3).

Fig. 3.8.3. Mean adult live conch density (no./ha) per depth zone. Error bars represent the bootstrap based $95 \%$ confidence intervals. 
The Saba Bank was stratified according to two depth zones, the corresponding areas in hectares of each depth category were calculated (Table 3.8.1). Based on these areas the conch stock of the Saba Bank in the 20-40 m depth range was estimated to 14.6 million (10.1-19.2 95\% confidence interval) live adult conch.

Table 3.8.1. Summary of the depth stratified (20-30m, Deep $>30-40 \mathrm{~m}$ ) population estimate (millions of adult conch) with bootstrapped $95 \%$ confidence interval (Mean population estimate, High population estimate, Low population estimate) and size of the corresponding area on the Saba Bank in hectares.

\begin{tabular}{llllll}
\hline & & & \multicolumn{3}{l}{$\begin{array}{l}\text { Population estimate } \\
\text { (million) }\end{array}$} \\
\hline & Area & $\begin{array}{l}\text { Density } \\
\text { ho./ ha (95\% CI ) }\end{array}$ & Mean & High & Low \\
\hline $20-30 \mathrm{~m}$ & 45196 & $164(116.6-212.8)$ & 7.4 & 9.6 & 5.3 \\
$30-40 \mathrm{~m}$ & 88962 & $80.9(54.5-107.2)$ & 7.2 & 9.5 & 4.8 \\
Total & 134158 & & 14.6 & 19.2 & 10.1 \\
\hline
\end{tabular}




\subsection{Lionfish}

Overall, lionfish were significantly more abundant (ca. $10 \times$ higher) in the deep-water redfish traps on the slopes of the Saba Bank than in the shallow-water lobster traps on the flat top of the bank (Fig 3.9.1). The abundance of lionfish in shallow-water lobster traps appeared to increase annually between 2012 and 2015. In the deep-water redfish traps, lionfish initially increased between 2012 and 2014 but demonstrated a (non-significant) decline in 2015.

One note of caution for interpretation purposes: the difference in catch rates between shallow and deep waters is likely not only due to any real difference in lionfish density but may have been strongly influenced by the fact that the lobster traps are not designed to catch fish while the fish traps obviously are.

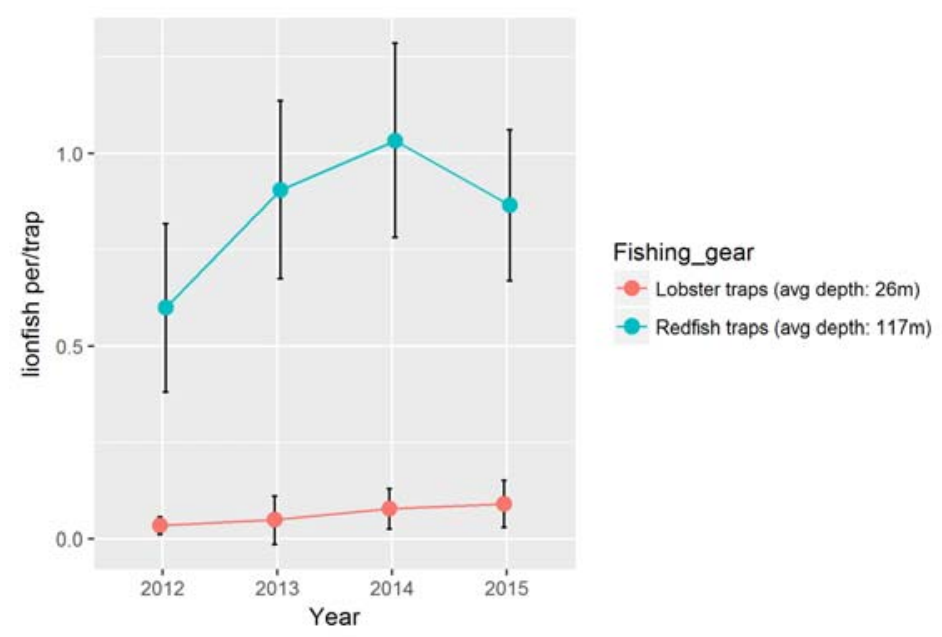

Fig. 3.9.1. Trend in the abundance (average catch rate) of lionfish in the deep-water redfish traps and shallow-water lobster traps on the Saba Bank. Error bars indicate $95 \% \mathrm{Cl}$ of the yearly average. 


\subsection{Historical overview Saba Bank fishery}

While in prehistory, earlier than 450 A.D., the Amerindian inhabitants of Saba consumed mostly terrestrial prey like land crabs and nesting seabirds (Hofman and Hoogland 2003), from 450-1450 A.D. they consumed about $40 \%$ marine prey in their diet and the possibility that they also fished on the Saba Bank cannot be excluded (Hoogland and Hofman 1993). Saba politician, statesman and wellknown island historian, Will Johnson, gladly tells about how modern Sabans have been fishing on the bank for generations. Boeke (1907) also discussed the heavy dependency of the Saban community on its fishing industry which primarily took place on the Saba Bank. The men fished with small boats generally propelled by a couple of rowers. The "Bank" season lasted from October to January, during which some 100 fishermen could be out hand-lining. In that time fish traps were not used as the catches were considered poor (Boeke 1907). The bank was practically only fished by Sabans because the island of Saba had little shelf area whereas St. Maarten and St. Eustatius had much more extensive productive shallow habitat close to shore. Fishing on the bank remained pretty much purely a Saban affair up through the 1960s. According to Saba fishermen the modern directed lobster fishery only started in the 1980 s associated with the rise of the tourism industry of St. Maarten. Traditionally, due to religious prescription, the inhabitants consumed very little lobster and preferred finfish. Table 4.1.1 gives a time line of principal evens for the Saba Bank, while tables 4.1.2. and 4.1.3.

respectively, give overviews of effort and catch development in the Saban fishery since the beginning of the $20^{\text {th }}$ century. No good data or estimates are available for vessels from other countries which fished on the bank till the mid-1990.

Table 4.1.1 Saba Bank timeline of major events.

\begin{tabular}{|c|c|}
\hline Pre $450 \mathrm{AD}$ & $\begin{array}{l}\text { Archaic age seasonal harvest of seabirds and land crabs by the people on } \\
\text { Saba; very little marine subsistence. Probably no fishing on the Saba Bank } \\
\text { (Hofman \& Hoogland 2003) }\end{array}$ \\
\hline $450-1500 \mathrm{AD}$ & $\begin{array}{l}\text { Ceramic age up to } 40 \% \text { reliance on marine food resources by the people of } \\
\text { Saba people. Fishing on Saba Bank suggested as possible (Hoogland \& } \\
\text { Hofman 1993) }\end{array}$ \\
\hline 1632 & $\begin{array}{l}\text { First mixed marriages Saban inhabitants of English European descent } \\
\text { shipwrecked and learn salsa, native fishing and farming techniques that } \\
\text { persist into the present }\end{array}$ \\
\hline 1640 & Dutch rule implemented \\
\hline $1700 ?-1971$ & Historic fishing ground of European Saban handline fishermen \\
\hline 1906 & First scientific publication with information on Saba fisheries (Boeke 1907) \\
\hline 1971 & $\begin{array}{l}\text { FAO research vessel M/V Calamar establishes that fish catch rates were } \\
\text { good by regional comparison. (M/V Calamar cruise report, Wolf \& Chislett } \\
1974 \text { ) }\end{array}$ \\
\hline 1972 & CICAR expedition with H.NL.M.S. LUYMES (van der Land 1977) \\
\hline 1981 & $\begin{array}{l}\text { Massive } 500-800 \text { tons/yr) catches being taken by foreign fishing vessels. } \\
60 \text { tons catch local, } 1000 \text { tons international (Guidicelli \& Villegas 1981, v } \\
\text { Buurt 1980). }\end{array}$ \\
\hline 1989 & Corwith-Cramer Cruise \\
\hline 1993 & $\begin{array}{l}\text { Two sea cargo containers full of conch from the Saba Bank are confiscated } \\
\text { in St. Maarten because of lack of? CITES permits. }\end{array}$ \\
\hline 1993 & $\begin{array}{l}\text { Exclusive Fishing Zone (EFZ) declared by the Kingdom for the Netherlands } \\
\text { Antilles }\end{array}$ \\
\hline 1993 (December) & $\begin{array}{l}\text { National Fisheries Act Netherlands Antilles comes into force, requiring a } \\
\text { fishing license for any fishing in the EFZ }\end{array}$ \\
\hline 1995 & Coastguard of Netherlands Antilles and Aruba established \\
\hline 1996 & 1st ecological assessment (Meesters et al. 1996) \\
\hline 1996 & Royal Dutch Navy hydrographical survey, HMS Snellius \\
\hline 1996 & $\begin{array}{l}\text { End to foreign fishing on the bank due to Coast Guard enforcement of } \\
\text { National Fishery Act }\end{array}$ \\
\hline
\end{tabular}




\begin{tabular}{|c|c|}
\hline 1999 & 1st Saba Bank fishery assessment study (Dilrosun 2000) \\
\hline 1999 & $\begin{array}{l}\text { AGRRA reef survey of Saba Bank (http://www.agrra.org/wp- } \\
\text { content/uploads/2016/08/Netherland-Antilles7-22-03F.pdf) }\end{array}$ \\
\hline 2005 & Catastrophic bleaching event in northern and eastern Caribbean \\
\hline 2006 & $\begin{array}{l}\text { 1st Conservation International Rapid Assessment Protocol (RAP) } \\
\text { biodiversity survey }\end{array}$ \\
\hline 2006 & Hydrographical survey by Dutch Royal Navy \\
\hline 2007 & 2nd Conservation International RAP survey \\
\hline 2007 & $\begin{array}{l}\text { Massive loss of coral cover due to mortality and major anchor damage by } \\
\text { tankers confirmed (Lundvall 2008) }\end{array}$ \\
\hline 2007 & 2nd fishery assessment study (Toller and Lundvall 2008) \\
\hline 2008 & Saba Bank Management Plan presented (Lundvall 2008) \\
\hline 2010 & $\begin{array}{l}\text { Special edition of PlosONE published on Saba Bank biological surveys led } \\
\text { by Conservation International (Hoetjes \& Carpenter 2010). }\end{array}$ \\
\hline 2010 & $\begin{array}{l}\text { Saba Bank incorporated into the Netherlands and biological resources now } \\
\text { responsibility of Dutch Ministry of Agriculture Nature and Food Quality } \\
\text { (LNV) }\end{array}$ \\
\hline 2010 & $\begin{array}{l}\text { Dutch Ministry of Economic Affairs, Agriculture and Innovation, together } \\
\text { with representatives of all six islands, drafts a management plan for the } \\
\text { marine biodiversity and fisheries of the Dutch Caribbean EEZ }\end{array}$ \\
\hline 2010 & $\begin{array}{l}\text { (1 October) designated "Nature Park" by the Netherlands Antilles; } \\
\text { (December) designated "Nature Park" by the Netherlands }\end{array}$ \\
\hline 2010 & $\begin{array}{l}\text { arrival of the invasive lionfish, Pterois volitans (July St. Maarten and Saba, } \\
\text { August St. Eustatius) }\end{array}$ \\
\hline 2011 & $\begin{array}{l}1^{\text {st }} \text { international multidisciplinary research expedition led by IMARES; start } \\
\text { of the fishery-(in)dependent surveys to collect base-line information on } \\
\text { status fish stocks and fisheries }\end{array}$ \\
\hline 2012 & Awarded "National Park" status by the Netherlands \\
\hline 2012 & Saba Bank Management Unit (SMBU) established and boat purchased \\
\hline 2012 & Ministry of Economic Affairs funds structural fisheries monitoring \\
\hline 2012 (October) & $\begin{array}{l}\text { "Particularly Sensitive Sea Area (PSSA)" as accorded by the International } \\
\text { Maritime Organization (IMO) }\end{array}$ \\
\hline 2012 (October) & $\begin{array}{l}\text { Entered as "Specially Protected Areas and Wildlife (SPAW) Protected Area", } \\
\text { within the SPAW Protocol. }\end{array}$ \\
\hline 2012 (December) & $\begin{array}{l}\text { Listed as "Ecologically or Biologically Significant Marine Area (EBSA)" within } \\
\text { the Convention on Biological Diversity (CBD) }\end{array}$ \\
\hline 2013 & $2^{\text {nd }}$ international multidisciplinary research expedition led by WMR \\
\hline 2013 & $\begin{array}{l}\text { The Dutch Ministry of Economic Affairs presents plans to establish a Dutch } \\
\text { Caribbean marine mammal sanctuary and to develop and implement a } \\
\text { protection plan for elasmobranchs }\end{array}$ \\
\hline 2013 & $\begin{array}{l}\text { First year of seasonal closure of the Moonfish Bank seasonal spawning } \\
\text { aggregations of red hind and queen triggerfish ( } 1 \mathrm{Dec}-31 \mathrm{Feb})\end{array}$ \\
\hline 2015 & $3^{\mathrm{d}}$ international multidisciplinary research expedition led by WMR and NIOZ \\
\hline 2015 & $\begin{array}{l}\text { Saba Bank becomes part of the "Yarari Marine Mammal and Shark } \\
\text { Sanctuary" encompassing all the waters of Saba and Bonaire }\end{array}$ \\
\hline 2016 & Waitt Institution expedition \\
\hline 2016 & $\begin{array}{l}\text { Saba Bank Symposium presenting main results of } 3 \text { Wageningen-led } \\
\text { expeditions and additional research } \\
\text { (http://www.dcbd.nl/document/bionews-31-dutch-caribbean-newsletter) }\end{array}$ \\
\hline 2017 & $\begin{array}{l}\text { Fisherman redfish agreement closed from April } 1 \text { to September } 30,2017 \text {, } \\
\text { after which limit of } 25 \text { traps per fisherman. }\end{array}$ \\
\hline 2017 & $\begin{array}{l}\text { First multi-year SMBU fishery monitoring assessment published (this } \\
\text { report) }\end{array}$ \\
\hline
\end{tabular}

Exploratory fishing by FAO in 1971 (M/V Calamar expedition) showed good catch rates of deep-water snapper on the bank compared to elsewhere in the Caribbean (Wolf \& Chislett 1974). This came at a time in the 1970s many nations began declaring their Exclusive Economic or Exclusive Fishery Zones. As a consequence, many foreign fishers were displaced to the Saba Bank and more than two decades of unregulated intensive fishing began. For 1980 the total catch by the Saban fishermen was estimated at about 50 tons of fish per year whereas fish extraction by foreign parties (St. Croix, St. Kitts \& Nevis, Anguilla, Venezuela) were estimated at 500-700 (van Buurt 1980) or possibly even 1000 ton per year (Guidicelli \& Villegas 1981). Meesters et al. (1996) recount that fishing boats utilising hookah gear (small compressors that transport air to divers through a long hose) and divers 
equipped with spear guns had harvested groupers, lobsters and conch throughout the bank. They also indicate that boats from St. Croix had trawled the bank with nets, harvesting everything (Meesters et al. 1996). Only after the Netherlands Antilles had declared their EFZ in 1993 and the newly established coast guard of the Netherlands Antilles and Aruba became active in 1996, was an end brought to the foreign excesses. Saban interest in participation in the Saba Bank fishery rekindled. The two main fisheries since then have been the spiny lobster fishery and the redfish fishery (Dilrosun 2000). Most fishing activity was concentrated in a limited part of the Saba Bank that lies closest to Saba (Gerwen 2013).

After 10 October 2010, when the islands of Bonaire, St. Eustatius and Saba acceded to the Netherlands, the Ministry of Agriculture, Nature and Fisheries (today the Ministry of Economic Affairs) acquired ultimate responsibility for the biological resources of the bank. Since then conservation policy, knowledge and management of the Saba Bank have rapidly advanced (Table 4.1.2). The Saban fishery has always remained limited in total effort (Table 4.1.2) and in total catches (Table 4.1.3), and has not shown the massive and detrimental increase in effort as seen in so many fisheries in the region. Today, large parts of the bank remain essentially unfished. There are several potential reasons for this. It could be due to absence of the target species, due to the being areas difficult to deploy gear, or because of the distance to the home port (Fort Bay Saba). Until independent sampling takes place it will not be exactly known what the reason is for the selective placement of gear by fishermen, nor what the potential value is of the areas currently not fished. Fishery independent research is dearly needed.

Table 4.1.2. Overview of number of fishing vessel and fishers on Saba.

\begin{tabular}{|l|c|c|c|c|c|l|}
\hline Year & \multicolumn{3}{|c|}{ Fishing boats } & \multicolumn{2}{c|}{ Fishers } & Reference \\
\hline & row & sail & motor & Full-time & Part-time & \\
\hline 1905 & \multicolumn{2}{|c|}{21} & & 25 & 100 & Zaneveld, 1961 and references therein \\
\hline 1908 & 20 & 2 & & \multicolumn{2}{|c|}{180} & Zaneveld, 1961 and references therein \\
\hline 1959 & \multicolumn{2}{|c|}{7} & 2 & 10 & Zaneveld, 1961 and references therein \\
\hline 1980 & \multicolumn{2}{|c|}{21} & & & Giudicelli \& Villegas 1981 \\
\hline 1996 & & & 4 & 8 & & Meesters et al. 1996 \\
\hline 1999 & & & 12 & 20 & 30 & Dilrosun 2000 \\
\hline 2007 & & & 10 & & & Toller \& Lundvall 2008 \\
\hline $2012-2015$ & & & 10 & & \\
\hline
\end{tabular}

Currently there is no commercial queen conch (Lobatus gigas) fishery on the Saba Bank. Historically this area supported a large unregulated conch fisheries up until the mid-1990s. Any fishery data on historical conch fishery or for any of the other fisheries is largely absent. In 1993 two containers full of conch meat from the Saba Bank, ready for export, were impounded on St. Maarten because they lacked the proper CITES documentation. Since the Coast Guard started patrolling the bank and enforcing the fishery legislation in 1996, there has been no commercial fishery for conch.

Table 4.1.3. Overview of estimated catches by Saban fishers.

\begin{tabular}{|l|l|l|l|l|l|}
\hline Period & Fish & Lobster & Conch & Turtle & Reference \\
\hline & & & & & \\
\hline 1908 & $66 \mathrm{t}$ & & & & in Zaneveld (1961) \\
\hline 1956 & $15 \mathrm{t}$ & & & & in Zaneveld (1961) \\
\hline 1980 & $50 \mathrm{t}$ & $2 \mathrm{t}$ & & & Villegas \& Giudicelli, 1981 \\
\hline 1992 & $60 \mathrm{t}$ & $5 \mathrm{t}$ & & & Proplan Consultants Group N.V. 1992 \\
\hline 1995 & $59 \mathrm{t}$ & $26 \mathrm{t}$ & $0.75 \mathrm{t}$ & $0.48 \mathrm{t}$ & Framhein 1995 \\
\hline 1996 & $113 \mathrm{t}$ & $36 \mathrm{t}$ & & & Meesters et al 1996 \\
\hline 1999 & $20 \mathrm{t}$ & $90 \mathrm{t}$ & $0 \mathrm{t}$ & $0 \mathrm{t}$ & Dilrosun 2000 \\
\hline 2007 & $59 \mathrm{t}$ & $84 \mathrm{t}$ & $0 \mathrm{t}$ & $0 \mathrm{t}$ & Toller \& Lundval 2008 \\
\hline $2012-2015$ & $43-64 \mathrm{t}$ & $37-77 \mathrm{t}$ & $0 \mathrm{t}$ & $0 \mathrm{t}$ & This study \\
\hline
\end{tabular}


The most recent important developments for the bank have been that in 2012 the IMO accorded the Saba Bank as a "Particularly Sensitive Sea Area (PSSA)" which disallows tanker traffic and anchoring on the bank, and its official national designation in 2015 as the "Yarari Marine Mammal and Shark Sanctuary". With all these new developments and the strong involvement of Saban fishermen, the long-term prospects for sustainable management of the bank resources are quite bright.

\subsection{Lobster fishery}

\subsubsection{Trend and status lobster fishery}

According to Saba fishermen the directed lobster fishery started in the 1980s associated with the rise of the tourism industry of St. Maarten. Traditionally, due to religious prescription, the inhabitants consumed very little lobster. The information and data collected over the years 2012-2015 covered by the present study indicated an increase in the effort (trap drops) of the lobster fishery, with a corresponding increase in the lobster landings. Over the longer term, the temporal trend observed in the lobster catches from Saba Bank is broadly in line with the trend at the scale of the whole Caribbean (Fig. 4.2.1), showing a long term increase and a highest level reached around 2000. The lobsters stock should be seen as a regional stock. This means that local lobster stocks are actually one large connected stock and that they should be managed based on a regionally coherent management approach (FAO 2015a). This is actually needed for most other species as well. The realization that management takes place within what are actually "Large Marine Ecosystems" which require coherent management approach is fairly new to non-migratory, coastal benthic marine resources such as groupers, conch and lobsters (Sherman \& Hempel 2008). This realization has prompted several relatively new regional fisheries management initiatives (e.g. CARICOM 2002).

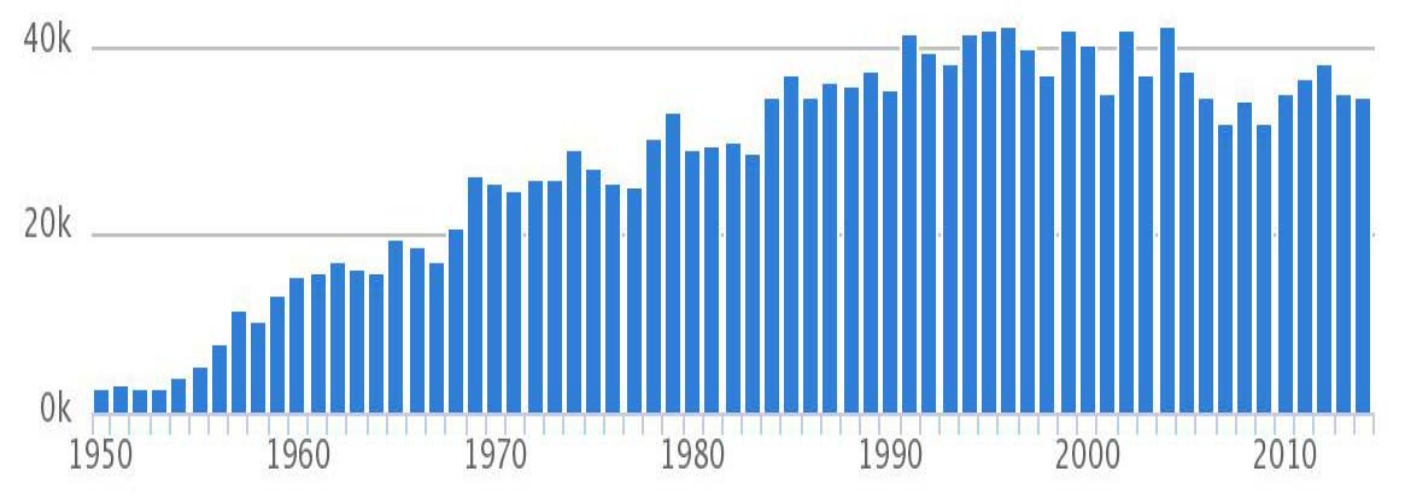

Fig. 4.2.1. Estimates of the lobster landings on Saba Bank (right, data for 1981-2000 from Dilrosun, 2000, data from 2007, from Toller \& Lundvall, 2008, data post 2012 from this report) and total landings (in thousand tonnes) for the whole Caribbean (top, FAO statistics).

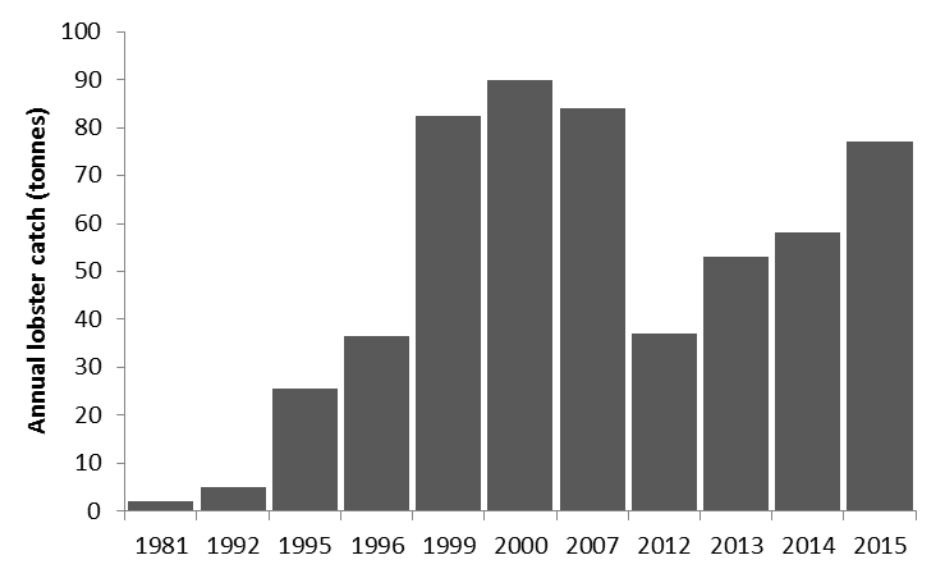


For the first time, this study developed an abundance index for legal sized lobster on Saba Bank by standardization of the catch rates, using the data collected by WMR since 2011, and also including the data available from previous studies (Dilrosun 2000 and Toller \& Lundvall 2008). The index obtained confirms the decline in abundance between 2000 and 2007 observed by Toller \& Lundvall (2008), and indicates that the abundance further decreased until 2012. The index indicated an increase in abundance since between 2012 and 2015, to a level in 2015 close to the 2007 level (Fig. 4.2.1, right).

Various studies have shown that trends in lobster catches are explained by the variation in the recruitment of juvenile lobster (Cruz \& Adriano, 2001, Butler et al., 2009). A good correlation was found between the abundance of settled post-larvae in a given year and the catches of the following year (in the Florida Keys, Butler et al. (2009) over 20 years, and in Cuba (Cruz \& Adriano 2001) over 14 years). Obviously, this was only a correlation and not a causal effect as lobsters can impossibly grow from post-larvae to adult in one year. The increase in stock abundance and catches on the Saba Bank, despite an increasing effort, suggests that the productivity of the stock (likely recruitment) has been increasing.

No recruitment index (post-larvae) is available for the Saba Bank. Successful trials with lobster puerulus larvae collectors were conducted on both Saba and St Eustatius (Poiesz, 2013). The puerulus collectors worked but due to conflicting priorities and capacity issues the standardized monthly collection of puerulus larvae was discontinued on both islands. An attempt was made in this study to use the information collected on the discards of undersize lobster to construct a predictive index for next year's catches. The undersize lobster index calculated, however, showed no correlation with the observed catches in the following year over the period 2012-2015. The approach should be revisited in the future, when more years are available, with potentially more contrast in the data. The undersize lobster index was informative on the seasonality of the availability of small lobsters to the fishing gear, with catches higher in late spring/early summer than the rest of the year.

The changes observed in the size composition of the catches (Fig. 3.2.5) may also indicate that the recent increase in abundance results from an increase in recruitment. Indeed, mean lobster length was high in 2011, and decreased abruptly in 2012, to slowly increase thereafter to similar length composition in 2015 as in 2011. A large lobster size in the catches can be indicative of a population having gone through a period of low recruitment, and therefore having an old mean age. A sudden increase in recruitment would first cause a rejuvenation of the population (as observed in 2012), and then contributing to an increase in its abundance.

There was a strong seasonality in the lobster catch rates, with higher catches from August to January, and lower catches from April to July. Toller \& Lundvall (2008) assumed that the catchability of the traps might be influenced by a series of factors, among which foraging movements, reproductive behaviour, lunar cycles, or migratory patterns. A seasonal pattern was also found in the abundance of berried females, but the peak of the reproductive activity occurred earlier in the year (February to May) than the period of low catch rates. The month of low catch rates corresponded quite well with the period of higher catch rates for undersized individuals, which could suggest that the increasing availability of the young lobster may interfere with the catchability of the older individuals.

Based on the results from this study, a rough estimate of the harvest is between $140 \mathrm{~kg} / \mathrm{km}^{2} /$ year (considering that the lobster fishery is concentrated in the areas B4, B5 and C5, representing approximately $400 \mathrm{~km}^{2}$ ). This harvest level appears to be higher than many areas including Brazil, most Antilles Islands and continental central/south America (Table 4.2.1). The yields on Saba Bank are similar to Florida or Bermuda, and only Cuba and St Eustatius have substantially higher extractions. 
Table 4.2.1. Overview of lobster landings in $\mathrm{kg} / \mathrm{km}^{2} /$ year throughout its distribution range (Buesa, 2016 and references therein) taken from de Graaf et al. (2016).

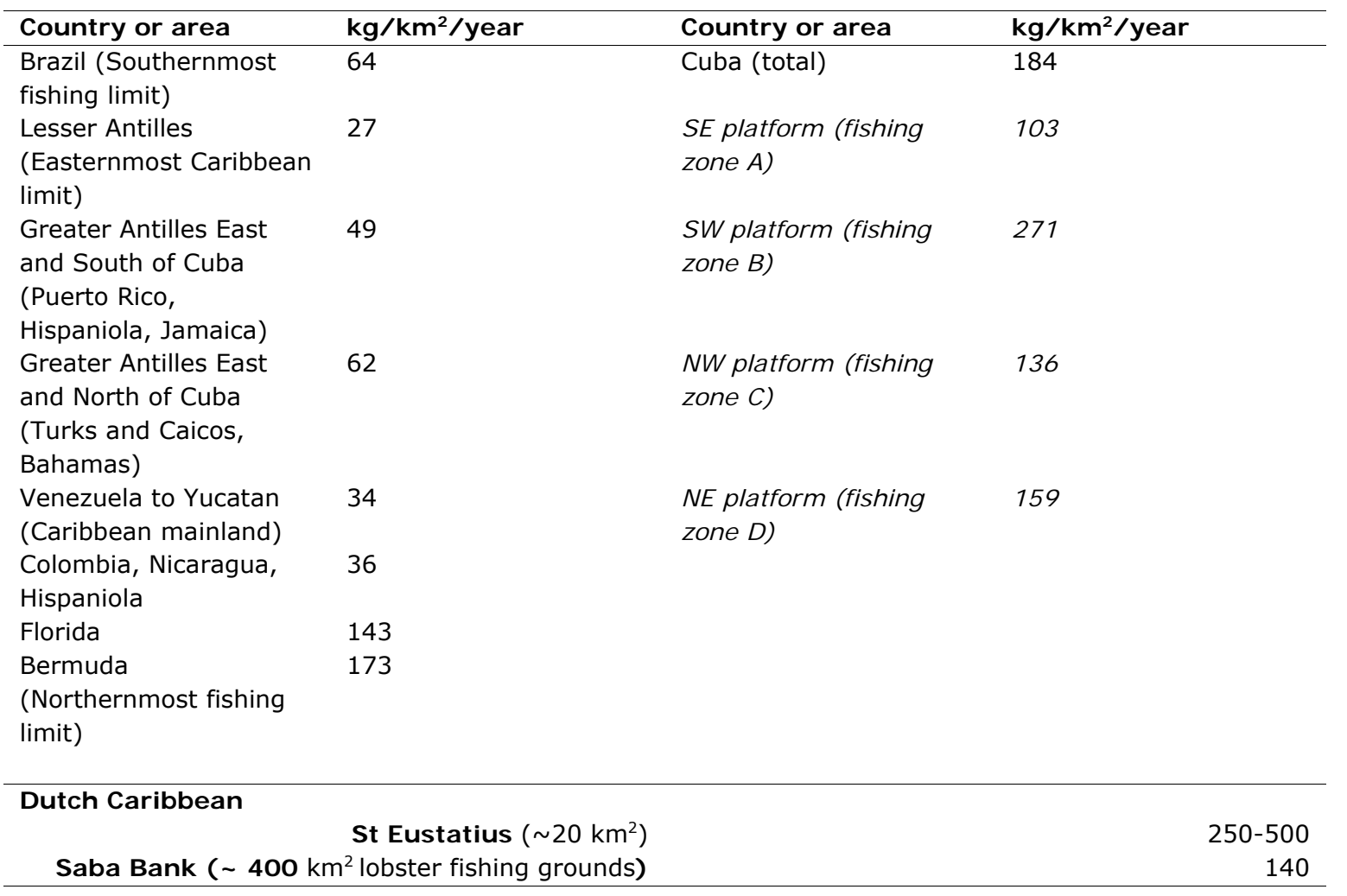

\subsubsection{Reproductive biology}

The analyses done on the catches of berried females indicate a main peak in reproductive activity from February to May, and a secondary peak in September (Fig. 3.2.9.). This is in agreement with observations made by Dilrosun (2000) of high proportions of berried females in the catches in March and September on Saba Bank. This seasonal pattern is similar to what is observed in southern Cuba and in Brazil, while the peak of the reproductive season occurs later (April to July) in Florida and the Bahamas (Fig. 4.2.1.).

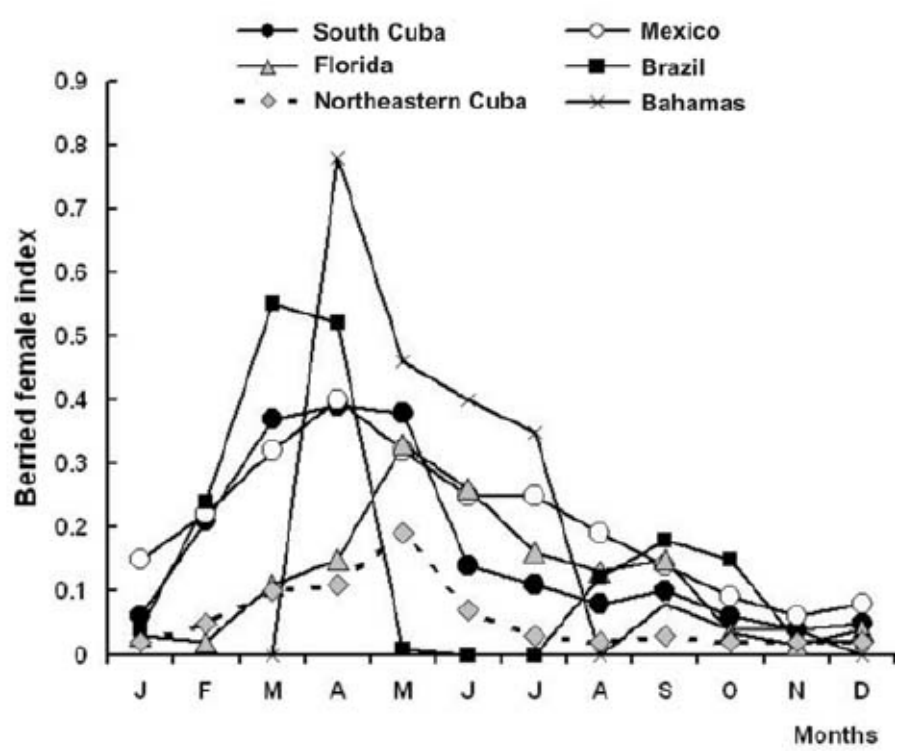

Fig. 4.2.1. Summary of the ovigerous females cycle for the spiny lobster Panulirus argus in various locations of the Greater Caribbean (Cruz \& Bertelsen 2008). 


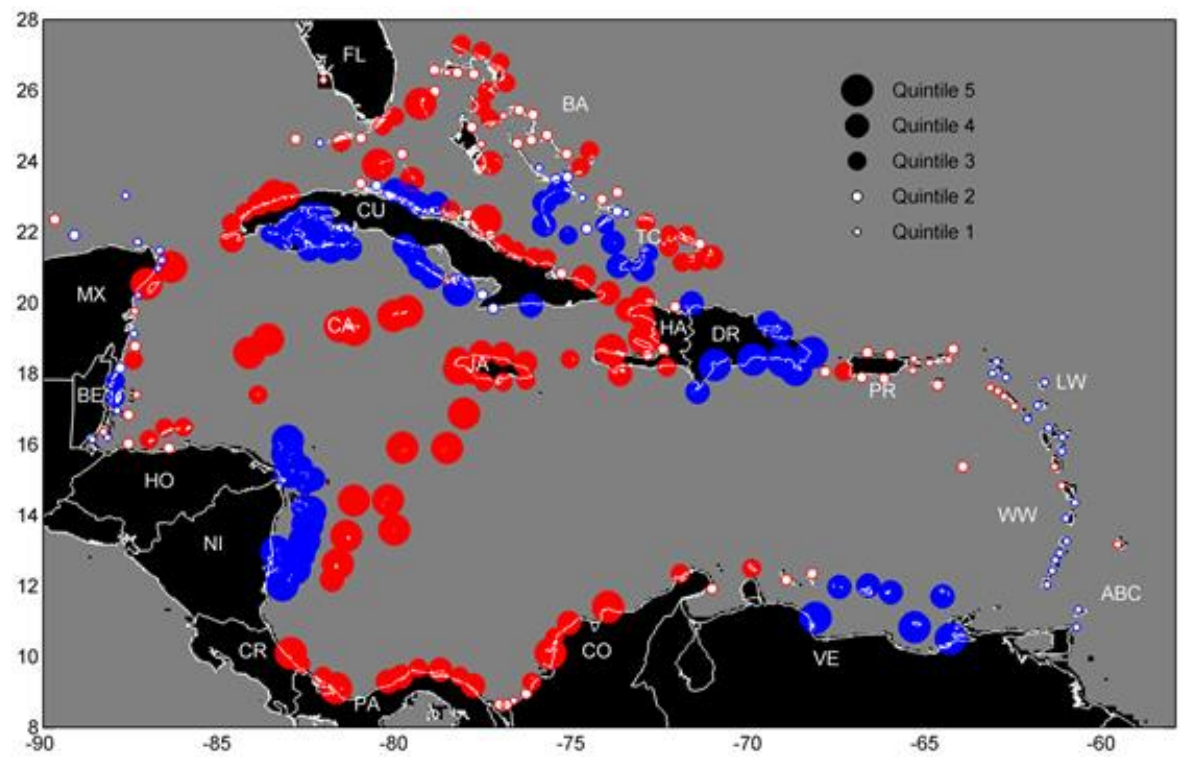

Fig. 4.2.2. The difference between larval exports and imports at a site $(n=261)$, after removing selfrecruitment. The size of the circle depicts the relative magnitude of the difference, grouped into 5 quantiles. The direction of the difference is shown as blue for positive (more larval exports) and red for negative (more larval imports). Copied from Kough et al. (2013).

The long duration of the pelagic larval stage (between 6 and 12 months) and the strong oceanographic currents carrying larvae over long distances, as well as genetic evidence suggest a single pan-Caribbean lobster stock (Silberman and Walsh, 1994). Recruitment of pueruli to any given location probably originates from any number of different sources (Briones-Fourzán et al., 2008). Using a biophysical larval transport model, Kough et al. (2013) estimated the degree of exchange of larvae among regions of the Caribbean (Fig. 4.2.2). Their results indicate that larval exchange is very limited for the Lesser Antilles islands, compared to the rest of the Caribbean. Even though Saba Bank was not included in the study, this would suggest that most of the larvae settling on the Saba Bank have an Eastern Caribbean origin.

Size at maturity (at which half of the individuals of a same cohort have become sexually mature) on the Saba Bank was $88 \mathrm{~mm}$ for females and $92 \mathrm{~mm}$ for males. The value found here for females is on the upper range of the values compiled from the literature by Cruz \& Bertelsen (2008) for different locations of the Caribbean $(75-85 \mathrm{~mm})$. These authors argue that size at maturity in Caribbean spiny lobster is usually inversely related to average temperature. Given the geographical position of the Saba Bank (northern end of the Lesser Antilles island), lower temperature might be an explanation for the larger maturation size. Despite this relatively large maturation size, the legal minimum landing size of $95 \mathrm{~mm}$ appears to be appropriate, and most of the lobster landed are larger than the minimum size (mean size of $113 \mathrm{~mm}$ ). The landing of sublegal lobsters ( $<95 \mathrm{~cm} \mathrm{CL}$ ) has steadily decreased from about $28 \%$ in 2012 to about $4 \%$ in 2015 . This is a positive development with regards to the question of IUU.

Overall status of lobster and lobster fishery appears reasonable. The average size at harvest is considerably larger than size-at-maturity, the average size at harvest has remained large since 2000 (>110 mm CL) and few under-sized lobster are landed ( $<5 \%$ ). In the period 2013-2015 number of traps per fish trip, number of lobster per trap and number of lobster per trip has remained stable while the number of annual fishing trips and annual landings have increased. Number of lobster per standardized fishing trip (a proxy for the abundance of lobster) also showed a slight increase between 2013 and 2015.

Due to its very long larval period and the pan-Caribbean nature of the lobster stock, collaboration among Caribbean nations and island is required to ensure appropriate management of the Caribbean 
lobster. On 15 May 2015, the 17 members of the Caribbean Regional Fisheries Mechanism (CRFM) signed the Declaration on Conservation, Management and Sustainable Use of the Caribbean Spiny Lobster (Panulirus argus) (See Annex 5).

The objective of the declaration is "to ensure the long-term sustainable use of the spiny lobster (Panulirus argus) resources through effective implementation of conservation and management measures for the stocks and their habitats based on the best scientific evidence available." With regards to research, management and conservation (Article 6) the declaration suggests, among others to implement:

- A Closed Season for the Spiny Lobster for a period of not less than 4 months, between $15^{\text {th }}$ February and $31^{\text {st }}$ August each year

- Prohibit the use of SCUBA and hookah gears for harvesting of lobster

- Establish a maximum size limit in addition to a minimum size limit for harvest

- Synchronize legislation to prohibit importation of sublegal-sized lobsters

- Establish a maximum number of traps per vessel (or per fisherman)

- Ensure that traps have escape panels for under-sized lobster and other marine organisms are (partly) build of biodegradable material to avoid ghost fishing

It is highly recommended that the management of Caribbean spiny lobster in the Caribbean Netherlands aligns with the principles outlined in the declaration. It might even be worthwhile to investigate whether the Netherlands could become a member of CRFM and co-sign the management agreement.

\section{Status \& trends:}

Over the last 5 years a $50 \%$ increase in the effort of the lobster fishery took place with roughly a corresponding doubling in the lobster landings. CPUE development shows that lobster abundance dropped from higher levels in 2000 to lower levels in 2011, with a progressive increase towards the level of 2007 since then. Nevertheless CPUE still remains lower than observed in studies carried out in the 2000s suggesting long-term depressed lobster populations. The observed pattern of catches since 2000 appears to generally mirror regional catch patterns which seem to be driven by regional recruitment patterns. The average size of landed lobsters has been consistently high compared to other fisheries of the region ( $108-118 \mathrm{~cm} \mathrm{CL}$ since 2000) with no signs of significant decrease in average lobster size landed (which might have suggested overfishing). The landing of sublegal lobsters ( $<95 \mathrm{~cm} \mathrm{CL}$ ) has steadily decreased from about $28 \%$ in 2012 to about $4 \%$ in 2015 . This is a positive development with regards to the problem of IUU.

\subsubsection{Mixed reef fish bycatch from lobster fishing}

Mixed reef fish caught in lobster traps are in part landed for sale, for own consumption, or to serve as food for the spiny lobsters in their holding traps in the harbor. The catch is composed of a broad range of reef fish species. The main species landed in 2012-2015 were the queen triggerfish (24\%, by weight), white grunt (19\%) and red hind (14\%). The queen triggerfish is an IUCN species listed as Near Threatened (NT) and is a species of concern. It is already separately managed in the waters of the U.S. Caribbean under the filefish and triggerfish Fishery Management Unit (FMU). The species composition, however, was variable between years, possibly reflecting the changes in the respective abundances of the different species but also possibly due to the small sample sizes achieved by port sampling.

Over the years 2012-2015, the discards represented on average 33\% of the catches in weight. The most discarded species in weight, by order of importance, nurse shark (19\%), honeycomb cowfish $(18 \%)$, cottonwick $(12 \%)$ and white grunt $(9 \%)$. Although a few specimens are actually observed in the discards, nurse shark appeared as the main discarded species in weight because of the high average weight of individuals. In number, nurse sharks were only $4 \%$ of the discards.

The abundance index derived by standardization of the mixed reef fish catch rates in the lobster traps showed an overall decrease between the period covered by earlier studies (1999-2000 13.8 kg/trap 
and $200713.3 \mathrm{~kg} / \mathrm{trap}$ ) and the period covered by this study (2011-2015). The abundance was the lowest in $20118.0 \mathrm{~kg} /$ trap and increased thereafter and remained stable over the last three years, at a level roughly $23 \%$ lower than in the earlier studies $(10.3 \mathrm{~kg} / \mathrm{trap})$. Observation from visual transect surveys also suggest a (small) recent increase in reef fish biomass (from 2011 to 2013, van Beek et al 2014) compared to 1990s reference levels. They also show that the measurable biomass of herbivores on the bank is much lower in recent years than in 1999.

Toller \& Lundvall (2008) indicated that the fishing effort (no. of trips) had increased between the years 2000 and 2007, and that the number of fishing trips in 2007 was close to 1000 . The estimates from this study indicate a lower effort in the first years of the study (600 and 760 trips in 2012 and 2013), but increasing towards values similar to 2007 (close to 900 trips in 2015).

The present study estimates that the landings of mixed reef fish (practically exclusively taken as bycatch from lobster fishing) have increased from 6.6t to 13.6t between 2012 and 2015, representing on average just under $20 \%$ of the overall landings of fish (reef fish, snapper, large pelagics) on Saba Bank. The landings of 2012 represents a significant reduction compared to the landings of $17.1 \mathrm{t}$ of mixed reef fish estimated for 2007, which was an increase for the main species compared to the levels from $1999-2000$ by Dilrosun (Toller \& Lundvall 2008). This pattern in the catch records broadly matches with the combined variations in the effort and abundance: relatively high abundance in 2000 and 2007 combined with increasing effort resulted in landings being the highest in 2007. Decreasing abundance between 2007 and 2011 (possibly linked to this somewhat higher effort in the late 2000s, but also potentially to natural causes) combined with lower efforts in the early 2010s results in a drop in the landings in 2007. The subsequent increase in abundance, combined with higher effort led to landings raising to levels close the 2007 landings.

Overall, reef fish yields on Saba Bank appeared to be low compared to other areas. Based on the results from this study, a rough estimate of the yield is between 0.025 and $0.10 \mathrm{t} / \mathrm{km}^{2} / \mathrm{year}$ (considering that the lobster fishery is concentrated in the areas B4, B5 and C5, representing approximately 100 to $400 \mathrm{~km}^{2}$ ). This harvest level appears to be very low compared to the estimates from other tropical reef ecosystems (0.8-8.6 t/ $\mathrm{km}^{2} /$ year worldwide) including Bonaire in the Caribbean (2.1 t/ $\mathrm{km}^{2} /$ year, de Graaf et al. 2016). A point of caution here is that these estimates do not include the data on the hand line fishery for reef fish. This is especially the case during the hind spawning season as the Data Management Officer (DMO) has typically not collected enough data during the months of December through February.

These low yields can be due to overall low fishing effort and can also be contributed to low reef fish densities on Saba Bank. Estimates from scuba-diving surveys on Saba Bank during successive expeditions are low (Beek et al. 2014), compared to the densities observed in the most fished location in the Caribbean (Hawkins \& Roberts 2004), and much lower than observed on the coast of Saba and on Bonaire, which are the least intensively fished locations in the Dutch Caribbean (Hawkins \& Roberts 2004).

In the case of Saba Bank however, the low fish density is unlikely to be caused by overexploitation. In the fisheries data collected in the present study, between 6 and 8 vessels were active in the lobster fishery. Fishing boats typically have a crew of 2 or 3 members (Gerwen 2013). Considering that the lobster fishery mostly takes place along the eastern part of the bank (this study and Toller \& Lundvall, 2008), extending for a distance of roughly $50 \mathrm{~km}$, a rough estimate of the fishing intensity is 0.35 fishermen $/ \mathrm{km}^{2}$ of reef, which is higher than Bonaire or the coast of Saba $\left(0.06\right.$ fishermen $/ \mathrm{km}^{2}$ and 0.12 fishermen $/ \mathrm{km}^{2}$ respectively), but much lower than more intensively fished areas ( 3 fishermen $/ \mathrm{km}$ and 7 fishermen $/ \mathrm{km}^{2}$ in Dominica and Jamaica respectively, Hawkins \& Robert, 2004).

A potential factor explaining the relatively low density of reef fish on Saba Bank could be that the Saba Bank is an offshore bank, of higher depth and lesser complexity than inshore coral reefs, and may be naturally hosting a lower biomass of reef fish (Toller et al., 2010, Beek et al., 2014). Over the recent decades the bank has suffered notable losses of habitat for reef fishes because of coral mortality due to massive bleaching events (Meesters et al., 2010). 


\section{$\underline{\text { Status \& trends: }}$}

Reef caught in lobster traps are in part landed for sale, for own consumption, or to serve as food for the spiny lobsters in their holding traps in the harbour. The catches of mixed reef fish have increased from 6.6t to 13.6t between 2012 and 2015, representing on average just under $20 \%$ of the overall catches of fish on Saba Bank. Overall, reef fish yields on Saba Bank appear to be low compared to other areas of the Caribbean. These low yields can in part be due to the low reef fish densities on Saba Bank as estimated in independent studies. Lower fish catchability of traps designed for lobsters likely also contributes to lower catches. The low fish density is unlikely to be caused by overexploitation. It is speculated that the carrying capacity is naturally low, and declining due to the deterioration of the habitat (coral mortality and the lionfish).

\subsection{Deep-water snapper fishery}

CPUE: Compared to 1970 , the CPUE of the snapper trap fishery has decline by $\sim 75 \%$. Since 2000 , the CPUE (in terms of landings) of the deep-water snapper fishery has been fluctuating between 2.5 and 5 $\mathrm{kg}$ per trap (Fig. 3.3.3, left). Because of the differences in trap design and mesh size (1.25 inch) in 1970 the CPUEs are not $100 \%$ directly comparable with the 2000-2015 values, the 1970 CPUE of the exploratory snapper fishery does provide a qualitative indication of a nearly underexploited or virgin stock of silk snapper from Saba Bank. CPUE of a fishery is often used as a proxy for the stock. Care has to be taken when using CPUE as a proxy for stock as changes in the fishery (technology creep, e.g. introduction of GPS and fish finders) will allow fishers to maintain a certain CPUE while the actual stock may be in decline. At least for the period 2000-2015, the fishery appeared to operate in a comparable way with negligible changes to the gear. Using the CPUE as proxy for the stock, stock size appeared slightly smaller in 2011-2015 than in 2000 and 2007.

Total annual landing: The fluctuations during 2000-2015 in total annual landings of deep-water snapper is predominantly driven by changes in fishing effort (no. trips per year, no. traps lifted per trip) as CPUE (Fig. 4.3.1) remained relatively stable. Number of trips per year increased between 2012 (369) and 2014 (537) and decreased again in 2015 (481). Number of traps lifted per fishing trip has been declining from 33 in 2012 to 25 in 2015 (Fig. 3.3.1). In 2000 few fishing trips were conducted due to the voluntary trap fishing ban that was in place. In 2007 the number of trips was low (312) resulting in a moderate catch compared to 2012-2015 despite a slightly higher CPUE in 2007.

Species composition catch: The species composition in 2012-2015 was dominated by silk snapper (69\% by weight) followed by $10 \%$ blackfin and vermillion snapper (7\%) (others: $14 \%$ ). The landed species composition was highly similar Dilrosun (2000) and appeared to have changed little since 2000. In 1971 under relative pristine conditions silk snapper dominated $(\sim 80 \%)$ the catch of an exploratory trap fishery (Wolf \& Chislett 1974). In 2007, Toller \& Lundvall (2008) reported a lower contribution (ca. 50\%) of silk snapper to the catch. Their species composition data were, however, unreliable as partial and sorted sampled (excluding silk snapper) were used in their analyses (Toller personal communication) resulted in a significant bias, i.e. an underestimation of silk snapper. The dominance of silk snapper in the redfish trap fishery has also been reported for other areas in the Caribbean (Boardman \& Weiler, 1980) and references therein; Prescod et al. 1996). Detailed analyses of the species composition (e.g. inter-annual, seasonal patterns) were not possible due to the low number of samples taken (less than one per month).

Species composition discards: In the period 2011-2015 only nine on-board sampling trips were conducted to collect data on discards. Roughly $50 \%$ of the discarded fish were silk snapper. Other important discarded species (in weight) were the lionfish, French angelfish and the nurse shark. Due to the very low sample size, the results may not be reliable and representative, therefore care has to be taken when interpreting these preliminary results. 
Length: In 1970 when the snapper stock could be considered pristine or underexploited, the average weight of a silk snapper was $\sim 450 \mathrm{gr}$ or $29 \mathrm{~cm}$ (Wolf \& Chislett, 1974). The average size of a silk snapper in the trap fishery has remained rather similar over the years: $\sim 24 \mathrm{~cm}$ in 2000 (Dilrosun 2000), $29 \mathrm{~cm}$ in 2007 (Toller \& Lundvall, 2008) and $27 \mathrm{~cm}$ in 2011-2015 (see Annex 3). Boardman \& Weiler (1980) reported a similar $(\sim 28 \mathrm{~cm})$ average size for silk snapper in the Puerto Rico trap fishery. Only Prescod et al. (1996) reported a relatively large average size $(\sim 32 \mathrm{~cm})$ for silk snapper in the Barbados trap fishery, but this was based on a small sample size. The size of snapper (silk, blackfin and vermillion) in the trap fishery appears always to have been small and is most likely caused by size selectivity of the snapper traps. Regtien \& Kemme (2015) were the first to demonstrate that the small size of snapper in the trap fishery is the result of size selectivity of the traps. Traps are usually operated between 150-250 m depth and Regtien \& Kemme (2015) clearly demonstrated that the average size $(\sim 27 \mathrm{~cm}$ ) of silk (mean size of maturity of females is $51 \mathrm{~cm}$ ), blackfin and vermillion snapper caught with traps were significantly smaller than specimen $(\sim 40 \mathrm{~cm})$ of the same species caught with longline at the same depth. Care has to be taken therefor with the interpretation of small size of snappers in the trap fishery as a sign of overfishing as traps appear to be size selective for small sizes. It is, however, clear that since the introduction of the snapper traps the majority of the catch (silk, blackfin and vermillion) has consisted of immature specimen with the average size at landing smaller than the average size at maturity (Boonstra, 2015, Regtien \& Kemme, 2015 and references therein; Annexes 3 and 4).

Longline fishery: In 2011-2015 only a small part $(<3 \%)$ of the total annual landings of deep-water snapper was harvested by the long line fishery (average $1.2 \mathrm{t}$ ). Toller \& Lundvall (2008) mentioned that in 2007 the use of hook \& line methods for redfish was uncommon. Species composition and length frequency differ significantly between traps and vertical longlines catch. While trap catches are dominated by silk snapper, longline catches on the Saba Bank were dominated ( $~ 80 \%$ in number and weight) by queen snapper (Etelis oculatus) and wenchmen (Pristipomoides aquilonaris). Prescod et al (1996) reported that queen snapper and vermillion snapper dominated the catches of line fishery on Barbados but did not report any wenchman. Long lines are usually operated at greater depth ( $>250$ $\mathrm{m}$ ) than traps $(150-250 \mathrm{~m})$ which is reflected by the occurrence of queen snapper and wenchman in the catch as both species are known occur at greater depths than silk, blackfin and vermillion snapper (Regtien \& Kemme 2015 and references therein). The average size of landed specimen is consistently larger in the longline fishery than in the trap fishery for the different snapper species. The difference in size is partly due to a difference in operating depth of both fisheries. Regtien \& Kemme (2015) and Boardman \& Weiler (1980) demonstrated that the size of different snapper species increased with depth, i.e. snapper undergo an ontogenetic habitat shift towards deeper waters with size. Regtien \& Kemme (2015) furthermore demonstrated that both gear are selective for different sizes of snapper when operated at the same depth.

Management: In 1997, Saban fishers self-imposed a ban on the redfish trap fishery, i.e. a so-called gentlemen's agreement independent of responsible management authorities. While the use of traps was voluntary banned a range of other gear types (e.g. hydraulic or electric snapper reels, bottom long lines and hand lines) was used to target deep-water snappers. The "gentlemen's agreement" was broken by one fisherman in March 2000. As a result the rest of the fishermen commenced the trap fishery again (Dilrosun 2000). Toller \& Lundvall (2008) reported that in 2007 the use of longline for redfish was uncommon. In 2012-2015, ca. $3 \%(1.2 . t)$ of the annual redfish catch was landed by vertical long lines.

Due to ongoing concerns regarding the redfish stocks, in May 2016, the Saban fishermen signed an agreement to the redfish fishery to:

- Establish a closed season for six months for the entire Saba Bank from the $1^{\text {st }}$ of April until the $30^{\text {th }}$ September 2017, after which leaving room for reflection and adaptation of the season system for the next years based on the results of the season system of 2017.

- Set a trap limit of 25 redfish traps from the $1^{\text {st }}$ of October 2017 until the next agreed closed season.

- Allow a maximum of 4 vertical longlines for redfish per fishing boat during the closed season for Red Fish. 
- Use bigger mesh sizes: all fishermen will use 2 inch square mesh for at least the doors of the redfish traps.

It is furthermore recommended to reach agreement on the maximum size of a snapper trap, the maximum number of hooks on a vertical longline and the obligation of a biodegradable panel with escape slot. Despite the establishment of a closed season on $1^{\text {st }}$ April 2017 it is unclear what the fishermen have done with the snapper traps. Apparently some fishermen have modified the funnel openings of the traps and are using the traps in the shallow water lobster fishery. Some fishermen have, however, moved their snapper traps to shallow water. At this stage it is unclear how shallow the traps are set and what fish species are being targeted. It is recommended to reach agreement on a maximum depth for modified snapper traps during the closed season.

\section{Status \& trends:}

The shifts in gear use from hook and line to traps coincided with a change in fish size, (and species composition) from large adult snappers to smaller sub-adults of about $30 \mathrm{~cm}$ total length. When looking at CPUE which is an index of population size, it is evident that CPUE has fluctuated between roughly $2.5-5 \mathrm{~kg}$ snappers per trap set, with no appreciable trend. We conclude that the recent changes in total annual catch appear to be largely driven by changes in effort. These most recent data hence suggest no worrisome new developments for this fishery, but do suggest that the current fish stock is significantly (75\%) lower than in the early 1970 s "virgin" state.

The status of the trap fishery is perceived by the fishers as undesirably overexploited. And on the $1^{\text {st }}$ April 2017 they decided to implement a six month closed season. It is recommended to develop a harvest strategy for the deep-water snapper fishery and ensure that sufficient (on-board) samples are collected.

\subsection{Pelagic fishery}

The pelagic fishery is a minor part to the fisheries on the Saba Bank. On average $2.2 \mathrm{t}$ of large pelagic fish is annually landed which forms only $2 \%$ of the total landings (lobster, reef fish, redfish, pelagics). The pelagic fishery (ca. $1 \mathrm{t}$ or 6\%; de Graaf et al., 2015) on nearby St Eustatius also forms a minor part of the total annual landings of its coastal fishery. The role of the pelagic fishery on the windward islands is in strong contrast with the leeward islands such as Bonaire where the pelagic fishery contributed ca. $85 \%$ to the annual landings (101 t; de Graaf et al. 2016).

The Saban fleet conducted annually roughly 50-100 pelagic fishing trips (trolling one or more lines) mainly between October and April with an average catch of a little less than 6 fish (ca. 25-50 kg) per trip. The average catch per trip is roughly similar to St Eustatius (ca. $20 \mathrm{~kg}$ per trip) and the large boats on Bonaire (ca. $30 \mathrm{~kg}$ per trip). The average duration of a Saban pelagic fishing trip (3 hours) was significantly shorter than a fishing trip on Bonaire ( 9 hours). Saban fishers seasonally target pelagic species while driving to and from the Saba Bank during lobster and/or redfish trap fishing trips. On Bonaire pelagic species are the main and only target species of the large boats in its fleet.

The species composition of the pelagic fishery on Saba and St Eustatius consisted predominantly of wahoo and dolphinfish with $<5 \%$ tuna. On Bonaire the catch was dominated by wahoo $(60 \%)$ followed by tuna $(10 \%)$ and barracuda (10\%). While barracuda is an important "b choice" species for fishers on Bonaire, due the risk of ciguatera poisoning hardly any barracuda was landed by Saban and Statian fishers.

Dilrosun (2000) did not provide any data on pelagic fishing activities on the Saba Bank and only mentioned that "Occasionally trolling lines and rod and reels are used to target pelagic species." 
The minor role of pelagic fishery was also reported by Toller \& Lundval (2008): “The frequency of trolling fishing trips generally follows seasonal abundance patterns of migratory pelagic species such as wahoo, tuna, and dolphinfish. Fish Attraction Devices (FADs) are also deployed by some Saban fishermen to increase catch rates for pelagic species. In several respects, these hook $\&$ line fishing activities resemble recreational fishing." According to Toller \& Lundval (2008) only 11 pelagic fishing trips were conducted in 2007 with a catch of ca. $40 \mathrm{~kg}$ per trip resulting in an estimated annual landing of just $0.4 \mathrm{t}$.

\section{$\underline{\text { Status \& trend: }}$}

Historically the pelagic fishery appeared to have played a minor role on the Saba Bank. The limited contribution of the pelagic fishery has not changed in 2012-2015 with ca. $2 \%$ of the total annual landings of the Saba Bank consisting of pelagic species such as wahoo and dolphinfish. Due to the lack of (historical) data it is difficult to determine the current status of the pelagic fishery and its main stocks. In 2012-2015 the average catch per fishing trip was similar to catches recorded for Bonaire (2014) and St Eustatius (2012-2015).

\subsection{Shark bycatch}

Dilrosun (2000) mentioned that nurse sharks were used as bait in the lobster trap fishery. According to Toller \& Lundvall (2008) "nurse shark, Ginglymostoma cirratum, is a common bycatch species in the lobster trap fishery. Saban fishermen consider the nurse shark to be a nuisance because the sharks consume catch and bait, and because they damage trap gear. Although nurse sharks are generally not marketed, they are moved, killed, or retained for personal consumption." Unfortunately both Dilrosun (2000) and Toller \& Lundvall (2008) did not quantify the number of released and/or retained nurse sharks in the lobster trap fishery.

The number of nurse sharks per trap lift in the lobster fishery was determined in two independent surveys. Since early 2016 the number of sharks caught in lobster traps (and other fishing gear) is recorded during short interviews with fishers. Based on these interviews the catch rate of nurse sharks was estimated at 0.013 per trap lift. The bycatch of nurse sharks was also recorded during on-board surveys and resulted in a similar catch rate of 0.01 nurse sharks per trap lift. The annual number of nurse sharks caught and released varies between 1712 and 2499 individuals, mainly coming from the lobster fishery. Only a few of the captured nurse sharks are landed, most nurse sharks are discarded although it is unclear at this stage whether the nurse sharks are discarded dead or alive. The unwanted bycatch of nurse sharks is a nuisance to fishers as they can damage both the fishing gear and kill lobster. It is recommended that in co-operation with fishers several trap modifications (e.g. adjustment entrance funnel [bar or fixed funnel ring], magnetic field) will be tested on the Saba Bank to develop a trap design that will significantly reduce nurse shark by-catch without affecting the catch of the target species, the Caribbean spiny lobster. Tagging released nurse sharks would also provide insight into whether the current estimate of between 1712-2499 sharks caught and released is an overestimation as some of the nurse sharks are expected to be repeatedly enter traps. While interviews suggest low average catch rates, observations made by on-board observes indicates that that catch rates can also be high (Debrot, pers. obs, 2008). In August 2017, one fisherman reported catch 60 nurse sharks during a single lobster fishing trip (J. Odinga, pers. comm.). This indicates that more on-board observation is needed to take a closer look at actual shark catch rates.

Based on short interviews with fishers and on-board sampling the catch and release of sharks is negligible in the deep-water snapper trap fishery. Unfortunately, hardly any structured on-board survey were conducted during deep-water long-line fishing trips for redfish. Based on personal observations (M. de Graaf) during one deep-water longline redfish trip, many Cuban dogfish (Squalus cubensis) were caught (see photo, right) and one six gill shark species (Hexanchus spp) were discarded alive. The recent self-imposed closed season (Apr-Sep) for the redfish trap fishery may increase the number of deep-water long line fishing trip and increase shark discards. Survival rate of 
discarded deep-water sharks is unclear. It is recommended to intensify the on-board sampling component within the fisheries research programme.

\subsubsection{Shark bycatch landed}

A fishery targeting sharks does not exist on the Saba Bank nor elsewhere in the Dutch Caribbean (Beek et al. 2014) and sharks are only caught as unwanted bycatch in the different fisheries. The number of landed sharks landed was recorded during the so-called long interviews during which data on species composition and length distribution was collected either on catches landed in the harbour, or during observer trips at sea. Among the 319 trips sampled between 2011 and 2016, a total of 11 landed sharks were observed, most of them from the lobster fishery (7 sharks in 139 samples). Nurse sharks contributed on average roughly $0.5 \%$ in weight to the total amount of landed mixed reef fish in the lobster trap fishery, i.e. $\sim 50-100 \mathrm{~kg}$ nurse shark. Just over half (6) of the recorded landed sharks were nurse sharks while the other five sharks were reef sharks (Caribbean reef shark, blacktip shark, sandbar shark). Considering that, roughly speaking, about $5 \%$ of the fishing trips were sampled, a crude estimate of the total landings of sharks can be obtained by multiplying the number of landed sharks in table 3.5.1 by a factor 20. Based on this line of reasoning ca. 40 sharks per year are landed in the whole Saba Bank fishery. The low number of observed shark landings is in agreement with historical observations. Dilrosun (2000) did not report any landings of sharks. Toller \& Lundvall (2008) estimated an annual landing of ca. $80 \mathrm{~kg}$ of blacktip shark from the lobster trap fishery and ca. $250 \mathrm{~kg}$ of Caribbean reef shark from the shallow reef hook \& line fishery.

Recently a shark protection plan was drafted for the Dutch Caribbean (Beek et al. 2012, 2014) and in September 2015 the EEZ waters around two of the Caribbean Netherlands islands (Saba and Bonaire) were declared shark sanctuaries by the Dutch Ministry of Economic Affairs and local island governments. The sanctuaries will prevent the development of new fisheries targeting sharks. The lack of a specific fishery targeting sharks on the Saba Bank is reflected by the results of the base-line shark survey using baited remote underwater video (Stoffers et al, in prep), demonstrating that nurse sharks and several reef shark species were commonly observed.

\section{$\underline{\text { Status \& trends: }}$}

Sharks are considered unwanted bycatch and are rarely kept for use as bait in traps. The annual number of nurse sharks caught and released varies between 1712 and 2499 individuals, mainly coming from the lobster fishery. Of 319 trips sampled between 2011 and 2016, a total of 11 sharks were landed. We estimate that 40 sharks per year (by far mostly nurse sharks) are landed in the whole Saba Bank fishery. Nevertheless, personal observations during on-board observation show that catches may amount to tens or even up to 60 sharks per lobster fishing trip (A. Debrot, and J. Odinga, pers. comm.). Further on-board observation is needed to obtain actual figures on shark catch rates. Also, as the Saba Bank is a designated shark sanctuary it is important to work together with the fishermen to fully eliminate all shark taken and ensure that they are released unharmed.

\subsection{Sustainable fish traps}

\subsubsection{Biodegradable panels}

Current fisheries regulations (National Fisheries Ordinance Official Bulletin 1991, no. 64, see appendices in Lundvall, 2008) require that: "Anyone fishing in the fishing zone, and license holders fishing in territorial waters shall be forbidden to use: fish traps not fitted with an escape opening, covered by a panel made of biologically degradable material, which, after use, disintegrates in the sea water, so that, after some 20 days, an opening of at least $15 \mathrm{~cm}$ by $15 \mathrm{~cm}$ is created in one side of the fish traps"). Mean breakage time of all tested materials exceeded the required 20 days. Hemp and cotton twine had the shortest breakage time but still it took nearly 3-4 months before all panels were released, similar to other studies testing natural fibres. Kimker (1990) observed similar breakage time 
for cotton twine during a simulated king crab fishing experiment in lower Cook Inlet (Alaska); mean and range breakage time 89 days for 30 thread, 101 days for 42 thread and 107 days for 60 thread. Kumpf (1980) tested on-oiled jute twine and parcel post sisal twine in static and free-flowing conditions; jute lasted 65 (static) and 42 (free-flowing) days, sisal twine lasted 85 (static) and 42 (free-flowing) days. The 16 gauge $(1.3 \mathrm{~mm}$ ) ferrous wire lasted nearly 400 days before all panel had broken loose, $50 \%$ of panels had broken loose after 300 days. Kumpf (1980) tested 16 gauge and 22 gauge galvanized wire and demonstrated that after 120 days none of the wire had broken. After 480 days only $50 \%$ of the panels connected with Maine hog rings and Atlantic and Gulf hog rings had broken free but all of the Dutch hog rings remained intact.

The biodegradable panels did not show any degradation. This material is based on polyhydroxyalkanoate (PHA) biodegradable polyester, assumed to be completely biodegradable by microbes. The rate of biodegradation can be controlled by adjusting the thickness of the polymer (Thellen et al., 2008). Microbes feeding on the polymer are killed off when exposed to UV light during trap retrieval requiring constant regrowth of bacteria on bio-panels of active traps. Lost traps, however, remain on the bottom of the sea, and are not exposed to UV light. Hence, populations of bacteria can flourish and in theory are able to continue consuming the polymer (Sieracki \& Sieburth, 1986, Bailey et al., 1983). At the exposed depth of 27 meters, the presence of UV light is thus not assumed to be the main cause of the lack of biodegradation. All biodegradable panels were still intact after 480 days, despite the fact that these biodegradable panels were designed to last only 6-8 months when not fished and left in the water.

Biodegradable panels attached to traps by material with short breakage time (max. 20 days) as required in the current fishery regulations may not be accepted by fishers due to potential loss of catch and time associated with replacing the panels. A short breakage time is, however, only really required if ghost fishing by traps are clearly proven to cause significant impact on fish stocks. As described in section 4.6.2, based on the current results, the impact of ghost fishing on fish and lobster mortality seems limited for lobster traps on the Saba Bank. If the regulations on biodegradable panels are to be maintained, it is recommended to adjust the breakage time to 3-12 months and to clearly describe in the regulations the type and diameter of the material that is to be used to attach the biodegradable panel.

\section{Results:}

The biodegradable panels did not show any degradation during a 480 day-long experiment but tested panel attachment materials did. Biodegradable panels attached to traps by material with short breakage time (max. 20 days) as required in the current fishery regulations may not be accepted by fishers due to potential loss of catch and time associated with replacing the panels. As the impact of ghost fishing on fish and lobster mortality seems limited lobster traps on the Saba Bank. If the regulations on biodegradable panels is to be maintained, it is recommended to adjust the breakage time to 3-12 months and to clearly describe in the regulations the type and diameter of the material that is to be used to attach the biodegradable panel.

\subsubsection{Ghost fishing}

Ghost fishing is the capacity of derelict commercial or recreational fishing gear such as lobster traps to continue to catch target and non-target species which may result in mortality of a proportion of the captured individuals. Dilrosun (2000) estimated trap loss on the bank to be between 210 and 795 lobster traps per year, and hence a potential detriment to fishery production and biodiversity. Beek (2012) discussed ways in which derelict traps can be located for removal from the bank. The mortality rate of derelict fishing gear depends on the type of fishing gear and the ability of animals to escape. Whether ghost fishing has an impact of a fish stock depends on the mortality rate of derelict fishing gear and the amount of derelict fishing gear in order to place ghost fishing in a wider perspective in relation to natural mortality, fishing mortality and stock biomass. In this study we also looked at 
mortality caused by derelict lobster/fish traps and the potential impact of ghost fishing on lobster and reef fish stocks.

Table 4.6.1. Overview of the main outcomes of three ghost fish studies in the Caribbean.

\begin{tabular}{|c|c|c|c|}
\hline & This study & $\begin{array}{c}\text { Butler \& } \\
\text { Matthews } \\
\text { (2015) }\end{array}$ & $\begin{array}{l}\text { Renchen et al. } \\
\text { (2012) }\end{array}$ \\
\hline Area & St Eustatius & Florida Keys & US Virgin Islands \\
\hline Duration & 3 months & 32 months & 6 months \\
\hline Type of trap (no) & rectangular; wire (4) & $\begin{array}{l}\text { rectangular; wood, } \\
\text { wire, hybrid (120) }\end{array}$ & $\begin{array}{c}\text { rectangular \& } \\
\text { chevron; wire (12) }\end{array}$ \\
\hline \multicolumn{4}{|l|}{ Reef fish } \\
\hline Avg no live fish per trap & 2.3 & 2.9 & 1.8 \\
\hline No fish live & 241 & 5909 & 1183 \\
\hline No fish dead & 5 & 100 & 20 \\
\hline Mortality (\%) & $2 \%$ & $1.7 \%$ & $2 \%$ \\
\hline Kg dead fish per trap per year & 2.7 & & 3.9 \\
\hline \multicolumn{4}{|l|}{ Lobster } \\
\hline Avg no live lobster per trap & 3.5 & $3.9-4.8$ & \\
\hline No lobster live & 261 & 12813 & \\
\hline No lobster dead & 2 & 229 & \\
\hline Mortality (\%) & $0.8 \%$ & $1.8 \%$ & \\
\hline No of dead lobster per trap per year & 2.7 & $3-7$ & \\
\hline
\end{tabular}

Overall, the results of the ghost fishing experiment in the inshore waters of St Eustatius did not deviate from the results of similar studies in the Caribbean by Renchen et al. (2014) and Butler \& Matthews (2015) (Table 4.6.1.). Mortality of reef fish and lobster was low and most fish and lobster appeared to be able to enter and exit the ghost traps freely. Munro (1974) analysed the mode of operation of Antillean fish traps and concluded that traditional trap designs had high daily escape rates of $\sim 12 \%$ and over $50 \%$ of the reef fish which entered a trap escaped during a 10 to 19 day soak. Renchen et al. (2014) remarked that "Overall, the number of observed fish mortalities was unexpectedly low, with most fish able to leave the traps." Renchen et al. (2012) observed the behaviour of reef fish using $24 \mathrm{hr}$ video observations and demonstrated the ease with which reef fish enter and exit fish traps.

In 2012-2015 Saban fishers lost on average 0.6 lobster traps per fishing trip, resulting in ca. 400-600 derelict lobster traps annually. A derelict trap kills 2.7 to 7 lobster and $2.7-3.9 \mathrm{~kg}$ of reef fish per year (Table 4.6.1.). Butler \& Matthews (2015) demonstrated that wire traps continue to ghost fish for roughly two years (on average 780 days). On the Saba Bank, ghost fishing may result in annual loss of $2160-4680 \mathrm{~kg}$ of reef fish (18-39\% of commercial reef fish landings in $\mathrm{kg}$ ) and 2160-8400 (2600$10000 \mathrm{~kg}$ ) lobster (4-16\% of commercial lobster landings in $\mathrm{kg}$ ). The annual financial loss of ghost fishing amounts to $\$ 23,000-\$ 51,000$ for reef fish and $\$ 46,000-\$ 176,000$ for lobster. Despite the recent ban for large vessels (e.g. tankers) to cross the Saba Bank, the average number of lost lobster traps per fishing trip did not change between 2007 (0.2-0.8 traps per trip; Toller \& Lundvall, 2008) and 2012-2015 (0.63 traps per trip).

Simple modification to lobster traps such as correctly functioning escape panels will significantly reduce mortality from ghost fishing (Renchen et al., 2014). The implementation of escape panels attached with ferrous metal wire would already roughly half the period of ghost fishing by derelict traps (1080-2340 kg fish; 1300-5000 kg lobster). Escape panels attached with natural fibres (e.g. cotton, hemp) would reduce ghost fishing of derelict traps by a factor 8 ; from ca. 24 months to a 3 months (270-580 kg fish; 325-1250 lobster). The current impact of ghost fishing on lobster and reef fish stocks is probably modest when considering the amount of killed animals compared to the large area and stock on the Saba Bank. If escape panel regulation are implemented and enforced the impact of ghost fishing will be negligible. 
Derelict traps may also have significant positive contribution to the marine environment as artificial habitat increasing structural complexity. Renchen et al. (2014) mentioned that "Not unexpectedly, the experimental traps deployed in our study functioned as fish aggregating devices within days of deployment, attracting hundreds of juvenile fishes and macro-invertebrates." As derelict traps provide shelter for juvenile fish and substrate for the marine community in an environment as the Saba Bank with low structural complexity, management authorities may consider leaving derelict traps on the Saba Bank as artificial habitat. Removing the derelict traps will probably cause more destruction than benefit for the marine community.

\section{Status \& trend:}

In 2012-2015 the Saban fishery lost 400-600 derelict lobster traps annually. We estimate the annual kill by ghost fishing amounts to $\$ 23,000-51,000$ for reef fish and $\$ 46,000-176,000$ for lobster. Fortunately, our experiments show that simple modification to lobster traps such as correctly functioning escape panels can significantly reduce mortality from ghost fishing.

\subsubsection{Escape slots}

\subsubsection{Lobster traps (including comparison of two trap types)}

The Caribbean spiny lobster is the main target species of the trap fishery on the Saba Bank. The most important result of the experiment is the observation that both $25 \mathrm{~mm}$ and $38 \mathrm{~mm}$ escape slots and trap size (4ft M-trap or 5ft D-traps) appeared to have little effect on lobster catches. The traps with 38 $\mathrm{mm}$ escape slots caught significantly more (ca. 0.5 lobsters per trap) but slightly smaller (ca. $5 \mathrm{~mm}$ $\mathrm{CL}$ ) than the control traps. The introduction of $25 \mathrm{~mm}$ or $38 \mathrm{~mm}$ escape panels is unlikely to have a negative impact on the catch of lobsters and therefore the main income source of a fisherman.

Munro (1983) mentioned that catch rates of mixed reef fish are related to the size of the trap. In our experiment a similar effect was observed with the $5 \mathrm{ft} \mathrm{D}$-traps catching nearly double the amount of mixed reef fish than the smaller $4 \mathrm{ft}$ M-traps but no more lobsters. Testing the effect of trap size on the number of mixed reef fish was not the original intent of the experiment. The observation that trap size does not influence lobster catch but does impact fish catch provides another management option to regulate the catch of mixed reef fish. Keeping lobster traps small will reduce fish bycatch.

Fish species caught in the lobster traps were classified in three groups depending on their economic value (High value: groupers, snappers; Intermediate value: grunts, jacks; Low value: all other reef fish). Surprisingly, the catch rates of $5 \mathrm{ftD}$ traps with $25 \mathrm{~mm}$ escape vents were nearly twice as high compared to control traps. This difference was mainly due to an increase in the catch rate of species of intermediate economic value (e.g. grunts). Catch rates of high value species in the $5 \mathrm{ft} D$ traps were low in the control traps, and almost zero for the traps with the $25 \mathrm{~mm}$ escape vents. In the $4 \mathrm{ft} M-$ traps, again the expected decline in catch rate was not observed and catch rates between control and $25 \mathrm{~mm}$ escape vent traps were similar. In the $4 \mathrm{ft}$ M-traps, catch rates of the high value species were low, with little difference between the treatments. In contrast to the $25 \mathrm{~mm}$ escape vents, the $38 \mathrm{~mm}$ escape vent reduced the catch rates substantially by about $60 \%$ in the $5 \mathrm{ft} D$-type traps, and even by $80 \%$ in the $4 \mathrm{ft} \mathrm{M}$ type traps. The decrease in catch rates was observed in all economic value classes, but the decrease was particularly strong for the low value species (i.e. Chaetodontidae) in $5 \mathrm{ft}$ D-traps.

The catch rate of herbivorous fish (Scaridae and Acanthuridae) was not affected in a consistent way by the $25 \mathrm{~mm}$ escape vent. The catch rate of herbivores surprisingly increased for the larger D-type traps and decreased for the $M$ type traps in the $25 \mathrm{~mm}$ escape slots treatment. Johnson (2010) reported a decline in key herbivores by $50 \%$ in traps fitted with $25 \mathrm{~mm}$ escape slots. The $38 \mathrm{~mm}$ escape slots did, however, considerably reduce the catch rates (ca. $80 \%$ ) of herbivores in both trap types. 
Johnson (2010) reported an increase in average size of reef fish in traps fitted with $25 \mathrm{~mm}$ escape vents. The effect, however, of the escape vents on the length distribution of the reef fish was inconclusive in our experiments. For the experiment with $25 \mathrm{~mm}$ escape vents, mean fish length was slightly smaller $(1.4 \mathrm{~cm})$ in the $5 \mathrm{ft} D$-type trap, and significantly larger $(2.6)$ in the $4 \mathrm{ft}$ M-type traps compared with the control traps. For the $38 \mathrm{~mm}$ escape vent experiment, mean length in the traps with escape vent appeared slightly larger $(1.5 \mathrm{~cm})$ for the $5 \mathrm{ft} D$-type traps and slightly smaller (1.2) for the $4 \mathrm{ft}$ M-type traps compared with the control traps, but the differences were not significant. The differences in mean length related to the type of trap (larger fish in the $5 \mathrm{ft} D$-type traps) were in general larger than the effect of the escape vents on mean length. It is unclear why the predicted increase in fish length was not consistently observed.

We conclude that trap design did not affect the average number of lobsters or fish caught per trap. The only exception was for the white grunt for which the catch rates were markedly higher in the larger D-traps. However, catch rates in terms of weight of bycatch were almost double for the type Dtraps with $25 \mathrm{~mm}$ escape vents compared with the control traps. This difference was mainly due to an increase in the catch rate of species of intermediate economic value. In other words, the larger $5 \mathrm{ft} D$ type traps catch no more lobster but do catch a lot more fish and bycatch. Hence the larger D-type traps are contra-indicated if fish bycatch is to be avoided.

The bycatch of mixed reef fish in the lobster trap fishery could be managed by the regulation of trap size and/or escape slots. Reducing trap size and/or implementing $38 \mathrm{~mm}$ escape slots will drastically reduce the amount of mixed reef fish without impacting on the catch of lobster, the main target species. Such measures will, however, also reduce the catch of high and medium valued fish species and as such impact the income of individual fishermen. A careful process, weighing the potential loss of income and benefit for the fish stocks will need to be carried out when trap size and/or escape slot regulations are to be considered.

\subsubsection{Deep-water snapper traps}

No literature is available on the effect of escape slots on the catch rate and species composition of deep-water snapper traps in the Caribbean. Minor differences were observed in species composition between the control and $25 \mathrm{~mm}$ treatments, with a slightly higher contribution of vermillion snapper in the $25 \mathrm{~mm}$ treatment. No differences were, however, observed in catch rate (both in number and weight) of deep-water snapper species and length distribution of the main target species, silk snapper (L. vivanus). In both the control and $25 \mathrm{~mm}$ treatments, silk snapper smaller than the theoretical minimum retention rate of $\sim 22 \mathrm{~cm}$ FL based on the length-body width relationship, were rare.

The catch rate of deep-water snappers in the $38 \mathrm{~mm}$ treatment was significantly lower (roughly 4 times) compared to the other two treatments. The average size of silk snapper was $5 \mathrm{~cm}$ larger (32 $\mathrm{cm} \mathrm{FL}$ ) in the $38 \mathrm{~mm}$ treatment compared to the other treatments.

The introduction of $25 \mathrm{~mm}$ escape slots appeared to be unlikely to achieve a reduction in the capture and landing of small deep-water snapper. A $38 \mathrm{~mm}$ escape slot may increase the average size of the main target species (silk snapper) above the lowest reported size at maturity $\left(\mathrm{FL}_{50 \%}=26.7\right.$; Rosario et al., 2006) but other studies report $\mathrm{FL}_{50 \%}$ above $40-50 \mathrm{~cm}$ (Boardman \& Weiler, 1980; Thomson \& Munro, 1983; Regtien \& Kemme, 2015). Larger individuals might also have a lower catchability in traps. Regtien and Kemme (2015) demonstrate that the average size of deep-water snappers caught by long lines at the same depth (176-225 m) as traps were significant larger; silk snapper 39 vs 27 cm FL blackfin snapper 41 vs $29 \mathrm{~cm}$ FL and vermillion snapper 38 vs $23 \mathrm{~cm}$ FL. Furthermore, silk snapper are most abundant between 80-180 $\mathrm{m}$ depth but the length mode increases progressively with depth (Boardman \& Weiler, 1980, Regtien \& Kemme, 2015).

A reduction in fishing pressure on small deep-water snapper may not be achievable through escape slot regulations. More effective and suitable management options to reduce fishing pressure on small deep-water snappers could be temporal and/or spatial closures, a shift from traps to long lines and/or a reduction of effort (e.g. regulating the number of traps per license). 
Results:

Trap type and escape slots/ lobster traps: Our results indicate that both trap designs with the escape slot had higher catch rates for lobster than the control traps. There was a significant difference of 0.55 lobster per trap for the experiment with the $38 \mathrm{~mm}$ escape vent. The difference for the $25 \mathrm{~mm}$ escape slot was not significant ( 0.20 lobster per trap).

It was different for reef fish bycatch. Escape slots of $25 \mathrm{~mm}$ greatly increased the catch rate of bycatch species like grunts. In contrast, the $38 \mathrm{~mm}$ escape vent reduced the catch rates of bycatch substantially; by about $60 \%$ for the $\mathrm{D}$ type traps, and $80 \%$ for the $M$ type traps.

The most important result of these experiments is the observation that both $25 \mathrm{~mm}$ and $38 \mathrm{~mm}$ escape slots and trap size (4ft M-trap or $5 \mathrm{ft} \mathrm{D}$-traps) appeared to have little negative effect on lobster catches. The traps with $38 \mathrm{~mm}$ escape slots even caught significantly more lobsters (ca. 0.5 lobsters per trap) Therefore, the bycatch of mixed reef fish in the lobster trap fishery could be limited by regulating trap size and the use of escape slots. Reducing trap size and/or implementing $38 \mathrm{~mm}$ escape slots will drastically reduce the amount of mixed reef fish without impacting on the catch of lobster, the main target species.

Escape slots/ snapper traps: Escape vents of $25 \mathrm{~mm}$ seem to increase snapper catch rate by about $20 \%$ (though not statistically significant). In contrast, escape vents of $38 \mathrm{~mm}$ greatly reduced snapper catches. A $25 \mathrm{~mm}$ escape vent also increased the proportion of vermillion snapper in the catch. Our experiments indicated that the $25 \mathrm{~mm}$ escape slot did function as intended and did not reduce the proportion of sub-adult silk snappers.

So as for the effect of escape slots on fish catch the results are consistent: the $25 \mathrm{~mm}$ vent increases fish catch while the $38 \mathrm{~mm}$ slot lets almost all fish escape and yields low catches. We suggest that this might mean that when traps become too crowded, less fish will enter. By using $25 \mathrm{~mm}$ escape vents, small, non-target species easily escape thereby creating more room in the trap for target species.

\subsection{Lionfish}

The catch of lionfish were not reported by Dilrosun (2000) and Toller \& Lundvall (2008), confirming the recent arrival of lionfish on the Saba Bank between 2008 and 2011. Overall, the CPUE (number per trap) of lionfish in both lobster traps and redfish traps increased between 2012 and 2015. The CPUE of lionfish was roughly 10x higher in the deepwater redfish traps than in the shallow water lobster traps. Since 2015 lionfish have commercial value and are landed, before 2015 nearly all lionfish caught in any type of trap were killed and discarded. Since 2015, lionfish are landed and sold locally for consumption. The possibilities of a selective lionfish fishery could be investigated. Instead of actual bait, artificial lures located in the center of open collapsible traps are used to attract and concentrate lionfish (photo, right).

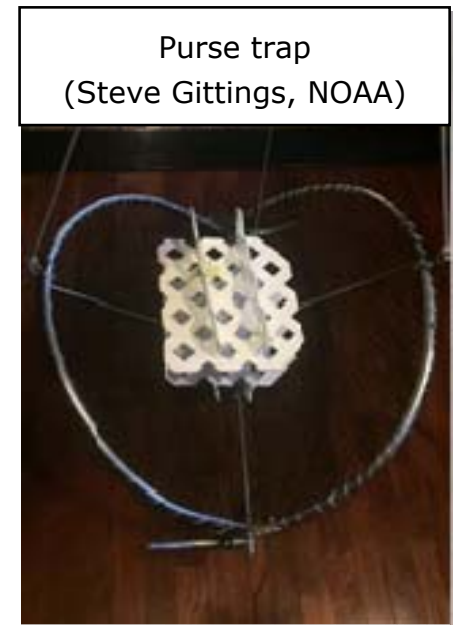

Status \& trends:

Lionfish arrived on the Saba Bank between 2008 and 2011. Since 2015 the species is being landed for local consumption. Catch rates were highest in deeper waters (avg: $117 \mathrm{~m}$ ) of the Saba Bank and may be sufficient to support a small-scale directed fishery utilizing specialised lionfish traps. 


\subsection{Cetaceans}

Humpback whales are easy to identify. They show a range of conspicuous behaviours, such as breaching, which makes it possibly easier to identify them. Of the 13 whale sightings for which species was identified, 12 were identified as humpback whales. A second large whale that may be represented amongst the 29 unidentified whale sightings is the minke whale which has in any case been documented for the bank (Risch \& de Haan 2016). The main occurrence of whale sightings was in the months January to March, which fits with current knowledge on humpback and minke whale migration patterns in the area (e.g. Swartz et al. 2003).

Seasonal occurrences of dolphins are apparent in the data. Dolphins were recorded every month, but there was a marked increase in sightings in March, also coinciding with an increase of whales. It is not clear if and how the increase in whale and dolphin sightings is related. Assuming most of the whale sightings are humpbacks, we know that they come to the Caribbean to reproduce and during that time generally do not feed (e.g. Clapham, 2000).

The spatial distribution of dolphin sightings from by fishing vessels operating out of Saba shows that Saba Bank is widely used by dolphins. The identification of bottlenose dolphins on the Saba Bank gives some credit to the hypothesis that there might be resident groups using this area, at least at certain times of the year. There have been a number of studies on bottlenose dolphins in other areas of the Caribbean describing resident populations (e.g. Rogers et al., 2004, Kerr et al., 2005, Whaley et al., 2006, Roland, 2014).

Spinner dolphins (Stenella longirostris) at times show specific aerial leaping in which they can turn around their longitudinal axis, rotating as many as seven times and up to a height of $3 \mathrm{~m}$ (e.g. Hester et al., 1963). This behaviour is species specific and as it was observed a number of times, indicating that that spinner dolphins are using Saba Bank.

Little is known on the local distribution of cetaceans in these waters (Debrot et al., 2013). The use of vessels that regularly occur in these waters provides year-round information that is not easily available. For Saba Bank the data has shown that dolphins are present all year round and the data indicates that there might be resident populations of bottlenose dolphins using the Saba Bank. This data could be used as a basis for more dedicated studies and it also leads to a number of potential research questions for the future.

Scheidat et al. (2015) made recommendations to improve the quality of the data collected through port sampling. Debrot et al. (1998) achieved a higher success rate working with artisanal fishermen by distributing free disposable cameras for photographic documentation.

\section{$\underline{\text { Status \& trend: }}$}

The cetacean sighting frequency for Saba bank fishing trips amounted to an average of one sighting for every 13.2 trips. Between 2012 and 2016 a total of 142 sightings were generated. Only $25 \%$ of whale sightings and $8 \%$ of dolphin sightings allowed reliable species identification. Of the $25 \%$ of confirmed whale sightings $23 \%$ concerned the humpback whale and $2 \%$ the sperm whale. In regions like Saba with no dedicated survey effort, a low number of stranding records and in general a low density of cetaceans, the use of port sampling provides some baseline data which can be used to design targeted research questions. Continuation of this programme to collect data on the occurrence of marine mammals will increase the value of the collected data. 


\subsection{Queen conch}

Queen conch (Lobatus gigas (Strombidae; Gastropoda) is a large, long-lived marine gastropod that is widely distributed throughout the coastal zones of the Wider Caribbean region. It is one of the most important commercially harvested marine animals in the Caribbean and has been heavily exploited for its meat, shell and pearls for decades. Because of concern for its future the species was listed in Appendix II of the Convention on International Trade in Endangered Species of Wild Fauna and Flora (CITES) in 1992. Appendix II species are species that are not necessarily threatened with extinction, but for which trade must be controlled to avoid unsustainable exploitation. Article IV of the Convention requires that exporting countries restrict trade in Appendix II species to levels that are not detrimental either to species' survival, or to their role within the ecosystems in which they occur. This is known as the so-called "non-detriment finding". At present, fishing for queen conch is prohibited on the Saba Bank. If the fishery and export of queen conch would be allowed again, one of the first tasks is to draw up a non-detriment finding. The outcomes of the queen conch research will be discussed in light of the potential establishment of a queen conch fisheries with appropriate regulations regarding quota, minimum legal size and closed season to ensure long term sustainability based on the recommendations of CMFC/OSPESCA/WECAFC/CRFM/CITES Working Group on Queen Conch (QCWG). Any development of a conch fishery will take time as both landing and export will require permits. CITES also requires a permit for "introduction from the sea" i.e., just to land conch on Saba, which is considered equivalent to import and thus subject to the CITES regulations. (Hoetjes, pers. Comm.)

\subsubsection{Reproductive biology}

Size-at-maturity: The observed minimum size at maturity and the calculated size-at-50\% maturity both expressed in lip thickness, of queen conch on the Saba Bank fell within the range of values reported for other areas in the Wider Caribbean Region (Table 4.9.1). Shell length is an inappropriate indicator for maturity status of queen conch due to its growth pattern. Juvenile queen conch shells increase in length until the onset of maturation, before forming a flared lip and increasing in thickness during maturation. Lip thickness instead of minimum shell length is the appropriate indicator for maturity in conch and is advised to be used in queen conch fisheries management regulations.

Table 4.9.1. Overview of spatial variation in male and female size at maturity in the greater Caribbean region. $\mathrm{LT}=$ lip thickness.

\begin{tabular}{llll}
\hline & $\begin{array}{l}\text { LT } \mathbf{m i n} \text { female } \\
(\mathbf{m m})\end{array}$ & $\begin{array}{l}\text { LT } \mathbf{m i n} \text { male } \\
(\mathbf{m m})\end{array}$ & Reference \\
\hline Sacation & $\mathbf{8}$ & $\mathbf{9}$ & Boman et al. (in prep) \\
St Eustatius & 9 & 6 & Boman et al. (in prep) \\
San Andres Archipelago, Colombia & 2 & 5 & Avila-Poveda \& Baqueiro-Cárdenas (2006) \\
Barbados & 3 & 3 & Bissada (2011) \\
Exuma Cays, Bahamas & 12 & 9 & Stoner et al. (2012a) \\
\hline & $\mathbf{L T}_{\mathbf{5 0} \%}$ female & $\mathbf{L T}_{\mathbf{5 0} \%}$ male & \\
Location & $\mathbf{( m \mathbf { m } )}$ & $\mathbf{( m \mathbf { m } )}$ & Reference \\
\hline Saba Bank & $\mathbf{7}$ & $\mathbf{9}$ & Boman et al. (in prep) \\
St Eustatius & 11 & 4 & Boman et al. (in prep) \\
San Andres Archipelago, Colombia & 8 & 4 & Boman et al. (in prep) \\
Barbados & 10 & 5 & Boman et al. (in prep) \\
Exuma Cays, Bahamas & 14 & 11 & Boman et al. (in prep) \\
\hline
\end{tabular}

Reproductive season: On nearby St Eustatius, reproductively active (female) conch were observed from March till November, peaking in the period May-Jul. Reproductive activities increased with increasing water temperature. The spawning season, defined as the observation of reproductively active (copulating or egg-laying) queen conch, on Saba is similar to conch spawning seasons reported for other areas in the Wider Caribbean Region (Table 4.9.2.) albeit somewhat shorter and peaking in July-August. 
Table 4.9.2. Overview of spatial variation in observed reproductive behaviour (copulating or egglaying) of for queen conch in the Wider Caribbean Region.

\begin{tabular}{|c|c|c|c|c|c|c|c|c|c|c|c|c|c|}
\hline \multirow[b]{2}{*}{ Location } & \multicolumn{12}{|c|}{ Months } & \multirow[b]{2}{*}{ Reference } \\
\hline & J & $\mathbf{F}$ & M & A & M & J & J & A & $\mathbf{s}$ & $\mathbf{O}$ & $\mathbf{N}$ & $\mathbf{D}$ & \\
\hline Saba & & & & & & & & & & & & & This study \\
\hline St Eustatius & & & & & & & & & & & & & Boman et al., (unpublished results) \\
\hline Bermuda & & & & & & & & & & & & & Berg et al. (1989) \\
\hline Florida Keys & & & & & & & & & & & & & D'Asaro (1965) \\
\hline Bahama's & & & & & & & & & & & & & Stoner et al. (1992) \\
\hline Turks and Caicos & & & & & & & & & & & & & Davis et al. (1984) \\
\hline Mexico & & & & & & & & & & & & & Pérez-Pérez \& Aldana-Arana 2002 \\
\hline St Kitts/Nevis & & & & & & & & & & & & & Wilkins et al. 1987 \\
\hline Puerto Rico & & & & & & & & & & & & & Appeldoorn et al. (1987) \\
\hline US Virgin Islands & & & & & & & & & & & & & Randall (1964), Coulston et al. (1987) \\
\hline Colombia & & & & & & & & & & & & & $\begin{array}{l}\text { Avila-Poveda \& Baqueiro-Cárdenas (2006), } \\
\text { Prada et al. (2008) }\end{array}$ \\
\hline Venezuela & & & & & & & & & & & & & Brownell (1977), Weil \& Laughlin (1984) \\
\hline
\end{tabular}

If a queen conch fishery is re-opened it is recommended to protect the breeding population by introducing:

- $\quad$ a closed season during the months May, June, July, August and September, and

- a minimum landing size of $10 \mathrm{~mm}$ lip thickness.

The obligatory landing of queen conch with shell could be considered to assist with the control of the compliance with the minimum landing size.

\subsubsection{Distribution and abundance}

During the mid-1990s the unregulated queen conch fishery on the Saba Bank stopped due to exclusion of foreign fishing by the then newly installed coastguard. There was no official closure, conch continue to be legal to catch with a fishing license. But the enforcement of the licensing system in $1995 / 6$ in effect excluded foreign conch fishers while the newly licensed fishermen had no interest in conch. During the past two decades adult queen conch densities seem to have recovered and appear to be relatively high compared to other (un)fished areas in the Caribbean (Table 4.9.3). The adult queen conch population is estimated at ca. 14 million individuals. 
Table 4.9.3. Overview of adult queen conch densities (no. ha) on the Saba Bank, ST Eustatius (de Graaf et al., 2014) and in the Wider Caribbean Region (Stoner et al. 2012b and references therein). PNE = Parque Nacional del Este, JNP = Jaragua National Park, Dominican Republic. USVI = US Virgin Islands, STT = St Thomas, STJ = St J ohn, STX = St Croix. Total area surveyed differed among reports and density estimates are not directly comparable. Density estimates involving breeding aggregations are not included.

\begin{tabular}{|c|c|c|c|c|c|c|c|}
\hline Year & Area & $\begin{array}{l}\text { Depth } \\
(\mathrm{m})\end{array}$ & $\begin{array}{l}\text { Adults } \\
\text { (no. /ha) }\end{array}$ & Year & Area & $\begin{array}{l}\text { Depth } \\
(\mathrm{m})\end{array}$ & $\begin{array}{l}\text { Adults } \\
\text { (no. /ha) }\end{array}$ \\
\hline 2015 & Saba Bank & $20-30$ & 164 & 2012 & St Eustatius & $1-16$ & 5 \\
\hline 2015 & Saba Bank & $31-40$ & 81 & 2012 & St Eustatius & $17-30$ & 120 \\
\hline 1994 & Bahamas, Cat Island & $15-20$ & 84 & 1996 & $\begin{array}{l}\text { Dominican Republic, } \\
\text { PNE }\end{array}$ & & 4.5 \\
\hline 1994 & $\begin{array}{l}\text { Bahamas, Eluthera, } \\
\text { Schooner }\end{array}$ & $2.5-5$ & 228 & 1997 & $\begin{array}{l}\text { Dominican Republic, } \\
\text { PNE }\end{array}$ & & 4.6 \\
\hline 1994 & $\begin{array}{l}\text { Bahamas, Walderick } \\
\text { Wells }\end{array}$ & $10-15$ & 270 & 1997 & Dominican Republic, JPN & & 1.6 \\
\hline 2009 & $\begin{array}{l}\text { Bahamas, Berry } \\
\text { Islands, Rum Cay }\end{array}$ & & 118 & 2000 & $\begin{array}{l}\text { Dominican Republic, } \\
\text { PNE }\end{array}$ & & 0.6 \\
\hline 1988 & $\begin{array}{l}\text { Bermuda, Entire } \\
\text { Platform }\end{array}$ & $0-20$ & 0.5 & 1996 & USVI, STT & & 32 \\
\hline 2001 & $\begin{array}{l}\text { Belize, Glovers Reef, } \\
\text { protected area }\end{array}$ & & 240 & 2001 & USVI, STT & & 24 \\
\hline 2000 & $\begin{array}{l}\text { Belize, Glovers Reef, } \\
\text { fished area }\end{array}$ & & $11-42$ & 2001 & USVI, STX & & 27 \\
\hline 2001 & $\begin{array}{l}\text { Turks \& Caicos, } \\
\text { Caicos Bank }\end{array}$ & & 204 & 2010 & USVI & & 135 \\
\hline \multirow[t]{3}{*}{2004} & Nicaragua, North & & 112 & 2010 & USVI, STJ & 35 & \\
\hline & & & & 2010 & USVI, STT & 121 & \\
\hline & & & & 2010 & USVI, STX & 46 & \\
\hline
\end{tabular}

The CMFC/OSPESCA/WECAFC/CRFM/CITES Working Group on Queen Conch (QCWG) recommends a conservative quota within the precautionary limits of $8 \%$ of the mean fishable biomass. Based on these conditions, a sustainable annual combined quota of commercial and recreational catches within the boundaries of the 20-40 depth zone of the Saba Bank could be set potentially at 1 million conch.

Mating success in queen conch is density dependent (Stoner \& Ray-Culp, 2000, Stoner et al., 2012 b). QCWG conch recommended that a minimum mean or median density of 100 adult conch/ha should be used (in the fished areas) as a reference point to avoid the risk that recruitment might be impaired. Regular fishery-independent surveys (every 2-3 years) will need to be conducted to determine changes in population densities and structure in order to avoid recruitment impairment and adjust the quota accordingly.

\section{Status \& trends:}

After the closure of the conch fishery on the Saba Bank in the early 1990s, the queen conch population has shown significant recovery. An estimated 14 million adult queen conch are currently present on the Saba Bank in the 20-40 depth zone. A sustainable annual quota could be set ca. 1 million adult queen conch (ca. $8 \%$ of the adult population). If a fishery is re-opened, it is recommended to: 1) introduce a minimum legal size at $10 \mathrm{~mm}$ lip thickness and an annual closed season during May-September, 2) ensure that queen conch are landed with shell, 3) regular stock assessment are conducted to adjust the quota and avoid recruitment impairment, 4) identify and open only those areas to the fishery where densities are high enough, 5) set strict regulations on harvesting methods to prevent development of dangerous 'hookah' fishing practices. 


\section{$5 \quad$ Conclusions and recommendations}

In this report we assess the current status of the fisheries on the Saba Bank and report on the monitoring results as funded by the Netherlands Ministry of Economic Affairs and as collected by the SBMU (Saba Bank Management Unit) hosted by the SCF (Saba Conservation Foundation) in collaboration with WMR (Wageningen Marine Research) during the period spanning 2012-2015. The work addresses a number of issues, and the conclusions pertaining to specific subjects are presented above under the various sections. Here we only present two overarching conclusions, discuss the issue of IUU and then give a few specific management recommendations as they pertain to the principle fisheries.

As should have become clear from this report, we are only at the beginning of the process of developing the knowledge base needed to understand the various fisheries of the Saba Bank and how they interact with each other and the ecosystem of the Bank. Continued fisheries and ecological research will be essential to addressing several applied fisheries questions and to developing a time series of fishery monitoring data which are needed to signal opportunities and problems ahead of time. To ensure the sustainability of the different fisheries on the Saba Bank the development of harvest strategies are highly recommended. A best-practice harvest strategy framework should be developed together with stakeholders to form an integrated and implementable management package.

The main requirements for that are:

a) a management plan with clearly defined quantifiable objectives, targets and reference points of fisheries and coral reef health indicators (e.g. coral, fish, water quality),

b) a continuous robust and standardised monitoring of fisheries and coral reef health indicators, and

c) a transparent decision framework with respect to conservation, coastal development, environmental and fisheries management strategies with active participation of all relevant stakeholders.

In addition to the development of an appropriate management framework, it is recommended to investigate whether proper management might create higher value. Recognizing that the (tourist) market that will only become increasingly more critical with regards to the origin of the food served by hotels and restaurants, the Saba Bank fishery might be developed as brand or obtain certification. By assuring sustainable and responsible harvest it could be possible to obtain a better price for its products.

\subsection{Precautionary management}

Without monitoring and further fishery science it will simply not be possible to fulfil the economic potential the bank represents in a sustainable way and into the future. Nevertheless, the implementation of the precautionary approach will place significant demands on data-collection systems if countries are to be full participants in developing the technical basis for management (FAO, 2001). For the Caribbean, established time series of catch and effort data are extremely rare. Mahon \& McConney (2004) conclude that most Caribbean countries:

'seem unwilling or unable to commit the resources required for ongoing catch and effort datacollection systems. This is likely to severely constrain their capacity to participate in the management of shared stocks and may undermine the strength of claims to "real interest" in these resources'.

(Mahon \& McConney, 2004)

FAO (2011; p 237) stresses that within the context of the precautionary approach, "lack of adequate scienti!c information should not be used as a reason for postponing or failing to undertake 
conservation or fisheries management measures". In the meantime, and according to the latest review, there seems to have been significant betterment in this respect, in any case with respect to the regional West-Indian spiny lobster fisheries (FAO, 2015a).

\subsection{Adaptive management}

Adaptive management (AM), is a structured, iterative process of robust decision making in the face of uncertainty, with an aim to reducing uncertainty over time via system monitoring (Holling, 1978). Decision making simultaneously meets one or more resource management objectives and helps create information needed to improve future management. It is a tool which should be used not only to change a system, but also to learn about the system, and was introduced to the Caribbean Netherlands fisheries management context at the first drafting of the EEZ management plan (Meesters et al., 2010). Adaptive management requires a) proper data collection and analysis to obtain new insights into system functioning and the effectiveness of management measures and $b$ ) a flexible system of management decision-making allowing for periodic review and adaptation of management measures. The many constraints on fish stocks likely change over time. This also means that the measures needed for a sustainable management scenario (mix of measures) will also change over time. Management is not static and management advice is time and space dependent. Periodic management reviews are needed to evaluate the effects of measures and the achievement of management goals. Given the very early current stage of development of knowledge and understanding of the various fisheries taking place on the Saba Bank, and the complexity of tropical coral reef systems, an adaptive approach to management of the Saba Bank fisheries is paramount. So in the end, the need for both cautionary management and adaptive management share the requirement for good data collection and proper fisheries monitoring.

\subsection{IUU fishing on the Saba Bank}

IUU fishing refers to illegal, unreported and unregulated fishing. Illegal fishing takes place any time fishing operates in violation of the law. It can happen in waters that are under the jurisdiction of a coastal state or in high seas fisheries managed by regional organisations. FAO estimates that illegal fishing causes losses estimated at as much as US $\$ 23$ billion per year (Agnew et al., 2009). The drivers behind IUU fishing are mainly the strong economic incentive - in particular the high financial value of fish species that are over-exploited and therefore are in short supply. While the economic incentives and conditions needed for modern industrial-scale fishing on the Saba Bank are largely absent, major IUU did take place in the past, particularly from the 1970s through the mid-1990s. As a consequence the populations of large groupers and conch were largely wiped out (Meesters et al., 1996). While grouper populations have not recovered to this day (Toller et al., 2010) the conch populations clearly have (this study).

Artisanal fishermen are often poorly informed and often do not respect regulations. In many areas of the world, IUU is hence known to be particularly common in small-scale artisanal fisheries (Farrugio, 2015). This because it is especially typical for small-scale fisheries to have multiple landing sites which makes monitoring and control difficult. Fortunately, such is not the case in Saba as all catches are landed in Fort Bay and fisherman commitment to management and cooperation with compliance are high.

The main problem with IUU on the Bank largely ended in 1996 after the then newly established Coast Guard of the Netherlands Antilles and Aruba started strict enforcement. Undeniably, some degree of IUU fishing continues to take place to this date. For instance, this latter includes the minor but documented take of sub-legal sized lobster in the current lobster fishery, and the undocumented or reported catches by recreational fishermen. Even though the capture and take of sharks on the Bank seems relatively limited, and even though there is no legal protection of sharks on the Bank as yet, the killing of sharks is contrary to the management principles accorded to the Bank as part of the Yarari Marine Mammal and Shark Sanctuary and should be framed as an IUU issue. This also holds for 
the unquestionable occasional take of ICCAT-regulated billfish and tunas in small-scale hand-line fisheries. The problem of ghost fishing is not considered part of IUU. Ghost fishing may worsen if a fishery is heavily controlled for IUU, because the IUU fishermen will often jettison gear overboard to destroy evidence of their illegal activities.

Based on the results treated more extensively in the above Discussion section, we conclude that there are several measures to help even further define and reduce the IUU-related issues on the Bank (FAO, 2015b). In this, the continued collection of port sampling catch statistics is essential.

Improved enforcement is also critical. Recently there have been regular sightings by fishermen and SBMU of fishing activities by foreign fishing vessels without commercial or recreational fishing license, also during and in the seasonal closed area during the Red Hind spawning aggregation season ( $\mathrm{J}$. Odinga, pers. comm.). The lack of regular patrols and enforcement here are the main challenge.

\subsection{Lobster fishery recommendations}

As the lobster populations seem to be driven by regional processes our key recommendation is that the Netherlands co-operates with Caribbean-wide initiatives to ensure a sustainable fishery and to align its regulations with those of neighbouring islands (FAO, 2015a). Nevertheless, there are significant differences between the national fisheries measures, and a "one size fits all" approach is probably not possible (FAO 2015a).

Because of the importance of unpredictable regional processes that appear to drive the lobster catches, an adaptive and cautionary approach is essential whereby total fishing mortality is capped and controlled. This can be achieved by any of a mix of potential measures such as catch quotas, gear type and number restrictions, area closures, seasons, limits to the number of licences etc. Which of any of a number of combinations of measures is used ("scenarios"), needs to be established in consultation with the principal stakeholders as part of the process to achieve an implementable and controllable fishery management plan with clear objectives and goals.

Some general remarks are in order. FAO (2015a) notes that in Caribbean lobster fisheries some gear restrictions appear not to affect stocks at all (due to their high catchability) and that gear restrictions are generally difficult to enforce, require training and a full "24/7" surveillance, which can make management very costly. Such measures also often lead to illegal fishing (IUU). Minimum size limits do have a positive effect on stocks; as evidenced from OSPESCA countries (Central American Organization of the Fisheries and Aquaculture Sector) (FAO, 2015a). Such restrictions are relatively inexpensive to enforce, and can be implemented at any stage of the supply chain. Minimum sizes could have negative effects in terms of reproduction as they lead to earlier maturity and reproduction. Again, the task of jointly developing a lobster fishery management plan with clear and agreed objectives, falls outside the scope of this baseline monitoring work.

With regards to the Saba Bank lobster fishery, harvest and enforcement strategies should be simple, robust and cost-effective. Options to consider would be limits to the number of fishing licences, the number of traps per fishermen/licence (currently about 300 per fisherman), a total limit to traps deployed in the fishery, registry and visible marking of all traps and trap sets. Effective marking of gear for identification can also help prevent gear loss, and gear theft. The use of escape slots and biodegradable panels is an easy way to help limit negative impacts of gear without major costs. Finally a total quota for the combined catch can cap the total harvest impact and is relatively easy to measure and monitor considering that all landings take place in one harbor (Fort Bay, Saba). Finally, it is highly recommended that the management of Caribbean spiny lobster in the Caribbean Netherlands aligns with the principles outlined in the lobster conservation and management declaration of the 17 island state Caribbean Regional Fisheries Mechanism (Annex 5). The Netherlands could become a member of CRFM and co-sign the management agreement for full participation in this regional management mechanism. 


\subsection{Redfish fishery recommendations}

The shifts in gear use from hook and line to traps has changed the fish size-frequency and species composition in the redfish fishery. When looking at standardized CPUE which is a relative index/proxy of population size, it is evident that CPUE has fluctuated between roughly $2.5-5 \mathrm{~kg}$ snappers per trap set during 2001-2015, with no appreciable trend. Therefore, the recent changes in total annual catch (decline) appear to be largely driven by reduction in number of fishing trips effort. These most recent data hence suggest no worrisome new developments for this fishery. However the current fish stock seems to be significantly (75\%) lower than in the early 1970 s "virgin" state. The status of the trap fishery is perceived by the fishers as undesirably overexploited. And on the $1^{\text {st }}$ April 2017 they decided to implement a six month temporary closed season.

In addition they decided to:

- $\quad$ Set a trap limit of 25 Red Fish traps from the $1^{\text {st }}$ of October 2017 until the next agreed closed season.

- Allow a maximum of 4 vertical longlines for Red Fish per fishing boat during the closed season for Red Fish

- Use bigger mesh sizes: all fishermen will use 2 inch square mesh for at least the doors of the Red Fish traps

The ability of fishermen to come with measures to restrain their own effort is much to be applauded. It is furthermore recommended to reach agreement on the maximum size of a snapper trap, the maximum number of hooks on a vertical longline and the obligation of a biodegradable panel with escape slot. Some fishermen have moved their snapper traps to shallow water. At this stage it is unclear how shallow the traps are set and what fish species are being targeted (likely the lane snapper (sand silk snapper or korá spañó, Lutjanus synagris). It is recommended to reach agreement on a maximum depth for modified snapper traps during the closed season. Finally, it is recommended to develop a harvest strategy for the deep-water snapper fishery and ensure that sufficient (on-board) samples are collected. Such a harvest strategy might include rotational area closures to allow local stock recovery.

\subsection{Conch stock recommendations}

The queen conch population has shown significant recovery since the closure instituted in the mid1990s. An estimated 14 million adult queen conch are currently present on the Saba Bank in the 2040 depth zone. A sustainable annual quota could be set ca. 1 million adult queen conch (ca. $8 \%$ of the adult population). If a fishery is re-opened, it is recommended to: 1 ) introduce a minimum legal size at $10 \mathrm{~mm}$ lip thickness and an annual closed season during May-September, 2) ensure that queen conch are landed with shell, 3) regular stock assessment are conducted to adjust the quota and avoid recruitment impairment, 4) identify and open only those areas to the fishery where densities are high enough, 5) set strict regulations on harvesting methods to prevent development of dangerous 'hookah' fishing practices. 


\section{References}

Agnew, D. J., Pearce, J., Pramod, G., Peatman, T., Watson, R., Beddington, J. R., Pitcher, T. J. 2009. Estimating the worldwide extent of illegal fishing. Plos one, 4(2), e4570.https://doi.org/10.1371/journal.pone.0004570

Appeldoorn RS, Dennis GD, Monterrosa Lopez O. 1987. Review of shared demersal resources of Puerto Rico and the Lesser Antilles region. In Mahon, R. (ed.), Report and proceedings of the expert consultation on shared Fishery resources of the Lesser Antilles region. FAO Fish. Rep. 383: 36-57.

Avila-Poveda, O. H., Baqueiro-Cárdenas, E. R. 2006. Size at sexual maturity in the queen conch Strombus gigas from Colombia. Boletín de Investigaciones Marinas y Costeras-INVEMAR, 35(1), 223-233.

Bailey, C.A., Neihof, R.A., Tabor, P.S. 1983. Inhibitory effect of solar radiation on amino acid uptake in Chesapeake Bay bacteria. Appl. Env. Microb., 46, 44-49.

Bakker de, D. M., Meesters, E. H., van Bleijswijk, J. D., Luttikhuizen, P. C., Breeuwer, H. J., \& Becking, L. E. 2016. Population genetic structure, abundance, and health status of two dominant benthic species in the Saba Bank National Park, Caribbean Netherlands: Montastraea cavernosa and Xestospongia muta. PloS one, 11(5), e0155969.

Beek, I. V. 2012. Lobster trap detection at the Saba Bank. Report/I MARES Wageningen UR (C091/12).

Beek van IJM, Debrot AO, de Graaf M. 2012. Elasmobranchs in the Dutch Caribbean: current population status, fisheries and conservation. Proc 65th GCFI, Sta. Martha, Colombia. 12 pp.

Beek van IJM, Debrot AO, Walker PA, Kingma I. 2014. Shark protection plan for the Dutch Caribbean EEZ. WAGENINGEN MARINE RESEARCH Report C209/13, 104 pp.

Berg CJ, Ward J, Luckhurst B, Nisbet K, Couper F. 1989. Observations of breeding aggregations of the queen conch, Strombus gigas, in Bermuda. Proc. Gulf Caribb. Fish. Inst. 42: 161-171.

Bissada, C. E. 2011. Aspects of the biology of queen conch Strombus gigas in Barbados with implications for fisheries management. Masters thesis, University of the West Indies.

Boardman, C., Weiler, D. 1980. Aspects of the life history of three deep water snappers around Puerto Rico. Gulf Caribbean Fishery Institute. 32: 158-172.

Boeke, J., 1907. Rapport betreffende een voorloopig onderzoek naar den toestand van de Visscherij en de Industrie van Zeeproducten in de kolonie Curaçao. Belinfante, Den Haag, The Netherlands, pp. 200.

Boonstra, M. 2014. Status of the redfish fishery on the Saba Bank. MSc. Thesis, University of Amsterdam. 103 pp.

Briones-Fourzán P., J. Candela,E. Lozano-Álvarez. 2008. Postlarval settlement of the spiny lobster Panulirus argus along the Caribbean coast of Mexico: Patterns, influence of physical factors, and possible sources of origin. Limnology and Oceanography 53(3):970-985

Brownell WN. 1977. Reproduction, laboratory culture and growth of Strombus gigas, S. costatus, and S. pugilis in Los Roques, Venezuela. Bull. Mar. Sci. 27:668-680.

Buesa, R. J. 2016. How much spiny lobster (Panulirus argus) can be harvested in Florida? paper prepared for the 2014-2015 season Lobster Fishery Review Panel March 28, 2016 Webimar.

Butler M. J.I.V, Mojica A. M., Sosa-Cordero E., Millet, M., Sanchez-Navarro P., Maldonado M. A., Posada J., Rodriguez, B., Rivas, C.M., Oviedo, A. 2009. Patterns of Spiny Lobster (Panulirus argus) Postlarval Recruitment in the Carribbean: A CRTR Project.2009. Patterns of spiny lobster (Panulirus argus) postlarval recruitment in the Caribbean: a CRTR Project. Proceedings of the 62nd Gulf and Caribbean Fisheries Institute, 62: 361-369

Butler, C. B., Matthews, T. R. 2015. Effects of ghost fishing lobster traps in the Florida Keys. ICES Journal of Marine Science, 72(suppl_1), i185-i198.

Buurt, G. van (1980). The fisheries situation in Saba and St. Eustatius. Report to DEPOS. pp. 14

Cado van der Lely JA, AE Warning, SW Schep, P van Beukering, E Wolfs 2014. The Total Economic Value of nature on Saba. Report R-14/11, IVM Institute for Environmental Studies

CARICOM. 2002. Strategic plan for: Caribbean Regional Fisheries Mechanism. Caricom Fisheries Unit. Georgetown, Guyana. $141 \mathrm{pp}$. 
Clapham, P.J. 2000. The humpback whale: seasonal feeding and breeding in a baleen whale. In Cetacean societies: field studies of dolphins and whales, ed. J. Mann, R. C. Conner, P. L. Tyack, and $\mathrm{H}$. Whitehead. 173-198. Chicago and London: The University of Chicago Press.

Coulston ML, Berey RW, Dempsey AC, Odum P. 1987. Assessment of queen conch (Strombus gigas). Population and predation studies of hatchery reared juveniles in Salt River Canyon, St. Croix, U.S. Virgin Islands. Proc. Gulf Caribb. Fish. Inst. 38: 294-306.

Cruz, R. \& R. Adriano. 2001. Regional and seasonal prediction of the Caribbean lobster(Panulirus argus) commercial catch in Cuba. Mar. Freshwat. Res., 52: 1633-1640

Cruz, R. and Bertelsen, R.D. 2008. The spiny lobster (Panulirus argus) in the Wider Caribbean: a review of life cycle dynamics and implications for responsible fisheries management. In: Proceedings of the Gulf and Caribbean Fisheries Institute, 61, pp. 433-446.

D'Asaro CN. 1965. Organogenesis, development and metamorphosis in the queen conch, Strombus gigas, with notes on breeding habits. Bull. Mar. Sci. 15: 359-416.

Davis M, Mitchell BA, Brown JL. 1984. Breeding behavior of the queen conch Strombus gigas Linne, held in a natural enclosed habitat. J. Shellfish Res. 4: 17-21.

Debrot AO, Esteban N, Bervoets T, Hoetjes PC \& Scheidat M. 2013. Marine Mammals of the northeastern Caribbean Windward Dutch Islands: Saba, St. Eustatius, St. Maarten, and the Saba Bank. Caribbean Journal of Science 47:159-172.

Debrot AO, de Meyer JA \& Dezentjé PJE 1998. An overview of the cetacean fauna of the Leeward Dutch Antilles. Caribbean Journal of Science 34:204-210.

Delgado, G.A., C.T. Bartels, R.A. Glazer, N.J. Brown-Peterson, K.J. McCarthy. 2004. Translocation as a strategy to rehabilitate the queen conch (Strombus gigas) population in the Florida Keys. Fish. Bull. U.S. 102: 278-288.

Dilrosun, F. 2000. Monitoring the Saba Bank Fishery. Environmental Section Department of Public Health and Environmental Hygiene, Curacao, Netherlands Antilles.

DLG (Dienst Landelijk Gebied) 2009. Koraalriffen in Nederland. Publ. RLG 09/04 juni 2009, DLG, Utrecht. 39 pp.

Etnoyer, P. J., Wirshing, H. H., Sánchez, J. A. (2010). Rapid assessment of octocoral diversity and habitat on Saba Bank, Netherlands Antilles. PLoS One, 5(5), e10668.

Evans, C.R., Lockwood, A.P.M, Evans, A.J., Free, E. 1995. "Field studies of the reproductive biology of the spiny lobster Panulirus argus (Latreille) and P. gutattus (Latreille) at Bermuda" Journal of Shellfish Research 14(2): 371-381.

FAO. 2001. Research implications of adopting the precautionary approach to management of tuna fisheries. FAO Fisheries Circular No. 963. Rome. 74 pp.

FAO. 2011. Review of the state of world marine fishery resources 2011. Marine resources - Western Central Atlantic. FAO Fish. Techn. Pap. 569 pp.

FAO. 2015a. Report of the first meeting of the OSPESCA/WECAFC/CRFM/CFMC Working Group on Caribbean Spiny Lobster, Panama City, Panama, 21-23 October 2014. FAO Fisheries and Aquaculture Report. No. 1095, Bridgetown, Barbados. 112 pp.

FAO. 2015b. Voluntary Guidelines for Securing Sustainable Small-Scale Fisheries in the Context of Food Security and Poverty Eradication. FAO, Rome. 18 pp.

Farrugio. H. 2015. Current situation of small-scale fisheries in the Mediterranean and Black Sea: strategies and methodologies for an effective analysis of the sector. Pp. 15-43 in: Proc. First Regional Symposium on Sustainable Small-Scale Fisheries in the Mediterranean and Black Sea, 27-30 November 2013, Saint Julian's, Malta. FAO Fisheries and Aquaculture Proceedings No. 39. Rome. 519 pp.

Framhein, R. (1995). The value of nature protection: economic analysis of the Saba Marine Park. The Bottom, Saba, The Netherlands Antilles: Draft summary for the Government of Saba.

Gerwen, van, I. 2013. The effects of trap fisheries on the populations of Caribbean spiny lobster and reef fish species at the Saba Bank. MSc. Thesis. AQUACULTURE AND FISHERIES GROUP LEERSTOELGROEP AQUACULTUUR EN VISSERIJ, Wageningen University. 66 pp.

Guidicelli, M., Villegas, L. 1981 Program for fisheries development in Saba and St. Eustatius. Interregional Fisheries Development and Management Program, FAO United Nations, WECAF Rep, 39. $36 \mathrm{pp}$.

Graaf, M. de, E Houtepen, E Tichelaar, DCM Miller, T Brunel, LAJ Nagelkerke. 2016. Status and trends reef fish and coastal fisheries Bonaire (Caribbean Netherlands): report card 2014-2015. Wageningen University \& Research rapport C087/16. 70 pp. 
Graaf, M., M. Meijer zu Schlochteren, E. Boman. 2014. Non-Detriment Finding Regarding the Export of Queen conch (Lobatus gigas) from St Eustatius (Caribbean Netherlands) C173/14. 37 pp.

Graaf, M. de, S. Piontek, .C.M. Miller, T. Brunel, L.A.J. Nagelkerke. 2015. Status and trends of St. Eustatius coral reef ecosystem and fisheries: 2015 report card. IMARES report C167/15. 41 pp.

Hawkins J.P., Roberts, C.M. 2004. Effect of Artisanal fishing on Caribbean coral reefs. Conservation Biology. 18(1) : 215-226.

Hester, F. J., Hunter, J. R., Whitney, R. R. 1963. Jumping and spinning behavior in the spinner porpoise. J. Mamm. 44, 586-588.

Hoeksema, B. W., van der Land, J., van der Meij, S. E., van Ofwegen, L. P., Reijnen, B. T., van Soest, R. W., de Voogd, N. J. 2011. Unforeseen importance of historical collections as baselines to determine biotic change of coral reefs: the Saba Bank case. Marine Ecology, 32(2), 135-141.

Hoetjes, P. C., Carpenter, K. E. 2010. Saving Saba Bank: policy implications of biodiversity studies. Plos One, 5(5), e10769.

Hofman, C. L., Hoogland, M. L. 2003. Plum Piece: evidence for Archaic seasonal occupation on Saba, northern Lesser Antilles around 3300 BP. Journal of Caribbean Archaeology, (4), 12-27.

Holling, C.S. 1978. Adaptive Environmental Assessment and Management. John Wiley \& Sons. ISBN 9781932846072

Hoogland, M., Hofman, C. 1993. Kelbey's Ridge 2, A 14th Century Taino Settlement on Saba, Netherlands Antilles. Analecta, 26, 20.

Johnson, A. E. 2010. Reducing bycatch in coral reef trap fisheries: escape gaps as a step towards sustainability. Marine Ecology Progress Series, 415, 201-209.

Kerkhof, S. van de, Schep, S. W., van Beukering, P., Brander, L., Wolfs, E. 2014. The Tourism Value of Nature on St Eustatius. IVM Institute for Environmental Studies, VU University Amsterdam, De Boelelaan 1087, 1081 HV AMSTERDAM.

Kerr, KA, Defran, RH and Campbell, SC. 2005. Bottlenose Dolphins (Tursiops truncatus) in the Drowned Cayes, Belize: Group Size, Site Fidelity and Abundance. Caribbean Journal of Science 41(1):172-177.

Kimker A. 1990. Biodegradable twine report to the Alaska Board of Fisheries. Alaska Department of Fish and Game, Division of Commercial Fisheries, Regional Information Report 2H90-05, Anchorage.

Kough AS, Paris CB, Butler MJ IV. 2013. Larval Connectivity and the International Management of Fisheries. PLOS ONE 8(6): e64970

Kumpf, H. E. 1980. Practical considerations and testing of escape panel material in fish traps. Proc. Gulf Caribb. Fish. Inst. 32: 211-214.

Land, J., van der. 1977. The Saba Bank, a large atoll in the northeastern Caribbean. FAO Fisheries Report, 200, 469-481.

Littler, M. M., Littler, D. S., Brooks, B. L. 2010. Marine macroalgal diversity assessment of Saba Bank, Netherlands Antilles. PloS one, 5(5), e10677.

Lundvall S. 2008. Saba Bank, Special Marine Area Management Plan. Department of Public Health and Social Development, Department of Environment and Nature, Willemstad.

Mahon, R.; McConney, P.A. (eds.) 2004. Management of large pelagic fisheries in CARICOM countries. FAO Fisheries Technical Paper. No. 464. Rome, FAO. 149 p.

Macintyre, I.G., D.J.J. Kinsman, RC German 1975. Geological reconnaissance survey of the Saba Bank, Caribbean Sea. Caribbean Journal of Science, 15, 11-20.

McKenna, S. A., Etnoyer, P. 2010. Rapid assessment of stony coral richness and condition on Saba Bank, Netherlands Antilles. Plos One, 5(5), e10749.

Meesters, E. H., H. Nijkamp, L. Bijvoet 1996. Towards sustainable management of the Saba Bank. A report for the Department of Public Health and Environment (VOMIL), Curacao, Netherlands Antilles. AIDEnvironment, Amsterdam, The Netherlands. 58 pp.

Meesters, H.W.G. D.M.E. Slijkerman, M. de Graaf, A.O. Debrot, 2010. Management plan for the natural resources of the EEZ of the Dutch Caribbean. $81 \mathrm{pp}$.

Melville-Smith, G.R., De Lestang, S. 2006. "Spatial and temporal variation in the size at maturity of the western rock lobster Panulirus cygnus" Marine Biology 150:183-195

MinEZ (Dutch Ministry of Economic Affairs) 2013. Natuurbeleidsplan Caribisch Nederland 2013-2017. The Hague, the Netherlands. 55 pp.

Moore JE, Cox TM, Lewison RL, Read AJ, Bjorkland R, McDonald SL, Crowder LB, Aruna E, Ayissi I, Espeut P, Joynson-Hicks C, Pilcher N, Poonian CNS, Solarin B \& Kiszka J. 2010. An interview-based 
approach to assess marine mammal and sea turtle captures in artisanal fisheries. Biological Conservation 143:795-805.

Munro JL. 1974. The mode of operation of Antillean fish traps and the relationships between ingress, escapement, catch and soak. J. Cons., Cons. Int. Explor. Mer. 35: 337-350.

Munro JL (editor). 1983. Caribbean coral reef fishery resources. ICLARM Studies and Reviews 7,276 p. International Center for Living Aquatic Resources Management, Manila, Philippines.

National Fisheries Ordinance Official Bulletin 1991, no. 74. Netherlands Antilles, National Decree of 5 November 1992 containing general measures implementing articles 3 and 12 of the National Fisheries Ordinance (Public Bulletin 1991, no. 74).

Pérez-Pérez M, Aldana-Aranda D. 2002. Strombus gigas L. 1758 (mesogasteropoda: Strombidae) y su periodo de desove en el Arrecife Alacranes, Yucatan. Proc Gulf Carib Fish Inst. 53:108-119.

Poiesz, S. 2013. The status of the Caribbean spiny lobster (Panulirus argus) and its fishery in the coastal waters of St Eustatius. MSc Thesis nr. T 1917. Wageningen University.

Prada M., E. Castro, E. Taylor, V. Puentes, R. Appeldoorn and N. Daves. 2008. Non-detrimental findings for the Queen conch (Stombus gigas) in Colombia. NDF Workshop case studies, WG 9 Aquatic Invertebrates, Case study 3 Strombus gigas. $51 \mathrm{pp}$.

Prescod, S.D. and Oxenford, H.A. Taylor, C. 1996. The snapper fishery of Barbados: present status and a preliminary assessment of the potential for expansion. In: Proceedings of the Gulf and Caribbean Fisheries Institute, 44, pp. 159-179.

Proplan Consultants Group NV. 1992. Projectdossier upgrading visserij Saba. 19 pp.

Randall JE. 1964 Contributions to the biology of the queen conch, Strombus gigas. Bull. Mar. Sci. 14:246-295.

Regtien, A. en J. Kemme. 2015. Size at maturity and depth distribution of deep-water snapper species on the Saba Bank. Unpubl. report Wageningen Marine research and HVHL. 35 pp.

Renchen GR, Pittman SJ, Brandt ME. 2012. Investigating the behavioural responses of trapped fishes using underwater video surveillance. J Fish Biol. 81(5):1611-1625.

Risch D., De Haan D, 2016. Humpback and minke whale acoustic presence with reference to fish sounds and ambient noise levels at Saba Bank, Caribbean Windward Dutch Islands. IMARES Report C067/16.

Rogers CA, Brunnick BJ, Herzing DL, Baldwin JD 2004. The social structure of bottlenose dolphins, Tursiops truncatus, in the Bahamas. Mar. Mamm. Sci. 20:688-708.

Roland, A. 2014. Population Size and Viability of Bottlenose Dolphins (Tursiops truncatus) off the Coast of the Parque Nacional de Este, Dominican Republic. Master Thesis submitted to the Graduate Faculty of George mason University.

Rosario, A., Rojas, J., Pineiro, E., Figuerola, M. Pena, N., Torres, W. 2006. Reproductive cycle and maturation size of silk snapper (Lutjanus vivanus). Final 83

Report to the Caribbean Fishery Management Council. $21 \mathrm{p}$.

Scheidat M, Boman E, Devaasuren N, Geelhoed S., de Graaf M. (2015) Monitoring cetacean occurrence in coastal waters of the Caribbean Netherlands (Saba, St. Eustatius \& Bonaire) using port sampling. IMARES Report C038/15.

Sherman, K., Hempel, G. 2008. The UNEP Large Marine Ecosystem Report: A perspective on changing conditions in LMEs of the world's Regional Seas. UNEP Regional Seas reports and Studies 182. UNEP, Nairobi, Kenya. 852 pp.

Sieracki, M., J. Sieburth, J.M. 1986. Sunlight-induced growth delay of planktonic marine bacteria in filtered seawater. Mar. Ecol. Prog. Ser. 33: 19-27.

Silberman, J.D., P.J. Walsh. 1994. Population genetics of the spiny lobster Panulirus argus. Bulletin of Marine Science 54:1084

Stamatopoulos C. 2002. Sample-based fishery surveys: a technical handbook. FAO Fisheries Technical Paper. No. 425. Rome, FAO. Pp. 132.

Stoner AW, Davis MH, Booker CJ. 2012b. Negative consequences of Allee effect are compounded by fishing pressure: comparison of queen conch reproduction in fishing grounds and a marine protected area. Bull Mar Sci 88: 89-104.

Stoner AW, Mueller KW, Brown-Peterson NJ, Davis MH, Booker CJ. 2012a. Maturation and age in queen conch (Strombus gigas): Urgent need for changes in harvest criteria. Fisheries Research 131-133: 76-84.

Stoner, A.W.,M. Ray-Culp 2000. Evidence for Allee effects in an over-harvested marine gastropod: density-dependent mating and egg production. Marine Ecology Progress Series 202: 297-302. 
Stoner AW, Sandt VJ, Boldron-Metairon IF. 1992. Seasonality in reproductive activity and larval abundance of queen conch Strombus gigas. Fishery Bulletin, U.S. 90:161-170.

Swartz SL, Cole T, McDonald MA, Hildebrand JA, Oleson EM, Martinez A, Clapham PJ, Barlow J \& Jones $M L$ 2003. Acoustic and visual survey of humpback whale (Megaptera novaeangliae): distribution in the eastern and southeastern Caribbean Sea. Caribbean Journal of Science 39:195-208.

Thacker, R.W., Dıaz, M.C., de Voogd, N.J., van Soest, R.W.M., Freeman, C.J. Andrew S. Mobley, Jessica LaPietra, Kevin Cope, Sheila McKenna 2010. "Preliminary Assessment of Sponge Biodiversity on Saba Bank, Netherlands Antilles" PLoS ONE 5(5): e9622.

Thellen, C., M. Coyne, D. Froio, M. Auerbach, C. Wirsen, J. Ratto. 2008. A processing, characterization and marine biodegradation study of melt-extruded polyhydroxyalkanoate (PHA) films. J. Polym. Environ. 16: 1-11

Toller W., Debrot, A.O., Vermeij, M.J.A., Hoetjes, P.C. 2010. Reef Fishes of Saba Bank, Netherlands Antilles: Assemblage Structure across a Gradient of Habitat Types. PLoS ONE 5(5): e9207. doi:10.1371/journal.pone.0009207

Toller, W., Lundvall, S. 2008. Assessment of the commercial fishery of Saba Bank. Saba Conservation Foundation, 47pp.

Weil E, Laughlin R. 1984. Biology, population dynamics, and reproduction of the queen conch, Strombus gigas Linne, in the Archipielago de Los Roques National Park. J. Shellfish Res. 4:45-62.

Whaley AR, Parsons ECM, Sellares R., Bonnelly I de C. 2006. Dolphin ecology and behaviour in the south-eastern waters of the Dominican Republic: preliminary observations. Scientific Committee. 58th Annual Meeting of the International Whaling Commission, St. Kitts \& Nevis. Retrieved from http://iwcoffice.org/_documents/sci_com/SC58docs/SC-58-SM12.pdf.

Wilkins RM, Goodwin MH, Reid DM. 1987. Research applied to conch resource management in St. Kitts/Nevis. Proc Gulf Carib Fish Inst. 38:370-375.

Williams, J. T., Carpenter, K. E., Van Tassell, J. L., Hoetjes, P., Toller, W., Etnoyer, P., Smith, M. 2010. Biodiversity assessment of the fishes of Saba Bank atoll, Netherlands Antilles. Plos One, 5(5), e10676.

Wolf, R., Chislett, G. 1974. Trap fishing explorations for snapper and related species in the Caribbean and adjacent waters. Marine Fishery Review. 36(9): 49-61.

Zaneveld JS. 1961. The fishery resources and the fishery industries of the Netherlands Antilles. Proc. Gulf Caribbean Fish. Inst., 14 (1961), pp. 137-171. 


\section{Quality Assurance}

IMARES utilises an ISO 9001:2008 certified quality management system (certificate number: 1873782015-AQ-NLD-RvA). This certificate is valid until 15 September 2018. The organisation has been certified since 27 February 2001. The certification was issued by DNV Certification B.V.

\section{Justification}

Report: C077/17

Project Number: 4308201109, 4318100013, 4318100049, 4318100097

The scientific quality of this report has been peer reviewed by a colleague scientist and a member of the Management Team of Wageningen Marine Research.

Approved: $\quad$ Drs. J.E. Tamis

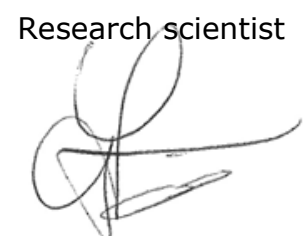

Signature:

Date:

6-10-2017

Approved: $\quad$ Dr.ir T.P. Bult

Director

Signature:

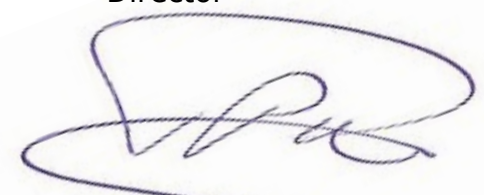

Date:

9-10-2017 


\section{Annex 1 Length composition fish by- catch from lobster traps}

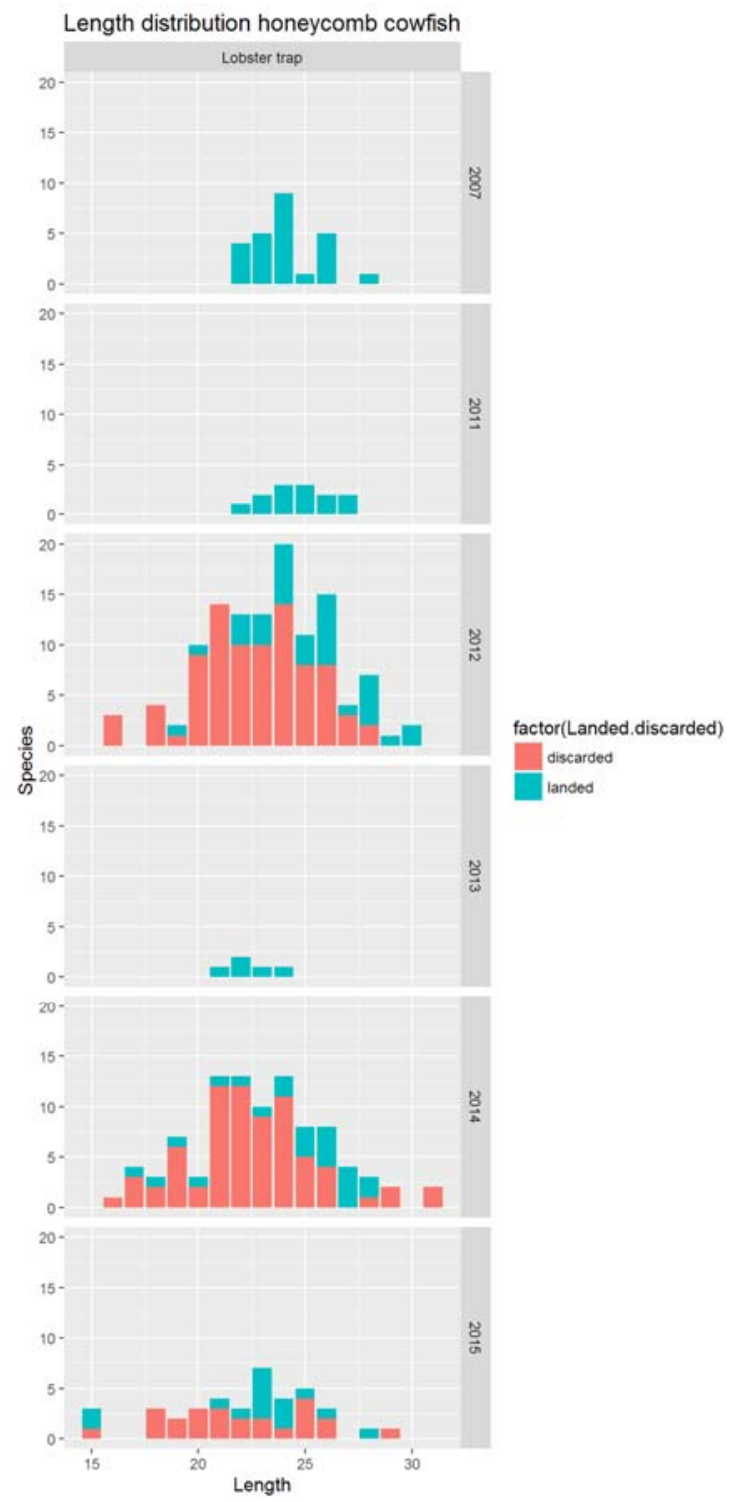

Figure A1.1. Length composition of honeycomb cowfish from lobster traps 


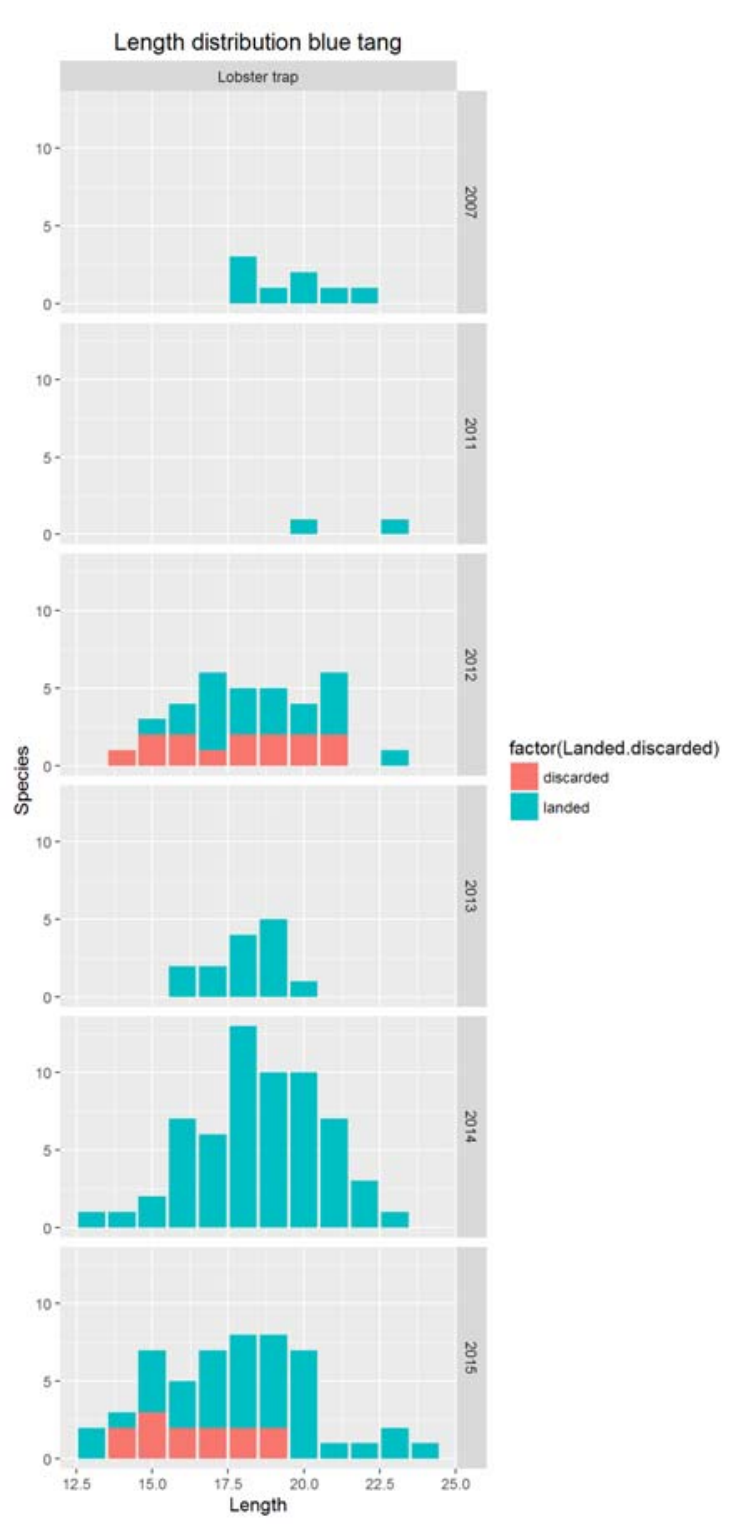

Figure A1.2. Length composition of blue tang from lobster traps 


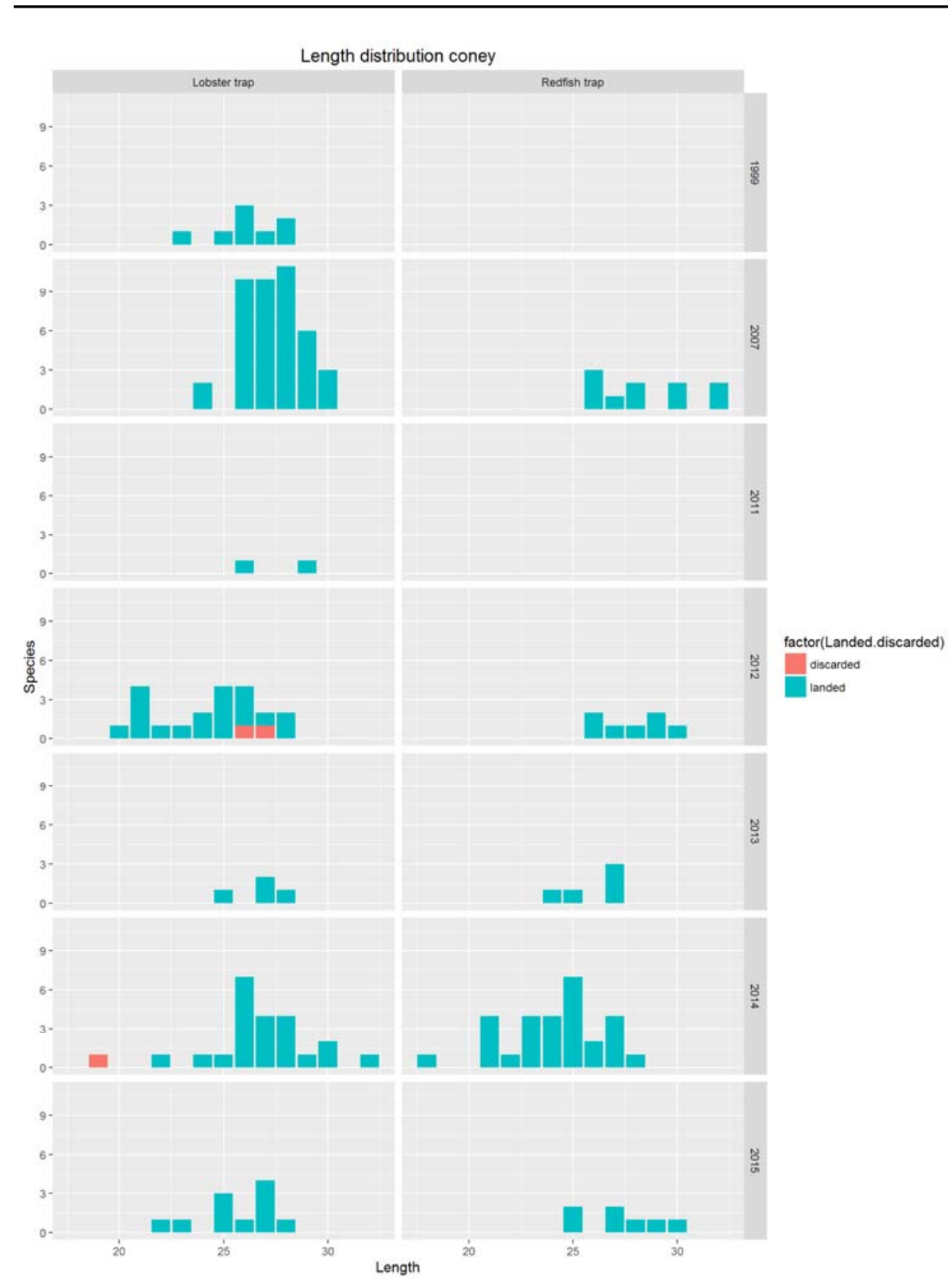

Figure A1.3. Length composition of coney from lobster traps 


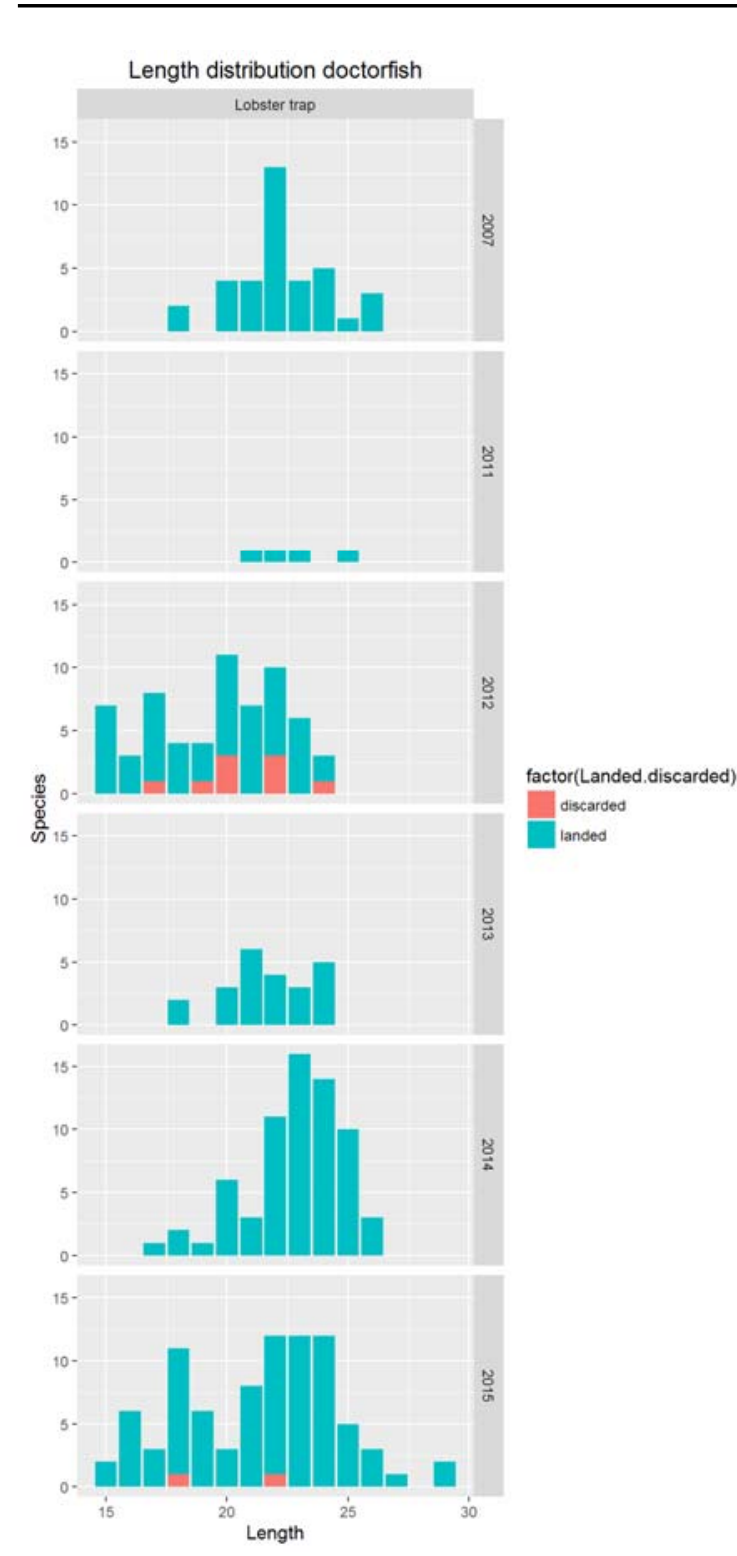

Figure A1.4. Length composition of doctorfish from lobster traps 


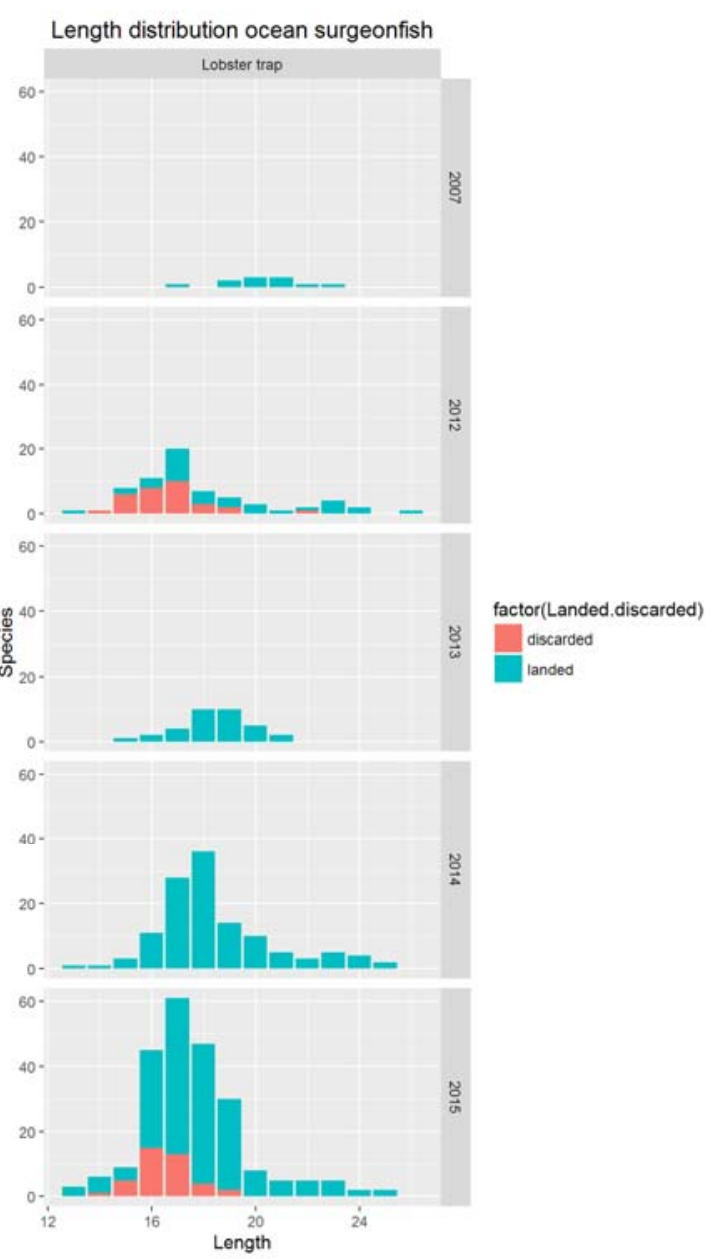

Figure A1.5. Length composition of ocean surgeonfish from lobster traps 


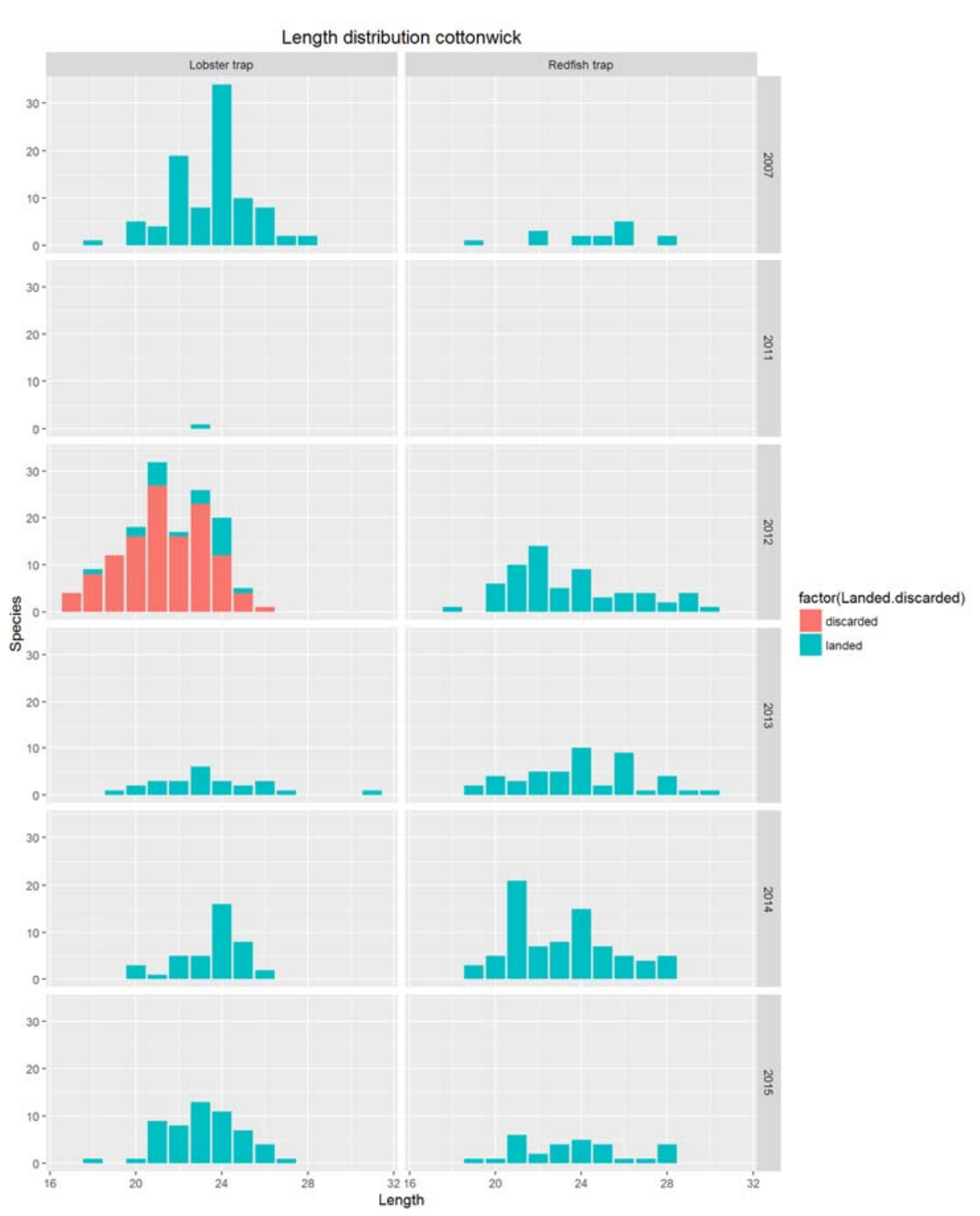

Figure A1.6. Length composition of cottonwick from lobster traps 


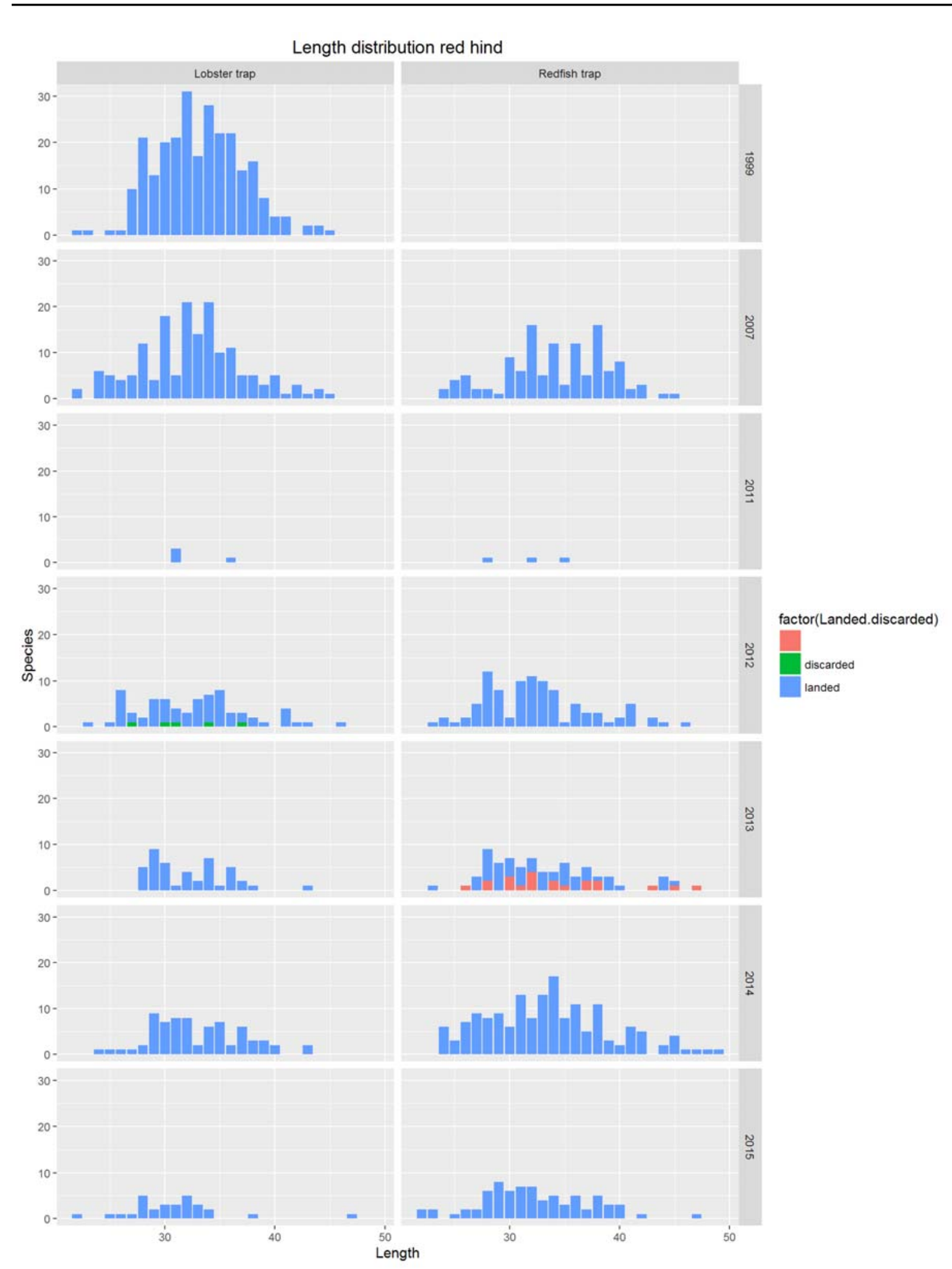

Figure A1.7. Length composition of red hind from lobster traps 


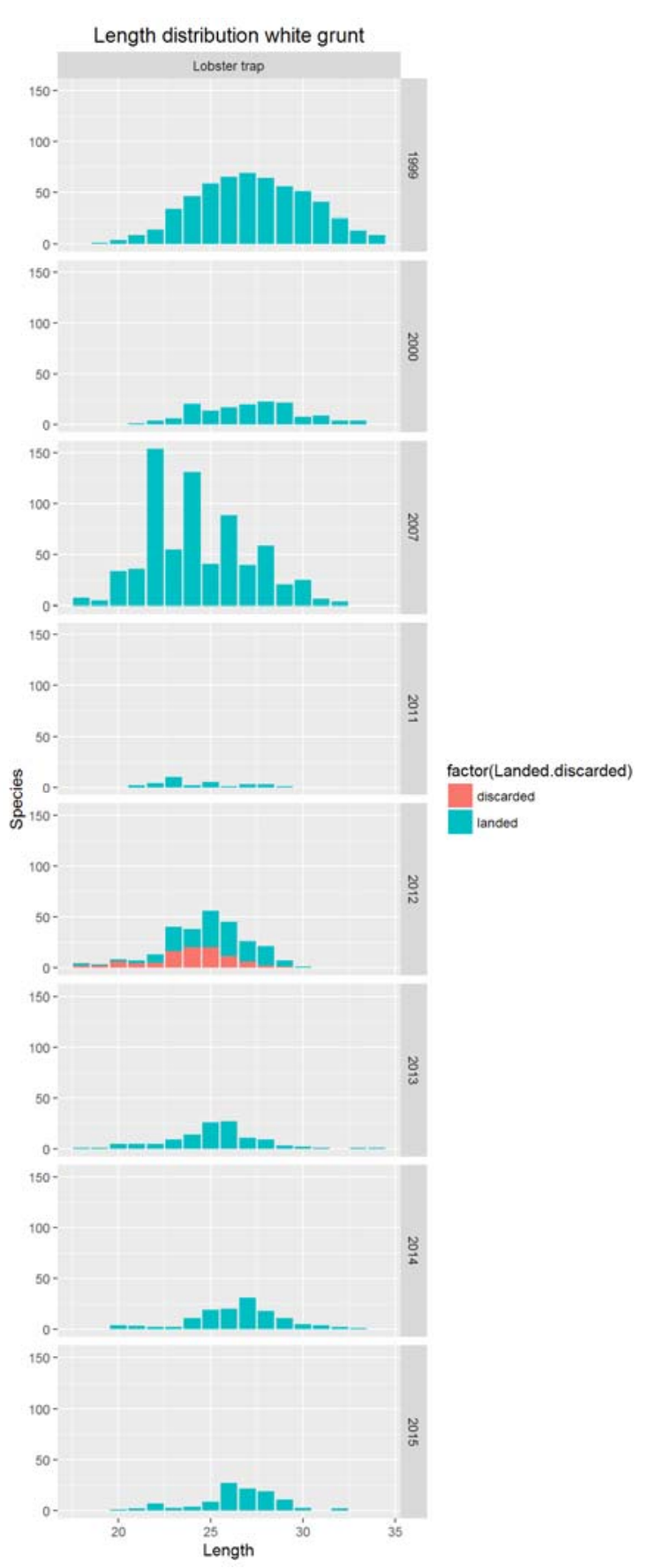

Figure A1.8. Length composition of white grunt from lobster traps 


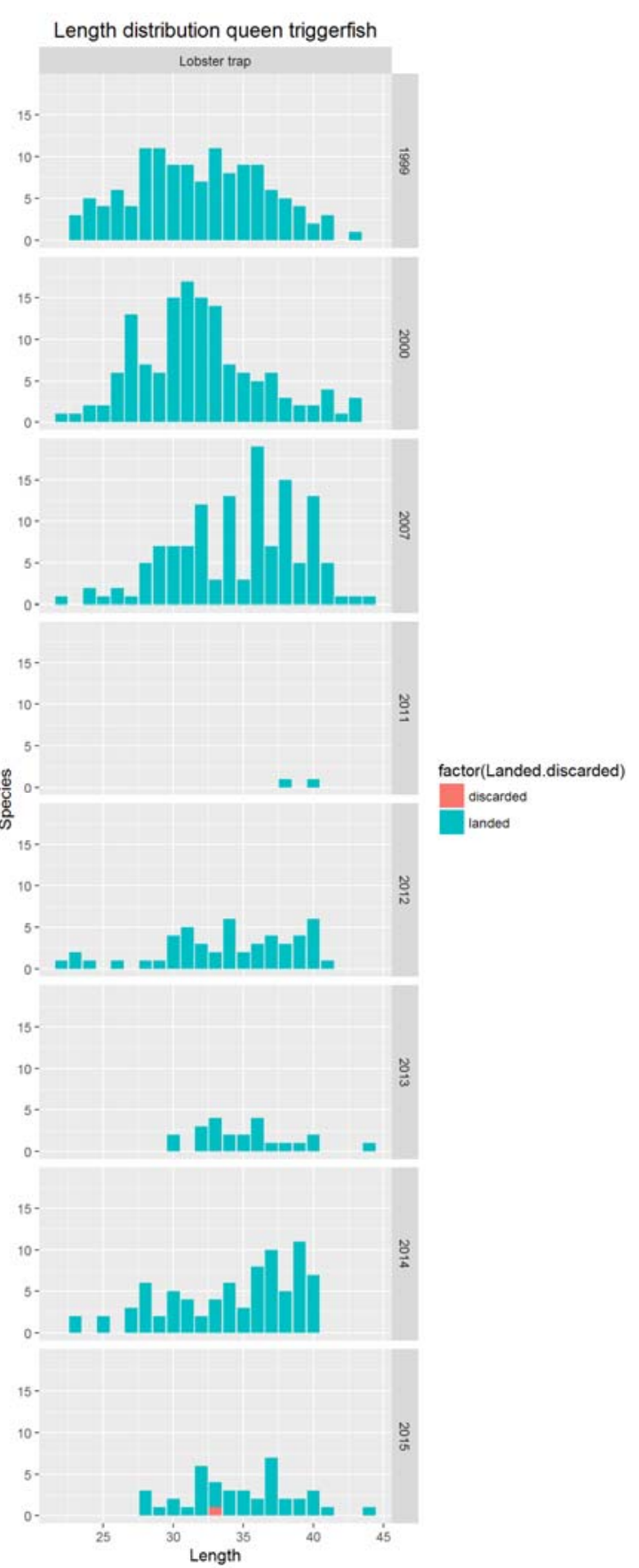

Figure A1.9. Length composition of queen triggerfish from lobster traps 


\section{Annex 2 Length composition of the catches for the escape slot experiments on redfish traps}

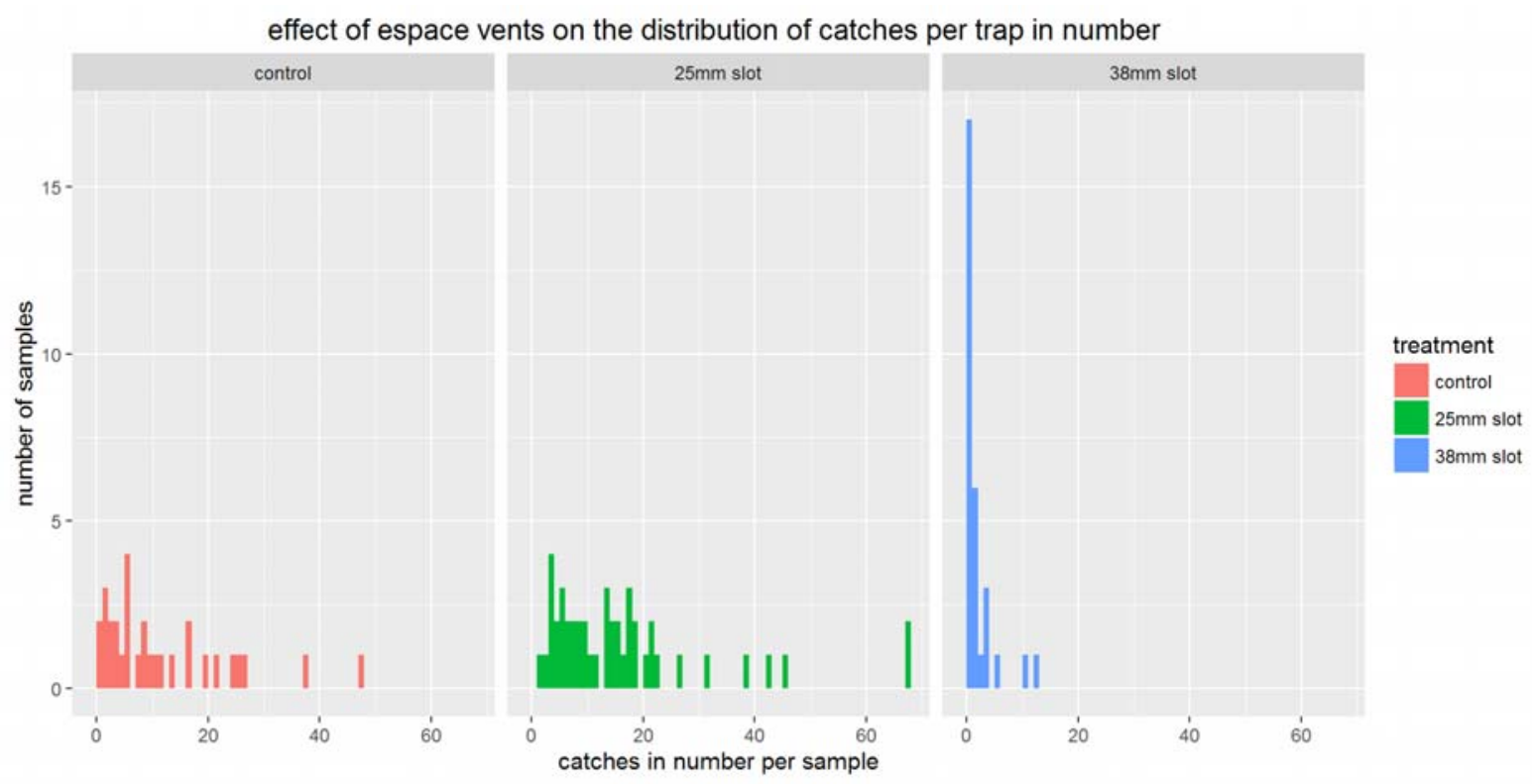

Figure A2.1 : distribution of the number of fish caught per trap for the traps with the 2 sizes of escape vent and the control.

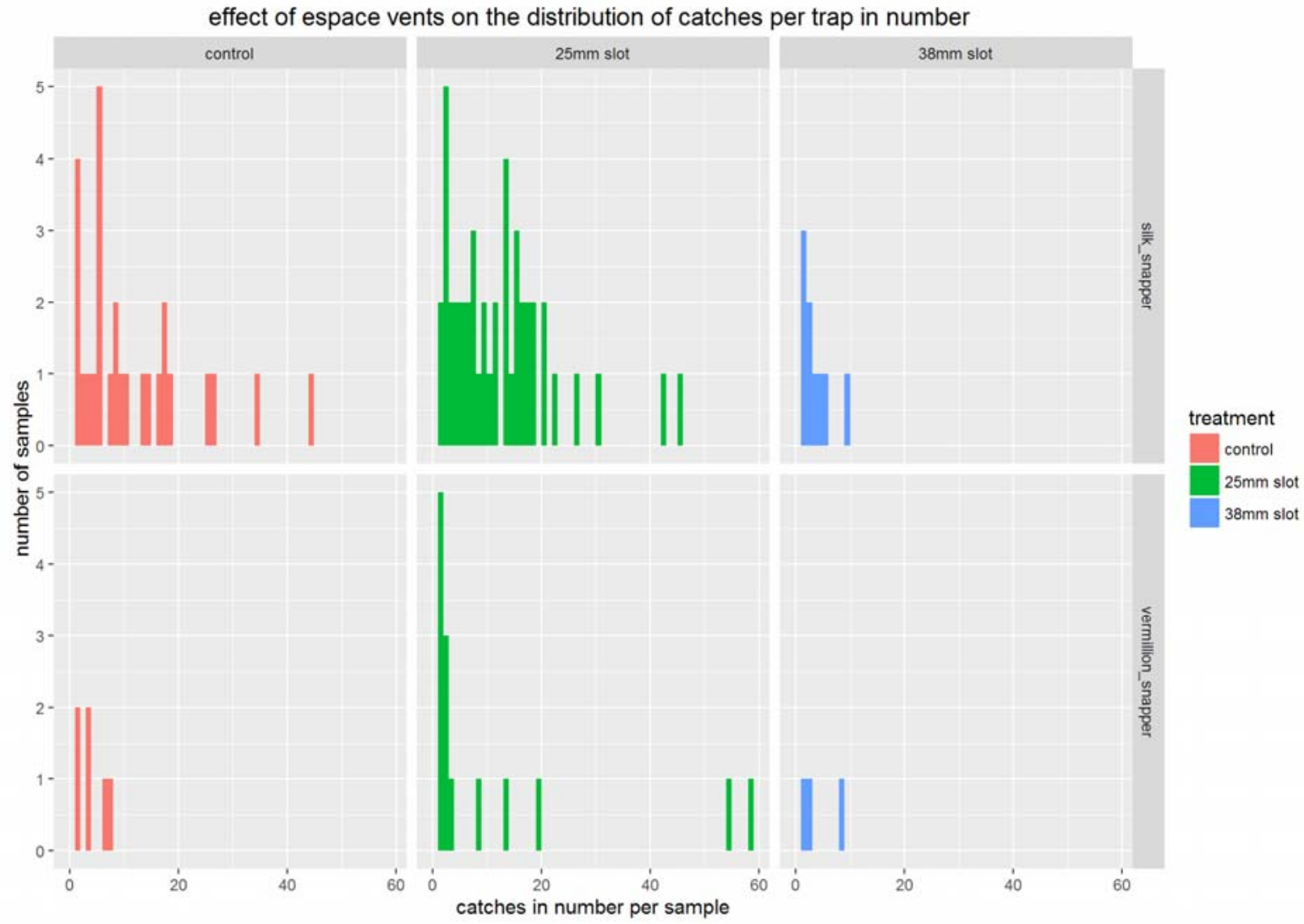

Figure A2.2. Distribution of the number of fish caught per trap for the two main species for the traps with the 2 sizes of escape vent and the control. 

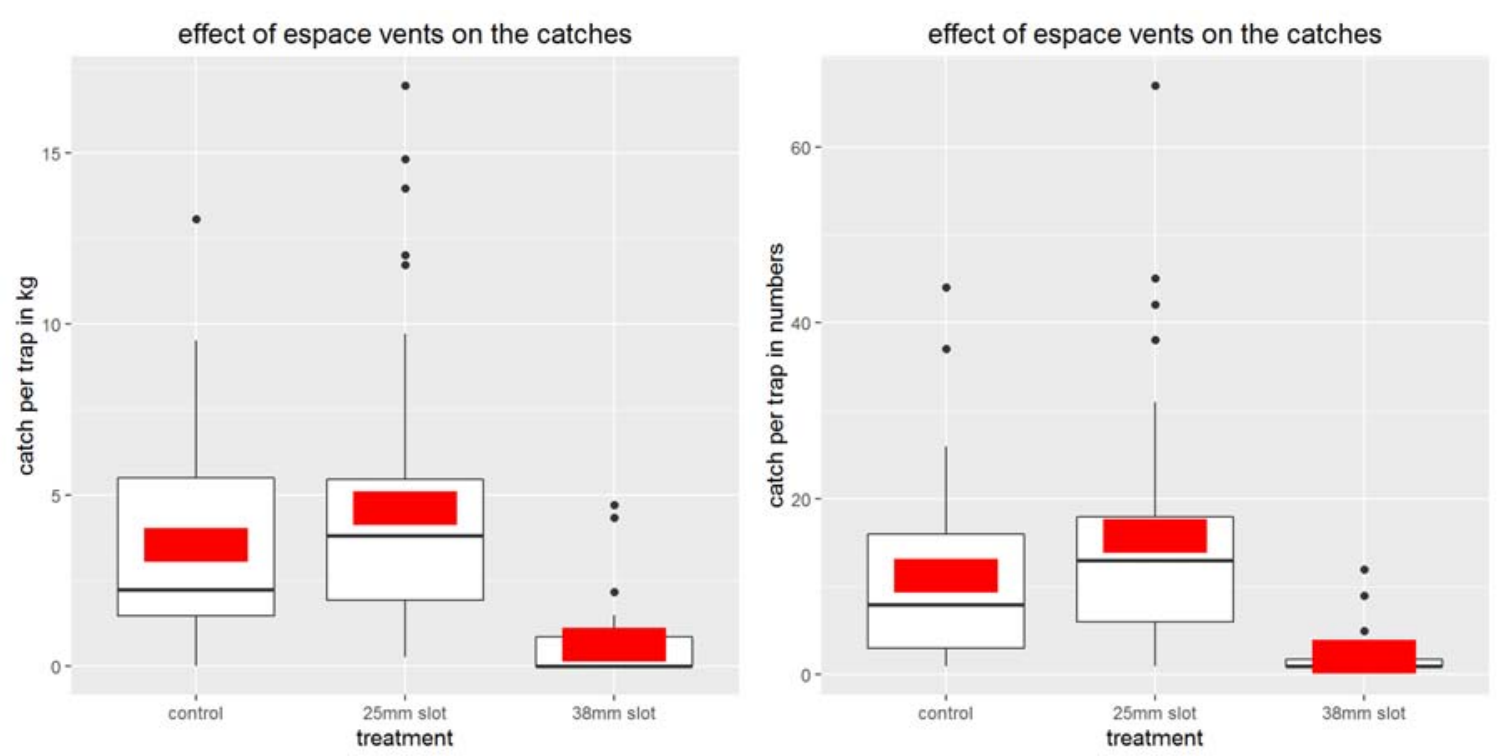

Figure A2.3. Distribution of the catches (in $\mathrm{kg}$ and in fish numbers) per trap over the 15 fishing trips (boxplot) and mean yield of the trap type (red horizontal bars). 


\section{Annex 3 Length composition red fish species}

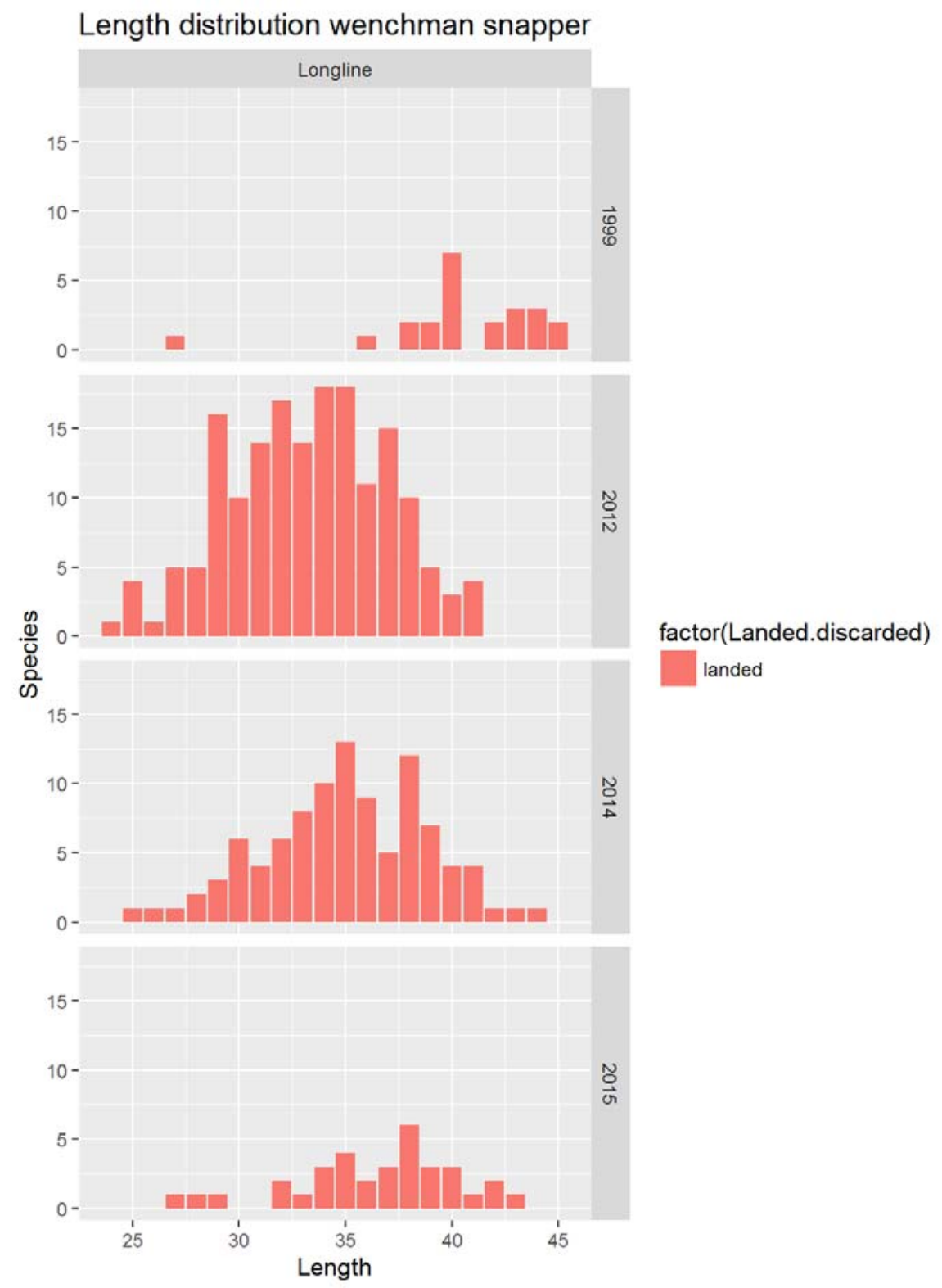

Figure A3.1. Length composition of wenchman snapper from redfish traps 


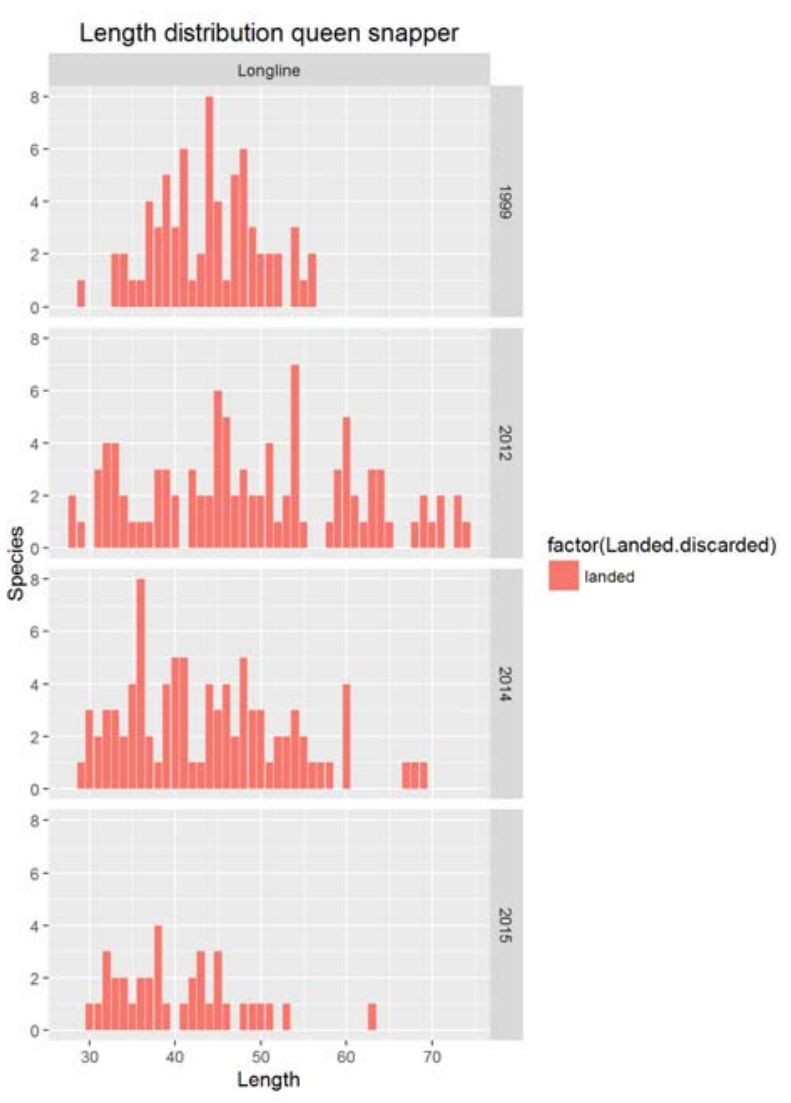

Figure A3.2. Length composition of queen snapper from redfish traps 


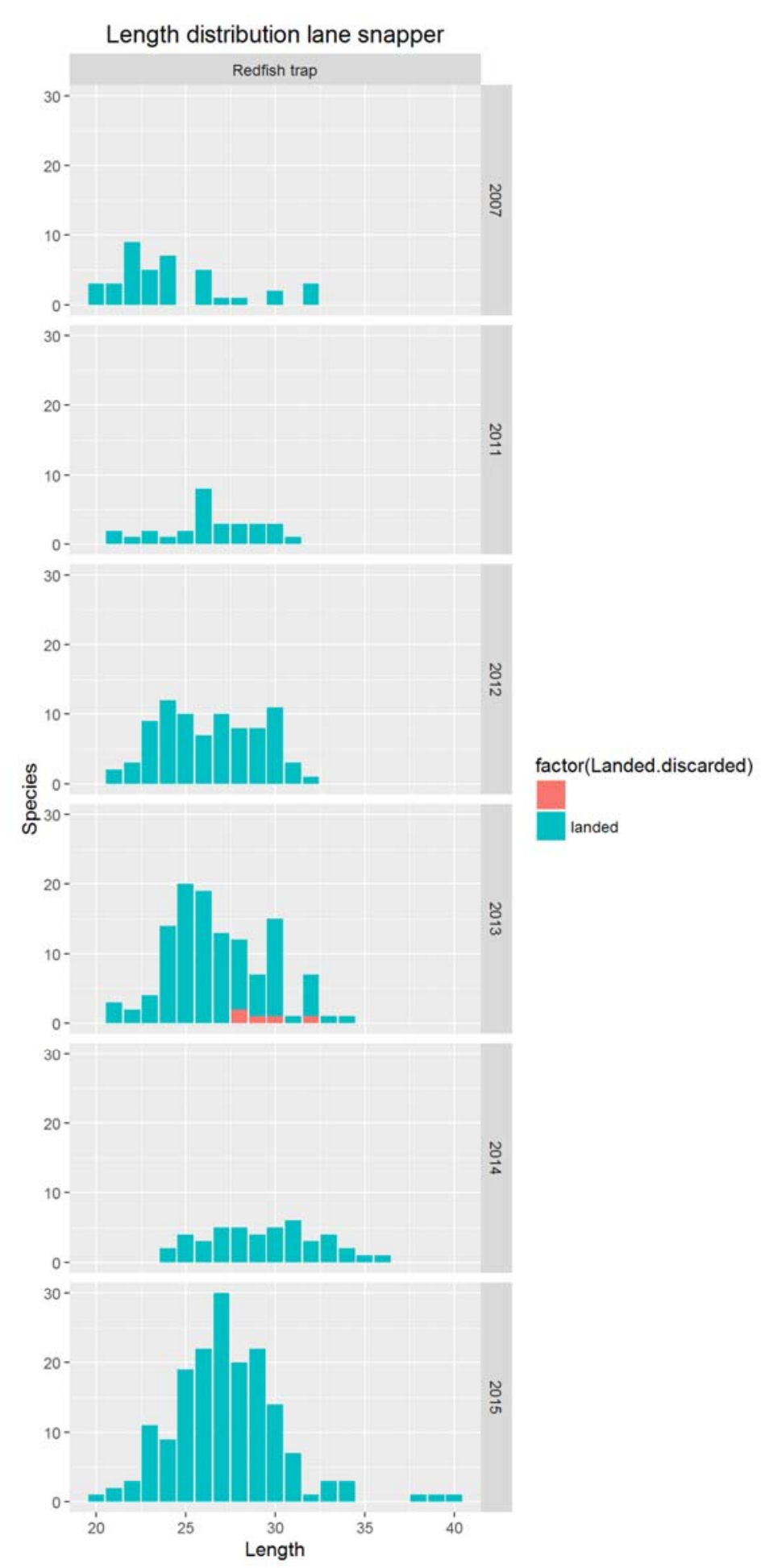

Figure A3.3. Length composition of lane snapper from redfish traps 


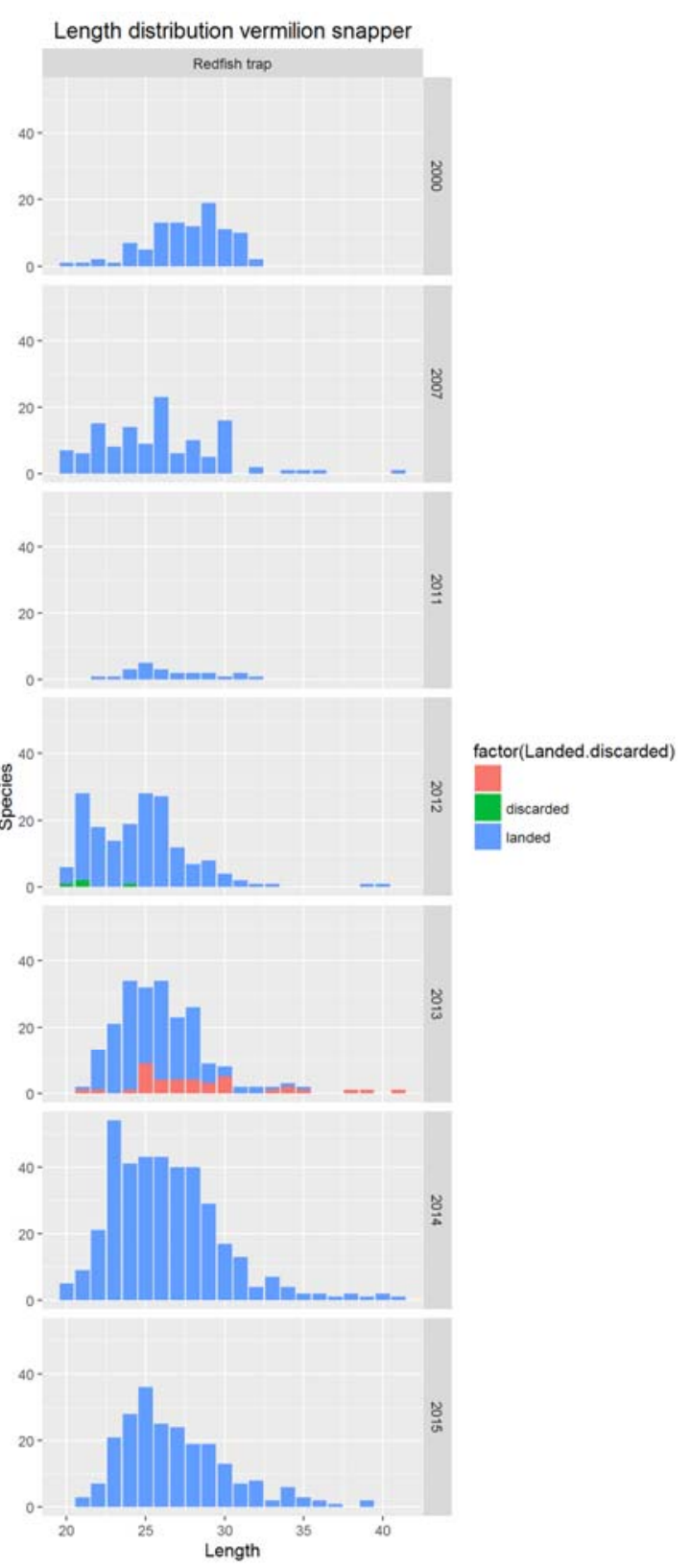

Figure A3.4. Length composition of vermillion snapper from redfish traps 


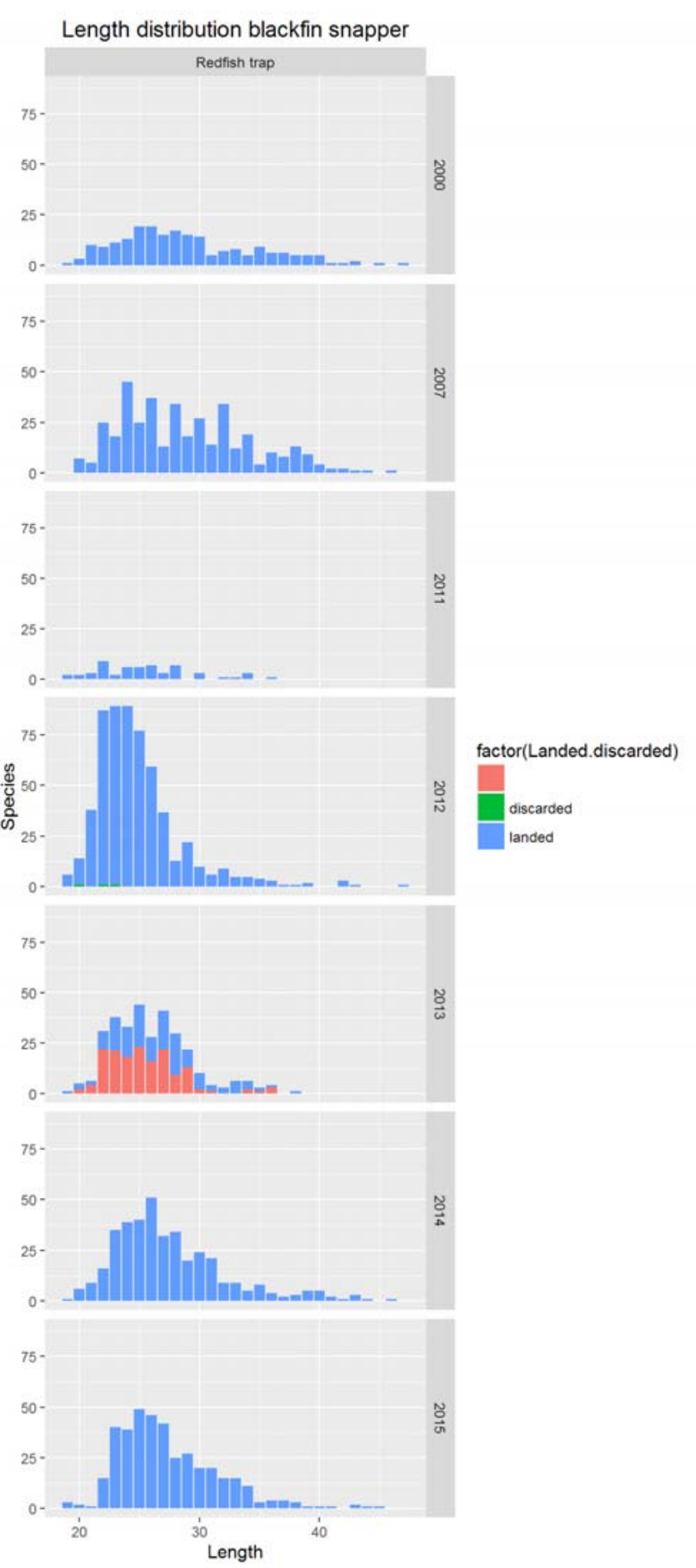

Figure A3.5. Length composition of blackfin snapper from redfish traps 


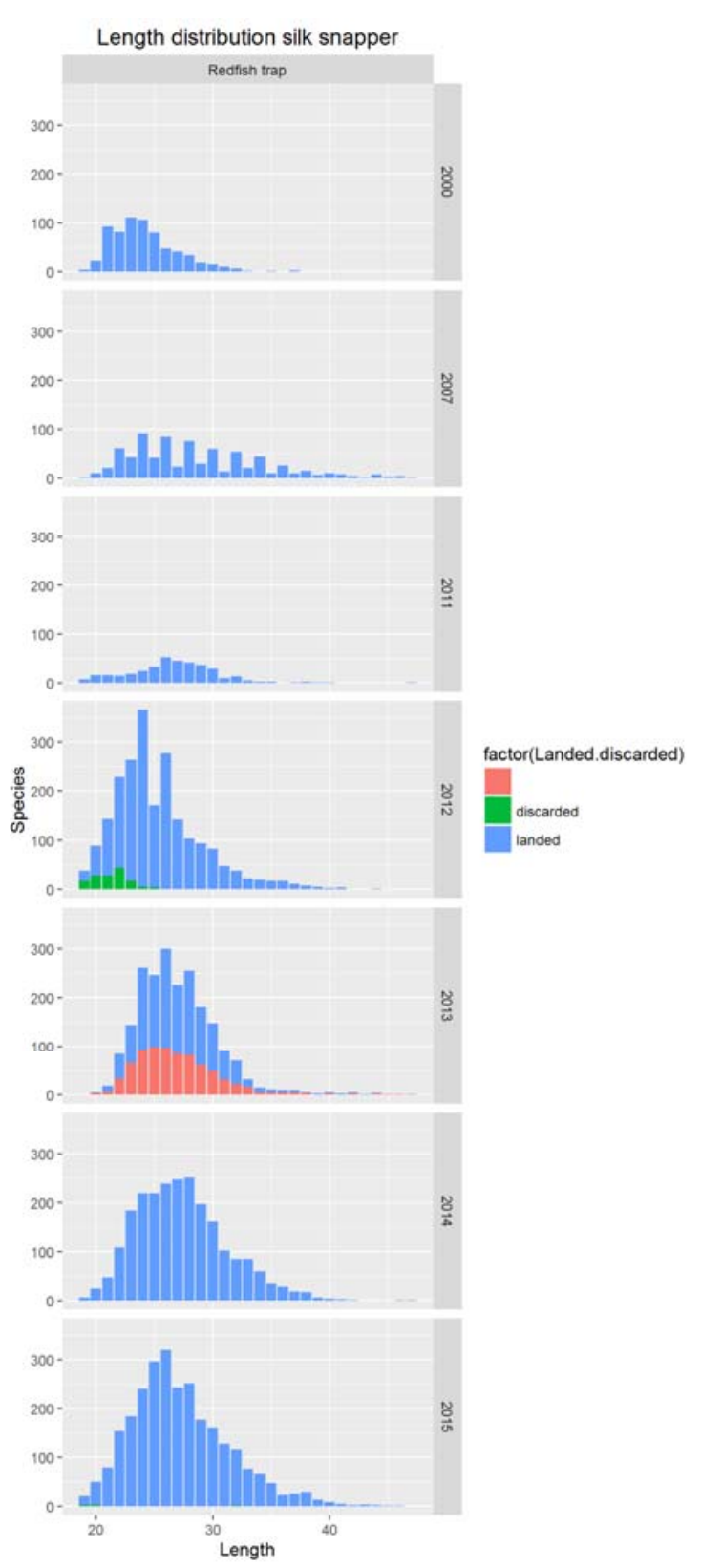

Figure A3.6. Length composition of silk snapper from redfish traps 


\section{Annex 4 Maturity information on snappers}

Blackfin Snapper size at maturity MALES

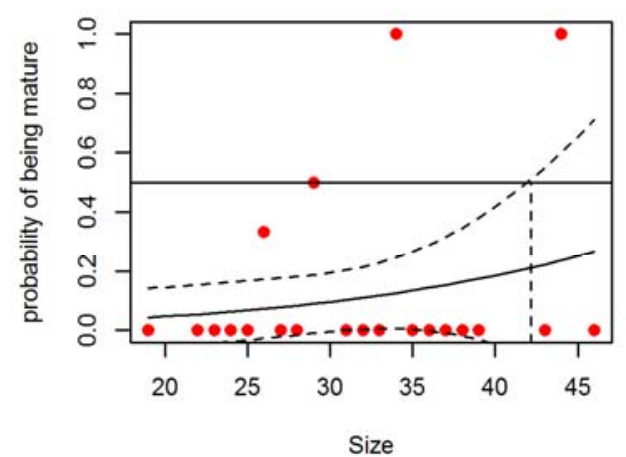

Queen Snapper size at maturity MALES

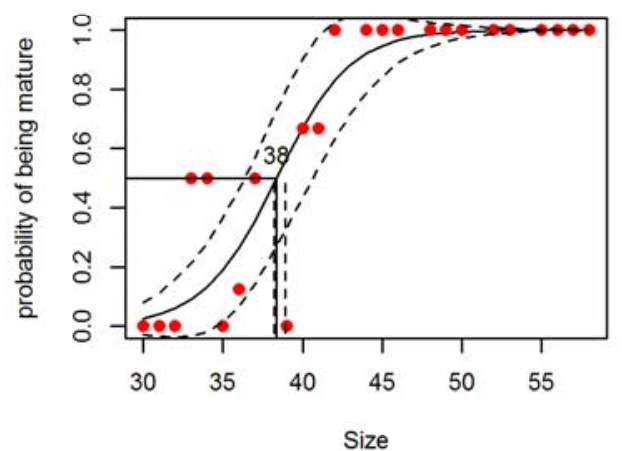

Vermilion Snapper size at maturity MALES

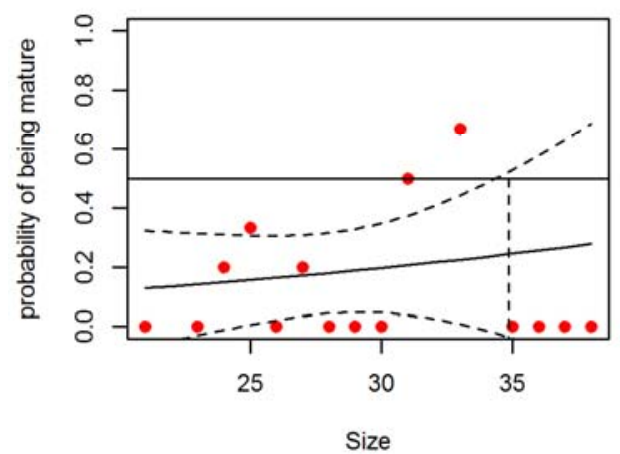

Lane Snapper size at maturity MALES

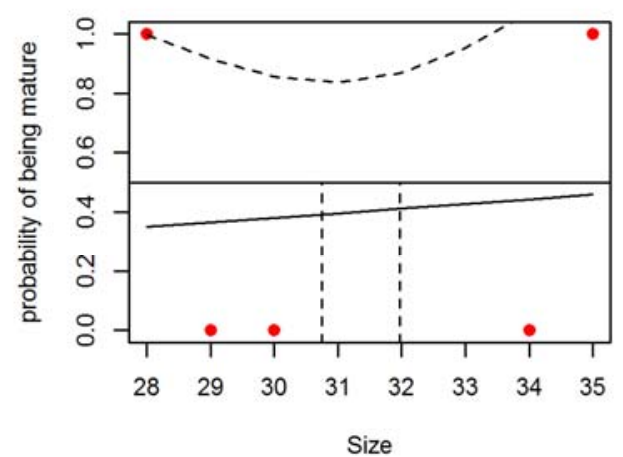

Silk Snapper size at maturity MALES

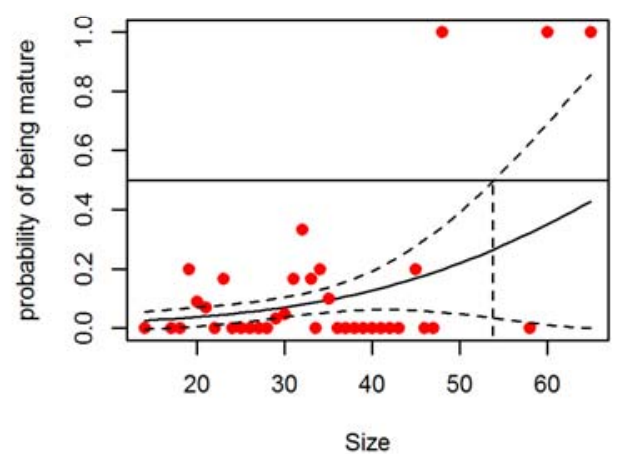

Wenchman Snapper size at maturity MALES

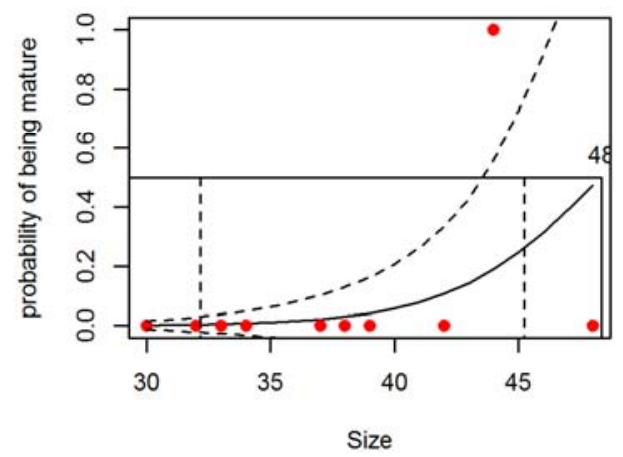

Figure A4.1. Proportion of individuals mature per $1 \mathrm{~cm}$ length class (red dots) for the male of the 6 main snapper species and corresponding maturity ogive (logistic model) with confidence bounds (black solid line and dashed lines respectively). The vertical dashed line is the estimated size at $50 \%$ individuals mature. 

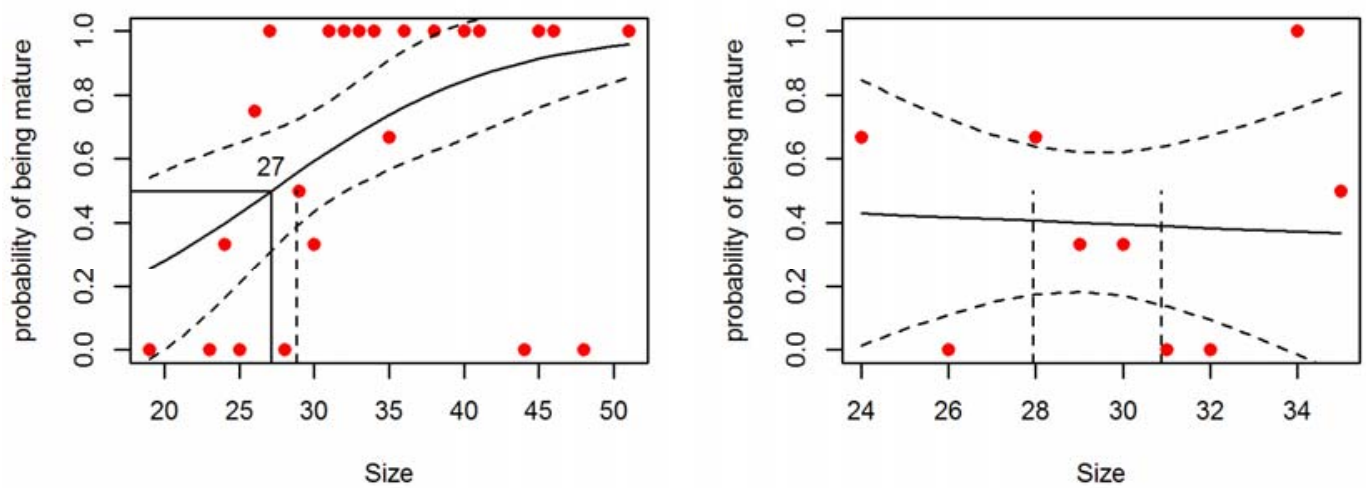

Queen Snapper size at maturity FEMALES

Silk Snapper size at maturity FEMALES
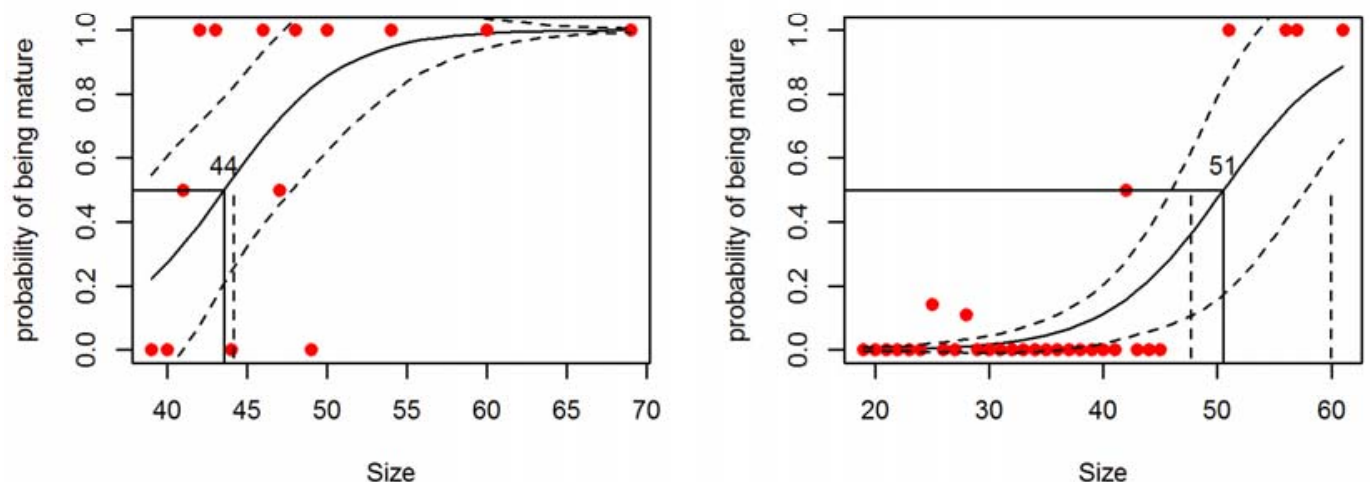

Vermilion Snapper size at maturity FEMALE؟ Wenchman Snapper size at maturity FEMALE
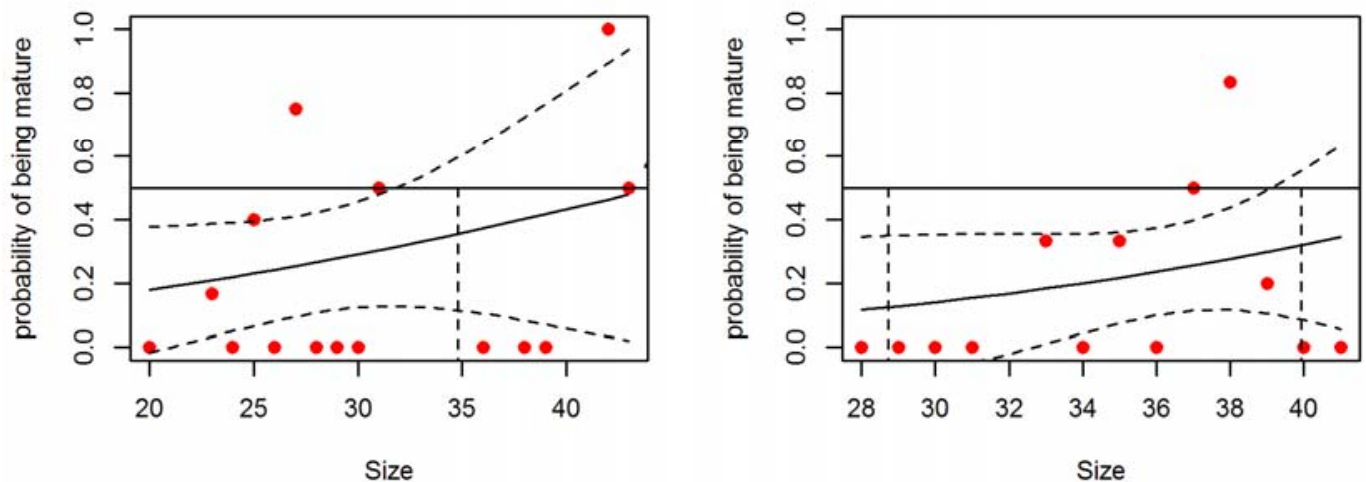

Figure A4.2. Proportion of individuals mature per $1 \mathrm{~cm}$ length class (red dots) for the female of the 6 main snapper species and corresponding maturity ogive (logistic model) with confidence bounds (black solid line and dashed lines respectively). The vertical dashed line is the estimated size at $50 \%$ individuals mature. 


\title{
Annex 5 Declaration on Conservation, Management and Sustainable Use of the Caribbean Spiny Lobster (Panulirus argus)
}

\author{
ST. GEORGE'S DECLARATION ON CONSERVATION, \\ MANAGEMENT AND SUSTAINABLE USE OF THE CARIBBEAN \\ SPINY LOBSTER (PANULIRUS ARGUS)
}

15 May 2015

\section{PREAMBLE}

WE THE CRFM MEMBER STATES,

RECOGNIZING the important contribution of the Spiny Lobster fisheries to food and nutrition security, employment, international trade, and the economic and social well-being of the people of the region;

RECOGNIZING that Spiny Lobsters play a role in proper marine ecosystem function and in the services that such ecosystems provide;

NOTING that the Spiny Lobster is a high-value and highly traded marine species which generates foreign exchange for Member States and Associate Members;

CONCERNED that the long-term sustainable use and contribution of the Spiny Lobster fisheries to the Region's social and economic development and food security is being threatened by illegal, unreported and unregulated fishing, inadequate conservation and management of the resource and its habitats, and climate change and related risks;

RECALING the Decisions of the $4^{\text {th }}$ and $5^{\text {th }}$ Meetings of the Ministerial Council of the CRFM in support of the conservation and management of the Spiny Lobster;

RECALLING ALSO the relevant provisions of the 2012 Belize Declaration on Caribbean Regional Fisheries Mechanism (CRFM) and the Central America Fisheries and Aquaculture Organization (OSPESCA) Cooperation for Sustainable Development of Fisheries and Aquaculture Resources, and the Joint Action Plan (CRFM OSPESCA);

RECALING FURTHER the relevant provisions of the Caribbean Community Common Fisheries Policy;

ACKNOWLEDGING the objectives of the Revised Treaty of Chaguaramas and more specifically Articles 58 and 60 which enjoin Member States to co-operate in all areas necessary to foster regional development and integration regarding Natural Resource Management and Fisheries Management and Development respectively;

ACKNOWLEDGING ALSO that the main objectives of the Caribbean Regional Fisheries Mechanism (CRFM) are to promote efficient management and sustainable development of marine and other aquatic resources, and promote and establish cooperative management arrangements for shared and highly migratory resources in conformity with the economic objectives of the Member States; 
AWARE that existing regional organizations, including OSPESCA, the United Nations Environment Programme, Regional Coordinating Unit (UNEP RCU) and the United Nations Food and Agriculture Organization / Western Central Atlantic Fisheries Commission (FAO/WECAFC) have programmes relevant to the conservation and management of Spiny Lobster and their habitats in the Caribbean region;

RECOGNIZING the importance of involving all relevant parties including intergovernmental, non-governmental and private sector organizations and resource users, in co-operative conservation and management of the Spiny Lobster and its habitats;

RECOGNIZING ALSO the rights and duties of States established in international law, as reflected in the United Nations Convention on the Law of the Sea of 10 December 1982, relating to the conservation, management and sustainable use of living marine resources;

INSPIRED by the principles contained in the 1992 Rio Declaration on Environment and Development, the 2002 Johannesburg Declaration on Sustainable Development, and the 2013 Rio+20 Outcome Document - The Future We Want;

INSPIRED ALSO by OSPESCA's Regulation OSP-02-09 for the Regional Management of the Caribbean Spiny Lobster (Panulirus argus) Fishery in Central America;

CONSIDERING the principles and recommendations set forth in the 1995 Code of Conduct for Responsible Fishing adopted by the Conference of the Food and Agriculture Organization;

RECALLING the United Nations General Assembly Resolutions on the Caribbean Sea and supporting sustainable fisheries and oceans management;

RECOGNISING the trans-boundary nature of the Spiny Lobster and the interconnectedness of the marine ecosystems in which they live and, therefore, the need for range States to cooperate and coordinate actions to achieve long-term sustainable use and effective conservation and management;

ACKNOWLEDGING our shared responsibility for long-term sustainable use through conservation and effective management of the Spiny Lobster populations and their habitats;

DESIRING to enhance the contribution of the Spiny Lobster fisheries to regional food and nutrition security and to support the progressive realization of the right to adequate food; and

DETERMINED to establish, through this Declaration, appropriate measures for the conservation, protection, management and long-term sustainable use of the Spiny Lobster and their habitats for the benefit of present and future generations;

2 | Page 


\section{ARTICLE 1 USE OF TERMS}

'Berried female' means a female Spiny Lobster bearing eggs attached to the abdominal appendages.

'Carapace Length' means the straight line measurement from the forward edge between the rostral horns, excluding any soft tissue, and proceeding along the middle to the posterior edge of the carapace.

'Closed Season' means a period in the year when it is prohibited to fish for, capture, kill, possess, sell or trade the spiny lobster.

'Competent Authority' means the Government Fisheries Department or Fisheries Division or any other body designated by the State as the competent body responsible for management, conservation and sustainable use of the Spiny Lobster.

'Escape Gap' means an opening in the side of a trap designed to facilitate the exit of juvenile and undersized Spiny Lobster from that trap.

'Escape Panel' means a panel, or other mechanism, designed to allow for the exit of Spiny Lobster from a trap after a period of time if the trap has been lost or abandoned at sea.

'Forum' means the body established by Article 6(b) of the 2002 Agreement Establishing the Caribbean Regional Fisheries Mechanism.

'Member States' mean the States Parties to the 2002 Agreement Establishing the Caribbean Regional Fisheries Mechanism.

'Ministerial Council' means the body established by Article 6(a) of the 2002 Agreement Establishing the Caribbean Regional Fisheries Mechanism.

'Industrial vessel' means a vessel over 20 meters LOA that commercially engages in the catching, taking, harvesting, storing or transporting of Spiny Lobster or an activity that can reasonably be expected to result in the catching, taking, harvesting, storing or transporting of Spiny Lobster; or any vessel designated as an 'industrial vessel' by the national Competent Authority and engaged in such activities. 
'OSPESCA' means the Fisheries and Aquaculture Organization of the Central American Integration System (SICA).

'Possession' means to have in one's custody or control, either personally, or by another who is under one's control.

'Spiny Lobster' means the Caribbean spiny lobster, Panulirus argus.

'Tail length' means the straight line measured from the anterior edge of the first abdominal segment to the terminal portion of the telson.

'Trap' means a lobster trap, pot, or other stationary device that may be set on the seafloor and used for catching or holding of Spiny Lobster.

\section{ARTICLE 2 SCOPE}

1. This declaration applies to the use, conservation and management of the Spiny Lobster (Panulirus argus) stocks and their habitats within areas under national jurisdiction or sovereignty of Member States and Associate Members of the CRFM.

2. Nothing in this declaration shall preclude Member States and Associate Member States from implementing stronger national conservation and management measures than those specified herein for the Spiny Lobster and its habitats.

\section{ARTICLE 3 OBJECTIVE}

1. The objective of this declaration is to ensure the long-term sustainable use of the spiny lobster (Panulirus argus) resources through effective implementation of conservation and management measures for the stocks and their habitats based on the best scientific evidence available.

\section{ARTICLE 4 GENERAL PRINCIPLES}

1. Member States and Associate Member States, in order to achieve the objectives of this declaration and in giving effect to their duty to cooperate in accordance with relevant regional and international law, shall apply the following guiding principles:

(a) The precautionary approach and the ecosystem approach to fisheries;

(b) Ensure long-term sustainability of the spiny lobster and promote the objective of their optimum utilization;

(c) Ensure that conservation and management measures are based on the best scientific evidence available and are designed to maintain or 
restore stocks at levels capable of producing sustainable yields, as qualified by relevant environmental, socio-economic and ecological factors;

(d) Protect biodiversity in the marine environment;

(e) Ensure that the levels of fishing effort do not exceed those commensurate with the sustainable use of the lobster stocks and that ecosystem impacts are taken into account;

(f) Take into account the interests of small-scale and subsistence fishers and promote their participation in the decision-making processes that affect their livelihoods;

(g) Take into account traditional ecological knowledge and local knowledge of fisheries and fishing communities regarding conservation and management of the resource and protection of critical habitats;

(h) Collect and share, in a timely manner, complete and accurate data and information concerning fishing activities; and

(i) Ensure compliance with conservation and management measures through effective monitoring, control and surveillance, and public education and awareness programmes.

(j) Utilize pre-agreed harvest control rules that are based on appropriate reference points.

\section{PART II CONSERVATION AND MANAGEMENT}

\section{ARTICLE 5 RESEARCH, DATA COLLECTION AND SHARING OF DATA AND INFORMATION}

1. Member States and Associate Members shall, as far as possible and as appropriate, ensure that fishing vessels, fishers and other natural or legal persons within their jurisdiction, who are directly or indirectly involved in the capture, processing, marketing or trade of Spiny Lobster provide such data and information as may be necessary in order to fulfil their obligations under this Declaration. To this end, Member States and Associate Members shall:

(a) Collect and share scientific, technical, and statistical data with respect to fisheries for the spiny lobster with each other and with other competent organizations and stakeholders including, but not limited to 
the CRFM, OSPESCA, WECAFC and their relevant Working Groups responsible for lobster assessment and management, fisherfolk organizations, and educational institutions.

(b) Ensure that data are collected in sufficient detail and accuracy to facilitate effective assessment, preparation of conservation and management advice, and monitoring of management performance; and

(c) Adopt provisions requiring vessel owners and masters, fishers, processors and traders to submit to the competent authority, data regarding the biology, ecology, catch, effort, sale, processing, marketing, social, economic, and trade aspects of the Spiny Lobster.

2. Member States shall cooperate through the organs of the CRFM to agree on the specification of data, the frequency and format in which they are to be provided for analysis by the appropriate regional Working Group or other competent body;

3. Member States and Associate Members shall promote and conduct scientific research related to the use, conservation and management of the Spiny Lobster, including aspects of the marine environment and ecosystems such as habitat and non-target species, and actively promote the publication and dissemination of the results of that research.

4. Without prejudice to the generality of paragraph 3, Member States and Associate Members should conduct research to:

(a) determine whether the introduction of casitas would be appropriate before their introduction and use in the commercial fishery; and where casitas have already been introduced, the relevant studies should be conducted to determine their economic and ecological impacts;

(c) determine and address, as appropriate, the impacts of climate change and ocean acidification on Spiny Lobster stocks and fisheries;

(d) establish an appropriate maximum legal harvest size for the Spiny Lobster; and

(e) determine ways of promoting value addition and optimizing economic and social benefits to Member States and stakeholders.

5. Member States and Associate Members shall seek to cooperate with neighbouring States in the wider Caribbean region in the conduct of scientific research related to the Spiny Lobster. Cooperation with the Central American States shall take place in accordance with the Memorandum of Understanding between CRFM and OSPESCA, the Belize Declaration on CRFM and OSPESCA Cooperation, and the CRFM-OSPESCA Joint Action Plan. 


\section{ARTICLE 6 CONSERVATION AND MANAGEMENT}

1. The Ministerial Council shall make policy decisions to ensure long-term conservation, management and sustainable use of the Spiny Lobster stocks, and protect and safeguard their habitats.

2. The Ministerial Council shall make the policy decisions mentioned at paragraph (1) above on the basis of scientific advice provided by the Forum or other competent technical or scientific body.

3. Each Member State and Associate Member shall, in accordance with its particular conditions and capabilities, and as appropriate based on the local fisheries:

(a) Develop or adapt existing national strategies, plans, programmes or regulations to, as far as possible and as appropriate, give effect to the decisions of the Ministerial Council regarding conservation, management and sustainable use of the Spiny Lobster stocks and protection of their habitats; and

(b) Integrate, as far as possible and as appropriate, the conservation, management and sustainable use of the Spiny Lobster stocks and protection of their habitats into relevant sectoral or cross-sectoral plans, programmes, policies and regulations.

4. Without prejudice to the generality of paragraphs 1 and 2, each Member State and Associate Member shall, as far as possible and as appropriate, taking into account the overall importance of the fishery, local conditions and the state of the stocks:

(a) Prohibit fishing for the Spiny Lobster without a valid licence issued by the Competent Authority;

(b) Within three (3) years from the date of adoption of this Declaration, implement a Closed Season for the Spiny Lobster for a period of not less than 4 months, between $15^{\text {th }}$ February and $31^{\text {st }}$ August each year, during which no Spiny Lobsters may be caught, sold, stored or possessed except as provided for in this Agreement;

(c) Each Member State may determine whether to establish a maximum number of Traps per vessel or per fisher, taking into account the nature of the fishery and the socio-economic condition of the fishers;

(d) Ensure that any Trap used for targeting, catching or holding the Spiny Lobster at sea is made wholly or in part from biodegradable material to avoid ghost fishing and other negative environmental impacts; 
(e) Ensure that any Trap used for targeting, catching or holding the Spiny Lobster at sea is equipped with an Escape Panel to permit the exit of Spiny Lobster or other marine species from the trap after a period of time if the trap is lost or abandoned at sea;

(f) Ensure that any Trap used solely for catching Spiny Lobster:

(i) has at least one Escape Gap for the purpose of facilitating the exit of juvenile Spiny Lobster from that Trap;

(ii) the Escape Gap shall be located on the opposite side of the line used to lift the Trap; and

(iii) the Escape Gap shall have an opening of 5.4 centimeters (2 1/8 inches) or larger between the bottom and the first rib from the bottom of the Trap, depending on each country's minimum size limit and country specific harvest strategy.

(g) Ensure that Traps and other gears used solely for the purpose of catching, holding or storing Spiny Lobster are removed from the sea by the beginning of the Closed Season as far as practicable. Thereafter, such traps must be removed within 5 days after the commencement of the Closed Season and any catch released.

(h) Adopt provisions that:

(i) require fishers, vessel owners, processors, traders, wholesalers, retailers and any other person in Possession of Spiny Lobster to submit to the Competent Authority by the third working day after the commencement of the Closed Season, a signed declaration of the inventory and exact location of Spiny Lobsters or parts thereof in their Possession;

(ii) require the Competent Authority to verify and certify the declaration of inventory as soon as possible within a period of not more than five days after receipt of the declaration;

(iii) empower and require the Competent Authority to carry out inspections as deemed necessary to ensure compliance with this provision, notwithstanding any other provision of control that each State Party may implement; and

(iv) during the Closed Season, prohibit any person from having in his Possession, processing, storing, selling or dealing in Spiny Lobster, except those declared and verified by the Competent Authority.

(i) Determine and establish the time period prior to the opening of the fishing season when persons authorized to fish for Spiny Lobster may place or return their Traps to the sea in order to prepare for the commencement of fishing when the season reopens. The maximum time allowed shall not 
exceed fourteen (14)days prior to the commencement of the fishing season;

(j) Adopt a minimum size for catching Spiny Lobster, of eighty millimeters ( 80 $\mathrm{mm}$ ) Carapace Length or greater, or alternatively one hundred forty millimeters $(140 \mathrm{~mm})$ Tail Length or greater, and prohibit the catching, handling, processing, storage, possession, sale and trade of Spiny Lobster less than the minimum legal size;

(k) Adopt, for packaging and marketing, a minimum weight of 142 grams (5 ounces) per unit of commercial packaging for each thawed Spiny Lobster Tail;

(I) Adopt an appropriate maximum legal size limit and prohibit the catching, handling, processing, storage, possession, sale and trade of Spiny Lobster greater than the maximum legal size;

(m) Prohibit the importation of Spiny Lobster below the minimum size and weight limits or above the maximum size limit in any area under its jurisdiction;

(n) Prohibit the catch, possession, processing, storage, sale, offer for sale, export or import of Spiny Lobster:

(i) with spermatophore or tar spot;

(ii) that is carrying eggs (Berried Lobster);

(iii) that is moulting;

(iv) that has been scrubbed or has in any manner other than natural hatching had the eggs removed from the tail; and

require that a Spiny Lobster with spermatophore (tar spot) or carrying eggs or moulting is returned to the sea immediately.

(o) Require fishing vessels and persons fishing for Spiny Lobster to land the Spiny Lobster whole, and prohibit the Possession on board a vessel or landing of Spiny Lobster parts such as shelled tails, or head meat;

(p) Prohibit or regulate, as appropriate, the use of scuba diving and hookah for Spiny Lobster fishing within four (4) years from the date of adoption of this Declaration.

\section{ARTICLE 7 MONITORING, CONTROL AND SURVEILLANCE}

1. Member States and Associate Members shall cooperate through the CRFM and other competent regional and sub-regional bodies in taking appropriate 
enforcement action, consistent with regional and international law and their respective domestic laws, to prevent, deter and eliminate Illegal, Unreported and Unregulated fishing activities for the Spiny Lobster.

2. The Ministerial Council shall adopt regional guidelines for use by Member States and Associate Members, as appropriate, in order to:

(a) Establish cooperative arrangements to enhance monitoring, control and surveillance systems;

(b) Establish sanctions for non-compliance by vessels, fishers and other natural or legal persons connected to the Spiny Lobster fisheries and trade, that are adequate in severity to effectively secure compliance, deter further violations and deprive offenders of the benefits arising from their wrongful or illegal activities, to be applied in accordance with national laws; and

(c) Evaluate their systems of sanctions to ensure that the penalties are effective in securing compliance and deterring violations.

\section{ARTICLE 8. PUBLIC EDUCATION AND AWARENESS}

1. Member States and Associate Members shall:

(a) Promote and encourage understanding of the importance of, and the measures required for, the conservation, management and sustainable use of the Spiny Lobster, and protection of its habitats and ecosystem;

(b) Cooperate, as appropriate, through the CRFM and other regional, international and non-governmental organizations in developing educational and public awareness programmes for the conservation, management and sustainable use of the Spiny Lobster; and

(c) Promote the use of information and communication technology tools including social media, in order to improve public awareness and understanding of the importance of the Spiny Lobster and the measures required for their conservation, management and long-term sustainable use. 
Wageningen Marine Research $\mathrm{T}+31(0) 317480900$

E: marine-research@wur.nl www.wur.eu/marine-research

Visitors' address

- Ankerpark 271781 AG Den Helder

- Korringaweg 7, 4401 NT Yerseke

- Haringkade 1, 1976 CP IJmuiden
Wageningen Marine Research is the Netherlands research institute established to provide the scientific support that is essential for developing policies and innovation in respect of the marine environment, fishery activities, aquaculture and the maritime sector.

\section{Wageningen University \& Research:}

is specialised in the domain of healthy food and living environment.

\section{The Wageningen Marine Research vision}

'To explore the potential of marine nature to improve the quality of life'

\section{The Wageningen Marine Research mission}

- To conduct research with the aim of acquiring knowledge and offering advice on the sustainable management and use of marine and coastal areas.

- Wageningen Marine Research is an independent, leading scientific research institute

Wageningen Marine Research is part of the international knowledge organisation Wageningen UR (University \& Research centre). Within Wageningen UR, nine specialised research institutes of the Stichting Wageningen Research Foundation have joined forces with Wageningen University to help answer the most important questions in the domain of healthy food and living environment. 